\title{
(b) $\mathfrak{a} \mathfrak{n} \boldsymbol{d} \mathfrak{b} \mathfrak{a} \mathfrak{d}$
}

Der

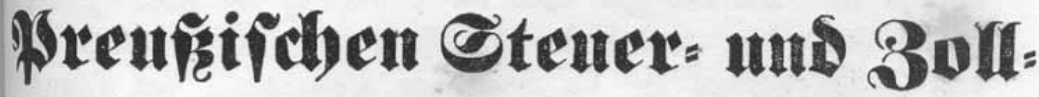

\section{Gepetsgebung}

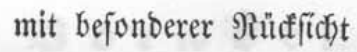

auf Den (Jebraud) bei Den (5eridten

зuјammengefteflt

bont

21. 25i r a ame,

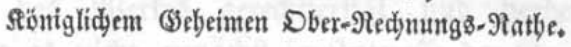

Supplement.

\section{3ૈerlit, 1848.}

Berlag von (5). Reimer. 


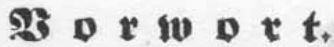

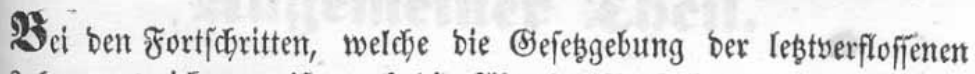

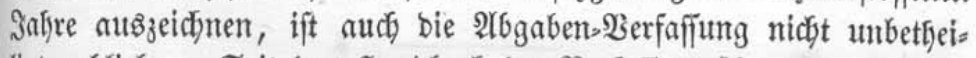
ligt geblieben. Seit bab Şanbbud bes Berfaffers über bie preufififde

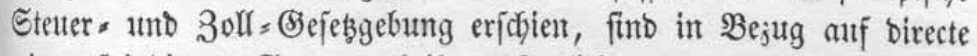
wie auf inbirecte Steutern theils wejentlich neute, theils erganzente ober erläuternbe Beffimmungen ergangen, welche eine volffänobige

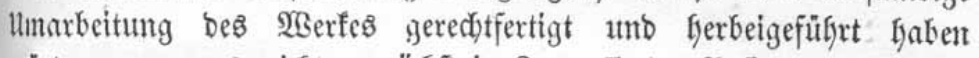

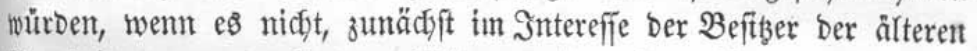
Bearbeitung, angemeffiener erfdjienen wăre, bas feitbem Errgantgene utmo einige ältere, zum $\mathfrak{T}$ geil erft fpäter veröffentliçfte, $\mathfrak{B}$ eftinumun= gen in einen bejonberen Supplement:Band zufammenjufafifen, weldjer

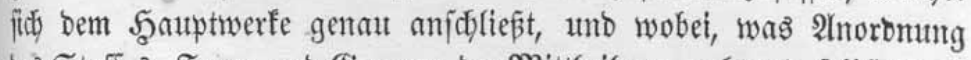
bes Etoffes, Form und Srenjen ber Mittfyeilung anlangt, fellfftrebent

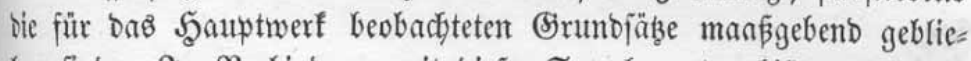
ben finto. In $\mathfrak{2}$ erbinbung mit biejen Supplementen bildet nunmefr

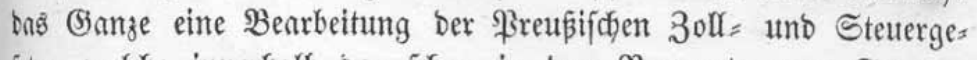
Feşe, weldye innerfialb ber fiffon in bem $\mathfrak{B o r w o r t e}$ bom Geptem=

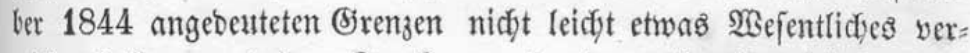

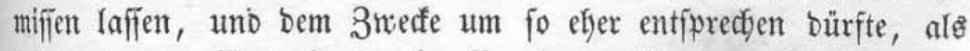

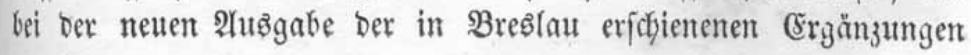




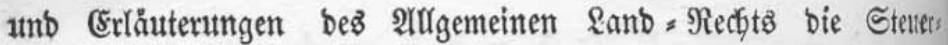

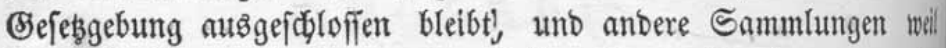
fie nidgt bis auf bie neutefte Zెeit reidjen, für ben currenten

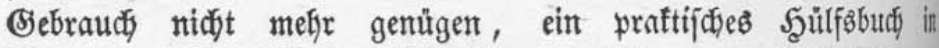

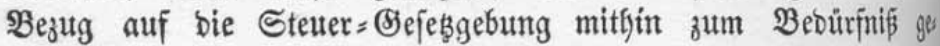
worbent ift. Sim Uebrigen wirb bie $\mathfrak{B}$ enuţung ber nadffolgenbon Supplemente feine wejentlidyen Sdymierigfeiten finben, . zumal in bem Terte jebesmal auf die betreffende Beftimmung bes Şauts werfes, unter Ingabe ber Seitenzall bes lebsteren, verwiejen ith and Das beigefügte Regifter fämmtlidje in Dem Supplement= Battr

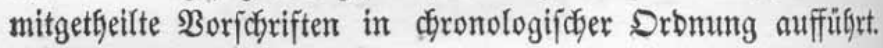

ßots̊am im Rowember 1847.

Der Berfafier. 


\section{2ulgemeiner Ibeil.}



nif̂e Ecitens Der Etäote.

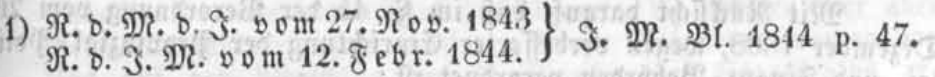

3ut ben von ben Stabt=(3emeinben nad) ber $\Omega$. D. $v$ 3. Det. 1821 nod ferner zu erfüflenten Berpflidtungen gebört namentlid, aud) bie unterbaltung refp. Erweiterung Der Juftizgefängniffe, fo wie bie Anlegung ber erforbertid, werbenben verfalofifenen 5öfe Darit

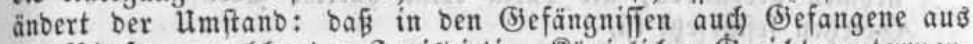
Dorfíd)aften, welde ber Surişoiction Röniglidjer (jeridte unterwor= fen fino, aufgenommen werben - nid)ts, fonbern giebt ben Stabt= gemteiben nur einen Anjprud auf Zablung eines fioftenbeitrages Eeitens bes Jišcts.

2) Befanntmadung b. S. Mi. vom 3. December 1846.

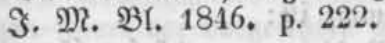

Durd) R. Drbres bout 15. 2uril 1842, 7. 2uguit unb 5. Dc= tober 1846 ift genefimigt, ba fflid)tung zur Unterbaltung ber (Siefängniffe, auf ibren Antrag unter 3uftimmung oes $\mathbb{F}$. MR. Durd, befontere Berträge gegen Lleberweifung ber Socalien unb Heberfaffung ber Jriid)te refp. Soften ber (Eriminal= (Berid)tsbarfeit, fo wie gegen eine fefte iäbrlidje Rente abgelöfet

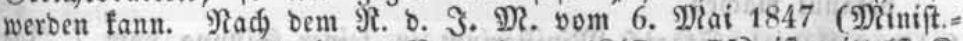
Bl. für bie gefaumte innere Berwaltung 1847 p. 75 ) ift mittelit $\Omega$.

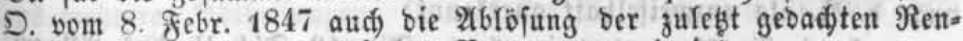
ten burd) 3ablung bes 25 fadjen Betrages genebmigt.

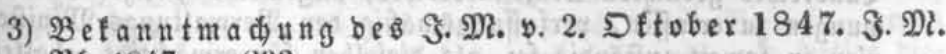
Bl. 1847. p. 293.

Dittelft $R_{a b}=$ Drbre yom 10. Septbr. 1847 ift für bie $\mathfrak{B}$ er= banblungen, welde bie Serträge megen Befreiung ber Stäbte von 
ber fuffibiarifden Berbaftung für bie \&aften ber Eriminal= (Feridjts. barfeit unb von ber Laft ber Bsefängniß̈= Unterbaltung betreffen, bie Freibeit von (S)rid)tågebübren uno Stempefn bewifligt.

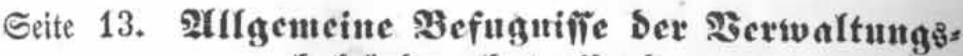 behörben betreffent.}

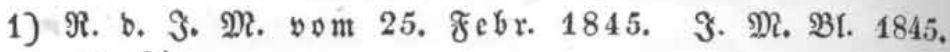
pag. 34 .

Ueber bie Befugniß ber Berwaltunggbeböroen allgemeine po= Iizeilide 2 trorbnungen uno Strafbeftimmungen zu erlaffen refp. über

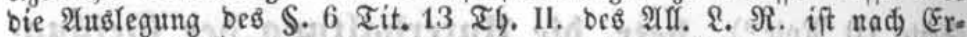
orterung bes Segenftandes in beut Staatóminifterio forgenoer $\mathfrak{B}_{\mathrm{c}}=$ (d) luk ergangen:

Rit Rüffid)t barauf, bafi im $\$$. 45 ber Beroronung som 26. Dezentber 1808, wegen verbefferter Einridtung ber Yrobinzial = Yyoli= $z e i=$ uno ginan $z=2$ Beborben veroronet ift:

2uf bie von ben Regierungen mit boberer (5) nefmigung in Yolizei=2lngelegenbeiten erfaffenen Publicanda fino bie Eanbes:

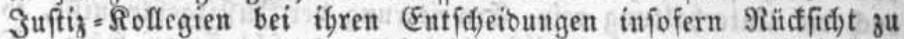
negmen verbunben, als barín teine Gärtere Strafe als in ben Befesen feitgejebt ift,

uno baß̄ nad) $\$$. 40 bajelbft

bie Regierungen zu fold)en $\Re_{0}$ olizei=ßerfügungen, burd weldje et.

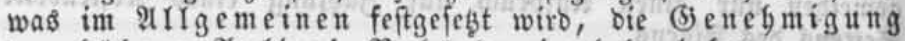

ber böbern golizei= Bebörbe einzubolen baben,

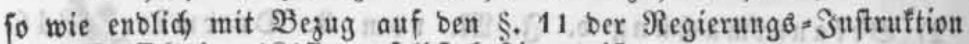
vom 23. Dftober 1817, wofelbft beftimmt ift:

AIlgemeine Berbote uno Straf = Beftimmungen bürfent fämmtlidje Regierungen nid)t obne böbere (5) enebmigung erlafien, cs

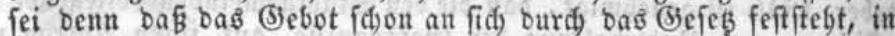
Yesterem aber bie Strafe nicht ausbrüdfid beftimmt ift. In biefent Faffe fönnen fie innerbalb ber Bremzen bes affgent. Zanbred)t Ib. II. Tit. 20 §§. 33,35 uno 240 bie Strafen beftimmen unt betannt madien,

Gat bas Rönigl. Staat $=$ Minifterium in feiner Siģung vout 7. Ja nuar b. 3. als unzweifelbaft anerfannt:

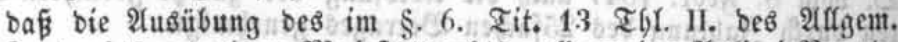
Qanbred)t ge gebadten Majeftätered)ts, allgemeine Wolizei=Berorb=

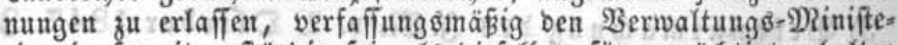
rien in poweit zuftänbig fei, alb biefelben für ermädtigt gebalten werben müffen, polizeilid)e $\mathscr{A}$ norbnungen uno Strafbeftimmungen innerbalb ber (5)renzen ber polizeilidjen Strafgewalt ju erlaffen, uno beren Ertaß̄ yon Seiten ber Regierung zu genebmigen. 
Die Bseriđtstsbegörben finb angewiefen, bergleiden alfgemeine

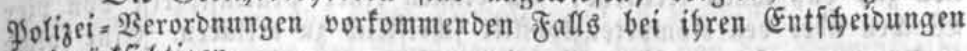
ju beruidfidtigen.

2) Befeß yom 8. April 1847, Die Eompetenz= Eonflicte betr. ㅎ. S. 1847 p. 170.

25 ir $2 c .2 c$. veroronen fliften zwifhen ben (Serid)ten und $\mathfrak{B}$ erwaltungsbegörben, auf ben $21 n=$ traß $\ln$ fereş Staatêminifteriums uno nad) vernommenem (5utad)ten

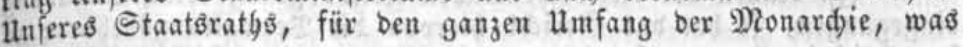
folgt:

\$. 1. Die Entfdeioung ber fiompetenztonflitte zwifd)en ben (Se= ridten unb ben $\mathfrak{B e r w a l t u n g s b e g a ̈ r b e n ~ w i r o ~ e i n e r ~ a u s ~ b l e i b e n b e n ~} \mathfrak{2}$ it= gliebern zu bifbenden Beborbe übertragen, welde unter ben Titel
"(S)eridistabof zur Entfdeioung ber Rompetengfonflifte"

befteben foll

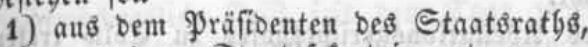

2) atts bem Staatşfefretair unb neun anberen Mifgliebern bes Staatsratbs, von benen Fünf Suftizbeamte, bie äbrigen $2 B$ ier aber Berwaltungsbeamte fein müffen. Diefe Mitglieber werben won Ilns auf oen Borfidlag bes Yräfibenten deß Staatỏratys er= mannt.

\$. 2. In ređtôträftig von ben (Serid)ten entfdiebenen Sadjen fann ber Rompetenzfonflift nidt mebr erboben werben; eben fo wenig finbet berfelbe nod). Statt, wenn in einem Srozeffe, bei weldjem eine Berwaltungsbebörbe als $3 a r t e i$ betbeiligt ift, bie von berfelben aufge=

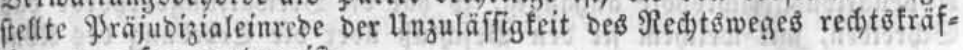
tig verworfen worben ift.

\$. 3. 3 ur Erfjebung bes Rompetenzfonflitts fino nur bie (Eens tral= unb bie Yrovimzial=23erwaltunggbeborben befugt. 5aalt eine un= tere Berwaltungsbebjorbe in einer zu ibrer Renntni fommenben Ned ts = fade bie Erbebung bes Rompetenz fonflifts für erforberlid, fo bat fie hiervon fofort ber vorgefesten Dienftbebörbe 2Anjeige zut madjen.

§. 4. Die Erbebung Des Rompetenzfonflifts erfolgt burd) Heber= fenoung eines bariber abzufaffenben motivirten Befíluffes ber $\mathfrak{B e r}=$ waltunģsbejorbe an bas (Serid)t, mit ber Erflärung:

bá̉ ber Rompetenzfonflift ertgoben werbe,

unb mit bem 2 ntrage:

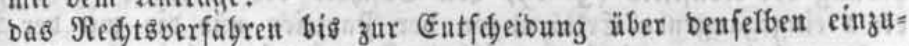
fteflen.

Beftebt bie YSrovinzialbegörbe, welde den Ronflift erbeben will,

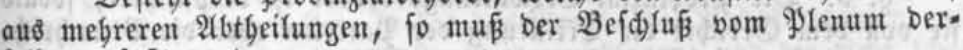
felben gefaß̧t werben.

\$. 5. Sobalo ber Sonflitt auf biefe $2 B e i f e$ (\$. 4) erfoben ift,

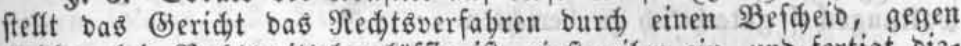

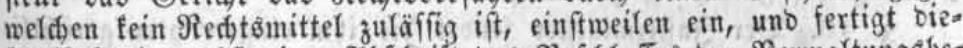

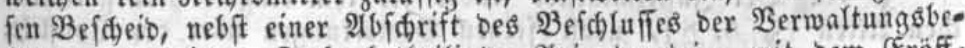
börbe, ben bei ber Sadje betheiligten Srivatparteien mit bem Eroff= 
nen $z^{u}$, bafi ibnen freiftebe, fid, binnen ciner Sräflufivfrift bon vier

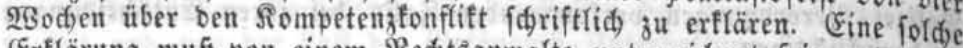
Frflärung muß̧ von einem Ređtşanwalte unterzeidjnet fein uno nebit einer 26 fdrift berfelben eingereidt werben.

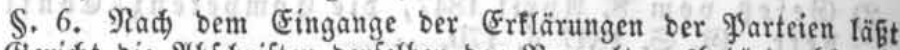

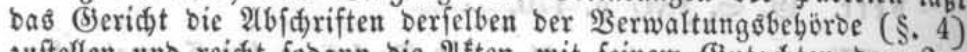
zufteflen uno reidht fobann bie eften mit feinem (Butad)ten bem Su= fisminifter ein.

Sit binmen ber viermödentliđen grift (\$. 5) feine Erflärung eingegangen, fo bat bas (jerid)t biervon bie Berwaltungsbeforbe ju benadridigen uno erft alsbann bie Aften an ben Suftijminifter ju beförbern.

\$ 7. Sit bie Sadje bei einem Untergerid)t anbängig, fo erftat: tet baffelfe ben gutad)tfiden Berid)t $(\mathbb{S}$. 6$)$ an bas vorgefeste Eane bes = Juftigfollegium, weld)es ign, unter Beifigung feines (Sutad)tens, bem Suftizminifter überreid)t.

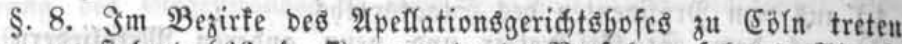
in bem vorftebeno (\$\$. 4-7) angeorbneten Berfabren folgenbe 21bweiфungen ein.

WBirb in einer bei einem friebensigeridbte anbängigen Sadje ber sompetenzfonflift erboben, fo ift ber in $\$$. 6 . gebadite 2 eridit won bem Friebensridter an ben Dber = Srofurator bes Eanbgerint t\$ zu erftatten uno von biefem alsbann gutadtlid, an ben Suftigminifter ju beriditen

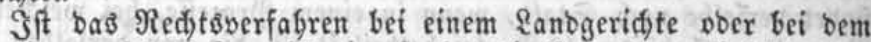
Appellationsgeriđtşofe anbängig, fo bat bie Berwaltungşbebörbe baß Sdreiben, mit weld)em fie ben Befdluß über bie Erbebung Des Rons

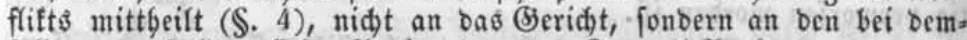
felben angeftellten Dber-9yrofurator ober Beneral=9rofurator zu rid. ten, welder bem (S)eridjte fofort bavon Mittbeilung zu maden unb,

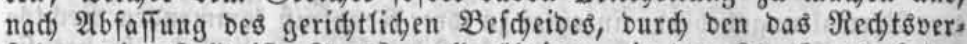
fabren eingeftellt ift $(\S .5)$, affe ibrigen, in ben $\$ \$ 5$ uno 6 ben (5eriditen vorgefdriebenen 5̧andlungen vorjunebmen bat.

Dem an ben Suftizminifter gu erftattenden Beridjte bat ber Dber=9rofurator ober Seneral= Srofurator ftatt Der Sieriditsaften, bie von ben garteien einjuforbernoen 2uften berílben, voer wenigiteng bie Labung, ferner ben Befd)luß̄ ber Berwaltungsbejörbe über bie (Er.

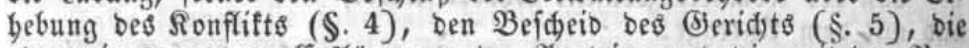
etwa eingegangenen Erflärungen Der Yarteien uno bie mit ber $23 e r=$ waltungsbebörbe na申 $\$ .6$ gefübrte forrefpondenz beizufügen.

§. 9. Die Yrovinzial=:Berwaltunggtebörbe ift verpfliditet, fobalo fie von bem (Seridte oie Erflärung ber Yarteien ober bie Benadrid). tigung empfangen bat, baß bergleiden Erflärungen niđt eingegangen fino $(\$ .6)$, unter Heberreidung ber Aften, an ben betbeiligten $\mathfrak{B} e r=$ waltungsobef gutadtlid zu beridsten.

\$ 10. Der Guftizminifter fenbet bie ifm eingereidyten geridfti= đen 2Aften ( $\$$ 6. $\times$ ), nebft feinen Bemerfungen über ben Rouffitt, weun er folde beizufügen für nötbig erad)tet, an ben im $\$$. 1 ges 
nannten (5eriatsbof, unb fest bavon ben betbeiligten Berwaltungs-

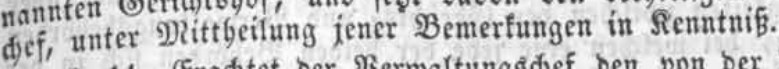

\$. 11. Eradtet ber Berwaltungsidef ben von ber Provinjialbe= borbe erfobenen Sompetenztonflift fur nidit begrimbet, fo bat er $D a=$ non ben (Seriditşof (s. 1) mit ber Erflärung, Daßi ber Antrag auf Einfteflung bes Rediteverfabrens zurüigenommen werbe, fu benad)=

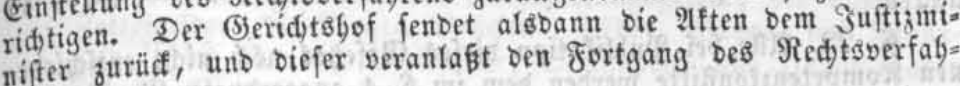
nifter furita, uno biefer veranlafit ben Fortgang Des Red)tsperfahs = xอก

\$. 12. 5ä̈lt bagegen ber Berwaltungg̊def ben Rompetenzfonflict für begriinoet, fo fteht igm frei, bem (berid)tshofe aud feine Bemer= fungen zu itberfenden; er hat biefelben aber bann aud bem Suftizminifiter mitjutbeilen.

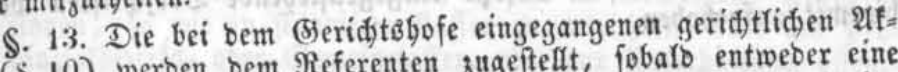
ten (\$ 10) werben bem Referenten zugeftellt, fobalo entweber eine Erflärung bes betheiligten Berwaltungşđefs eingegangen, ober eine ad) twödentlide frift feit bem Tage verfloffen ift, an weldhem ber Berwaltungsbebobroe bie zuleß̧t eingegangene Erflärung ber Yarteien,

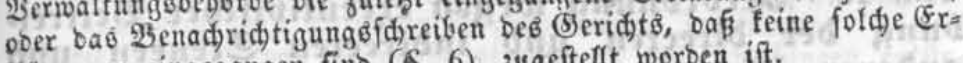
tlärungen eingegangen fino (\$. 6), jugeftellt worben ift.

\$ 14. Die Entfdcibung bes Eseridtshofes erfolgt auf ben (d)rifticiden Bortrag eines $\Re$ cferenten und cines Rorreferenten. Zum Meferenten fann ciner ber beim Staatşratbe angeftellten Biebeimen Yeferendarien ober fommij̄arifaen Şülfsarbeiter ernannt werben; ein Etiumredit ftebt iebod einem folden Referenten nidit $z^{\text {it. }}$

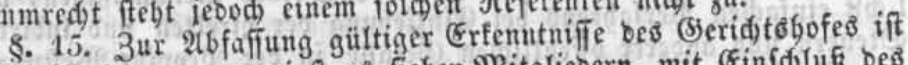

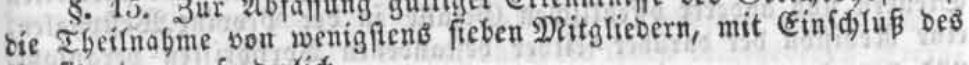
Sorfikenben, erforberifia).

\$. 16. Der Juftizminifter, fo wie ieber ber betbeiligten $B$ erwal= tungsdefs ift befugt, zu ben $\mathfrak{B}$ eratbungen bes Beridjtsbofes einen Ratb feines Departements abzuorbmen, weldjer nötbigenfalls über bie Gade näbere 2tubtunft ju geben bat, an Der Entideibung aber nidt Theil nimmt.

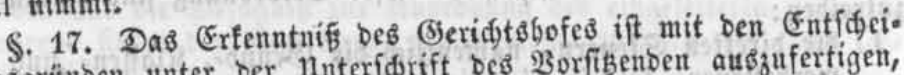

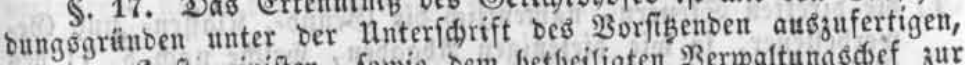
uno bem Suftigninifter, fowie bem betheiligten Berwaltungodsef jur Mittbeifung an bas (Seridt unb bie Derwaltungsbebörbe zuzuftellen. Das (5ierid)t bat ben Warteien Das Erfenntnif befannt zu madjen. Bie Beröfentlidung folder Erfenntniffe bleibt bem Ermeffen bes Juftizminifters, fowie ber 2 serwaltungsidefo uberlaffen.

\$. 18. Sît bie Entide. oung (\$. 17) gegen bie 3utaffung bes

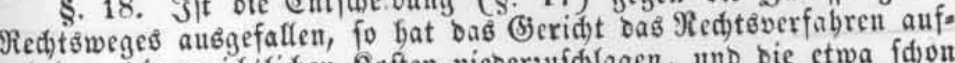
kubeben, bie geridtlid)en Soften niebergufdlagen, unb bie etwa fdon bezablten ju erftatten. 3ur Erftattung aufergeridytlidjer soften ift in eimem folden Falle feine ber Warteien verpflidetet.

\$. 19. Durd) Erbebung Deś Siompetenztonflitts wirb ber \&auf ber भुrällufinfriften im Sroieffe gebemmt, aud ift bie (Exefution bis zur Entid)cioung über ben Siompetenztonflift, unzuläfítg. 


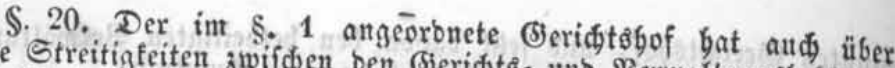
folde Streitigfeiten awifhen ben Seridts = uno Berwaltungsbeborben gu entifheiben, bei welden eine jebe ber beiben Beborben fid in ber Sadje für infompetent, unb bagegen bie anbere für tompetent bält.

\$. 21 Den $\mathfrak{B}$ erwaltungsbeböroen fint in ben vorftebenben $\mathfrak{B}_{e=}$ frimmungen (SS 1 bis 20) bie 2usseinanberfeşungsbebörben gleid) zu

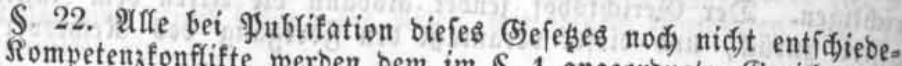
nen Rompeten $z_{3}$ fonflifte werben bem im $\$$. 1 angeorbneten (Beridjt tşbofe

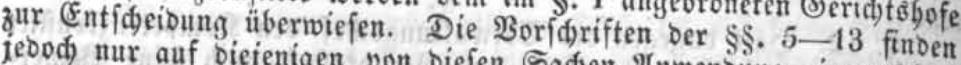
jebod) nur auf biejenigen von biefen Sadent 2tnwenoung, in welden bie 2ften bei bem Suftizminifter nod nidft eingegangen finb.

\$. 23. 2tfe biefem Befeşe entgegenfeyenbe Borfdiften werben biermit aufgefoben.

\section{Seite 15. Serorbunt twegen executivif cher 3 eitrei= bung ber birecten uns inbirecten Steuern unb anberer öfientlicher $21 b \mathrm{gaben}$ uns (Sefälle in $\mathrm{ber}$

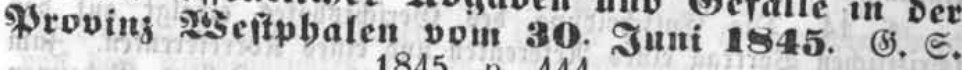 1845. p. 444.}

2Bir 2c, 2c. baben, zur Serftetlung eines gleifmäßjigen, mög= lidift einfaden $\mathfrak{B e r f a b r e n s}$ bei (Einziebung ber bireften uno inbireften

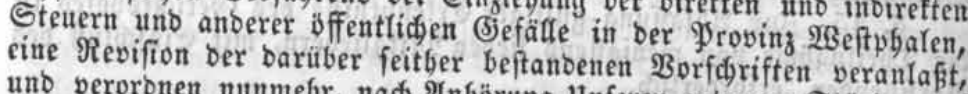
unb veroronen nummebr, nad, $\mathcal{A n f b ̈ r u n g ~} \mathfrak{H n f e r e r}$ getreuen Stänbe, auf ben 21ntrag unferes Staatsminifteriums, für bie gebadjte Yroving,

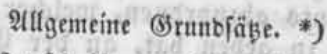
zutreiben:

§. 1. Rad ben $\mathfrak{B}$ oridjriften biefer $\mathfrak{B}$ erorbung finb fortan bei-

1) bie bireften Steutern, namentlid bie Srunb=, filafien= unb Bes: werbefteuer, fo wie biejenigen 216 gaben, welde nad) $\$ 11$ bes

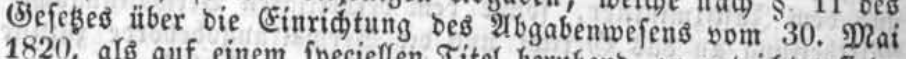
1820, alB auf einem fpeciellen Titel berubent, zu entridten finb;

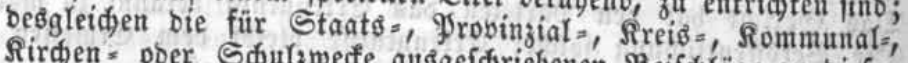

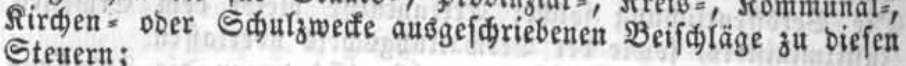
Steutern;

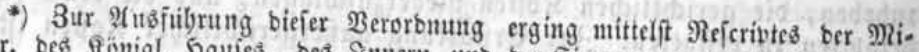

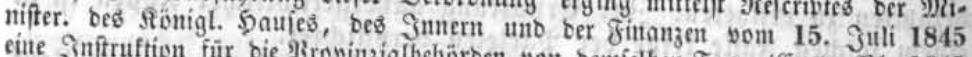

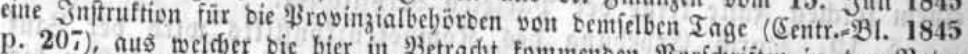
3u ben betreffenben $\$ S$. mitgetbeilt fint. 
2) bie bei bem Srunbfteutertatafter vorfommenben fortfdoreibungs:=, Bermeffung $s=$ uno anberen Bebübren, beren Eingiebung burd bie Steuer $=$ Berwaltung erfolgt ;

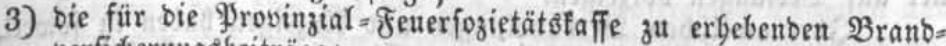
verfid)erungşbeiträge;

4) bie inbireften Steuern, bie Salzablöunggigeloer, bie Blei= unb

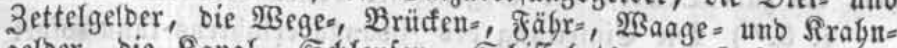
gelber, bie Rianal=, Sd)leufen=, Sdiffabrts= unb 5qafenabgaben und bie Nieberlagegelder;

5) bie von ben Berwaltungsbebjoben innerbalb ber (5renzen ifrer Amtsbefugniffe ausgefprod)enen Beloftrafen, Soften unb Entidä= bigungen;

6) biejenigen öffentlid)en $26 g a b e n$, weldje an Bemeinen, Rorporae tionen, fo wie an ftänbif̧̣e Raffen zu entriqten, ober als 9 ro= vinjialbejirf $8=$ ober Siemeinelaften, ober zur Itnterbaltung öffent= lider $\mathfrak{A}$ italten aufzubringen fino, als: Sommunal $=$, אirdjen =, Sd)ul= uno Armenabgaben;

7) bie (5) buibren ber $\mathfrak{B} e$ irfłs= צmpfärzte für bie in ben bffentlid be= fannt gemaditen Ierminen vorgenommenen Smpfungen;

8) bie in Jolge von Semeinteitstbeilungen und थblöfungen entfte= Genben, von ber (s)eneraltommiffion feftgefesten Roften und Sie= bübren;

9) Die Domanial = unb Forftgefälle, fofern fie ofne vorgängige ges ridutlide Rlage auf Eruno blofer Zablungebefegle beigetrieben werbent tönnen.

8. 2.*) Das 3mangşerfabren wirb won ben mit ber Erbe= bung ber Steuern ober (Befälle beauftragten Bebörben ober Beamten angeorbnet unb unter ifrer \&eitung ourd) oie ifnen beigegebenen (Exefu= toren ober biejenigen Beamten, beren fie fid als foldher zu bebienen Gaben, ausgefübrt. Einer geridtlidjen Bifirung ober Bolliftrectbar= erflärung ber von ben $\mathfrak{B}$ erwaltungşbeamten ausgebenben Exefutiongs befeble bebarf es überafl nidht.

s. 3. Heber bie Berbindlichteit zur Entridjtung ber geforberten

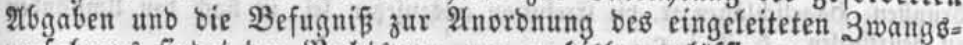
verfabrens finbet ber ßed)toweg, wo er bisber juläfíg war, aud fer= ner Statt.

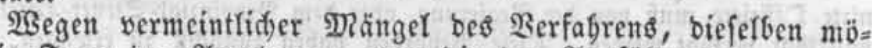
gen bie frorm ber 2 norbnung ober bie ber 2lusfügrung, ober bie zrage, ob bie abgepfänbeten Sadjen ju ben pfänbbaren gebören? be= treffen, ift bagegen nur bie Befdwerbe bei ber vorgefegten Dienftbe= biorbe bes Beamten zuläffig, beffen Berfabren angefodten wird.

*) zu \$\$. 2 unt 3. Dem \$rov. Steut-Direftor ftebt, wenn er fich ber

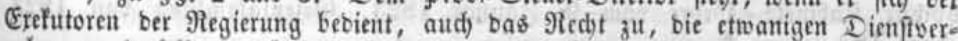

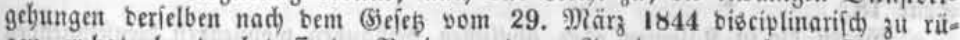

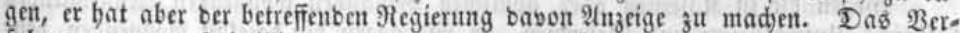
fabren wegen unfreibilliger Entlafiung eines jolden Exefutors verbleibt aber ber

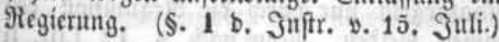


\$ 4. Die Exefutoren müffen bei igren amtliden Berriđtungen ben empfangenen fdrriftlidjen 2 fuftrag bei fid fübren unb Dem Sdjulde. ner auf $B$ berlangen vorzeigen.

SGre amtliden Berbanblungen unb 2 ngeigen baben in foweit, als fie fid auf bie ifnen übertragene (Eimziegung ber Eefäfle bezies ben, biš zum Beweife bes Bsegentbeil's vollen Bllauben.

§. 5.") Die (Finfeitung bes 3wangseerfabrens fann fofort nad Hetauf ber gefestlich feftfebenben ober ben Sdutonern befonbers bes= fant gemaditen 3ablungstermine Statt finben.

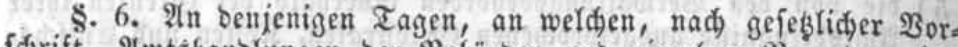

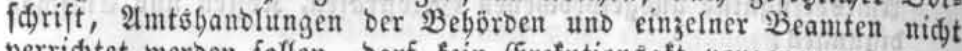
verridtet weroen follen, barf fein (Exefutionsaft vorgenommen wer= ben, eben fo wenig gegen Suben am Eabbath unb an jübiffoen Jeft tagen.

2Bägrent ber Saat = uno Ernotę̧eit bürfen gegen Yyerfonen, welde fid mit ber Eanowirtbfidaft beidaftigen, Exefutionen nur wenn Befabr im $\mathfrak{B}$ erzuge ift, eingeleitet, fortgefégt uno ausgefübrt
weroen.

Für bie Saat werben im grübjabre uno 5̧erbft iebesmal vicr. jeln $\mathfrak{Z}_{a g e,}$ für bie Ernote vier 280 en in berjenigen Sabreszeit, in welde nad, Der Dertlidfeit Saat uno (Ernote bauptfäd)lid) ju faflen pflegen, freigelaffen.

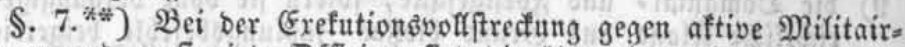
perfonen uno penfionirte Dffijiere fino bie über bie vorberige 3 enad)= ridtigung ber fompetenten Plititairbegoroe uno ïber bie Exefutions= volfftrecfung in Safernen ober anbern zu bemfelben 3wect beftimuten Dienftgebäuben beftegenben allgemeinen $\mathfrak{B}$ orjariften zu beobadten.

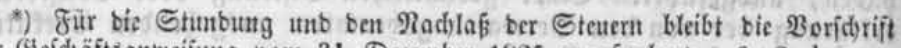

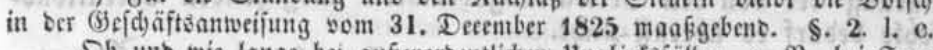

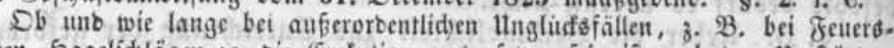

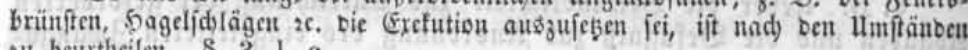
ou beurtbeilen. \& 3. 1. c.

**) Die Excfutionswollftrefung gegen aftive Militairperfonen unb penfio-

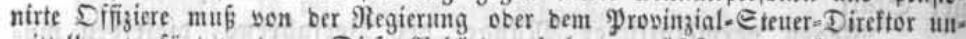
mittelbar verfingt werben. Diefe Beborten baben zunädif zu ervaigen, ob bie

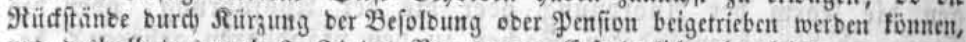
unb besblalb bas nad $\$$. 34 ber $\mathfrak{B}$ eroronumg Erforberlide einjulleitent.

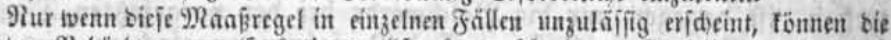

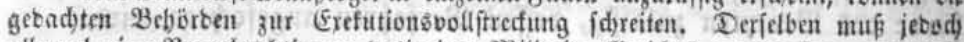
allemal eime Bentadridftigung beej jenigen Militair = (jerridfts vorangehen, von wel-

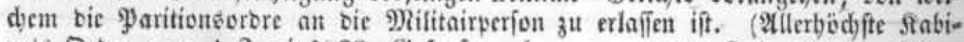

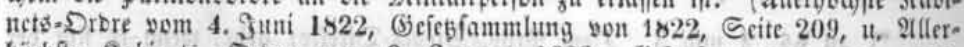

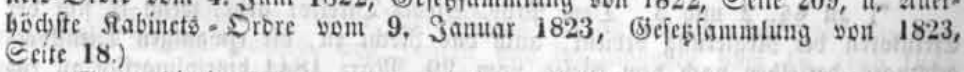

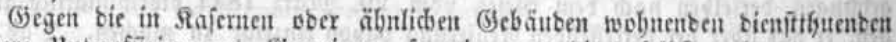
Sfifitiere, luntervfi

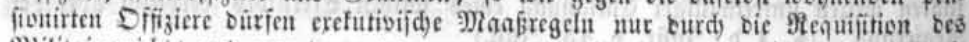

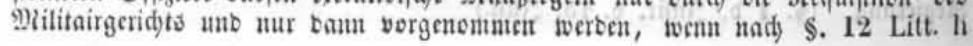


Mabunth unb Exefutions - Nnfüntigung.

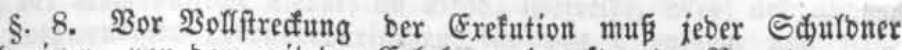
burd) einen, von bem mit ber Erbebung beauftragten Beamten aubs= jufertigenben und von bem Exefutor augatgebenben Mabnzettel auf= geforbert werben, bie barin fpeziell verzeidneten Rüđftänbe binnen 8 ¿agen einjujablen, wibrigenfall' zur গ̧fänoung ober zu anbern zuläf= figen 3 wangsmitteln werbe gefdoritten werben.

§. 9. 3u biefem Befufe werben bem Exefutor bic autgefertigten Mabngettel nebft einem, mit ber fdriftliden Rnweifung zur Mabnung verfebenen unb von bem betreffenten Raffenbeamten voll 3 ogenen $\mathfrak{B e r}=$

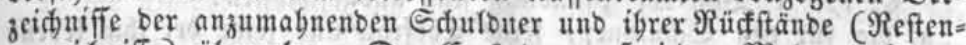
verzeidniffe) übergeben. Der (Exefutor muß jeben Dabnzettel Dem Edulber felbft ober einem erwadfenen familiengliebe ober 5aautge = nofien beffelben befänoigen uno, wie foldes geideben, unter Angabe beś Ramens Desjenigen, bem ber 3ettel jugeftellt worben, uno bes Tages ber Bebänbigung in sem $\mathfrak{D a b n z e t t e l ~ u n d ~ D e m ~ \Re e f t e n v e r g e i d = ~}$ nifle befideinigen.

Diejenigen $\mathfrak{M a b n g e t t e r , ~ b e r e n ~} \mathfrak{A n}_{n}$ abme verweigert wirb, ober berent Bebänbigung wegen $\mathscr{A}$ bwefenbeit ber vorgebadten Ferfonen nidit bewirft werben fann, hat ber Exefutor an bie 5̧aus= ober Stue bentbür bes Sdjuloners anzubeften. Die adttägige grift mirb in biefem Falle von Dem Iage gerednet, an weldem ber Exefutor bie Rabnjettel angebeftet bat.

\section{Exefution; veridjiebene 2 rten ber 3 wang gెmittel.}

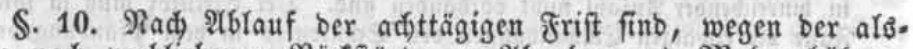

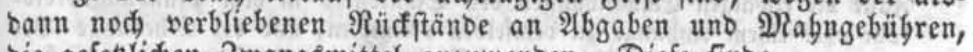
bie gefrgliden 3wangsimittel anzuwenoen. Diefe fino:

a. Die צyfänoung,

b. bie Befd) lagnabme ber Früd) auf bem Şalme,

c. bie Befdilagnabme ber ausftebenben Forberungen,

d. bie Subbaftation.

Die Subbaftation ber Srunbftüfe bes Sdulbners barf nur in bem Falle, weun auf andere 2 eife teine 3ablung zu erlangen ift, veranlafit werben.

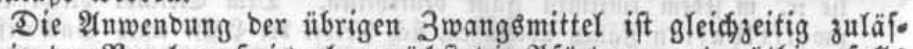
fig, in ber Regel muß jebod) junäd)t bie Yyfänoung unb nỏthigenfalls

ber $\mathfrak{B}$ erorbnung unb \$. 8. Lilt. c. ber Infruftion bie Erefution in bag Mobi= liar berielben juläfíg ift (20llerbüd) fre Rabinets = Drbre yom 8. November 1831,

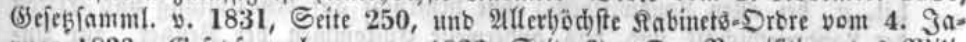

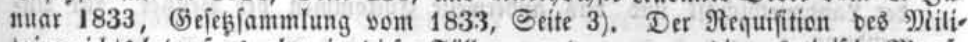

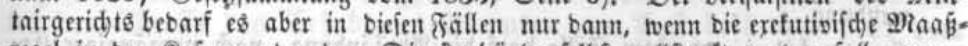
regel in ber $\Omega$ ajerne ober bem Dienitgebäube felbjt vollftreft werben foll, woges gen biejenigen erefutiong]äbigen (5egentünbe einer it ber Sajerne wobnenben शi:litnirperion, weld)e fid) außerbalb bes Dienifgebäubes befinben, obne Mtitwirfung

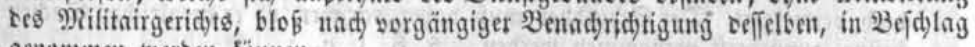
genommen werben fömen. 


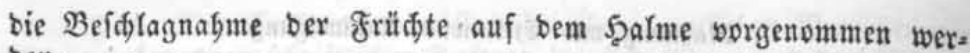
ben.

gfä̀ntung.

\$. 11. Die Yyfänbung barf nur auf ben (5runt eines, von bem Raffenbeamten ausgefertigten Yfä̈nbungsbefegls vorgenommen werben. Sraft beffelben ift ber Exefutor befugt, bie im $B_{e}$ efibe bes Edjuloners befindlidyen pfanbbaren bewegliden Sadjen, imgleiden bie Fridgte auf

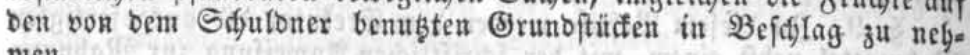
men.

S. 12. ") $\mathfrak{B o n}$ ber gyfänbung fint autsgefdfoffen:

a. Die für ben Eduloner, feine Eggefrau uno feine bei igm leben= ben Sinber unb EItern nah iGrem Stanbe unentbefrliden Betten,

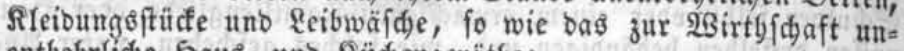

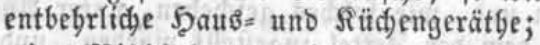

b. eine Mildfuly ober, in beren Ermangefung, zwei Zirgen, nebft bem zum Unterhalte und zur Etreu der freizulaffenden Thiere erforberligen Futter unb Strog für einen 2onat;

*) Sinfidutlich ber, ber gfänoung nidjt unterworfanen (Segenftinbe if Mad.

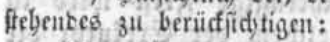

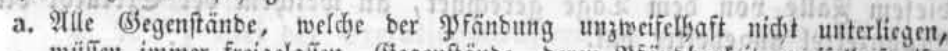
militent immer freigelnijen, (5egenftänbe, beren $y$ füntbarfeit ztweifellbaft ift, bagegen in Beidlag genemmen werben, went mbere tauglidge yfanteftude

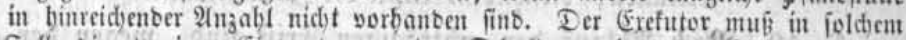
Jafle tie etwahgen Emtventungen bes Edjuloners in bem भifäntungsproto= folle oter cintem 2tnbange zu bemifelben vermerfen, unt ber (Ert)ebungs. Be. nute bemnädft befimunen, ob bie Sndjen freizugeben voer zu veräufent fint. (3) egen bie Entidjribung bes Erbebungs - Benuntent if fluar eine $\mathcal{B}_{c}$ -

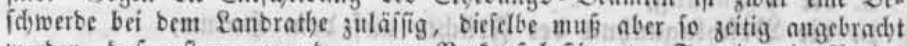
werben, bnf erferem ver bem zum Berfauf beftinumten Termine eiu 2 erbot zugebent faum.

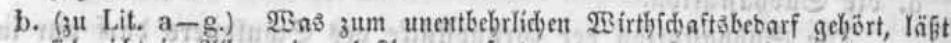
iid nidft im 2llgemeinen befimmen, fonbern nur nad ben obwaltenben $11 \mathrm{~m}$.

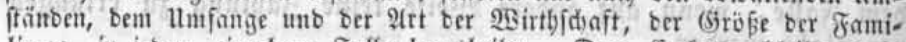
lie 2c. in jebem einzelnen falle beurtbeilen. Dem (Erefuter bleibt es itt

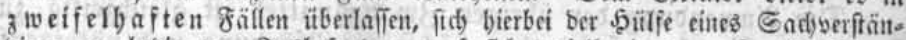

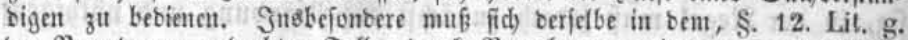
ber $\mathfrak{B e r o r b n u n g}$ gebadten Falle, Durd) $\mathfrak{B}$ ernehmung mit bem Drtsvorftante

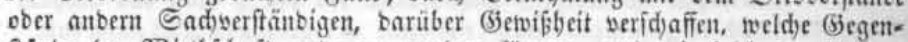

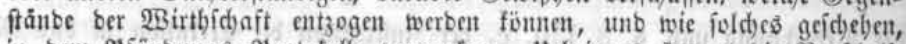

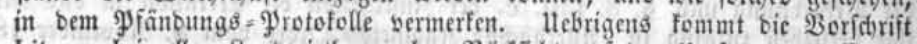
Lit. g. bei allen Lanbwirtbent, obue Rüfficht auf ben llmfang umb Ertrag ber \&anowirtbidjait uno bas anberweite Eimfommen ber Befíber, zur 2thtwenbung.

c. in bent Lit, i. gebadjten falle barf bie 2tbpfänbung, nad) vergängiger (Ertwirfung einer 9aritionsorbre, nur erfolgen, went bie 27ilitairperjon (5)genftänbe ber bezeidjneten 21rt zu befiken cinrüumt, bie Seraußgnbe berjelben je. bod) verweigert. Der Sdjulbuter muß baber baribber, ob er bergleidjen Sadjen beifige, zuvorberf vernomment tverben, 5.8 . 1, c. 


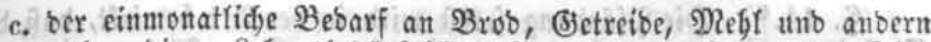
notgwentigen \&ebensbebuirfniffen für ben Sdulbner: uno feine Familic;

d. ein zum Ђ̧eizen unb Rodjen beftimmter eifernter $D$ fen;

c. bei Rünft'ern unb Şanbwerfern und Tagelöbnern bie zur fort= fesung ibrer Runft, ibres (5ewerbes unb ibrer 5aanbarbeiten er. forberliden 2 Gerfzeuge uno anberen Begenftänoe, mit ber in bem Bsewerbefteuergefeģe vom 30 . Dai $1820, \$ .35$ vorgefdricbenten Maaßigabe;

f. bie Büdjer, welde fid auf bas (5ewerbe bes (S)epfänbeten be= zieben, fo wie bie $\mathfrak{M}$ afdinen unb Inftrumtente, welde jum $\mathfrak{H}_{\mathrm{n}}=$ terrid)te ober fur 2 usïbung einer $2 B i f i e n f d a f t$ uno funft gebö= ren, bis zu einem $2 B$ ertbe von $80 \Re$ tblrn. uno nad ber $\mathfrak{B a b l}$ bes (B)evfänoeten;

g. bei Yerfonen, weld)e \&anowirtbfjaft betreiben, bas bierzu nös thige (Seräth, Bieb) uno Feloinventarium, ber nòthige Diunger, fo wie bas bis jur näditen Ernote erforberliche Saat= uno Jut= tergetreide;

h. bei Pilitair= und Civilbeamten bie zur Berwaltung ibres Dien = ftes erforberticjen (Begenftänbe, ingleidien anftänbige RTeiber unb 23ä́d)e, welde aud ben penfionirten Beamten uno Militairper= fonen att belaffen find;

i. bas Mobiliar bienftthuenber Dffiziere, Itnteroffiziere unb Sol= baten, weldes fid an bem (jarnifonorte berielben befindet, in= gleidyen bas Mlobiliar ber mit Wenfion zur Dispofition geftellten Dffiziere, weldies fich an bem Drte befinbet, ber ibnen zum (SsenuE bes Serwifes angenviefen ift, fofern fie fid bafelbit auf= Galten.

(S) Rleinobien finb von ber Yffänoung nid)t ausgenomment.

\$. 13. Ojegen bie grfänoung fann fíd, ber Sdjulbner nur fdyïzen, wenu berfelbe entweber:

a. bie volfitänoige Beriđtigung ber beizutreibenbent Summe burd Duittungen ober Borlegung eines Yoftfdecines fofort madureift, voer

b. cine friftbewilligung ber fompetenten Bebörbe vorgeigt, ober aber

c. zur 2 bfïgrumg ber beizutreibenben Summe und Bezablung ber Exefutionsfoften fogleid bereit unb im Etanbe ift.

In biefem lebten Falle, fo wie in bem Jalle, wenn ber Edulbner einen Tbeil feiner Sdulo fofort abtragen wíl, mus bie abzufübrente Summe in Siegenwart bes Exefutors verpact uno un-

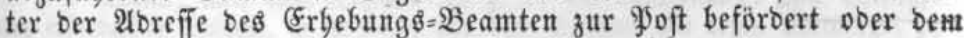
Drtôvorftande jur weitern $\mathfrak{B}$ eförberung übergeben werben.

Ân ben Exefutor bürfen feine Zablumgen, felbft nidit für (Exe= futionsfoften, geleiftet werben; Die S̄duloner baben basienige, was an biefen gezablt ift, bei etwaiger Ridhtablieferung nod) einmal zu entrictjten. 
\$. 14.") Die आfänbung felbft wirb in ber 2 rt bewirtt, bafi ber Exefutor von ben vorbanbenten pfänbbaren Begenftäntent eine zur Defung ber beizutreibenben Summe anb ber Exefutionstoften nad feinem Ermefien Ginreidjenben Betrag in Befdlag nimmt unb fider= felft; unb zwar zunädfit biejenigen Begenftänbe, welde am leidgte. ften transportirt unb veräufiert werben fönnen.

Der Sdjutbner ift, nadbem ifm ber Yfänbungsbefebl vorgeYegt worben, verpflidstet, feine Effeften unb 5 sabfeligfeiten vorzuzeigen

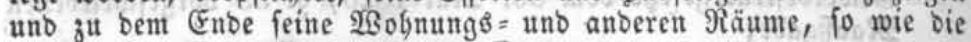
Darin befinoliden Bebältnifie zu offnen.

2lud Eadjen, weldje angeblid britten Yerfonen gebören,

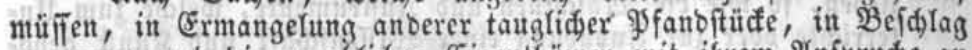
genommen uno bie angebliden Eigentbümer mit ibrem 2 nffprude an bie Belbörbe, von welder oer Yyfänbungsbefebl ausgegangen ift, ver= wiefen werben.

\$. 15 Sadjen, weldie auf bas 2(nbringent anberer Bläubiger be= reits gepfänbet worben, finb nur in Ermangelung anberer tauglidjer Yfanoptitcfe, burd, Antegung eines Euperarreftes, mit Befdlag jube legent. Dies gef́diebt in ber $\mathfrak{A r t}$, baß̄ ber Exefutor bent etwa ange= Yegten Siegeln fein 2 Amtsfiegel beifügt unt bem Sd)urbner vber bem

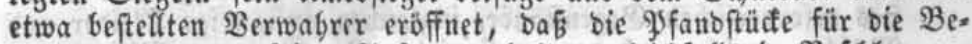
Görbe, won ber er feinen 2tuftrag ergalten, gleidffall in Befdlag ge= nommen feien.

Der Bebarbe, auf beren Berfüguthg bie frübere Yfäntung Statt gefunben, ift bie 2Antegung bes Superarreftes anzuzeigen; bie=

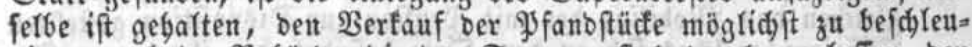
nigen, audy ber Bebörbe, bie ben Stuperarreft bat antegen laffen, ben Berfaufştermin betaunt zut madjen uno barauf zu feben, bá̉ beibe Forberungen, nämliđ biejenige,

wegen welder zuerft bie Exefution soffiprectit,

unb biefenige,

wegen welder fpäter ber Superarreft angelegt ift, aus bem gelöfeten Raufgelbe nađ ber gefę̧lichen Dronung befriebigt werben.

Finbet ber $\mathfrak{B}$ erfauf nidjt Statt, fo bürfen bie Yyfanbffüffe nutr nit Benebmigung ber Befgorbe, in beren 2 fuftrag ber Superarreft angelegt worben ift, freigegeben werbent.

§. 16. Bei ber Yyfänbung ift bie 3uziefung bes Drtsvorftanbes, eine ober mefrerer Bemeinex ober \$oligeibeamten, ober zweier unbes

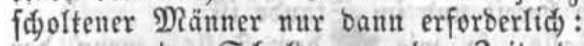

a. wetu ber Sdiulbner zu ber Zeit, ba bie \$fänoung vorgenommen werben foll, fid) entfernt bat,

*) Sobalo eine zur Dečung ber fidjer ju fteflenben Summe binreidjente

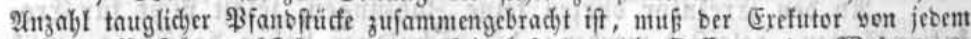
weiteren 2 erfabren nbiteben, uno barf inbbejonbere bie Deffinung ber 25 olnumggs unto anberent Räume, - jo twie ber barin befintlidjen $\mathfrak{B}$ ebältnifife nidjt tweiter verlatgett. \$. 9. I. c. 
b. went ben Anorbnungen bes Exchutors wegen Deffnutth ber 1306 :

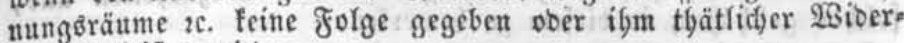
ftano geleiftet wirb.

Sn (Seqenwart ber obgebaditen જerionen fant bie Y̧fänbung nöthigenfalls mit (S)ewalt vorgenommen werben. Sift ber 2 Biberftano auch auf bicfem $23 e g e$ nid)t zu befeitigen, io muf ber Exefutor bas you ber 2 ebörbe, in beren 2 uftrage er banbelt, 2 nzeige madjen, bieie aber bas Erforberlide wegen ber bem Exefutor zu gewägrenben ફ̧ülfe nad ben bierüber beftebenden (Sefeken veranlaffen.

\$. 17.") 2Ugepfänbete baare Gieloer uno auf jeben Snbaber laue tenbe Yapiere miffien, wenn bie Raffe fid nidjt am Drte felbit be= finbet, won bem Exefutor in (5)egenwart beछే Sd)ufoners ober ber bei

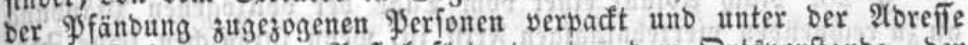
bes Raffenbeamten jur Y̧oft beförbert, ober bem Drtsెvorftanbe, ber fur $\mathscr{A}$ nabme unb weiteren Beföberung verpfliditet ift, übergeben werbent.

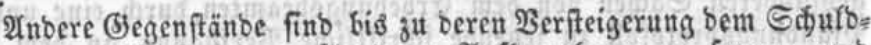
ner gegen bas Berfprechen, für beren $\mathscr{A}$ ffbewabrung zu forgen, unb unter Berweifung auf bie Strafen ber $\mathfrak{B}$ ereitelung ber Pfänoung łu belafien.

Nur bei 1tnguberläffigfeit bes Sdulbners finb bie gepfänbeten Sađen einem zablungsfäbigen (5emeinemitgliebe ober bem Drtsvor= fande zur $\mathscr{A}$ ufbewabrung zu übergeben.

Werben Sadjen, beren Benubung ofne Berbraud nidht mög=

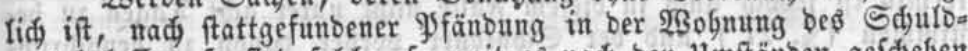
ners belafien, fo fino folde, fo weit es nad) ben Umftänben gefdeben

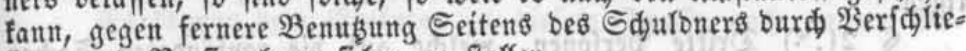
fung uno Berfiegelung fider fut ftellen.

\$. 18.*x) Ueber ben Jeergang bei ber צffänoung muß ber Ere= futor an Drt utto Stefle eitre Berbanblung aufnebmen, uno forde nidit nur felbft unterfidreiben, fonbern aud von bem Edulbner ober beffen Steflvertreter unb affen bei ber જyfänoung zugezogenen Yyerio: nen unterfdreiben laffen, ober aber ben (Srunb ber feblenben Unters fdriften vermerfen.

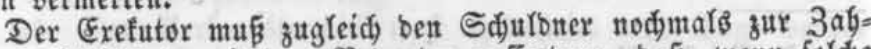

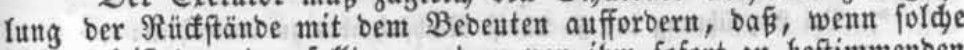
nidjt geleiftet werben follte, an bem von ibm fofort zu beftimmenten Tage jum Berfaufe ber 9 fanbftïcfe gefódritten werben wiurbe.

Dem Sdulbner, fo wie Demienigen, bem bie gepfänbeten Sadien etwa in Berwabrung gegeben finb, ift von bem Exefutor fo

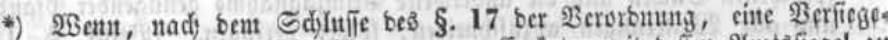

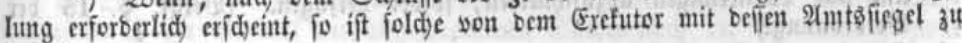
betwirfen, \$. 11. I. c.

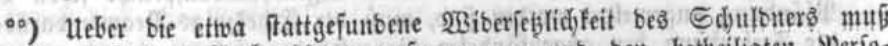
immer eine bejonbere $\mathfrak{B}$ erbanblung aufgenommen uno bett betbeiligten \$erionen, weldje babei gegenwärtig geive[en finb, żur thnteridjrift worgelegt werben. 6. 12. I, c. 


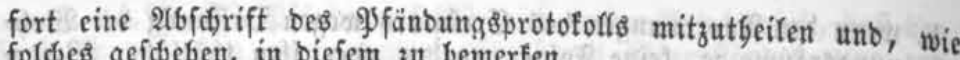
foldes geideben, in biefem zu bemerfen.

Die 2 ufnabme einer Berbanblung if aud bann erforberlid, wenn bei bem Sdulbner feine yfänbbaren Begenftänbe vorgefun
Den finb.

\$. 19. Sa anblungen, burdh welde eine in $\mathfrak{B}$ erwaltungswege be. wirfte 9 fänbung beweglider Saden vereitelt wirb, folfen eben to beftraft werben, wie biejenigen, burd, welde eine geridttidge Yfän. bung vereitelt wird.

\section{Berfaut ber abgepfähtbeten ভadjen.}

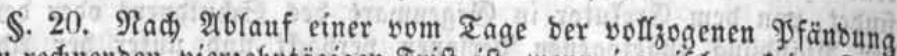
an gu redjuenben vierzebntägigen grift ift, wenn inzwifden teine 3ab. lung erfolgt, uno feine (Eigentbumsanfprudde Dritter red) tzeitig ans gemeloet und befdeeinigt worben fimb, ber bffentlide Berfauf ber $a b=$ gepfänbeten Saden von bem (Ergebungsbeamten burd) eine unter bas

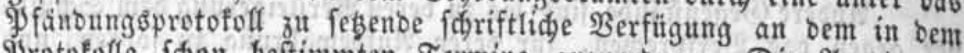

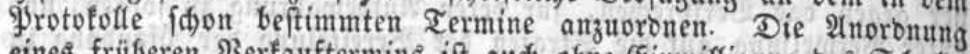
eines früberen Bertauftermins ift aud ofne Crimwifligung bes Sduto. ners zuläffig, wenn bie abgevfänbeten Saden bem Berberben unter: worfen find, ober in ber bebaufung bes Edjutbners wegen befien ulnzuverläffigteit nicht belaffen, anberweitig aber nur gegen unverbalt= nifmäß̈ig bobe Sioften untergebradit werben fönnen. Der $\mathfrak{B}$ erfaufs $=$ termin if jebod aud in biefem galle nidjt unter adyt Iagen $z^{u}$ bea ftimmen (\$. 21) uno ber Sdulbner vorber bavon za benadrids= tigent.

\$ 21.*) Dritte gerfonen, welde auf bie gevfänbeten Sadien Eigentbumşanfprüd)e baben, milffen biefe, obne Hnteridieb, ob fie bei ber Sfänbung angemeloet worben fino ober nidjt, binnen ad, Iagen

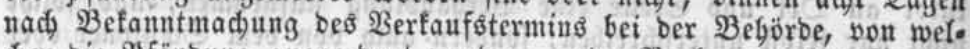
dier bie \$f fänoung angeorbnet worben, unter Borlegung ober 2ugabe ber Titel, worauf fie fid grimben, befdeinigen.

*) Bei 2(usfiübrung bes \$. 21 ift Madjiftebenbes zu beobadjtent :

1) 2Berben innerbalb ber adjttägigen zrift (Eigentbumbaniprüd)e nigemelbet,

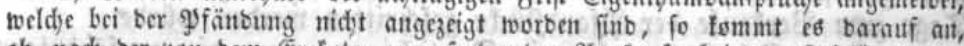
ob, nad) ber yon bem Erefutor zut erforbernten 2ubfunft, bei bem Edyulbuer an-

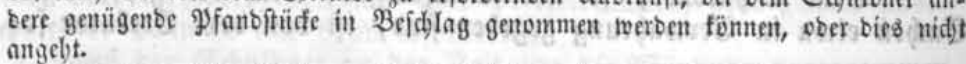

a. In bent erftent Falle mur ber Erbebungsbeamte bie freigebung ber ange-

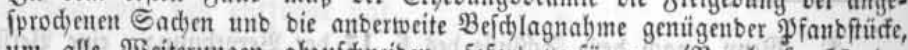
um alle 28 eiterumgen abzufd)neiben, fofort yerfügen. (Bergl. \$. 15 ber Berorbunug.)

b. In bem zweiten falle, fo twie, went Eigentfumbanfiprüdye fidon bei ber

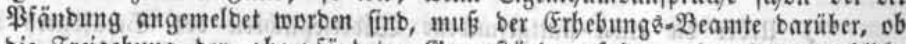
bie Freigebung ber abgepfänbeten (j)genftänte erfolgen ober ber angeblide

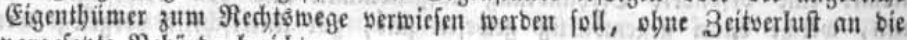
vorgeféţe Bebürbe beriditent. 
2Birb ber 24nfprud nidgt beideinigt, fo begäIt ber Berfauf fei= nen Fortgang; if aber eine Befdeinigung beigebradt, fo ift, nad Befinben ber Umitänoe, bie Freigebung ber Sadien zu veranlaffen voer ber angeblidje (Eigentbümer burd) eine fdififtlidje $\mathfrak{B}$ erfügung zum

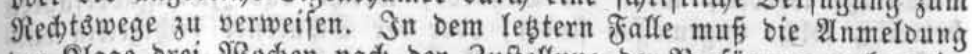
ber Slage brei 280 oden nad) ber 3uftellung ber Berfügung nadggewiefent werben, wibrigenfalls mit bem $\mathfrak{B}$ erfaufe ber Sadjen vorgefdrit= tenl wirb.

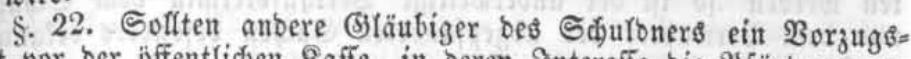

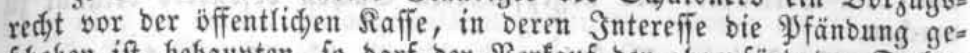
fdeben ift, begaupten, fo barf ber $\mathfrak{B}$ erfauf ber abgepfänbeten Eachen

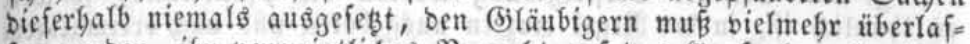
fen werben, ifgr vermeintlides Borredjt auf bas̉ Saufgelo gelteno ju madjen.

EG biger gepfänbeten Eadjen auf 2intrag bifer (5läubiger verfauft wor-

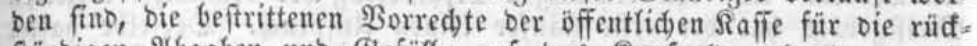

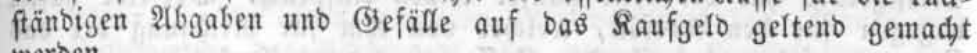
werben.

§. 23. Die 2G6galtung bes $\mathfrak{B}$ erfaufes muß burd ben Exefutor auf Dem $\mathfrak{D a r f t p l a b e}$ ober an einem andern offentliden Drte ber (Bjes meine, wo bie gffänbung ftattgefumben, gefdeeben. (Es bleibt jebod) bem $\mathfrak{B}$ eamten, welder bie Einleitung bes 3 wangeverfabrens angeorb= net bat, unbenommen, ben Exefutor bei bem Serfaufe, fo wie bei ber Yfänoung, ̧u beauffidtigen uno zu leiten, uno beşgalb bei diefem Exefutionsafte gegenwärtig zu fein.

amte beigegeben werben.

(Es fönnen bem Exefutor zu biefem 3wefe aud anbere $\mathfrak{B}_{e}=$

Berjpridit ber Berfauf an einem benadbarten Drte eine vor= theilfaftere Berfilberung ber YS fandftüffe, ofme bie Trangporttoften unverbältnif́mäfig z̆ vermebren, fo ift biefer anz̧uoronen.

Der 2 erfauf in ber Bebaufung bes Shulbners ift mur bann nadjugeben, went nidjt obne Serwenbung bebeutenber Soften ber Berfauf anberşwo auşufübren ift.

§. 24. Der Berfaufôtermin muß̄ fpäteftens ađt Tage vorber

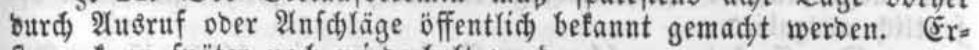
fterer fann fpäter nod wiebergoft werben.

Şaben bie in bemfelten Termine jut verfteigernbent Begents

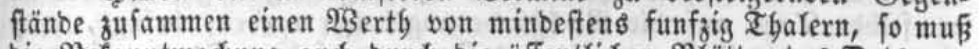

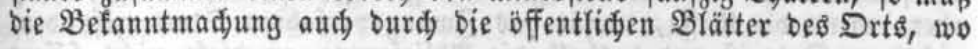

2) Bei einer yerfpäteten 2 (nutelbung unb Bejojeinigung ber Eigentfumb. Pnfprüdje ift ber Berfauf ber angefprodienen Sadjen nady ber Berorbuung $3^{\text {twar }}$ zuläjifig, aber nidjt unbebingt yorgejdrieben. 2tud) veripätete 2(nmelbungen muifien

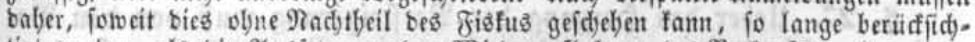

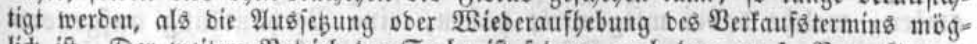
lid) ift. Fer weitere Betrieb ber Sadje ift fobam nad) bem żu 1. Bemerften ju leitent. §. 13. l. c.

Supplement. 
ber Berfauf ftattfinben foll, ober, wenn bafelbft feine folde Brätter erfdeinen, burd bie cines zunädfft belegenen Drtes erfolgen. Rod anbere 2 rten ber $\mathfrak{B}$ efanntmaduntg, als bie vorgefdriebenen, tönnen veranlafit werben, wenn bie Beborbe, welde bas 3wangsverfabren betreibt, folde angemeffen finbet, ober ber Sdjuloner red)tzeitig bar. auf anträgt unb bie erforberlidjen Roften bezablt. Rann ber Berfauf nidit in bem, im Sy fänbungg̈protofolle anberaumten Termine abgebafe ten werben fo ift ber anberweitige Berfaufstermin bem Sdylonet unb bem $\mathfrak{B e r w a b r e r}$ ber abgepfänbeten Sadjen befonbers belamnt ju madjen.

\$. 25. Bei ber פerfteigerung werben bie IJfanbftüde, fo weit es tbunlid, ift, in ber $\Re$ egel einzeln ausgeboten unb nad) breimaligem

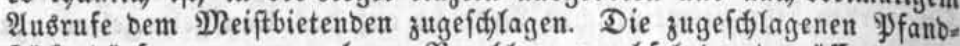

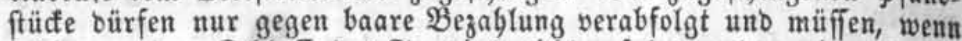
folde vor bem Sdgluffe bes Termins nidjt erfolgt, anberweit ausgebo= ten werben. 2Af ben etwanigen $\mathfrak{D e b r b e t r a g}$ bes bemnädft ergielten Meiftgebots bat ber erfte Räufer feinen 2unfprud). Derfelbe baftet

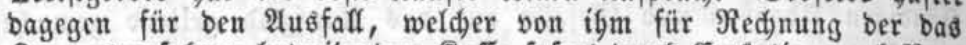
3wangsverfabren betreibenben Raffe fofort burd) Exefution nad $\mathfrak{B} 0$ r. fidrift biefer Dronung beigetrieben werben fann.

Der Drtgoorftand ober ein von biefem bezeidneter S5emeines ober Solizeibeamter muß̧ Dem Berfaufe beiwobnen.

Diefer Beamte fowobl, ald berienige, auf beffen Betreiben bas 3wangsiverfabren angeoronet ift, uno ber Exefutor bürfen auf bie gu verfteigernben Begenftänbe weber felbft mitbieten, nod burd $\mathfrak{A} \mathfrak{n}=$ bere für fid) mitbieten Yalfen.

§. 26. Die Berfteigerung mús eingefteflt unb bie nod unver=

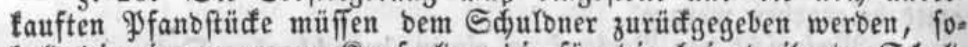
balb bie eingegangenen Raufgelber bie für bie beizutreibenbe Sduld unb für fämmtliáse fioften binreiđenbe Decfung gewäbren ober bie feblenbe Summe baar eingezablt wirb.

(5) faut bie Fortfeşung bes Exefutionşverfabrens baburd abgewenbet

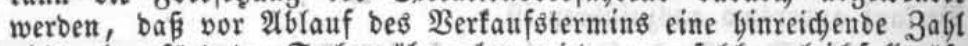
niđt abgepfänbeter Sadjen übergeben wirb, um foldje gleidffalls öfs fentliđ auฐ์

Der Exefutor, welder ben Şerfaufgitermin abbält, ift zur $\mathfrak{A}$ = nabme alfer (Jelber, welde aus ber Berfteigerung eingeben, ober an bemfelben Tage auf bie Rüffftänbe angeboten werben, befugt, muß aber, wenn bie Raffe, wofür bas 3wanggeverfabren Statt gefunben, nidit am Drte ift uno besbalb bie 2ublieferung an biefe nidit fofort erfolgen fant, biefelben in (S) genwart bes Sd)ulbners oder ber bei bem Berfaufe zugezogenen Yerfonen verpacfen uno unter ber 21breffe beß Raffenbeamten zur \$oft beförbern ober bem Drtß = Borftanbe zur wei= tern $\mathfrak{B}$ eförberung ïbergeben.

\$. 27. Heber ben 5ergang ber $\mathfrak{B}$ erfifeigerung mußs von ben $\mathfrak{B} e=$ amten, welde babei mitgewirtt baben, eine Berbanolung aufgenout= men unb foldse aud) bem Ed)ulbner, wenn berfelbe gegeniwärtig ge= wefen ift, zur unterfdrift vorgelegt werben. 
\$. 28. Späteftens binnen 8 Tagent nađi ber $\mathfrak{B}$ erfefeigerung muß ber Siaffenbeamte bem Sdjutbner, weldem auf befonberes Berlangen eine Nadyweifung über bie Berwenbung ber 2Auttionslofung, nebft ei=

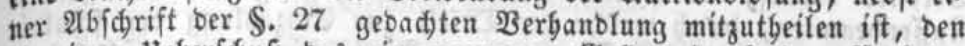
etwaigen Meberfouf bes eingegangenen (5elbes burd) ben Exefutor guftellen laffen. Sft bie 2tuftionslofung unzureidient, fo ift bem

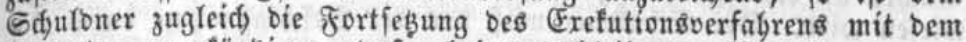

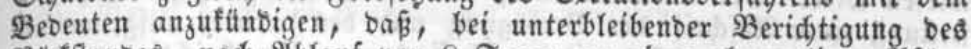
Ritufftantess, nad 2iblauf von 8 Tagen zu einer abermaligen 95 fän* bung ober fu andern 3 wangsmitteln gejd)ritten werben würbe.

§. 29. Bon ben $\$ \$ .20$ bis 26 aufgeftelften $\Re$ egeIn finben nach=

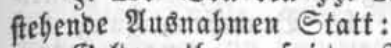

a. Bielowertbe, auf jeben Sngaber lautente \$apiere finb, wenn nidyt binnen 8 Tagen nad) ber Befd́lagnabme (Eigentbumsanfpridide won Dritten angemeloet worben finb, an bie Negierung $\delta=5$ Saupt $=$ Eaffe zur $\mathfrak{B} e r f i b$ berung eingufenbent.

b. 2usgebrofdenes Setreibe, Seet, Eebensemittel unb anbere Begen= ftänbe, weld)e einen gemeinen Marftverfegr Gaben, fönnen mit 3uftimunung bes Sduldoners obne vorberige Serfteigerung uno Betanntmadyung, an Drt uno Stelle für ben Ieß̧ten Marttpreis verfauft, voer aber, wo möglid mit bem (sefpanne beß Sduld = ners, auf ben nädffen 2 arft gefabren unb bafelbft verfilbert werben.

c. Bjoldene und filberne Beräthe bürfen nidjt unter ifrem Borb= ober Silberwertbe zugefdilagen werben, Rleinobien unb Runfte facjen nidt unter bem \$reife, zu weld)em fie von Runftperftän

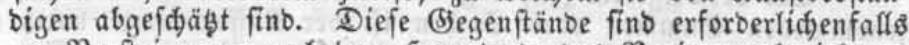

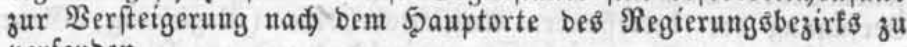
verfenten.

Befd)lagnalyme ber friidte alf bem Şalme.

§. 30. Früd)te auf bem 5JaYme büfen nur in ben Yegten fed)s

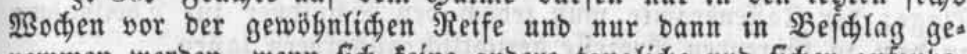
nommen werben, went fid feine anbere tauglidje unb fidjer aufjube= wabrente Wfanoftüfe vorfinben. (Fin Drittel ber Ernote ieber grudytgattung ift von ber Befidlagnabme frei zul Iaffen.

Bon ber beabfidtigten Befdlagnabme muß bem Sdurbner pber feinen 21ngeförigen mit ber 2ufforberung, babei gegenwärtig zu fein, Nadyridt gegebent werben. Die Befdlagnagme wirb bemnädit in ber $\mathfrak{A}$ rt volfogen, baß̧ ber Exefutor bie gelber, auf welden bie

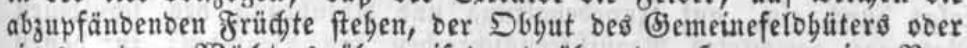
eines anbern $\mathfrak{T}_{\mathcal{B}}$ ädters tiberweifet uno über ben Syergang eine $\mathfrak{B}$ er= Ganolung aufnimmt, von weldjer bem felbyjuter poer 23 ähter, fo wie bem Sdulbner, 2abfdrift zu ertbeilen ift.

Sm Heorigen fommen bie $\mathfrak{B}$ oridgriften $\$ \S .11$ bis 27 zur $\mathfrak{2} \mathfrak{t}=$ wernbung.

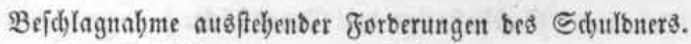

\$. 31. Die Befdlagnagme aufftebenter, won bem 2trrefte ges feģtidi nidht befreiter gorberungen voer bei einem Dritten befinblider 
Sađien bes Sdulfoners erfolgt, nit ber ${ }_{2 B i r f u n g}$ einer geridflident

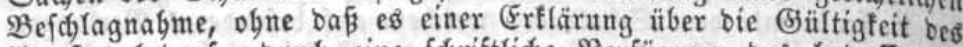
2(rreftes bebarf, burd) eine fdriftlide $\mathfrak{B}$ erfügung bes betreffenten Raffenbeamten, burdh weldye ber Dritte zur Einzablung ber fouldi= gen Summe an bie Rafife ober zur 2tusgänbigung ber fdurtigen Sadjen an ben Exefutor fum 3weffe bes öffentlichen $\mathfrak{B}$ erfauffo ange-

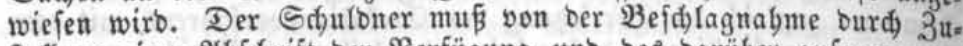
fteflung einer $\mathfrak{A} b[d$ rift ber $\mathfrak{B} e r f u ̈ g u n g$ unb bes bariber aufgenommes nen 3uftellunggvermerfes mit ber Aufforberung benad)ridfigt werben, bie iiber bie Sdjuld vorbanbenen Urfunben, bei $\mathfrak{B} e r m e i b u n g$ ber zus

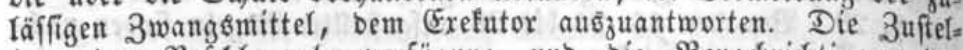

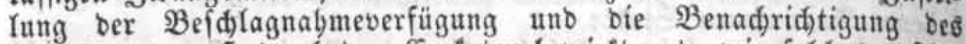
Ed)ulbners muß̧ burd ben Exefutor berwirtt unb, wie fold)es gefdese

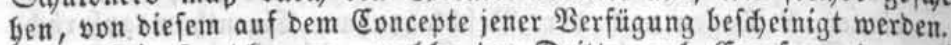

Die Şantlungen, welde ber Dritte nad) Empfang ber, oie

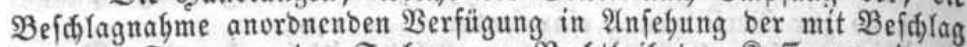
belegten Summen ober Sadjen zum Radjtbeil ber Raffe vornimmt, werben in $B$ ezug auf bie lekztere bergeftalt als nidjt gefidelyen ange=

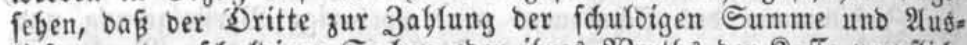

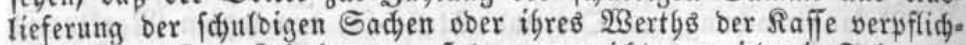
tet bleibt. Der Sdjulbner muß bagegen nidjt nur jeoe in golge ber Defdlagnabme zum Beften jener Rafle geleiftete 3ablung ober gea fisebene 2tustieferung anerfennen, fonbern fid aud, alter Eeffiton, Berpfänbung ooer anderweiten Dis̄pofition inber bie in Befálag gea nommenen Summen ober Saden enthalten.

Bei verweigerter 3 ablung ober 2 tusantwortung ber in $B e f d l a g$ genvmmenen Summent voer Sadjen ift ber Raffenbeamte burdi eine

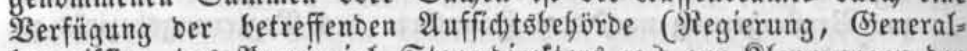
fommiffion, bes Grovinzial = Steuerbirettors $2 c$.) zur ßilage gegen ben Dritten zu ermädtigen. Diéfe Ermäd)tigung vertritt bie Etelle eí ner, Seitens bes Sdyufoners ertyeilten 2(nweifung unb 20 oflumadt zur Silage; ber Raffenbeamte muß jebod) ben Esfuloner zur Ifgeilnagme an bem zu fübrenden \$rozeffe geridytlid, aufforbern Yafien.

\$. 32. Befteft bie Forberung bes Sdjuloners in Renten, beren offentlidge Berfteigerung zuläffig it, to fann ber Siaffenbeante, auf

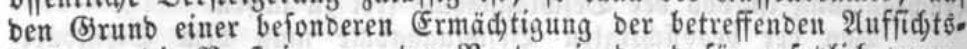

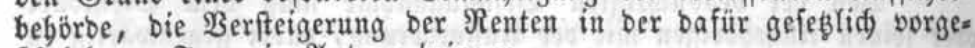
fodriebenen Form in $\mathfrak{A}_{\text {ntrag bringent. }}$

\$. 33. Die Befdlagnabme von Befortungen uno \$enfionen er= forgt ourd ein, auf Snnebelaltung uno 2affitgrung bes iffuldigen

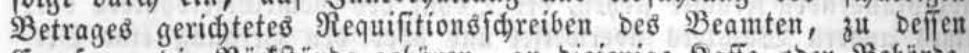
Empfange bie Rütffänoe gebören, an biejenige Rafije ober Beböroe,

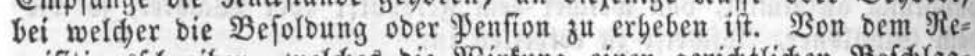
quifitionsfdereiben, weldes bie $2 B$ irfung einer geridttiden $B_{e}$ fd lags nabme bat, muß bem Sdjuloner Nadjridt gegeben werben.

Subignftation ber (jrumbifitufe.

\$. 34. Die Subgaftation von Grunbftufifen bes - Sdurbners ift nur mit Sjenegmigung ber in ben $\$ \$ \$ .31$ und 32 begeidneten 
Bebörbe zuläffig unb mú alsbann bei bem fompetenten (5)eridite in Antrag gebradt werben.

\section{Erefution gegen forenien.}

§. 35. 3wangsmaakregeln, weldie in einem anbern (Empfangs= bezirte zur 24usfübrung gebradt werben müffen, als bemienigen, in weldem bie 3ablung zu entrid)ten ift, fino burd Requifition bes fur jenen Bezirf beftellten Empfängers zu bewirfen.

Soften bes Erefutions - Beriabrens.

§. 36. Die Roften bes Exefutionsoerfabrens finb nad) bem an= gefängten Tarife, unter Berïcfict)tigung ber nadftebenben näberen Beftimmungen, zu liquibiren:

a. Die Bebürenfolonme wirb burd, ben Befammtbetrag ber 2 (bga= benrefte unb rïcftänoigen soften beftimmt, auf welde bie betref= fende $B$ erfitigung lautet.

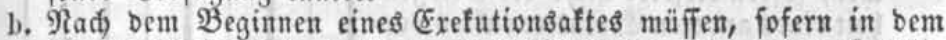
Tarife felbft nidit ein 2 nberes beftimmt ift, die vollen (S)ebuib)= ren bezablt werben, wenn gleid) berjelbe wegen ingwifden einge.

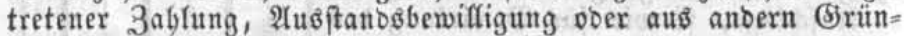
ben nid)t zur $\mathfrak{A}$ usfübrung gefommen. ift.

c. Die Erefutionsigebubren mitfen, aud) wenn ber (Exefutor megh= rere Exefutionşatte in berfelben (5)emeine zu gleidjer 3eit vorge= nommen bat, yon jebem Sduloner bejonoers entridjtet weroen. Die Roften für bie iffentlide Betanntmad)ung uno ben $\mathfrak{B e r f a u f}$ ber abgepfänbeten Sadjen werben jebod, wenn mebrere $\mathfrak{2 a f f e n}$ infammengenommen worben, nur einmal nad ber Shefammt= fumme entridtet uno unter bie babei betbeifigten Sdjuloner, nad)

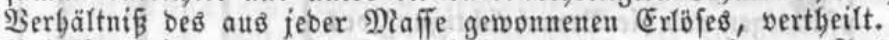

d, Bei Bertbeifung ber Trangportfoften unb anberer baarer $248=$ lagen, welde mebrere Sduloner gemeinfdaftlid zu tragen baben, muß ber Daś 3 wangsverfabren betreibende Saflenbeamte auf

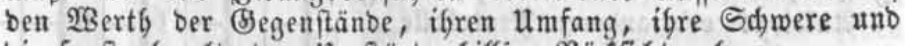
bie fonft obwaltenben Umitänbe biflige Riucficht nebmen.

\$. 37. Die Esebülyren bes Exefutors uno alle anberen Exefu= tionsfoften werben won bem bas 2 erfagren betreibenben Raffenbeam= ten aus ben burd) ben 2 erfauf ber verpfänbeten Sadjen ober anber= weit eingehenben (Belbern gezabft. Bei IInzulänglid)feit biefer (5)el= ber werben-aus benfelben zunäd) fie (Siebübren bes (Exefutors berid). tigt, bie itbrigen Exefutionsfoften aber, fo weit fie nid)t geoeft wer= ben, auf bie baju geeigneten. offentfiden. Fonbs übernommen poer von berienigen Bebörbe eingezogen, für weld)e die Exefution Statt gefunben bat.

§. 38. Alfe bişberige $\mathfrak{B}$ orfdoriften über Begenftänoe biefer $\mathfrak{B e r}=$ oromung werben bierourd aufgeboben.

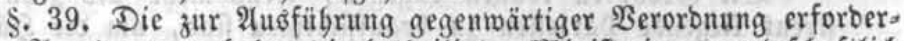
liden Anorbunngen baben bie betbeiligten 2 inifterien gemeinfdaftlid) zu erlaffen. 


\section{Excfutipusg gebübren = Tarif.}

\section{A. (5) butbren bes Exefutors.}

1) Für bie Mabnung

2) Jür bie Yुfänoung uno Siderfteflung ber gepfänbeten Sadjen, fo wie für bie $\mathfrak{A} n=$ legung eines Superarreftes
Jn bem \$. 13 gebadten Fafle wer: ben, wenn es zu teiner YYfandziebung fommt, nur bie Galben (S) buibren ent= ridtet. Diefelben Sebübren paffiren für bie Freigebung abgepfänbeter $S_{a}=$ d)en, fofern biefelbe nid)t bei (5)elegen= beit eines anberen (5xefutionsaftes vor= genommen wirb.

3) Fü bie Anfertigung unb Anbeftung ber थ̇nfd)läge, fo wie für $\mathfrak{B}$ emirfung beફ

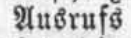

4) Für bie Berfteigerung. fo paffiren, wenn ber Steuterbiener fid bieferbalb an ben Drt bes $\mathfrak{B e r f a u f}$ begeben bat, bie balben (S)ebuitbren.

5) Fitr bie 3ufteflung eines 3ablunggobe= febls an ben Sdoulbner beș 2ugaben. pfliditigen uno bie Benadyridtigung bes Eesteren, fo wie für jebe fonftige $3 \mathrm{ut}=$ ftellung.

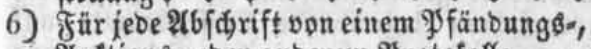
2uttions = ober anberem भrototolle . .

B. $\mathfrak{A}$ nbere $\Omega$ often.

7) (Sebübren ber bei einer Y̧änbung zuge= zogenen 3eugen .

8) (B)ebübren bes 2 Aufbewabrers von $\mathfrak{D}_{0}$ biliareffeften, täglid

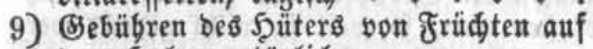
Dem Şalme, tägliá.

3u 8. uno 9. werben, wenn bie 2 ufbewabrung ober Dobut Yän. ger als adt Tage bautert, von bem neunten $\mathfrak{I} a g e$ an nur bie bal= ben Giebübren bewifligt.

Die Bsebübren fömen bagegen, wenn megr als zebn zer: ftreut liegenbe \$arzeffen zu beauffid)tigen finb, um bie Şälfte, unb wenn mebr als zwanzig zerftreut liegenbe গyarzeffen zu bes auffiđtigen fino, um bas Doppelte erböbt werben.

Sanf์puci, ben 30 . Jัuni 1845. 
Eeite 30. In Bejug auf bie Beffanblung ber Silafien= unb Bje=

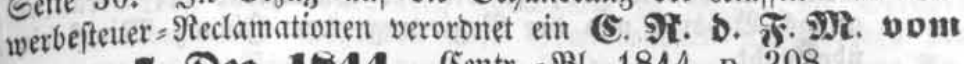
ə. Dec. 1844. Eentr. = BI, 1844. p. 208.

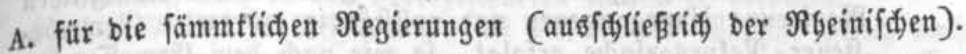

1) Die gebadjten Refurs. (Se fudje finb tiunftig, wenn fie bie Rlaffen= fteter betreffen, bem Eanbratge, wenn fie fich auf bie Sewerbe= fteuer bezielen, in Drten ber brei erften 2ibtbeifungen ber Rom= munalbegobre, welde bie Eewerbefteuer $=\Re 0 \mathbb{R l}_{e}$ anfertigt, aus Drten ber vierten 26theilung bem Raubrathe fut tiberreidjen. Se

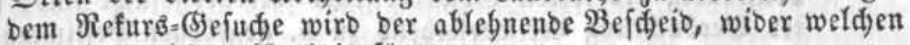
baffelbe geridstet ift, beigefitgt.

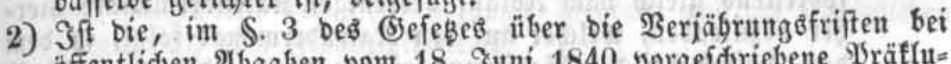

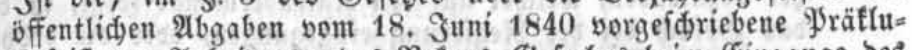
fivfrift zur 21nbringung bes $\Re$ efurs = Befuddes beim Eingange bes resteren bereits verftriden, fo weifet bie zu befien 2(muabme vor= ftebenb zu 1. beftimmte Beförbe bas Befud fogleid zurialf.

3) St bie Refursfrift nod nidt abgelaufen, fo nimmt bie vorer= wäbnte Bebörbe ungefäumt biejenigen Erörterungen vor, ̧u wel=

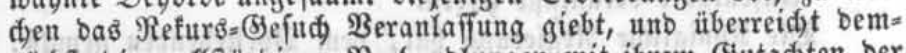
näd)ft bie volffänoigen ßerbanblungen mit ibrem (Sutad)ten ber borgefesten Rönigliçen Regierung.

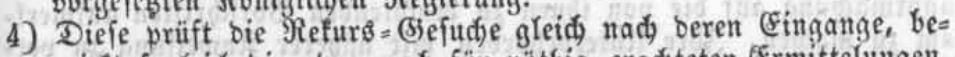
wirft fogleid bie etwa nod für nötbig eradyteten Ermittelungen, uno verfäbrt bennädit nadjftebenbergeftalt :

a. Die bis zum 1. 2luguft bel ber Rönigliden Regierung einge=

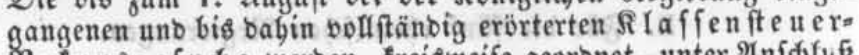

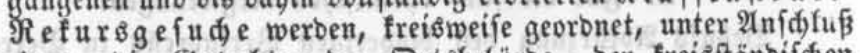

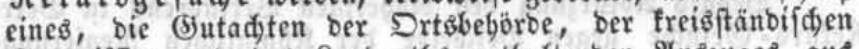
Rommiffion uno bes Qanbraths enthaltenten 2tuszuges aus Der Reflamationslifte, fo wie unter Beifügung Der in Folge bes Refurb $=$ Sefudes etwa aufgenommenen Berbanofungen und bes (S)utadten' ber Rönigliden Regierung iiber jebes cinzetne $\Re$ efurs $=$ (3efud, bis zum 20. 2Auguft bem Finanz= Minifterio ïberreidt. Die nad) bem 1. 2luguft éngegange= nen ober erft nad) biefem Iage volfitänbig erörterten Slajien=

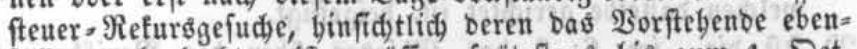
falls zi beobadten ift, müfien fpäteftens bis zum 1 . Det. bem פinifterio vorgetegt werben. - Eollten nad, bicfem Tage nod bergleiden (sefudse bier eingeben, fo fint in jebem Falle bie Esrünoe befonbers angugeben, weldje ben 2 affentgalt berbeigefübrt gaben.

b. Die Esewerbefteuer= Refursgefude werben, nadjem bie etwa für notbig eradteten Ermittelungen beenbet finb,

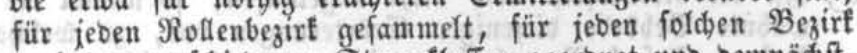
nad ben verfdiedenen Steutertlafien georonet uno bemnädit, unter $\mathfrak{B}$ eifügung ber auf 2 Inla $\beta$ Des Refurs $\beta=$ Sefudye fonft binfintlfid ber vortiegenben Reflamationen aufgenom= 
menen $\mathfrak{B e r b a n \delta l u n g e n , ~ f o ~ w i e ~ b e s ~ ( 5 ) u t a d ) t e n s ~ b e r ~ B e r a u l a = ~}$

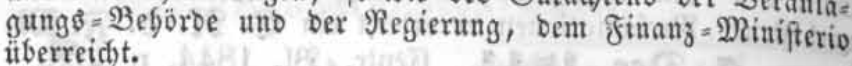

Die Einreidung ber vor bem 1. Juli bei ber Rönigliden Regierung eingegangenen unb volfftänbig erörterten Bewerbe= fteter = Refursgefude erfolgt, fo wie nad) bem Ermeffen ber

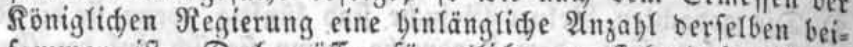
fammen ift. Dod müffen fämmtliche, vorftebento bezeidjuete Siefud)e bis fpäteftens zum 20. Suli bierber gelangen.

Die nad bem 1. Juli bei ber Regierung eingebenben ober volfftänoig erörterten (5)ewerbefteuer = Refurb̊gefude fino, un=

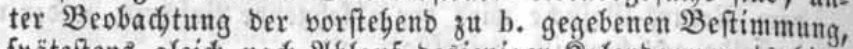
(päteftens gleid) nad) 2(blauf begjenigen Ralenbermonats bier= Ger abzufenoen, weldyer auf ben Ralenbermonat folgt, in bem bas (5efud, bei ber Regierung eingegangen, ober bie besbalb veranlafite Erörterung beendet ift.

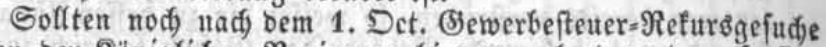
von ber Röniglidjen Regierung bier vorgelegt werben, fo find in jebem Falle bie (Srünbe befonbers anzugeben, welde ben 2ufentbalt veranlafit baben.

Die Röniglide Regierung bat, bem $\mathfrak{B o r f t e b e n b e n ~ g e m a ̈ f , ~ b i e ~}$ Steuerpfliditigen burd eine, in bas 2 mt\$blatt aufaunebmente $\mathfrak{B}_{e}=$ fauntmadung auf bie von ifmen zu bead)tenben $\mathfrak{B}$ ordidriften aufmerf= fam zu madjen, Ggre Unterbebörben mit näberer \{tnweifung zu ver= feben uno auf geborige unb rafde Bearbeitung ber vorbejeidneten Sadien ju balten.

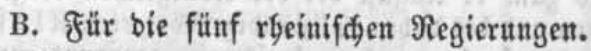

Bebufs 2 tbürgung bes bisberigen $\mathfrak{B e r f a b r e n s}$ it $\mathfrak{B}$ etreff ber

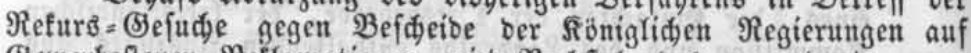
S)

1) Die Refurs = (Befudde finb fünftig in Drten ber brei erften (5e=

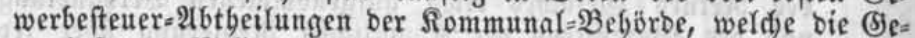
werbefteuer $=$ Rofle anfertigt, aus Drten ber vierten 2abtbeilung bem Ranoratbe zu überreid)en.

Sebem Refurs: (Sefudje wirb ber ablegnenbe Befdeib, wiber welden baffelbe geridtet ift, beigefiigt.

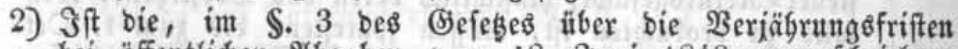
bei öffentliđen 2 bgaben vom 18. Juni 1840 vorgefínriebene

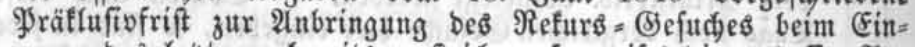
gange bes leţteren bereits verftriden, fo weijet bie zu beffen $\mathfrak{A n}_{\mathrm{n}}=$ nabme vorftebeno zu 1 . beftimmte $\mathfrak{B}$ eböroe bas (5efud fogleiథ zurïc.

3) Sft bie Retursfrift nod nidjt abgelaufen, fo nimmt bie vorer= wäbnte Bebärbe biejenigen (Erörterungen vor, ju weld)en bas Refurs = (Befud, Beranlaffung giebt, uno uiberreid)t bemnädif bie

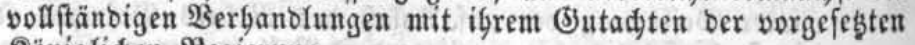
Rönigliden Regierung. 
2Bo, einer beftefenben $\mathfrak{A}$ norbunt zu Folge, bie Beridte ber Rommunal $=$ Bebörben über Sewerbeftener $=\mathfrak{B} e[$ d werben ber

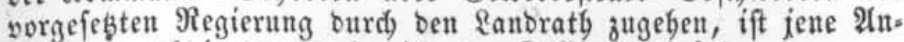
oromung aud in ben vorbezeiduneten rätlen zut befolgen.

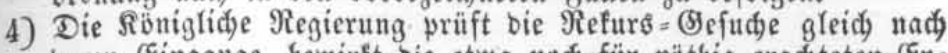
beren Eingange, bewirft bie etwa nod für nötbig eraditetent Era mittefungen, fammelt, nadyem biefe beentet fino, bie Refurs $=$

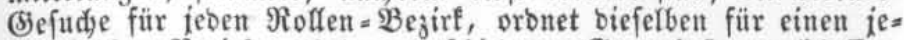
ben folden $\mathfrak{B}_{\text {ejirf }}$ nadi ben verfdiedenen BSewerbefteuter = Silaffen, uno überreidt bie Befuthe bemnäd,t, unter $\mathfrak{B}$ eifügung ber auf

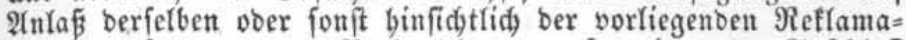

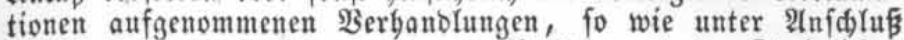

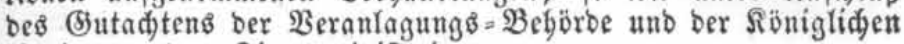
Regierung, bem ginangminifteriv.

(Der Sdulus bes Rejcripts lautet wie ad A.) 
Befouberer abeil. 


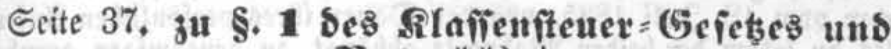 Pote **) b.}

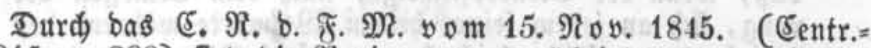

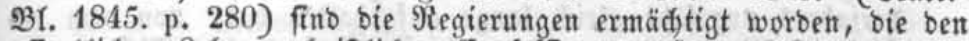
iffentlidgen \&egrern driftlidger Confefionen zuftegente Rlaffenfteter= freibeit aud ben bei ben (5ymmafien, 9rogymnafien uno gobleren Bür= gerfwulen, nad Beendigung bes Yrobejabres befäftigten, ben felbit =

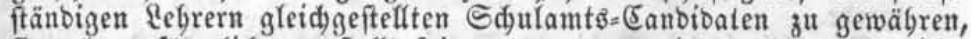
fie mogen formlid) angefteflt feit, ober remunerirt werben ober nidft.

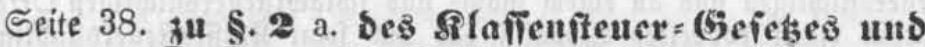

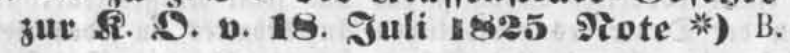

1) Befanntmadung yom 8. $\mathfrak{F}_{\mathrm{ebr}}$ 1844. Dinift. = $\mathfrak{B l}$. 1844. p. 80.

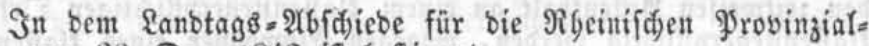
Stänbe vom 30. Dec. 1843 if beftimmt:

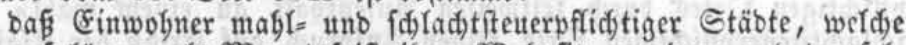
auf länger als 2 onatsfrift ibren $2 B$ ofnfib an einem uno bemfel= ben flaffenfteuterpflidtigen Drte nefmen, yon bem Ablauf biefes 3eitraums an, für bie fernere Dauer ibres 2uffentbalts an bem gebadten Drte Rlaffenfteuer ju entridten baben, wogegen aber aud (Einwobner tlaflenfteuerpflid)tiger Drte, welde auf länger

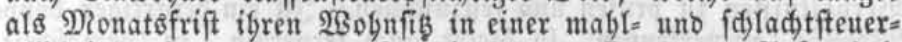
pflidtigen Stabt nebmen, fïr bie längere Dauer beş 2lufentbal= tes in biefer Stabt von ber Slaffenfteuer z̆ befreien fint.

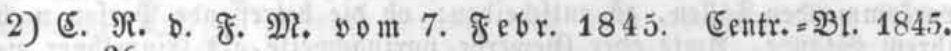
p. 36.

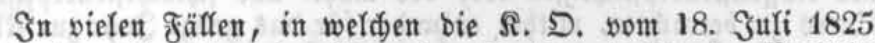

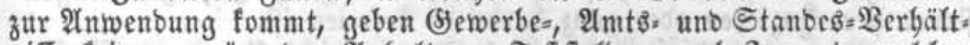
niffe feinen genügenden 2Angalt zur Feftftellung: ob Semant, welder cinen 230 bnfit an einem Elaffenfteuerpflidtigen uno einen zweiten an einem mabl= unb fdladtfteuerpflid)tigen Drte bat, unb fid theils an biefem uno theils an jenem Srte perfönlid) aufbält, in Bezng auf 
feine Steuteryflidigtigfeit für einen Einwobner biefes ober ienes Drtes gu baften fei; es mús mitbin feffgefteflt werben: ob er fid wäbreno bes Ralenberiagres länger am flafienfteuerpfliditigen ober länger am mabl = unb fidlad)tfteterpflidstigen Srte periönlid aufgeyalten bat. Diefe Feftftellung ift aber, wie bie Erfabrung gelebrt bat, bäufig mit

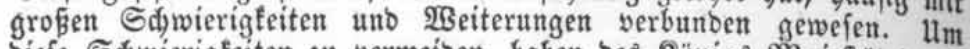

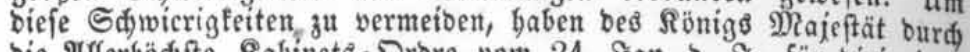

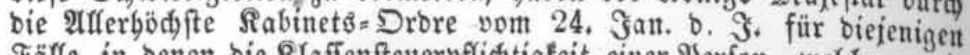
Fälle, in benen bie RTaffenfteuerpflidtigteit einer \$erfon, welde an eis nem flaffenfteuerpflid)tigen unb zugleid an einem mabl= unb fdilacht:

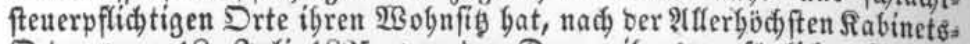
Drore vom 18. Jufi 1825, von ber Dauter ifres perfönlidien 2ufent, balts an jebem ber beiben 280 hnorte abgängt, zu genebmigen gerubt, bafi, wenn ber Steuerpflidstige, nad, bem Ermefien ber Regie. rung, fid) an febem feiner beiben 2 gobnorte wäbrenb bes Ralen= berjabres ungefäbr gleíd) lange aufgebalten bat, bon bem be=

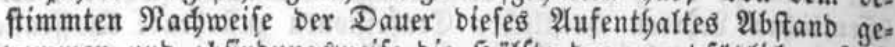

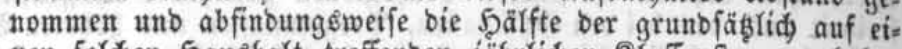
nen folden Şausgalt treffenden jäbrlidyen Rlaffenfteuter ergoben werbe.

Die 2fferbödfte Rabinets = Drore vom 24. San. b. I beziebt fid übrigens nur auf biéęnigen Fâfle, wo Semano an einem flaffentftetterpflidftigen uno an einem mabl= uno fdlad)tfeuterpfliditigen Drte, mitbin einen boppelten $\mathfrak{B}_{0}$ bnfith Gat uno feine Rlaffenfteuerpfliditig. feit yon ber Dauer bes perfonlichen 2 Aufentbaltes an jebem ber bei=

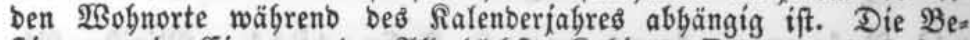
frimmung im Eingange ber 2 fferbödften Rabinetse = Drore vom 18. Suli

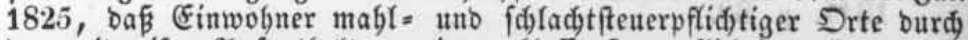
ben zeitweifen 2 uf fentbalt an einem flaffenfteuerpflidgtigen Drte nidjt flaffenfteuerbflidtig werben, wogegen (Einwogner eines flafienfteuer. pflididigen Drtes ourd) zcitweifen 2 ufentbalt an einem mahl = unb

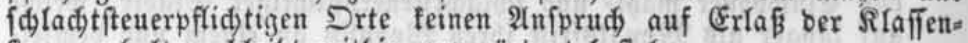
fteuer erbalten, bleibt mitbin unveränbert beftegen.

D6 Semant einen zweifaden 280 hnfiB, ben einen an einem mafl= unb fidladifteuerpflidtigen, ben zweiten an cinem flaffenfteuer pfliditigen Drte bat, ift in ben einzelnen Fällen nady ben obwaltenden Berbältniffen zu prüfen uno feftzufteflen. Sft ein berartiger boppelter

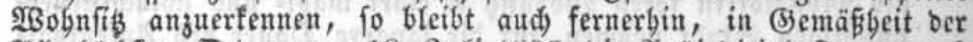

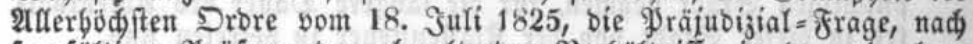
forgfältiger Yrüfutng ber obwaltenten Berbältniffie in ben einzelnen vorfommenben Fäflen, zu entidjeiben: ob bie betreffente Yserfon nady igrem Stanbe, 2 mte ober Eewerbe vorgugsweife als CEinwobner eines flaffenfteuerpflidtigen voer bes mabl= unb fdlad)tfteuterpflidfigen Drtes zu betradjten, mittin entweber für baş ganze $3 a b r$ zur Rlaffenfteuer beranzuzieben ober ganz bavon zu befreien ift.

Rur wenn biefe \$räjubizial = Fragen nid)t flar zu entfđjeibent finb, fann bie Afferbödjte Rabinets = Drore vom 24. Jan. b. S. jur

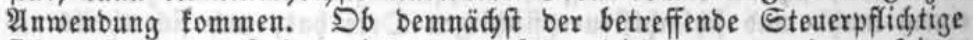
fid wäbreno bes Salenberjabres ungefäbr gleid) lange an jebem feiner 
belben 2 Bobnorte aufgebalten babe, wirb, als in ber Rotorität be= rufent, won ben Drtábebörben Ieidjt befdeinigt werben tönnen. Dem Ermelfen ber Rönigliden Regierung ift aber bie näbere Yriffung ber 2ngaben bierüber vorbebalten. Ergiebt fid bierbei offentunbig ober erweisłlid, ein erbeblid) fürzerer 2tufentbalt am mabl= uno fdladt= fteuerpflidstigen, als an bem flaffenfteuerpflidigen 280 bnorte, to if ber Stetterpfliditige für bas ganze Эahr zur 3ablung ber Rlaffen= fteuer verpfliditet, wäbrenb umgefebrt ein erweişliđ längerer 2 ufent= balt an bem mabl - uno fidladtfteuerpfliditigen 20 ognorte von ber Rlaffenfteuer für bas gange Jabr befreit.

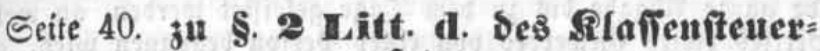 geietses.}

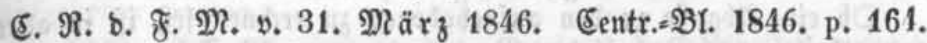

Durdi eine $\Re_{a} b_{0}=$ Drore vom 31. Mär 1846 fint von ben Subivibuen, bie in bem vaterlänbifdyen ober in einem ber anbern verbinbeten Speere an ben Felbjügen von 1813 bis 1815 Theil ge: nommen Gaben, Dieienigen, weldye zur unterften Rlaffenfteuerftufe eingefdäbt fint, für ibre ஒerfonen, fo wie für bie 2 nngebörigen igrer Sausbaltungen, unt auferbem Diejenigen, welde als Einzelnifeuternbe is. 4 bes Rlaffenfteuer $=$ (S)efézes vom 30. Dai 1820) ber vorlesten Eteuerfufe angegören, von ber Rlaffenfteuter befreit. Es wirb bier= bei bemertt, baf bie Befreiung von ber Riaffenfteter nidt von ber 3 eit ober von ber 2 rrt ber $\mathfrak{M}$ ifitair $=$ Dienfte in ben Jabren $18 \frac{13}{15}$, ob yor bem Feinte, in Feftungen u. f. w., wobl aber von bem glaub.

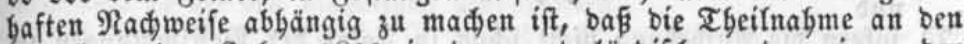
Jelbzïgen ber Gabre $18 \frac{13}{13}$ in bem vaterlänbifden ober einem ber verbinbeten 5̧eere wirtlid Statt gefunben gat.

\section{Eeite 45 sq. 3ur Getwerbefteuer $=$ Gefetsgebung im atlgemeinen.}

Arlgemeine (5ewerbe = Dronung vom 17. \an. 1845.

$$
\text { ङ. S. } 1845 \text {. p. } 41 .
$$

2Bir ac. Gaben bie in ben werfdiebenen Ranbestbeilen beftebens

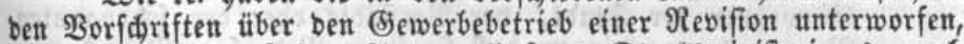

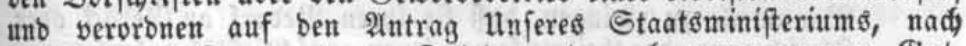
Angörung $\mathfrak{u}$ nfercr getreuen Stänbe unb nady vernommenem (Sut:

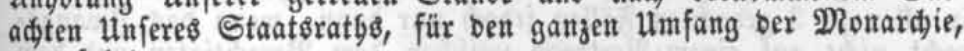
wå folgt:

Titel I.

Aafbebung beftebenber $\mathfrak{B}$ ef (3) werbebetriebes.

8. 1. Das in einzelnen \&anbestbeilen mit ङ゙ewerbeberedotigungen

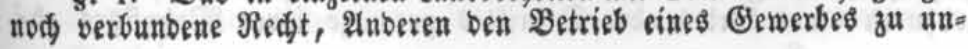


terfagen ober fie barin zu befdränfen (ausfd)lięlid)e (S) etwerbebered. tigung), wirb bierburd aufgefoben, ofne Unterfichieb, of bie Bered. tigung an cinem (Grunoftide baftet ober nid)t.

\$. 2. Ferner werben aufgeboben afle $\mathfrak{B}$ eredigungen, foncefition fu gewerblidien 2 nlagen ober zum Betriebe von Ëewerben zu er. theilen.

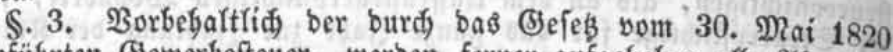
eingefübrten (S) werbeftener, werben ferter aufgeboben alle Abgaben, welde für ben Betrieb eines (S) werbes entridtet werben, fo wie bie Bered)tigungen, bergleid)en Abgaben aufaulegen. Sft iebod mit ber (Gewerbebered)tigung bas Red)t zur Unterfagung ober Befderäntung Des 2 etriebes eines ftebenden (5iewerbes verbunben, fo muß bie barauf rubenbe ganze 2 lbgabe bis $z^{4}$ bem Tage geleiftet werben, an weldem ber Betrieb biefes (S) werbes von einer Serfon begonnen wirb, gegen

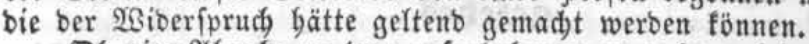

Db eine $\mathscr{A} b g a b e$ ou ben aufgebobenen zu redinen fei, ift in alfen qanbestbeilen nad) Snbalt ber Beroronung vom 19. Febr. 1832 (ङe= feşfammlung Seite 64) ju beurtbeilen.

S. 4. Bon ben nod beftebenben 3 wangs: = unb Bannrediten wer: ben Gierburd) aufgeboben:

1) alle Zwangs= unb Bannred)te, weld)e bem Fisfus, einer Rämmerei ober Semeinde innerbalb ibres Rommunalbezirfes, ober einer fior= poration von Bsewerbetreibenden zuftegen, ober von Cinem biefer Beredtigten erft nad bem 31. Dec. 1836 auf einen 2 uberen iibergegangen fino;

2) alle 3 wangs = und $\mathfrak{B a n n r e d}$ te, beren 2 uffebung nad bem $3 \mathrm{nt}=$ balte ber \$erleibungsourfunbe ofne Entídäbigung zuläffig ift; und

3) fofern bie 2Aufgebung nidgt folon in golge ber Beftimmungen zu

1. unb 2. eintritt,

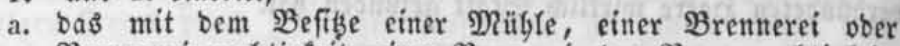
Brennereigered,tigfeit, einer Brauerei ober $\mathfrak{B}$ raugeredjtigfeit, Doer einer Sd)anffitätte verbunbene Redft, bie Ronfumenten 3u zwingen, baß̧ fie bei bem Beredtigten ifgren $\mathfrak{B} e$ barf malg:

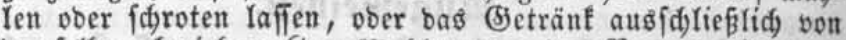
bemfelben Kejiegen (ber Mablywang, ber Branntweingwang und ber Brauzwang),

b. bas ftäbtifđen $\mathfrak{B a ̈ d e r n ~ u n b ~ g l e i f d e r n ~ z u f t e f e n b e ~ \Re e d j t , ~ b i e ~}$ Einwogner ber Staot, ber Borftäbte ober ber fogenaunten

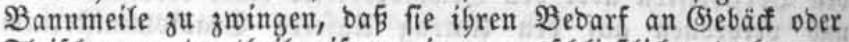

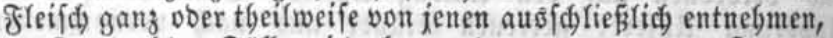
in affen zu 3 gebacten Fäflen jebod) nur bann, wenn bas 3 wanggs red)t nidit auf einem $\mathfrak{B}$ ertrage zwifden bem $\mathfrak{B}$ eredftigten und bem Berpflidsteten berubt.

\$. 5. Diejenigen 3wangs= unb Bannredfte, welde nidjt burd bie $\mathfrak{B}$ eftimmungen bes $\mathbb{S}$. 4 aufgefoben finb, fömnen you ben $\mathfrak{B} e r=$ pflidyteten abgeloft werben, wenn bie Serpflichtung auf Srrunbbefits Laftet, bie Ditglieber einer Rorporation als Eolde betrifft, voer $\mathfrak{B}_{e}$ s

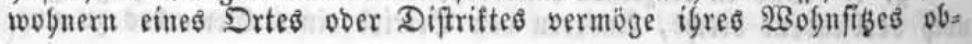




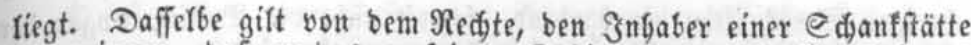

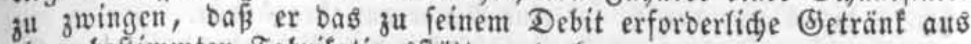
einer beftimmten gabrifationsftätte entnegme. niät 3ut.

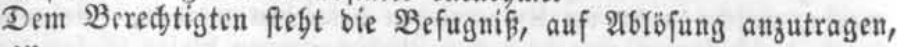

\$. 6. In ben beftegenben $\mathfrak{B o r f d r i f t e n}$ wegen ber Regalien unb Minopole bes Strats uno ben barauß entipringenben Befdränfungen bes 2 Betriebes einzelner (5ewerbe wiro burd) bå gegenwärtige (3)efes nidfts geänbert. Snģbefonbere gift bießs von ben bas Bergwefen be treffenten $\mathfrak{B o r}$ ordriften.

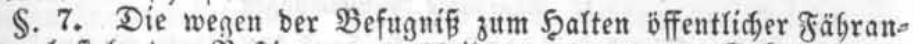
falten beftelgenben Beftimmungen bleiben unveränbert Sofern ₹äbr= gered)tigfeiten auff(d)lieflidde Beredytigungen fint, fönnen fie von ben Dinifterien gegen eine nă ben Srunbfäß̨en bes Bsefeß̧es yom 16. Suni

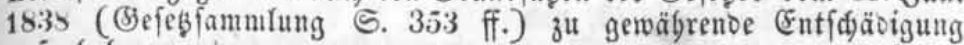
aufgclyoben werben.

\$. 8. Die zur 3eit in ben einzefnen Ranbestffeilen geltenben Borfdriften itber bas abbectereiwefen bleiben bis zur beenbigten $\Re_{e}=$ vifion berfelben in Sraft.

\$. 9. Die befonberen Borfdriften über Erttgeifung unb Benuţung ber Errfinoungspatente fommen ferner zur 21nwentung.

\$. 10. Unter weldjen $\mathfrak{U m}$ ftänoen und in welder 2 rrt für bie burd bie SS. 1 bis 5 aufgebobenen poer für ablöşbar erflärten Bered)ti= gungen eine Entfódabigung gewäbrt wirb, beftimmt ein befonberes

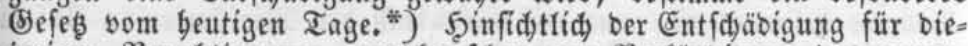
jentigen Bered)tigungen, weldhe fdjon vor $\mathfrak{B}$ erfünoigung bes gegen= wärtigen (5)ef́çes aufgeboben ober für ablösbar erflärt worben finb, bewendet es bei ben bisherigen $230 r f$ riften.

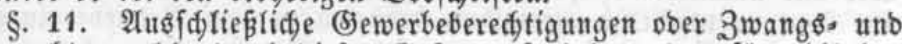
Bannredte, welde burd biefes (B)efę aufgegoben voer für ablösbar erflärt worben fino, fömen fortan ourd Berjäbrung nidjt mebre er= worben werben.

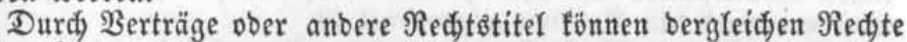
nidgt auf einen längeren, als zebnjäbrigen 3eitraum begrünbet werben. Serabrebungen, woourd für ben Fall ber Nidjterneuerung bes̉ $\mathfrak{B}$ er= trageş eine (Entfdäbigung feftgefelşt wirb, fino nidjtig. bürt auf.

\$. 12. Die Befdränfung gewiffer (Jewerbe auf bie Stäbte

\$. 13. Der gleidjzeitige Betrieb verfdiebener Bewerbe ift Se= bem geftattet, foweit nidjt befonbere gefeşlidje $\mathfrak{B}$ orfdjriften eine $\mathfrak{B} e$. fdjräntung anoronen.

\section{Titel II.}

Bebingungen bes sewerbebetriebes.

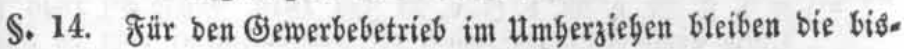

*) Dię - in ber (3). S. $1845 ;$ p. 79 xc. abgebrufte (Entfdäbigung

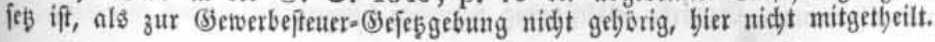

Supplement. 
berigen Borfdriften maafgebeno, foweit nidst bie Beftimmungen ber $\$ S$. 1 bis 4 unb bes $\$$. 60 eine Aenberung begrünoen.

\$. 15. Die polizeitiche 3uläifigfeit bes $\mathfrak{B}$ etriebes berienigen $\mathrm{Bre}_{\mathrm{e}}$,

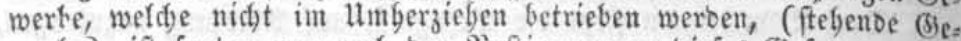
werbe), ift fortan nur nad) ben Beftimmungen biefes (sefeses zu be urtbeilen.

Ber gegenwärtig zum Betriebe eiteB (5ewerbes berechtigt ift, fann yon bemfelben um besbalb nid)t ausgefdyloffen weroen, weif er ben Erforberniffen biefes (Befeşes nid)t geniigt.

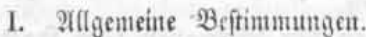

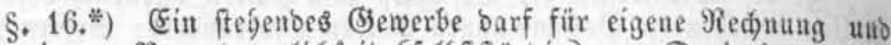
unter eigener $\mathfrak{B}$ erantwortlidfeit (felGfteänoig) nur Derjenige betreibeit, welcher

a. Dispofitionsfätig ift, uno

b. imerbalb Unferer Staaten einen feften 280 bufib bat.

\$. 17. ${ }^{*}$ ) Minberjäbrige, weldje ber väterlid)en (Sewalt unter= worfen finb, müffen, bevor fie ben felbfttänbigen Betrieb einez ftehene ben Bewerbes beginnen, bie auforütlide (B)enebmigung bes $23 a t e r s$ zu bem (S) werbebetriebe nadjweífen. Sm Bezirfe bes 21ppellationts geridftébofes zu Sïln ift bie 3ulaffung ber Minberiäbrigen zum $\mathfrak{B}_{e=}$ ginn bes felbititänbigen Betriebes eines ftebenben (jewerbes nad) $21 \mathrm{rt}, 2$

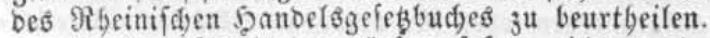

§. 1R. Aนส์länoer bürfen, fofern nid)t burd) Staatg̃verträge ein Anberes beftimmt ift, nur mit Erfaubnif ber Minifterien in Hnjern Staaten ein ftegendes Bjewerbe betreiben.

\$. 19. Die in Reibe uno Blfied ftebenben Militairperionen, fo wie alle unmittelbare uno mittelbare Staatsbeamten, aud foldje, bie

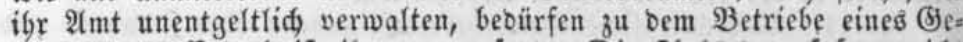
werbes ber Erlaubní; ibrer vorgefegten Dienftbeborbe, fofern nidt

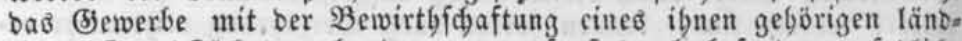
lidjen (Brundefüdes verbunben, ooer fonft burd befonoere gefeglidje $\mathfrak{B e f t i m m u n g e n ~ e i n ~} \mathfrak{2}$ noeres angeoronet ift.

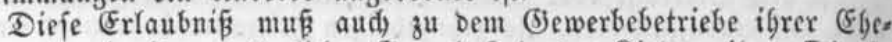
frauen, ber in igrer vaterlidjen (5emalt ftebenben finber, ifrer Dienft= boten unb anderer Mitglieber igres Şausftandes cingebolt werben.

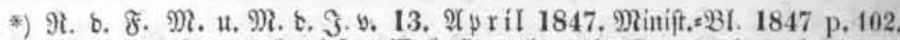

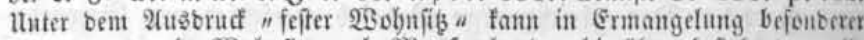

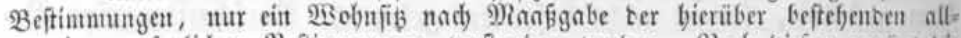
gemeinen gejesliden Beftimumugen veritanten werben. Fiad) biefen genugt bie

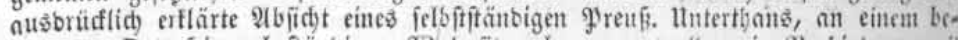

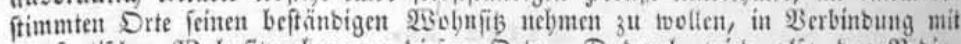
ber factijden 2 Bobnifibmaljme an biejem Drte. Daburd wirb aljo ben Bobingutugen bes $\$ .16$ b. genügt.

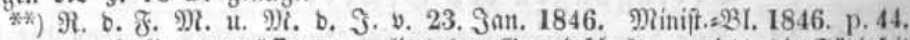

Durd) (Eoncurberöfunt verlicrt ber (semeinjouloner nicht bie fäbigfeit ein (35emerbe zu betreiben mo eben io ift nad) ten Beftimmungen in ben $\$ \$ .195$

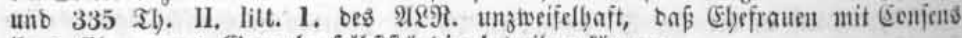
ibreø Ebemantes SSewerbe felbifttänbig betreiben fönten. 
\$ 20. Bon bem Befize bes Burgerredts foff bie 3ulafinung fum (Sewerbebetriebe in feiner Stabt uno bei feinem (S) werbe abbän= gig feín. Sn ber Berpflidtung ber (S)ewerbctreibenben zur Erwerbung beB Bürgerred)to, foweit fold)e in ber beftebenoen ftäotifd)en $B e r=$ fafiung begründet ift, wiro burd) gegenwärtiges (sefes nid)ts geän= bert; bie Exefution auf Erfülung biefer Berpflidtung barf aber nidjt bis zur Unterfagung bes (5)ewerbebetriebes ausgebebnt werben.

\$. 21. 25er wegen eines von elrlofer Biefinntung zeugenben Berbredjens, insbefonbere wegen Meineios, Raubes, Diebftabls ober Betrugs verurtheilt worben, bebarf zum Beginn eines jeben felbft: ftänoigen (5emerbebetriebes, Derjenige aber, weldem ber Betrieb ei= nes beftimmten (S) werbes burd ridjterlides (Erfenntnis unterfagt wor= ben ift, zum Beginn bes felbitfänoigen Betriebes eines anberen ver: wanten Bewerbez, ber befonberen Erlaubniz ber Solizeiobrigfeit bes Drteš. Diefe Erlaubnifi ift zu berfagen, wenn nad) ber (Eigentbüm=

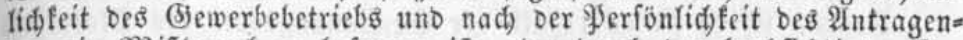
ben ein Plifbraud zu beforgen ift, ober burd) ben beabfidtigten (5e= werbebetrieb ber 3 wed bes Etraferfenntniffes vereitelt werben würbe.

Diefe Borforiften finden aud Anwentung auf bie Egefrauen folder Gerfonen, ifre nod) unter väterlider (Sierwalt ftebenben finter,

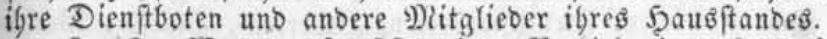

\$. 22. 2Ber ben felbiffänoigen $\mathfrak{B e t r i e b}$ eineş (Sewerbes anfan=

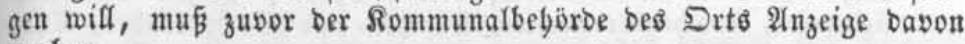
madjen.

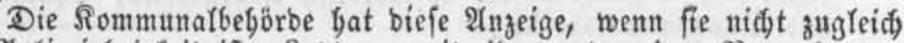
bie פolizeiobrigfeit ift, \&eß̧terer mit igren etwanigen $\mathfrak{B e m e r f u n g e n ~}$ juguftellen.

§. 23. Die gorizeiobrigfeit yat zat priffen, ob ben in biefem Biefeçe für ben felbftfändigen Bsemerbebetrieb im Aflgemeinen ober fur bas beabfidtigte (Sewerbe insbefondere vorgefdriebenen Erforber= niffen gentigt ift.

Sit einem biefer (Erforberniffe nidit genügt, fo ift ber $\mathfrak{B e g i n n}$ pber bie Fortfeb̧ung bes (B)ewerbebetriebes mittelft Befdeibes zu un= terfagen, fonft aber bem Anmeloenben eine Befdeinigung über bie er= folgte 2lnmeloung zu ertbeilen.

\$. 24. Heber bie Anmeloungen find burd bie Solizeiobrigfeit genaue Regifter zu fübren.

§. 25. Beffumerben über bie Hnterfagung bes (5)ewerbebetriebes fömen uur bei ben Berwaltungşbebörben angebradit werben. Der Fechtsิweg finbet Dagegen nid)t Statt.

\section{Erforbentí befonterer polizcilidjer (5)entejmigung.} berlich:

\$. 26. Eine befondere polizeifide Ejenelymigung if nut erfor

1) zur Erridtung gewerblider Inlagen, welde burd) bie brtlide

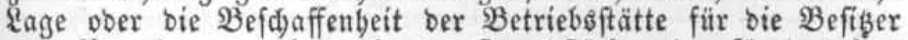
voer $\mathfrak{B}$ ewobner ber benabbarten (Brunbftüfe, ober für bas ฟu=

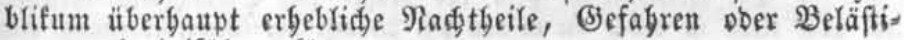
gungen berbeifübren tönnen; 
2) รu bem Beginn forder (S)ewerbe, bei welden entweber

a. Durd) ungefdicften Betrieb, boer

b. burd, Ilnzuverläfígfeit bes (jewerbtreibenben in fittlidjer bas (jemeinwolgl ober bie Erreidjung affgemeiner poligeilidger 3 wecte gefägroet werben faun.

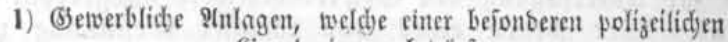
(jieneb)migung biourfen.

\$. 27. $3 \mathfrak{u}$ ben gewerbliden $\mathfrak{A n l a g e n}$, weldye einer befouberen polizeiliden @ienelgmigung bebürfen (\$. 26, zu 1.), follen für jeg̣t gered)net werben:

Sdiefputverfabrifen, 21nlagen zur Feterwerterei unb zur Berei=

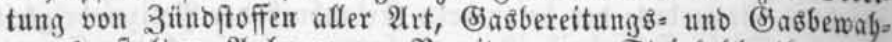
rungøanftalten, 2lulagen zur $\mathfrak{B}$ ereitung von Steinfoglentbeer unt Roafs, fofern fie aukerbalb ber (Sewinnungsorte bes Daterials erridgtet werben, Spiegelfabrifen, Yorzellan=, Fayence unb rbont

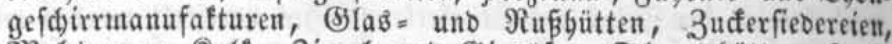

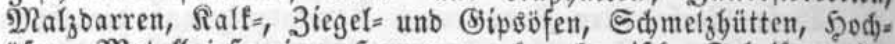
ofent, Metallgiefereien, Şammerwerfe, demif́de Jabrifen atler

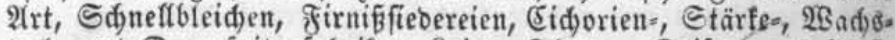
tud $)=$ unb Darmfaitenfabrifen, \&eim $=$, Lgran $=$, Seifen $=$ unb Sluf $=$

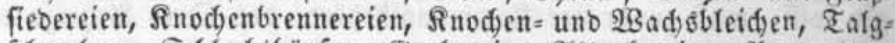

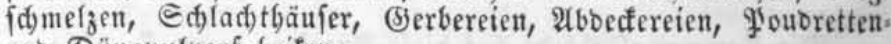
uno Düngpulverfabriten;

es gebören babin ferner:

Dampfmafdinten, Dampfeefifer unb Dampfentwidfter (\$. 37),

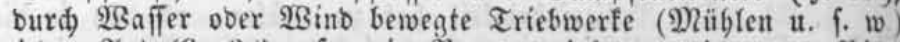
jeber 2Art (\$. 3×), fo wie Branntweinbrennereien unb 2 Bier= brautercien (\$. 39).

Bei aflen biefen 2ulagen madjt es teinen Unterfdieb; ob fie nur auf

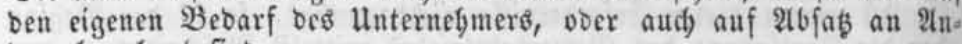
bere berednet fint.

\$. 28. ") 3ur Erridutung netter Antagen biefer 21rt (\$. 27) ift bie Benelgmigung bei ber Regierung nadjzufudjen. Dem (Sefude múfien bie zur Erfäuterung erforberlidfen Zeid)nungen uno Befdereibungen beigefügt werben.

S. 29. $28 e n n$ bie beabfidtigte 2 fnlage, nad) bem Ermefien ber

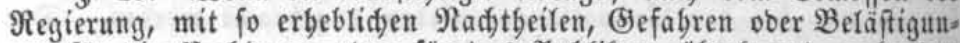
gen für oie Nadgbaren ober für bas Youblifum itberbaupt verbunben ift, bafi bieferbe fid of ne $2 B$ eiteres als unzuläffig barftellt, fo ift bas (Se)fud) fogleidy zurüđfumeifen.

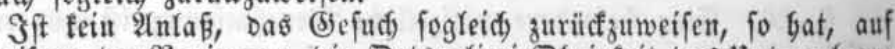

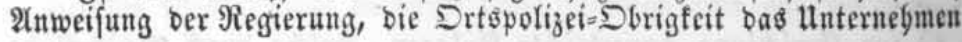

*) Die Boridyrift im $\$ .7$ bes Mabl- uto Sd)lad)titeuter-(5eję̧es vom 30. शRa 1820 ift burd) bie in ben $\$ \$ .28$ sq. ber (5enerbeoronung ertbeilten sbeftimumungen nicht aufgeboben. cfr. bic Supplentente zut bem gebad)ten $\$ 7$. 
mittelft einmaliger Finriifung in bas 2 mtsblatt, unb auferbem in ber für anbere polizeilid)e : Beroronungen am Drte vorgefdriebenen

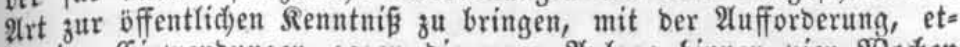
wanige Einwenbungen gegen bie neue 2 nlage binnen vier 20 den anjumeloen.

Die vierwödentfid)e Frift nimmt igren 2(nfang mit bem $\mathfrak{T} a g e$, an weld)em bas bie Befanntmad)ung entbaltenbe 2 mtsblatt ausgege= ben worben, uno ift fitr affe (Eimwenbungen, welde nidgt privatred)t= lider Ratur finb, präflufivifd.

\$. 30. Merben teine Finwenoungen angebradt, fo bat bie Re= pierung, fobald bie $\mathfrak{A n z}_{\text {eige }}$ ber Sylizetobrigfeit eingegangen ift, un= ter Feftefęung ber fich etwa afs nötbig ergebenden Bebingungen, bie (Benebmigung zu ertbeilen. Dieje ift fdrriftlid auşzufertigen uno muß bie feftgefez̧ten Bebingungen entbalten.

\$. 31. Die bei ber Yyolizeiobrigfeit angemeloeten Einmendungen

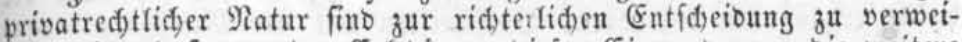
fen, obne baß von ber Erlebigung biefer Einwentungen bie weitere Berbanolung iiber bie polizeilide (j)enebmigung ber Anlage (\$. 32) abbängig gemad)t wirb.

Anvere (Finwentungen bagegen bat bie Yolizeiobrigfeit, unter $3 \mathfrak{u}=$ ziefung bes llnternebmers, zum Grotofofl volfiänoig zu erörtern. Demnachft fino bie gefd)loffenen 2erbanolungen mit beigefuigtem (5)utadjen an bie Regierung einzureid)en.

\$. 32. Die Regierung bat Gierauf bas (5efud mit Rücfidt auf bie beftebenben feutr $=$, bau= uno gefunobeitspolizciliden 2 (noronun= gen uno bie Erbeblidfeit Der auf angeblidge Nad)tbeile, (S) fabren ober belätrigungen gegrünbeten- Einwenoungen zu prüfen uno nad) bem Defunde bie (5)enebmigung entweber zu verfagen, voer unbebingt zut ertbeilen, ober enolid bei Ertbeifung berfelben biejenigen Borfebrun= gen uno Einridtungen vorzufdreiben, weld)e zur abbülfe geeignet fint.

\$. 33. Der von ber Regierung abgefapte Befdeit ift fowobl

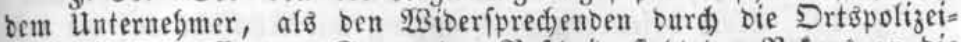
obrigfeit $j^{\mathfrak{u}}$ eröffnen. (5egen ben Befdeib ftegt ber $\Re$ efurs an bie Miniterien offen; berfelbe muE binmen ciner praffufivifden Frift von zebn Iagen, vom Iage ber (Eröffnung bes $\mathfrak{B} e$ fdjeibes an gered)net, bei ber Folizeiobrigfeit angemeloet werben. Die Redtfertigung ber

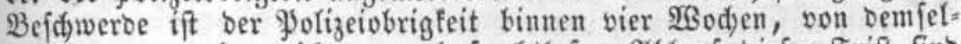
ben Tage an, einzureiden; nad) frudstlofem 2Hblauf biefer Frift fino

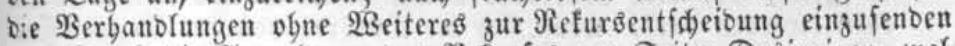

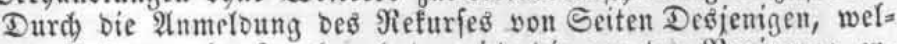

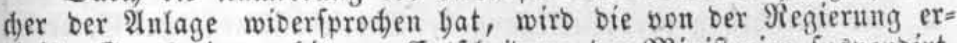
theilte (5)enebmigung bis zur Entfdgciouug ber Minifterien fušpenoirt.

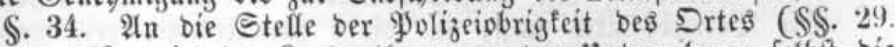
30. 31. 33) tritt ber Eanoratb, wenn ber Unternebmer felbjt bie Yolizeiobrigfeit ift, ober bie Drtşpolizei zu verwalten bat.

\$. 35. Die baaren 2luslagen, welde burd) die Befanntmad)ung

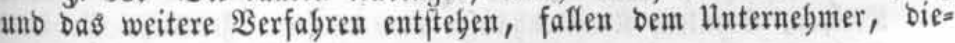


jentgen Soften aber, welde burd unbegrünbete cinmenbingen er. wad) fen, bem $\mathfrak{B}$ iberfpredjenten zur \&aft.

Die Regierungen uno Pinifterien Gaben in ben Defdeiben uiber

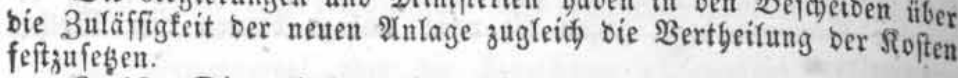

\$. 36. Die polizeilide (Jenefmigung 3u einer ber im $\$ .27$ bes geiduneten 2 nnlagen bleibt fo lange in Sraft, alş teine Beränberung

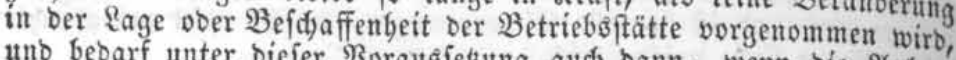
unb bebarf unter biefer $\mathfrak{B}$ orautsegsung aud bann, wenn bie 2rirlage
auf eimen neuten Erwerber itbergebt, einer Erneuerung nidjt.

Sobarb aber eine $\mathfrak{B}$ eränoerung ber Betriebôftätte vorgenvumen

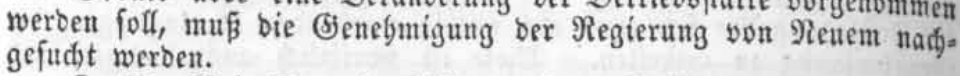

\$. 37. Bei Dampfunafdinen, Dampfeefieln unb Dampfent=

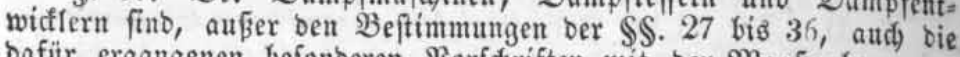
bafür ergangenen befonberen Borfdriften mit ber Mlaaß̧̧abe anzu=

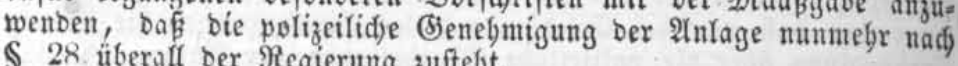
$\$ 28$ itberall ber $\Re$ egierung zuftelt.

5. 38. 2(14) bei ben burd) $2 B a f f e r$ pber $2 B$ ino bewegten Triebs

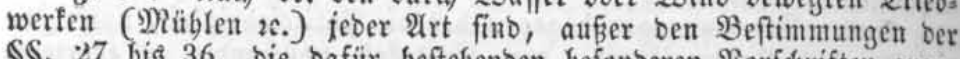
\$\$. 27 bis 36 , bie bafitr beftebenben befonberen $\mathfrak{B}$ bridgriften anzu= wenten. (Fs werben jeovd) bie in einzelnen Ranbestbeilen beftebenben Borfdriften, wonad) bie Alnlage neuter unb bie Erweiterung unb $\mathfrak{B e r}$. änberung vorganbener, auf bie Sonfumtion ber Humgegeno beredfneter

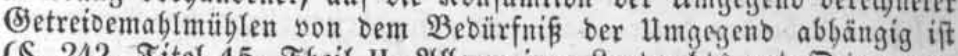
(\$ 242. Titel 15. Theil II, Allgemeinen Ranbredt ts uno Drber vom 23. Dit. 1826. (Befebfammfung Seite 108), bierburd aufgefoben.

\$. 39. Die in einzetnen Eanbeğtgeilen beftebenben $\mathfrak{B}_{0}$ ridgriften, wonad, bie Benelmigung zur Anlage neuer 2 Brantweinbrentercien uno Bierbrautereien bei länolidgen Srundftuicfen nur baun ertbeilt wer= ben barf, wenn biefe (Brunbititife nad) lanowirtlfidufftlider Taxe ei-

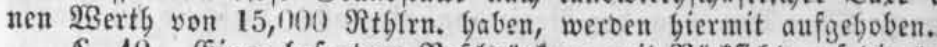

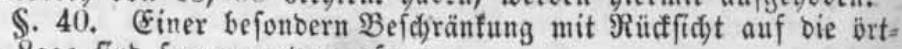
lide sage fint ferner unterworfen:

a. Tanz= unb Feđttf(fulen, fo wie Turn= uno $\mathfrak{B a b e a n f t a l t e n ; ~ z u r ~}$ Erridgtung ober $\mathfrak{B}$ erlegung berfelben ift eine polizeilfide (Senels: migung erforberlidf, weld)e in ben Stäoten bei ber \$yolizeiobrigs feit, auf bem Qanbe, unter Borlegung eine 2 tteftes ber Yolizei= vbrigfeit, bei bem ganbratbe nadjufudjen ift uno erft bann ers theilt werben barf, wenn fid bie 2 egojrbe von ber 2 (ngemeffen = Geit bes \&ofars uno ber beabfichtigten Einridftung überzengt bat;

b. bie (Erridtung ober Berlegung ber Betriebsffätte folder (Sewerbe,

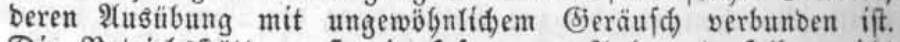
Die Betriebsftätte mußs, in fofern zur 2tulage berfelben nid)t fdion nady ben $\mathfrak{B}$ orfdyriften ber $\$ \mathbb{S}$. $27-36$ bie Benefmigung Der Regierung einzulyolen ift, ber yblizetobrigfeit angezeigt wer= ben; biefe bat, wenn in ber Räbe ber gewäblten $\mathfrak{B}$ etriebsftatte Rirdıen, Sduulen, Rranfenbäufer ober antere iffentlidje (jebäube

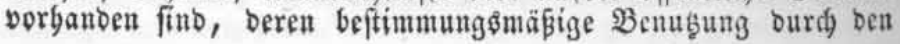


Sewerbebctrieb auf biefer Stelle eine erbeblide Störung ober Beläfigung erleiben würbe, bie Entficeibung ber $\Re$ egierung bar= iiber einzubolen, ob bie 2húbubung bes (S)ewerbes an ber gewäbl=

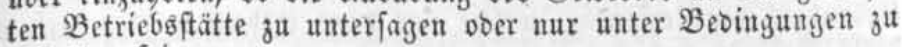
geftatten fei.

$\$ 41 .{ }^{\circ}$ ) Die burd bie Steucrgefese in Bejiefung auf bie

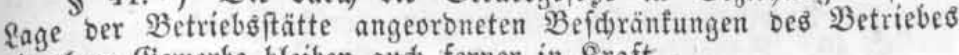
cinzeIner (S) werbe bleiben aud) ferner in Sraft

2) (5twerbtreilenbe, weldte einer bejonberent polizeilident (5inel)migung bebürfen.

\$. 42. Aerzte, 23un๖ärzte, Augenärzte, Zabnärzte, Sjeburts̊bel=

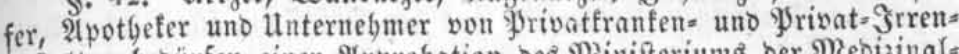
anftalten bebirfen einer 2tpprobation bes Dinifteriums ber Mebizinal= angelegentreiten.

$\$$ 43. Sinfidtlid ber Unternefomer von (Erzielungs= uno $1 \mathrm{n}=$ terriditsanftalten, fo wie ber Yribatfebrer bewenoet es bei ben befon= beren $\mathfrak{B}$ orfdtriften.

\$. 44. Baumeifter, weldse aut ber \&eitung von Bau= 1 nterneb= mungen ein Bewerbe madyen, beoürfen eines brüfungşzugnifics ber Dber $=$ Baubeputation.

5. 45. Eecfdiffer uno Eeeftenerfente, Borfteber offentfidjer Fäbren (Fäbrmeifter), Maurer, Eteinbauter, Ediefer= uno Biegel=

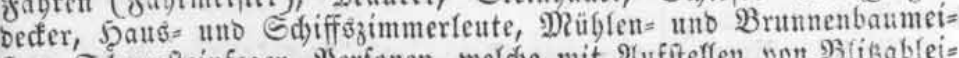
fter, Ed)ornfteinfeger, Werfonen, weldye mit 2lufiteflen von Blibablei=

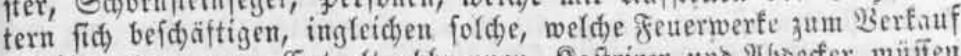
bereiten ober gegen (Entgelt abbrennen, Raftrirer uno \&boeffer müfen fid) itber ben Befig ber erforberfidgen Renntniffe uno Fertigfeiten burá) cin Befäbigungşzengnif ber Regierung ausecifen Daffelbe gift von Jebanmen, $\mathfrak{B}$ andagiften uno $\mathfrak{B}$ erfertigern dirurgifder Jnftrumente.

Sumeit in Betreff ber Sdjiffer uno Eootfen auf Strömen in Folge von Etaato̊verträgen befonoere 21norbnungen getroffen fino, be= bält es babei fein Bewenten.

\$. 46. 2Bie bie Yrüfungen ber in ben $\$ \$$. 44 unb 45 bezeid)= neten (Biewerbtrcibenten vorjunefmen finb, uno in wieweit bie unter ifrem (B)ewerbe begriffenen Berrichtungen aud) von ungeprifften Fer= fonen aug̊geibt werben bürfen, wirb burd) 2Anorbunngen ber Minifterien beftimmt. Diefen ftebt aud Die Befugnif́, zu, Werfonen, Deren $\mathfrak{B}_{\mathfrak{c}}=$ fäbigung unzweifelfaft ift, auถึabmsweife von ber vorgefdriebenen Trifung zu entbinben.

\$. 47. Sdaufpiel=Unternebmer bebüfen einer befonberen $F_{x}=$

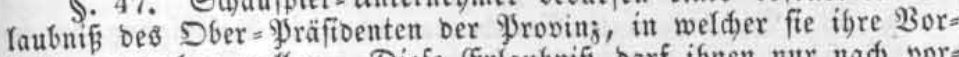
fteflungen geben wollen. Diefe (Erlaubnifi barf ifnen nur nad) vor= gängigem ßad)weife geböriger 3 uverläffigteit uno Biloung ertbeilt, fam jebod) aud bann, went fie biefer Beoingung entipreden, nad bem Ermefifen bes Dberpräfidenten, verfagt werben.

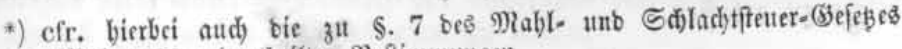
yom 30. Mini 1020 mitgetbeilten Beftimumugent. 


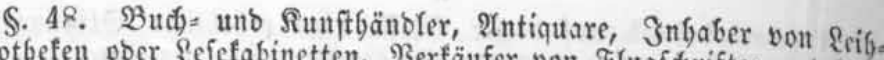

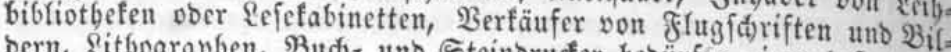
bern, Eitbograpben, $B$ utd)= uno Steinbruder beburfen einer befonberen Erlaubniś ber Regierung, welde nur bann ertbeilt werben barf, wenn biefe Bebörbe von ber Inbefdoltenbeit uno Zuverläffigteit, fo wie won einer zum Betriebe bes Biewerbes genügenden affgemeinen $\mathfrak{B}_{i}$. bung bes Unternebmers fid Hebergeugung verfdafft bat.

\$. 49. Edflofiern, Pfanoleibern, fo wie Denjenigen, welde mit gebraudten Rleibern ober Betten, mit gebraud)ter $23 a ̈$ dje ober altem Metallgerätb, mit Sđiefpulver ober (Siften bandeln, ferner Denjenigen, welde aus ber Bermittelung von (S)efdäften ober ber lleber.

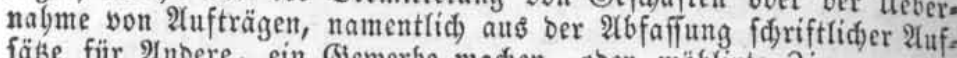
fäbe für Anbere, ein (Bemerbe mad)en, ober möblirte 3immer voer Ed)lafiteflen gewerbşweife vermietben, Rammeriägern, Robnlafaien

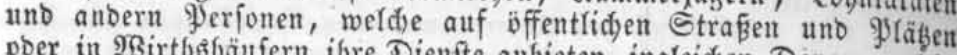
voer in $2 B$ irtbsgäufern igre Dienfte anbieten, ingleidjen Denen, weldse

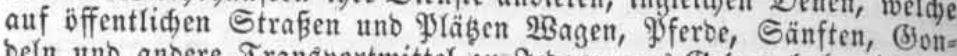
beln uno anoere Transportmittel zu Jebermanns (Sebraud) bereit bal= ten, ift ber (B)werbebetrieb erft bann, wenn fid) bie Beborben von ibrer Unbefdoltenbeit uno 3 uverläffigfeit überzeugt baben, zu geftatten.

Diefe Crlaubniß ift in ben Etäbten bet ber Solizeiobriafeit, auf bem Ranbe, unter $\mathfrak{B}$ orlegung eines 21tteftes ber Solizeiobrigfeit, bei bem Ranbratb nadjufudjen.

\$. 50. Unternebmern von $\mathfrak{T} a n_{z}=$ ober Fectifdulen, Babe- ober Iurnanftalten ift bie nad) $\$$. 40 zu a. exforberfiche (Stenebmigung erft bann zu ertbeilen, wenn fie fid über ifre llnbefdoltenbeit uno 3 us verläffigteit ausggewiejen baben.

\$. 51. Die Sefdäfte ber $\mathfrak{B a u f o n b u l t e u r e , ~ F e l o m e f f e r , ~ \Re i v e f l i r e r , ~}$

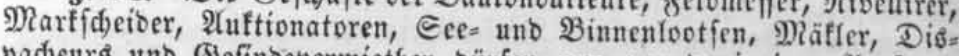
pad)eurs unb (5efinbevermietber bürfen nur von benjenigen Yyerfonen betrieben werben, welde als folde von ben verfalfungsmäjig bazu be= fugten Staats $=$ ober Rommunalbebörben ober Rorporationen ange= ftellt ober fonzeffionirt find.

\$. 52. Ein Bleidges (\$. 51) gift won Denen, weld)e ben Jein= gebalt ebler Metalle ober bie $\mathfrak{B e f}$ daffenteit, Menge voer ridjtige $\mathbb{B} e r=$ paçung von $2 B$ aaren irgenb einer 21rt feftftellen, von (3) ïterbeftätigern, Sdjaffnern, $\mathfrak{B a ̈ g e r n , ~ D e f f e r n , ~ B r a a f e r n , ~ E d ) a u e r n , ~ S t a u e r n ~} u$. f.w., fo wie bon Denjenigen, weldje ein (jewerbe baraus madjen, Qeidjen zu reinigen unb allzufleiben, ober bie zur Beftattung von Reiden er= forberfidien (5)erätbid)aften und 2 agen ju balten.

$\$ 53$. Die bişberigen $\mathfrak{B}$ orfdriften iiber bie $\mathfrak{B} c$ fäbigung ber in ben $\mathbb{S} S .51$ uno 52 bezeidneten Ferfonen, über bie $3 a b l$, fo wie ben Ulmfang ber Befugniffe uno Berpflidutungen berfelben bleiben ferner in Rraft. Seood wirb oen Dinifterien vorbegalten, bie notbigen शैänberungen unb Ergänzungen $z^{u}$ treffen.

Aud find bie Minifterien befugt, $b a$, wo iiber bie Anftelfung unt ben (S)efdäftsbetrieb biefer \$erfonen feine Borfdriften befteben, foldae zu erlaffen. 
3) Bejonbere Beftinmuntyen.

\$. 54. 211fer ber Ipprobation (\$. 42) bebürfen 2 potbefer, melde fid nidt im Befibe eines Realprivilegiums befinben, einer Ronzeffion bes Dber-\$ुräfioenten, in weldyer ber Drt uno baв (5)rund= ftiic, wo bab Bewerbe betrieben werben folf, beftimmt fein mus.

\$. 5.5. Sinfidutlid, bes SIeinbanbels mit (S)etränten, fo wie ber (5aftwirtbfdaft uno ber Sdanfwirtbfd)aft bebält es bei ben unterm 7. Februar 1835 (B)efebfammlung Seite 18) uno unterm 21. Juni 1844 (B)efeşfammlung S. 214) ergangenen Beftimmungen mit ber

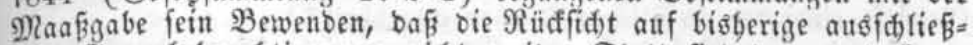
lide (S) bie Stefle ber in ienen Beftimmungen angebrohten Strafen bie bes gegenwärtigen Béfę̧eø๋ treten.

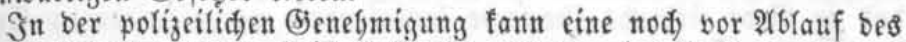
Ralenderjabres enbenbe grift beftimmt werben, innerbalb beren bas Bewerbe bei Berluft ber $\mathfrak{B}$ efugní̧ zum Betriebe beflelben begonnen werben muk.

\$. 56. Die Siebrbezirfe ber Sdjornfteinfeger fönnen, nad bem

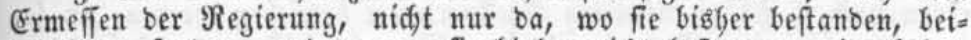
bebalten, fonbern auds $b a$, wo fie bisber nidit beftanben, eingefübrt, anbererfeits aber aud aufgeboben uno veränbert werben, obne baf beşbalf ben Bezirfäfdornfteinfegern ein $2 B$ iberjprudjored)t ober ein 2nfprud auf (Entfidabigung jufteft. Nur ba, wo 3wangsired)te be= fteben, ift eine 2lufbebung ober Befdränfung ber biefen Red)ten unter= worfenen Rebrbezirfe erft nad) vorgängiger Ablöfung ber 3wangs: redite $(\$ .5)$ zuläffịg.

\$. 57. In 21nfebung bes \$ुfanbleiggewerbes bebät es bei ben

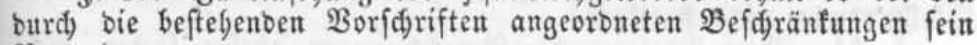
Bewenten.

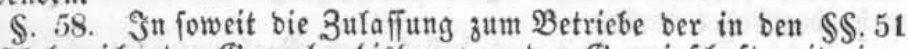
bis 55 bezeidyneten (bewerbe bisher bon ber (5)emeinfdhaft mit einer ber driftliden firdjen abbängig gemad)t worben ift, foll bies bis auf weitere Beftimmung aud ferner Statt finben.

\section{Sitel III.}

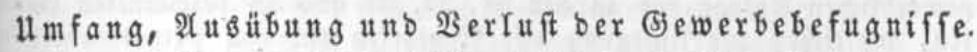

§. 59. $\mathfrak{B e r}$ zum felbft fänbigen Betriebe eines ftebenben (sewerbes befugt ift, unterliegt babei nur benjenigen $\mathfrak{B}$ efdränfungen, welde burd) geféblide ober polizeilide Beftimmungen angeorbnet fino. Ins" befonbere Darf er an feinem 2 Bobnorte in feften $\mathfrak{B}$ erfaufsffätten bie Erzeugniffe oder fonftigen (5)egenftänbe feines Bserwerbetriebes feil hal= ten, aud in und auber feinem 5 aufe befteflte 9 rbeiten vornebmen, ingleiden verfaufte $\mathfrak{B}$ aaren verfenden unb, foweit $e \mathfrak{B}$ nad) Iitel IV zuläffig ift, auf $\mathfrak{D a ̈ r f t e n}$ verfebren. $E r$ ift befugt, bie zu bem $\mathfrak{B}_{e}=$ triebe feines (5emerbes erforberlid)en Materialien unb $\mathfrak{B}_{\text {erf }}$;euge zu

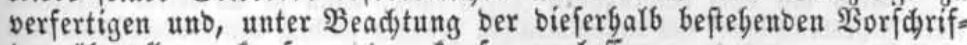
tent, überall anzufaufen und anfaufen zu laffen.

3um Feilbalten und $\mathfrak{A n b i e t e n}$ ber gewerbliden Ergengniffe ober 
Dienfte auf Etrafien ober an anberen bffentfichen Drten aufier ber ge. wöbnitiden Marftzeit ober auferbafb ber zum Marftverfebr beftimmten

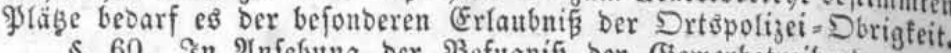

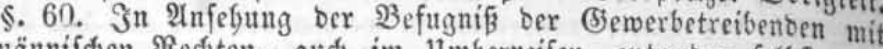
faufmännifden Rediten, aud im llmberreifen, entweber felbft ober burd) Bsebillfen, 2 Baarenbefteflungen zu fudjen ober zum 2 ebufe bec

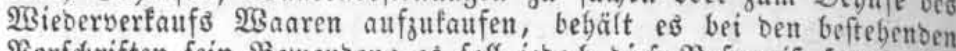

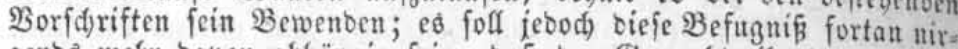
genbs mefr bavon abbängig fein, baj ber (Semerbtreibende ober ber Siebuilfe einer ber dyriftliden firdsen angebört. *)

\$. 61. Die Befugniffe zum (Semerbetetriebe fönnen burd) Etell. vertreter ausigeübt werben; biefe müfen jebod) nidt nur ben für ben felbft fänoigen (5ewerbebetrieb im Allgemeinen, fontern aud ben für bas in Rebe ftebende (s)werbe insbefondere vorgefdriebenen Erfor: berniffen genügen.

\$. 62. Nac, bem Tobe eines Siewerbetreibenten barf bas Be=

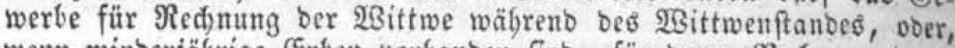
wenn minberiäbrige (Erben vorbanben finb, für beren Red)mung burd) einen nad $\$$. 61 qualifizirten Steflvertreter betrieben werben, in fos fern bie itber ben $\mathfrak{B} e t r i e b$ einzelner Bewerbe beftebenden befonberen Borfdriften nid)t ein 2 nberes anorbnen. Daffelbe gilt wäbreno ber Dauer einer Furatel ober Mad)lafregulirung.

$\$$. 63. In wiefern für bie in ben $\$ \$ .51$ bis 54 begeidjueten Serfonen eime Steflvertretung zuläfifg ifi, bat in jebem eimzefnen Falle bie Bebörbe ju beftimmen, weldjer bie Anfteflung ober Ronzef= fionirung zufteft.

Bei ben im $\$$. 55 bejeidneten Gewerben if ber Betrieb burdi Stelfwertreter nidyt ftattbaft.

$\$$. 64 . Neue Realgewerbe $=$ Bered)tigungen bürfen fortan nidst megr begrünbet werben.

$\S$. 65. Die zur 3eit nod beftebenben $\Re$ ealgemerbeberedtigungen fönnen auf eine anbere gefeß̧lic) qualifizirte tragen werben, baß ber Erwerber bie Eewerbeberedtigung für eigene Red)nung ausitben barf.

§. 66. Bei Ertbeifung ber polizeiliden Benebmigung zu einer gewerbliden 2 nlage ber in ben $\$ \$, 27,37$ unb 38 bejeid)neten $\mathfrak{A r}=$ ten, ingleiden zur $\mathfrak{A n l e g u n g ~ v o n ~} 2$ potbefen uno von Frivatfranfen: uno Srivat= Эrrenanftalten, fo wie zu Sd)aufpielunternebmungen fant won ber genebmigenoen $\mathfrak{B} e$ börbe, ben Hmfä̈loen nadh, eine grift fefta gefestst werben, binnen weld)er bie Anlage ober bas llnternel)men bei

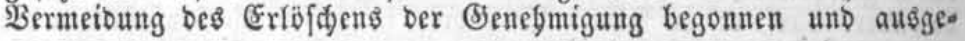

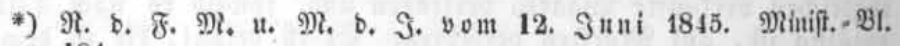
1845. p. 184.

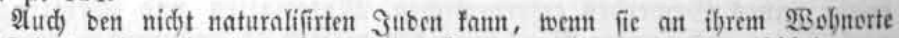

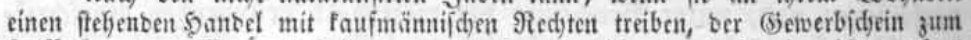

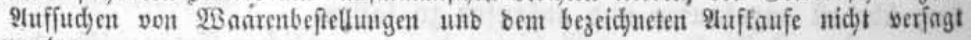
werben. 
fitbrt, unb ber Giewerbebetrieb angefangen werben mufs. Ift eine fold)e Frift nid)t beftimmt, fo erfifd)t bie ertgeilte (Sienebmigung, went ber Gntlaber nad) (Fmpfang berfelben ein ganzes Jabr verftreiden läjt, ogne bason (Stebraud zu madjen.

Fine Berlängerung ber Frift fann von ber Bebörbe bewifligt werben, fobalo ergeblide Girinte nidyt entgegenfteben.

\$. 67. Şat ber gnbaber einer folden (Senefymigung $(\$ .66)$ fei= nen (semerbebetrieb wäbrend eines 3eitraumes von brei Jabren eín= geftellt, fo erlifidt biefelbe.

\$. 68. 2uf bie Эnbaber ber tereits-yor bem Erfdeinen bes ge= genwärtigen (5efeb̧es ertheilten Ronzeffionen finben bie in ben $\mathbb{S} S .66$ unt 67 beftimmten Friften ebenfalls 2 (nwenbung, jebod) mit ber $\mathfrak{D a}$ a gabe, baß̧ biefe Friften von bem. Tage ber Bertünoigung bes (5) efeß̧es all jul laufen anfangen.

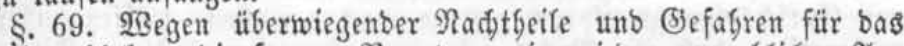
(B) meinwob) fann bie fernere Benubung einer jeben gewerbliden $21 \mathrm{n}=$ lage zu jeoer Seit unterfagt werben. Dod muß bem Befiger als̈ = bann für ben erweiglidjen wirtliden Sđaben Erjałs geleiftet werben.

§. 70. Die Beftimmung bes $\$$. 69 finbet aud auf bie zur 3eit ber פerfinbung bes gegenwätigen (jefebes bereits vorbanoenen ge= werbliden 2 Anlagen (nwenoung; bod) entipringt aus ber Unterfagung

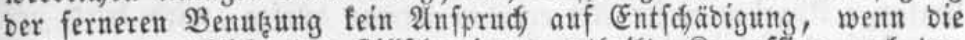

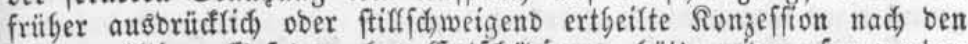

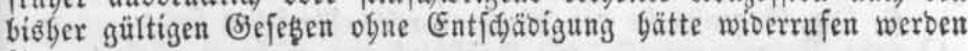
fönnen.

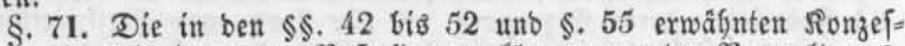
fionen, 21pprobationen unb Beftaflungen fönnen von ber Berwaltungs: beforroe zurüfgenommen werben, wenn bie Huridjtigfeit ber Nad)weife bargetfan wirb, auf beren Srund foldge ertbeilt worben, poer wenn

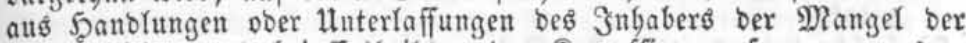

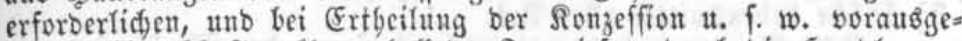
feģten (Eigenfid)aften flar erbellet. In wiefern burd) bie Scanolungen boer Unterlaffungen eine Strafe verwirft ift, bleibt ber ridjterlidien Beurtbeifung überlaffen.

\$. 72. Die Grübe ber beabfidtigten 3urüđnabme ber Ronzef= fionen it. $\{. \mathfrak{w}$. (\$. 71) fino bem Betheifigten befaunt zu mad)en unb wollftänoig fu erörtern, bie Berbanblungen aber fobann mit ber $\mathfrak{B e r}=$

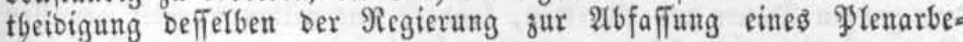
fditufes vorzulegen.

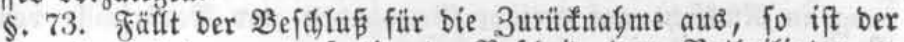
banađ mit (5rünben ausizufertigenbe Befdeib bem Betbeiligten zu eröfnen. Begen biefen $\mathfrak{B} e f(d) c i d$ ift ber Refurs an bas fompetente Dinifterium zuläffig; ber $\Re$ fefurs muß jebod, bei $\mathfrak{B}$ erluft beffelfen binnen zebn Tagen, yon ber Eröffung beș Befdyeibes an gered) net, angemeloet werben.

\$. 74 Dem Ermeffen ber Regierung bleibt überlaffen, in brin= genben Fällen bie 2 ușübung bes (sewerbes entweber fogleich bei Ein=

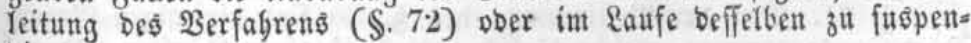
biren. 


\section{Titel IV.}

\section{Rartt berfebr.}

\$. 75. Der Befud ber Mefien, Gafr $=$ unb Bodjenmärfte, fo wie ber Rauf und Berfauf auf benfelben ftebt einem Seben mit gleiden Befugniffen frei. Befdrränfungen bierin gegen 2lus̆länber, als Erwieberung ber im 2utslanoe gegen bieffeitige Untertbanen ange= oroneten $\mathfrak{B}$ efdränfungen, bleiben ben $\mathfrak{R}$ inifterien vorbebalten.

\$. 76. Die Minifterien fino befugt, bie 3abl, 3eit uno Dauter ber $\mathfrak{D}$ lärtte feftzufeß̧en. Dem Marftbered)tigten ftebt gegen eine folde Unoronung fein $2 B$ iberiprud) $\delta^{u}$; ein (Entidabigunģs=21nfprud) gebübrt Demfelben nur bann, wemn Durd) bie Anoronung bie 3abl ber bis ba= bin abgebaltenen $\mathfrak{M}$ ärfte verminbert wiro, uno eine größere $3 a b !$

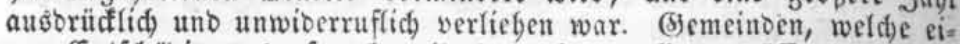
nen (Entidäbigungganfprud) gelteno maden wollen, müffen auferbem nadweifen, Daß̧ ibr Red)t auf einen fpecieflen läjtigen ritel fid) grünbet.

\$. 77. Der $\mathfrak{M a r t t w e r f e b r}$ barf in feinem Fafle mit anbern,

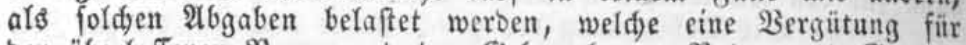

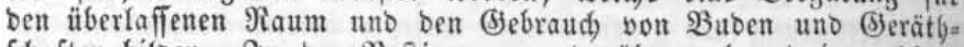
fd)aften biloen. Sn ben Beftimunugen bariber, ob unb in weldeu Himfange 2 bgaben biefer 2 rt erboben werben burfen, wirb ourd) ge= genwärtiges Gefę̧ niđbtỏ geänbert.

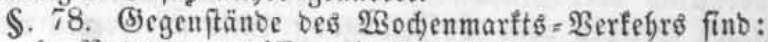

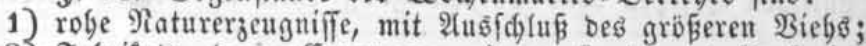

2) Fabrifate, beren Erzetgung mit ber \&anb = unb Forftwirtbfofaft ober ber Fifderei in unmittelfarer $\mathfrak{B e r b i n o u n g}$ febt, ober zu ben Rebenbefdaftigungent ber Sanbleute ber Segeno gebört, ober burd) Tagelobnerarbeit bewirtt wirb, nit 2uछfdluß ber $\mathrm{BS}_{\mathrm{e}}=$ tränfe;

3) frifde Qebensmittel affer Art.

Sebe Regierung bat, unter (B)enebmigung ber Minifterien, ein Bergeidniß ber (Begenftände befannt zu maden, weld)e biernad ober nad) Drts = S5ewolngeit uno Bebürfnifi in igrem Bezirf überbaupt Doer an gewifīen Drten zu ben 280 benmarfts $=2$ Urtifeln gefören.

\$. 79. Einrid)tungen, nad) weldhen ber (Einfauf von Qebensmit=

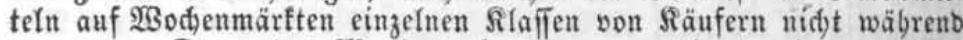
ber ganzen Dauer bes Marftes, fondern nur wäbreno einer gewifien 3eit geftattet wirb, bürfen nur bann fortbeftegen, wenn ibre Beibebals tung in Rü̊ffidt auf örtlidge (5ewolgnbeit uno Beoürfniffe von ber Regierung genebmigt wirb.

\$. 80. (5egenftänbe, welde an fid zum Marftwerfebr gefören anb von auferbalb zum Marftort gebrad)t werben, birfen an Marfttagen an teinen anbern, als an ben für ben Marft beftimmten, yon

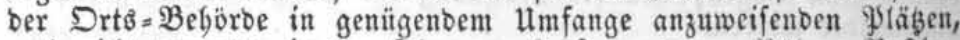
aud nidjt vor ober in ben İgoren gefauft werben. Näbere Beftim= mungen bieriber bleiben ben einzefnen Marftorbnungen vorbebalten.

$\$$. 81. Bon ber Beftimmung bes $\$$. 80 find Diejonigen Begen= faürobe ausgenommen, welde täglid zum Bertauf in Şäufern uno auf 
ben Strafen umbergetragen werben bürfen ( $(\$ 86)$. Tutd bleibt ber Bertauf aus befonberen Rotalen zuläffig.

\$. 82. Tuf Gabrmärften bürfen, aufier ben im $\$ .78$ benannten

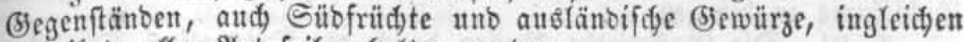
Fabrifate alfer $\mathfrak{A}$ rt feil geflalten werben

\$ 83. Der Serfauf von Getränfen uno zubereiteten Speifent 3um (Semuß auf ber Steffe barf auf Sabrmärften nur nad) Maaß́=

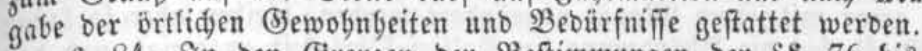

\$. 84. Sn ben Grenzen ber Beftimunungen ber \$\$. 76 biz 83 fann bie भolizei= Dorigfeit, unter Benebmigung ber Regierung, bie

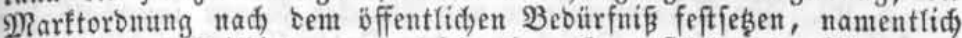

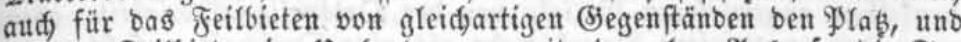
für bas Feilbieten in $\mathfrak{U}$ mbertragen, mit ober obne $\mathfrak{A}$ uşuf, bie $\mathfrak{T} a=$ geşeit unb bie SSattung ber 2 Saaren beftimmen.

\$. 85 . Die Beftimmungen ber $\$ S .76,77,79,80,81$ unb 84 finben aud auf biejenigen $\mathfrak{M a ̈ r f t e} 2$ nnwenbung, welde an einzefnen Drten bei befonberen Belegentyeiten ooer für einzelne Ssattungen von

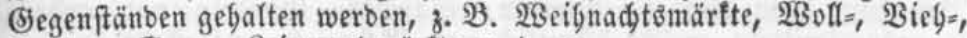
Butter $=$, (5arn=, Reimwanbmärfte u. b. m.

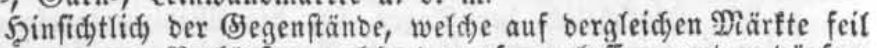
gefarten, uno ber Berfäufer, weldhe barauf zugelaffent werben bürfen, bleibt es bei ber bişberigen DGfervanz. Erweiterungen biefes $\mathfrak{M a r f t}=$

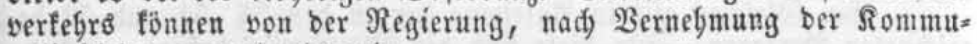
nalbeborbe, angeoronet werben.

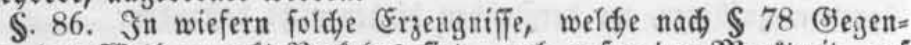

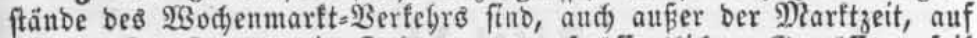
offener Straße ober in Fabrgeugen auf offentliden (Sewäfifern feí gebalten ober zum $\mathfrak{B}$ erfauf in 5äufern umbergetragen werben bürfen,

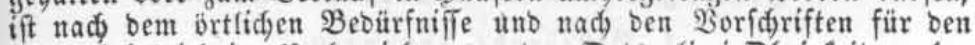
(5ewerbebetrieb im Umberzieben von ber Drtspoligei=Dbrigkeit fut be= fimmen.

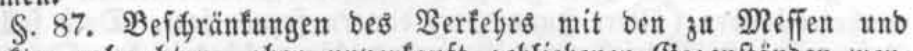
Därtten gebradten, aber unverfauft gebliebenen Bjegenftänden wers bell bierburd) aufgegoben. Der (Eimzennverfauf foldser Begenftänbe auffer ber Marttjeit ift jebod) nutr unter benfelben Bebingungen ju= läffig, unter weldjen berferbe ftattjaft fein wirbe, wenn bie Bjegen= fäube nidjt auf Den Marft gebrad)t wären.

\section{Titel}

\section{Taxen.}

\$. 88. Tyolizeifidje Taxen follen, foweit nidyt cin $\mathfrak{2}$ nberes nad $=$ fefeno angeoronet worben, fünftig nidjt vorgefdicieben werben; ba, wo folde gegenwärtig beftefen, find bieferben in einer, von ber $D$ rtố $=$ polizei = Dbrigfeit zu beftimmenben, Gödffens einjäbrigen grift auf= zulfeben.

\$. 89. Brobtaxen fönnen an eingelnen Drten, wenn unb fo lange bies burdf befonbere $\mathfrak{u m}$ ftänbe geredftfertigt er [deint, mit (Senegmi= gung ber $\mathfrak{M}$ inifferien beibebalten ober eingefübrt weroen. 
\$. 90. Die Drtspolizei=Sobrigfeit ift ermäd,tigt, bie Bäđẹ an. zufalten, monatfid) bic greife uno bas (senvidjt ibrer verfólebenen Bađtwaaren burd cinen Ânf Sublitums zu bringett.

§. 91. Die (Baftwirtlge fünnet burch bie Drtspolizei $=$ Dorigfeit

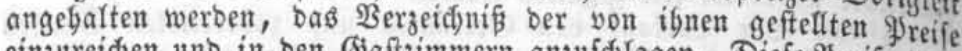

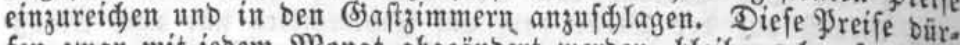
fen zwar mit jebem $\mathfrak{M}$ onat abgeänbert werben, bleiben aber fo lange in Rraft, bis bie Afuänberung ber \$olizeis Dbrigfeit angejeigt, unb bas abgeänberte $\mathfrak{B}$ erzeidfnif in ben (jaftzimmern angefd)lagen ift.

§. 92. Für Sdyornfteinfeger und 2 fboeffer töntent imterbalb ber benfefben angewiefenen $B_{\text {ezirfe }}$ von ber Srt\&polizei=Sbrigfeit, ober, wenn ber angewiefene $\mathfrak{B}_{\text {ezirf }}$ megr als eine Drtfdaft umfast, von bem Eanbratbe Taxen aufgeftellt werben. Sngleichen ift bie Drts.

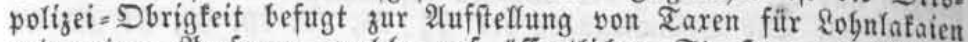
uno anbere \$erfonen, weldbe auf öffentlident Straßsen uno gräben ober in 2 Sirtbshäufern ibre Dienfte anbieten $(\$, 49)$, fo wie für bie

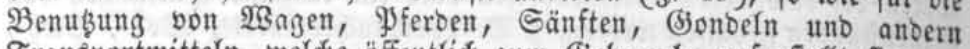
Iransportmitteln, weld)e iffentlid zum (Sebrauche aufgeftellt fino.

\$. 93. Şinfidtlid, ber $\mathfrak{T}$ axent für bie Mebizinalperfonen unt Apotbefer, fo wie ber Taren für rofe $\mathfrak{B}$ ergwerfserzengniffe wirb burd gegentwärtiges (B̉efeß̧ nichts geänbert.

Fin (S) Teiches gilt in 21nfebung ber in ben $\$ \$ 51$ unb 52 be. zeidneten Yerfonen. Für biefe fint bie Minifterien befugt, aud ba כaxen einzufübren, wo bergleidgen bisger nidjt beftanden.

\section{Titel vI.}

\section{Snnutugen von bewerbetreibenben.}

\section{Beftebenbe 3 unungen.}

\$. 94. 2Afle zur 3eit gefestidid beftefenbe Sorporationen von (5ic= werbetreibenben (altere Snnungen) bautern ferner fort. Dod foll bie Befugnifís zum Betrieb eines (3ewerbes, für weldes in bem Drte ober Diftrifte eine folde Rorporation ( $3 n n u n g$ ) beftegt, von bem Beitritt 3u berferfen nirgenbs abtängig fein.

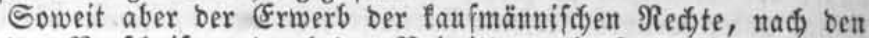
beftebenben Borfdriften, burđ̆ ben $\mathfrak{B}$ eitritt zur faufmämnifjen Rorpo. ration bebingt ift, bebält es babei fein Bewenben.

\$. 95. Die Statuten ber älteren Snnungen (\$. 94) foffen einer Revifion unterworfen unb, mit Berüdfichtigung ber $\mathfrak{B}$ orfdriften ber S\$. 101 bis 117, fo weit es nötbig ift, abgeänbert werben. Diefe

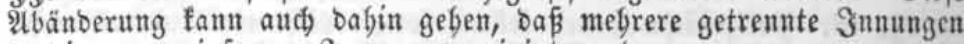
fu einer gemeinfamen Stmung vereinigt werben.

Die Feftifteflung uno Beftätigung ber revibirten Statuten erforgt burd bie Minifterien. Berweigert eine Snmung bie 2lnnalgme Der revibirten Statuten, fo wirb biefelbe aufgeloft.

\$. 96. Die Mitglieber ber gegenwärtig beftebenben Snnungen fönnen, nad) volfftünoiger (Erfüflung igrer 2 erpflid)tungen, ausf fdeioen uño burfen bas (sewerbe nad) bem 9 tustritte fortję̧en. 


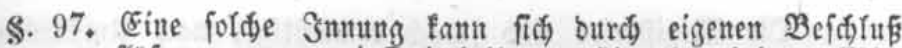
nur baun auflofen, wenn zwei Drittbeile ber ftimmberechtigten MRitglieber bafür ftimmen, bie $\mathfrak{B}$ erid)tigung ber vorbantenen Edjulben fider gefteflt ift uno bie 2luflofung von ber Regierung genebmigt wirt.

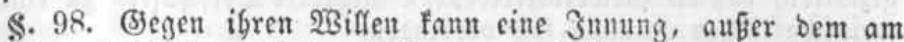
Sd) luife bes $\$ .95$ erwälynten Falle, nut aus überwiegenben Brünben bes (S) emeinwohts burd) bie Minifterien anffgelyoben werben.

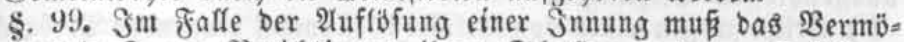
gen zuvörberft zur Berid)tigung ibrer Sd)ulben und zur Erfüflung ibrer fonftigen $\mathfrak{B}$ erpflidftungen verwenbet werben. Der fooann ver=

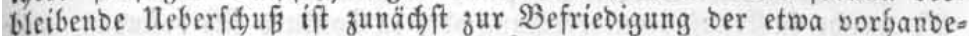

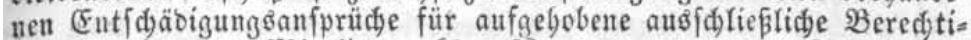
gungen eimzelner Mitglieber $(\$ .10)$, zu verwenden. Soweit ber

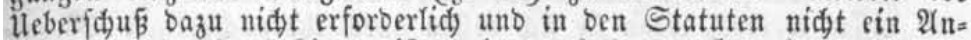
beres ausbrüffich beftimmt ift, wirb berfelbe ber (5emeittoe, in wel= der bie aufgelöfte Jnnung ilgren Siß̧ batte, jur Benubung für ges meimübige 3wedfe iiberwiefen; Die 2erwenoung faun nad bem Er.

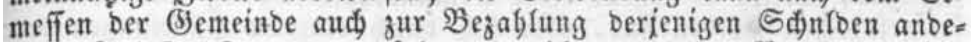
rer aufgelöfter Snnungen erfolgen, weldhe aus beren $\mathfrak{B e r m o ̈ g e n ~ n i d f t ~}$ gebectt werben.

\$. 100. $2 B e r b e n$ megrere Snnungen zu einer gemeinfamen $\Im \mathrm{n}=$ nung vereinigt $(\$ 95)$, fo faun $\mathrm{bas}$ Sermögen berferben mit ibrer Einwifligung ber neuen Jnnung überwirfen werben. Soweit cine Bereinbarung über bas $\mathfrak{B e r m o ̈ g e n ~ b e r ~ f e i t g e r ~ g e t r e n n t e n ~ S u n u m g e n ~}$ nidit erreidyt wiro, ift nad) ben Borfdriften bes $\$ .99$ zu ver= faljent.

II. Reue Sunugen.

1) Snnutgen, bei benen bie Mitgliebidjaft von ciner befonteren Fufunbute abbüngig ift.

\$. 101. Diejenigen, welde an bemferben Drte gleide ober ver=

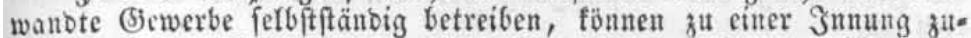
fammentreten. Die Bifoung einer foldyen netten Sunung ift jeood) für biejenigen (Semerbe, für weld)e am Drte cine ältere Sunung bes ftebt, nur bann zuläfíg, wenn bie ältere Junung anfgelijft ober mit ber netten Snnung verfigmolaten wirb.

Reue Şnungen erlangen burd) bie Beftätigung igrer Statu=

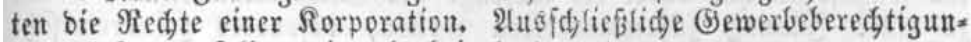
gen bürfen Denfelben niemalo beigelegt weroen.

\$. 102. 3ur Bifoung einer Smung fino erforberlid): in ben

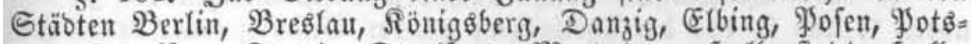
Dam, Franffurt, Stettin, Stralfuno, Magoeburg, Salberftaot, 5̧alle, Erfurt, Mitinfter, Röln, Düffeloorf, Eiberfelo, Barmen, Rrefelo, 2laden, Soblenz unb Trier 24 Werfonen, weld)e ifgr Betwerbe bercits cin $\Im a b r$ binburd) felbeffänbig betrieben voer einer aufgelöften älte= ren Sumung angegort baben, in affen übrigen Drten 12 bergleidgen भyerjonen. 
Die Ninifterien finb iebođ ermäđtigt, nađ $t m$ ftänben bie Bifbung von Snnungen aud bei einer geringeren $3 a b l$ von Theifnebs. mern zu genebmigen, anbererfeits aud in fleinern Stäbten bie ge= ringfte 3 abl ber Theifnebmer bis auf 24 zu erboben, ingleiden gu geftatten, baß bie (jewerbetreibenben megrerer Drtidaften zu einer ge=
meinfdaftlidjen Snnung fid verbinben.

\$. 103. Bon ber Theilnabme an ber Bitbung einer Snuming fint ausgefdioffen Diejenigen,

1) welde wegen eines von efrlofer Biefinnung zengenben $\mathfrak{B} e r b r e d e n s$, insbefonbere wegen Meineibes, Raubes, Diebftabls ober Betrut ges verurtbeilt worben find;

2) welde in Rriminalunterfudiung ober in Ronfurs fid befinben, ober

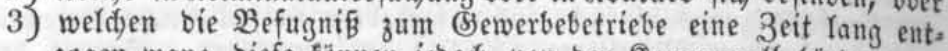
zogen war; biefe fönnen iebod, yon ber Sommunalbegörbe juges laffen werben, wenn fie fid beffen burd) ifge nadberiges 2 ertgals ten würbig gezeigt faben.

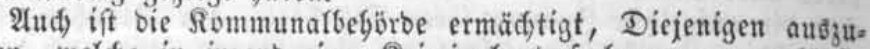
fd) lie ह̧en, weldfe in irgento einer Rriminalunterfutdung nur vorläufig freigefprodjen worben finb, ober fid burd) eingelne Şanblungen ober burd igre Rebensweife bie offentlidge Beraditung zugezogen baben.

\$. 104. Der 3weff ber neu gu grïnbenben Snnungen (\$. 101) beftegt in ber gorberung ber gemeinfamen gewerbliden Sutereffen; infonbergeit fotten bie Gnungen

1) bie 2 tufuabme, bie Atusbiloung uno bas Betragen ber Refrlinge, (S)efellen unb (Befülfen ber Snnungsgenofien beaufficdtigen,

2) bie Berwaltung ber Rranten $=$, Sterbe $=$, 5eülfg = uno Sparfaffen ber Ŝnnungsggenvffen Yeiten,

3) ber Fürírge für bie $\mathfrak{B}$ ittwen uno $2 B a i f e n$ ber Sunungsgenoffen, namentfid) burd) Förberung ber (Ergiefung unb bes gewerblidjen Fortfommens ber $2 B$ aifen, fid untergiegen.

§. 105. Die Reitung Der Borberathungen wegen Erriditung eis ner Snnung ftegt ber Rommunalbelörbe unter 2 uffidit ber Regierung, bic Jefftellung uno Beftätigung ber Statuten aber ben 2)inifles rien zut. $^{\text {th }}$

§. 106. In ben Statuten finb bie Bebingungen ber 2 unfuabume

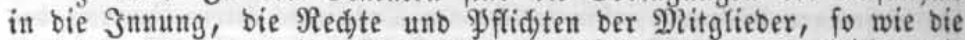

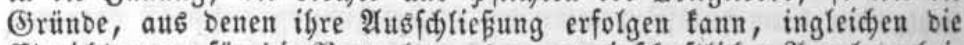
(Einrid)tungen für bie $\mathfrak{B}$ erwaltung ber gemeinf(d)aftlidfen 2 (tngelegenbeis ten feftzufę̧en unb babei bie 2Inträge ber Bjewerbetreibenden, welde zu einer Snnung zufammentreten wollen, befonbers zu beriaffich: tigen.

§. 107. Denjenigen, weldje nad ben Beftimmungen bes \$. 103 unter 1, und 2. von ber Theilnabme an ber Bifoung einer netten $\}^{n}=$ nung unbebingt autgefédloffen fino, barf aud ber Eintritt in cine be: reitş gebilbete Snumg nidht geftattet werben. Sn ben Fällen, in wel= den nad) \$. 103 bie Sommunalbeg̈̈rbe bei ber Bifoung einer neuen

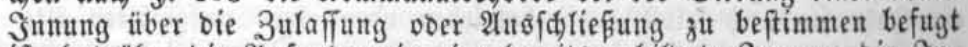
ift, Gat inber tie 2lufnabme in eine bereits gebildete Snnung bie Sts nung ferbft zu befdfliefen; zu bem Befflulfie ift jebod, went baburd 
bie 2ufnahme augsgefproden wirb, bie 3uftimmung ber Rommunal= beforbe erforberlid.

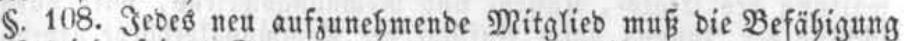
fum Betriebe feines Setwerbes befonbers nad)weifen.

Die Yriifungşzeugniffe ber für einzelne Bewerbe angeoroneten Yrüung $=\mathfrak{B}$ chörben, ber Dber $=\mathfrak{B}$ aubeputation ober bes tectunifjen Sewerbe $=\Im$ nftituts, fo wie bie von ber 2 fabemie ber Sïnfte iiber bie 2ufnabme und Einfodreibung bei berfelben auggefertigten Diplome find ald genügender $\Re a d$ weis ber Befábigung zum Betriebe ber (5)e= werbe, über weld)e fie ausgefteflt finb, anzufeben. Auth bebürfen Mitglieber älterer Jnuungen feines befonoeren $\Re a d$ weifes ber $\mathfrak{B} e=$ fäbigung.

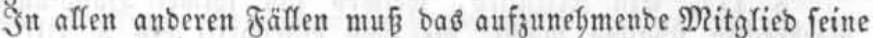
23efäbigung burd) eine, nach) ben $\mathfrak{B}$ eftimmungen bes Titels VIII. $a b=$ gelegte Wrüfung nad)weifen.

Diefe Yrüfung fann febod, Denienigen, bie bas (5iewerbe an bemfelben ober an einem anbern Drte fdon einige 3eit binourd) mit

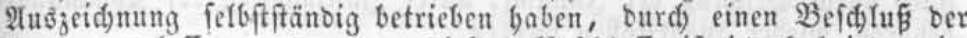
Snnung erlafjen werben; ju biefem Befd)luje ift iebod bei ben im \$. 131 genannten Sewerben Die 3ufitimmung ber \$rifungsbebörbe (\$§. 162, 167), bei aflen anberen (5)ewerben bie (5)enebmigung ber Rommunalbeforbe erforberlid).

\$. 109. Die \$s. 107, 108 finben auf bie fanfmännifden fior= porationent feine 2tnwendung; in Anfegung bicfer bewenbet es bei ben beftebenoen Borfdriften.

\$. 110. Dei ber Tufnabme in eine Snnung ift bie Erbebung cincs mäpigen 2utrittögeldes zuläfig, Deffen 2 etrag burd das Sta= tut uno zwar für alle Benoffen ber Jnuung gleidmäjig feftgefeģt werben muß.

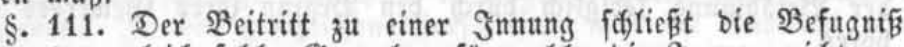
nidit auts, jugleid folde (5ewerbe, für weld)e bie Snnung nid)t ge= birbet ift, zu betreiben, fo wie an anberen Эnnungen Theil ju nebmen. (Es fanu jebod) einem (S)ewerbetreibenben ber 3utritt ju einer auferbalb feines 280 gnorts beftebenden Snmung mur bann geftattet werben, wenn an feinem $2 B$ bnorte für bas von ifm betriebene (5)e= werbe eine Snuung nidt vorbanben ift.

§. 112. Sebe Sunung muk einen ober mebrere Sorfteber baben, welde von ben $\mathfrak{R}$ itgliebern zu wäblen unb burd bie Rommunalbe= börbe zu befätigen fino

\$. 113. Seber Beratfung ber Snnung muß ein $\mathfrak{M}$ itglieb ber fiommunalbeförbe beiwobnen, um uber bie Gefesmäfigfeit ber $\mathfrak{B} e=$ (d)litife fu wadjen. Daffelbe barf fein (Sewerbe Derjenigen 2 rt be= treiben, fitr weldie biefe Junung gebiloet ift.

\$. 114. Der Maafitab, nad weldem Iaufende Beiträge ber

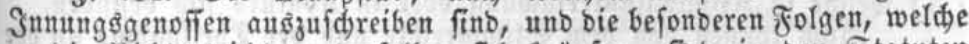
an bie Yidftentrid)tung berfelben fid) fnüpfen, fino in ben Statuten feftuftellen. Snsbefonbere fann barin aud bie exefutivifoe Beitrei= bung biefer Beiträge im Berwaltungşwege uno ba babei Statt fit= bende $\mathfrak{B}$ erfabren beftimmt werben.

Supplement. 
Die 5̧öge uno bie $\mathfrak{B e r w e n t}$ ung ber $\mathfrak{B e}$ eiträge, fo wie bie $\mathfrak{B e r}$.

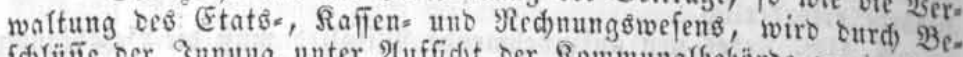

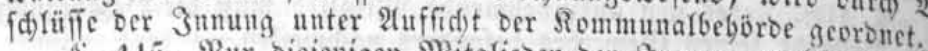

\$. 115. Fur cicicnigen Mitglicoer oer Jnuung, weldye ifr Gse. werbe wäbrenb oco vorbergebenoen Gabres felbettänoig betrieben ba. ben, fino bercdtigt, bei ben Beid)!ülien mitzuftimmen.

Durch rie Etatuten fann bas Etimmred)t von einem geviffen Itmfange bes (b) ewerbebetriebes abbängig gemad)t ober verid)iebenartig abgefuft werben.

$\$ 116$. Der 2 astritt aus ber Jnnung ift unter ber im $\$ 96$ bezeidneten $\mathfrak{B}_{\text {ibingung geitattet. }}$

§. 117. Ein Mitglico, weldhes fidd) fold)er Saanblungen ober Berbredjen fduldig madt, bie nad) Borfdrift bes \$. 1177 vou ber

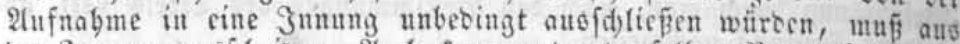

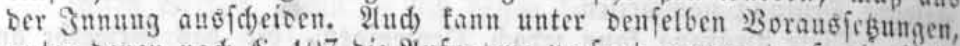
unter benen nad $\mathbb{S} .107$ bie 2 ufnabme verfant werben barf, cin 2)it. glieb ourd) Bef(d)luß ber Snnung, unter Sultimmung ber Sioumunal. beborbe, wiedcr ausgeftofen werben.

Die Befugní jum fermeren Betriebe ocs (5) won bem Berlufte ber Mitgliebfdaft nid)t abbängig.

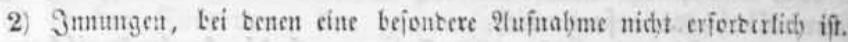

\$. 118 2us Denjenigen, welte an bemfelben Drte gleide ober werwandte (Bswerbe felbitfanoig betreiben, fann auf Bruno cines Be: meinoebefdluffes, im Einverftanonifie nit ber bitbeifigten Smumg, ober, wenn cine folde nidft vorbanoen ift, nach 2 nbörung betheifigter (Sewerbetreibenoen, eine Jumung aud) in ber 2 rt gebiloct werben, baß berfelben afle Gewerbetreibenbe biefer (B)attung obne Yad) weis

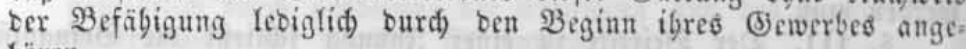
bören

2(uรgenommen biervon fint Dicjenizen,

1) weld)e ausorücflid, erflärt baben, ber 3 num nid)t beitreten ober aแร่ oerfelben aแ⿰์ d)eiben zu woflen, ooer

2) welde wegen $3 e r b r e d) e n$ voer unwüroiger 5anbfungen burd) $B$ e. (đ) lū ber Sonung, unter 3uftimmung oer Sommumalbeboroe, aแbijef dolfien worben finb.

\$. 119. In ben 3nmungen biefer 2 rt (\$. 118) ftebt Stimmrecht unb Ígcilnafyme an Der Berwaltung benjenigen Mitgliebern nidht ju,

1) wefde ibre Befäbigung jum Sietriebe bes Bewerbes nidt naゆ \$. li) nadigetwiefen baben,

2) welde wegen cines vou ebrlofer (5icfinnung ;engenben Berbred)end, insbcjondere wegen Meineibes, Raubes, Dieblabls oder Betru: ges verurtbeilt worben fint, ober

3) weid) in Siriminalunterjud)ung ober in Sonfurs fid) befinten.

2(ư) fönnen won bem Stimmrechte unb ber Theilnafme an ber Berwaltung burd, Befdyfú ber Snnung, unter Zuftimmung ber fom: munalbebiorbe, Dieienigen ausgefd)loffen werben,

a. welden die Befugnif zum Siewerbebetriebe eine 3eit lang ent. zogen war, ober 
b. weldfe in irgend einer Rrimitralunterfuffung nur vorläufig frei= gefprodhen worben fint, ober fith ourd eingelne 5̧andiungen voer burd) igre \&ebensweife bie offentlide Beradtung jugejo. gen baben.

\section{3) G5emeinfame Beftimmutgen.}

\$. 120. Die (5ewerbetreibenden, weld)e zut einer Snnung zufam= mentreten wollen, fönnen bei 2 (ufiftellung ber Statuten von ben $\mathfrak{B}$ or $=$ id)riften ber $\$ \mathbb{S} .101$ ff. nur in foweit abweidfen, alo bie Bemeinde bamit einverftanoen ift, uno bie im $\$ .170$ beftimmten Erenzen nidst iberfdyritten weroen.

(Fin (S) feides finbet Statt, wenn bei 2 bänterung beftefyenber Statuten berglcidgen 21bweid)ungen Gerbeigefübrt werben follen.

$\$$ : 121. Die Statuten ber umgebibeten äteren, fo wie ber nen= gebiloeten Snnungen, fönnen auf ben 21ntrag ber 23etgeifigten ober im offentliden Sntereffe von 2 (misswegen jedergeit revibirt und unter Deftätigung ber MRinifterien afigeänocrt werben.

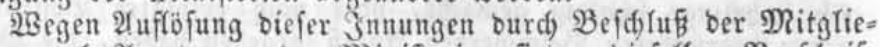

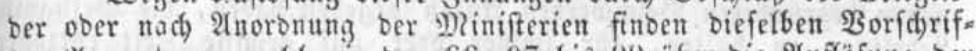

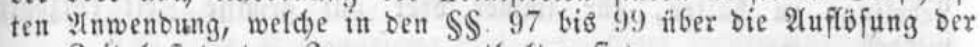
3ur 3eit beftelenben 3nnungen enthalten fino.

$\$ 122$. Streitigfeiten iber bie 2 fufnafme uno 2 tusfd)liefang von Mitgliebern, fo wie iiber bie Redtte uno yflidten berfelben uno ber Boritänbe, fino von ber Sommunalbeföroe zu entideiben. Begen biefe Entfdeioung fegt ber Refurb an bie Regierung offen, welder binnen einer prällufivifden grift von vier 2 godjen bei ber Rommunats begorbe anjumeloen ift.

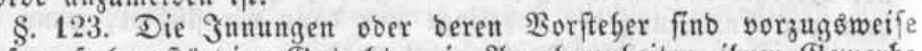
berufen, fadyerftänoige (s)utad)ten in 21ngelegenteiten igrer (Semerbe abjugeben. Sn ben gefestidjen Boridgriften über bie 2Auşwabl vou Sadjverfitänoigen in Yrojeffen wiro bierourd, nid)ts geänbert

\$. 124. Esefellidaften sum Bsemerbebetriebe auf gemeinfdaftlide

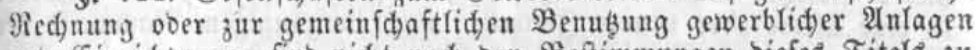
uno (Einridtungen find nidft nad) ben Beftimmungen biefes Titels zu beurtbeilen.

\section{Titel. VHe.} (5) werbegegülfen, (5) efellen, Fabrifarbeiter und

1. Befugní, (Befellen, (jebülfen unb gebrlinge zu balten.

\$. 125. 2Ber befugt ift, ein ftegenbes Bewerbe felbftitänbig zut

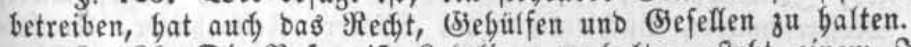

$\$ 126$. Die Befugni $\bar{\beta}$, Qegrlinge zu balten, ftegt einem Seben 3u, ber zum felbftftänoigen 'Betriebe eines ftegenben Bewerbes befugt

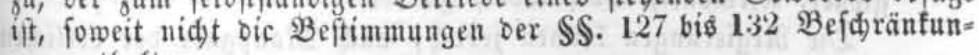
gen entbalten.

fen Dirjenigen, 
1) welde wegen eincs wou efrlofer (B)efintung zeugenben $B e r b r e d) e n$, insbefonoere wegen Meineibes, Raubes, Diebftafls ober Betru= ges verurtlyeift worben find.

2) weld)e in Rriminalunterfud)ung ober in Ronfurs fid befinben, ober

3) welden bie Befugniß̄ zum Generbebetriebe cine Beit lang ent. sogen war; bicfen fann iebod) son ber fiommunalbebörbe bie 211 . nabme von gebrlingen geftattet werben, wenn fie fid beifen ourd, ifr nadberiges $\mathfrak{B}$ erbalten würbig gejcigt baben.

5. 128. Die Rommunalbebörbe ift ermähtigt, vorbebaltlid bes Refurfes an bie Regierung, Diejenigen von ber Befugniß̧, Rebrlinge fu balten, augुufd)liefien, weldse in irgeno einer friminalunterfud)ung nur vorläufig freigefprod)en worben fino, ober fid) burd) einjelne 5̧ant. lungen ober burd ibre Rebenswsife bie offentlidje Berad)tung ju= gejogen baben.

\$. 129. Durd Befd)luß ber Regierung fann (Sewerbetreibenten, welde fid) grober 9 flid)twibrigfeiten binfid)tlid) ber ibnen anvertrau-

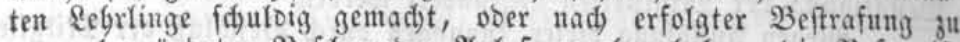
neuen begrunbeten Befdwerben 2 nläß gegeben Gaben, bie Befugnifi, \&ebrlinge zu balten, für immer ober auf gewiffe. Seit entzogen werben.

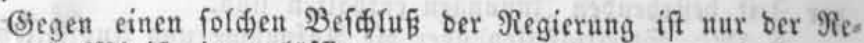
Łurs an bie MRinifterien juläffig.

\$. 130. Sn ben Fallen, in benen nad, ben $\$ S \$ 127$ bis 129 bie 2ư์ barf ber \&ebrberr aud bie bereits angenommenen \&ebrlinge nidt ferner beibebalten; in ben gäfen bes $\$ .127$ z 2 . ift jeovd ber \&ebr= Gerr jur Entlafiung ber Eebrlinge nur bann verpfliditet, wenn fold)e von ber Rommunalbebörbe verlangt wirb.

\$. 131. Die nadjfebeno benannten (5iewerbetreibenben erlangen bie befugniß̈, Rebringe zu balten, fofern ignen fold)e bei \$ublifation

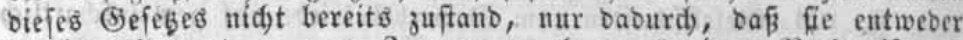
it eine ältere ober neuere Snnung, nad) vorgängigem Niad)weife ber Befäbigung zum Betriebe ibres (S)emerbes, aufgenommen werben, ober biefe Befäbigung befonoers nadyeifen (\$. 132).

Diefe Biewerbetreibenben fint:

Siserber affer \&rt, Reberbereiter, Rebertauer, Rorbuaner, Serga= menter, Sdjubmad)er, Şanbidjubmad)er, Beutler, fiüridner, Rie=

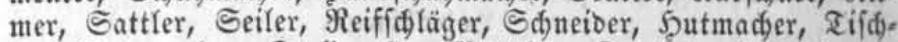

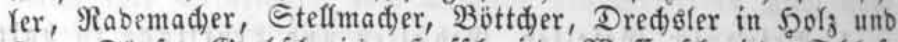

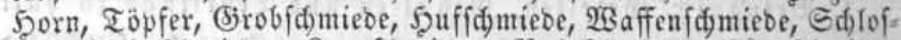
fer, 3irfelfduiebe, 3eugfhmiebe, Bobrfdumiebe, Sägefdmiebe, Mefferfidniebe, Büdfenfdumiebe, Sporer, Jeilenbauter, Supfer=

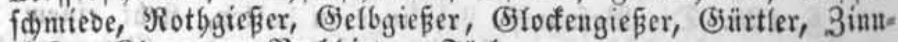
giefer, Ritempner, B3udbinoer, Färber.

Die Regierungen töntmen jebod, nad) Maafigabe ber ïtliden Berbält niffe, unter (Senebmigung ber Minifterien, ben Nadjweis ber Fefabigung für cimzefne ber vorftebeno benannten Gewerbe erlaffen, fo wie für anbere, als biefe Serwerbe anoronen. 


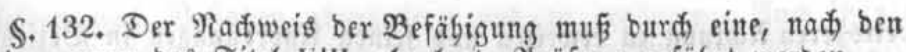
Beftimmungen bes Titel VIII. abgelegte अrüfung gefübrt werben.

Die 2 blegung einer förmliden Yyrüfung fann jebod) Denjenis

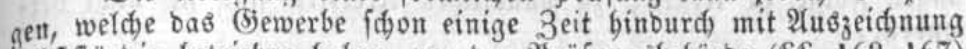
feflefftanoig betrieben Gaben, von ber Yrüfungsbeförbe (\$S. 162, 167) erlafien werben, wenn biefe fid auf andere 28 eife bie Hebergeugung

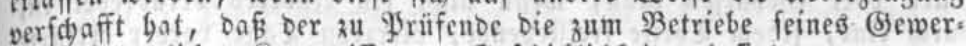

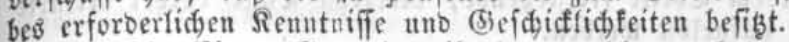

\$. 133. Einem (Sewerbetreibenoen, welder nad) ben $\$ \$ .126$ bis 132 nidjt befugt ift, \&egrlinge ju balten, ift beren 2 tunabme oder $B$ ei= bebaltung in ben Stäbten burd) bie Sommunalbebörbe, auf bem \&anbe burd) bie \$ofizeiobrigfeit zu unterfagen. Dag 23 erbot fann im $2 B$ ege ber poligeiliden Exefution zur 2lusfüurung gebrad)t werben.

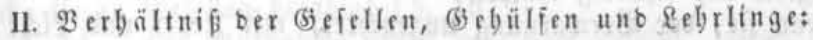

\section{1) im 9!lfgemeitrm.}

\$. 134. Die Feftfę̧ung ber Berbältniffe zwifđen ben felbffttän=

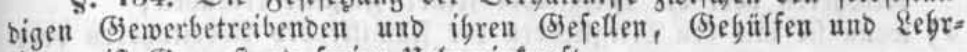
lingen ift Biegenftand freier Hebereinfunft.

s.. 135. 3n Ermangelung vertragsmäfiger Beftimmungen fin biefe Sergältnille, infofern die felbêfftandigen Bewerbetreibenben ei= ner Snnung angelobren, nad, ben Snunngsiftatuten, in anbern fäflen aber, ingleiden wenn bie Borfdgriften ber Etatuten niḑt auşreiden, nad) bem gegenwärtigen (Befése zu beurtbeilen.

\$. 130. Die Drtspolizei=Dorigfeit bat Darauf zu adjten, baf́ bei Beficäftigung unb Bebanolung ber (jefeflen, Bebülfen uno Eebrlinge

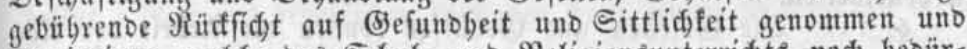
Denjenigen, weld)e bes Sd)ul = uno Religionsunterrid)ts nod) bedür= fen, 3eit bagu gelaffen werbe.

5. 137. Etreitigfeiten ber ferbfttänoigen Bemerbetreibenben mit

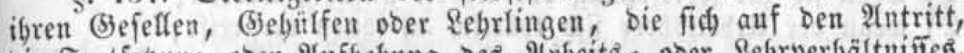

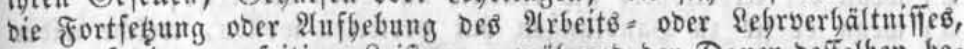
Doer auf oie gegenfeitigen Reiftungen wälrento ber Dauer beffelben be= jiegen, fino, foweit für biefe 2(ngelegenbeiten befonbere Beböroen bes fegen, bei biefen zur Entídjeibung zu bringen.

Entfdeioung,

Sil foweit foldje befondere Begörben nidjt befteben, erfolgt bie

1) wenn ber felbffttänoige Gewerbetreibenbe Mitglieb einer Snnung

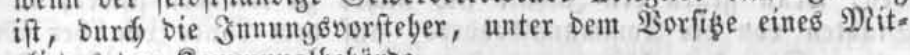
gliedes ber Rommunalbelobroe,

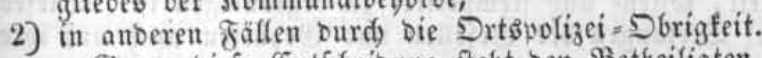

Bisgen biefe (Entfacioung ftebt ben Betbeiligten bie Berufung

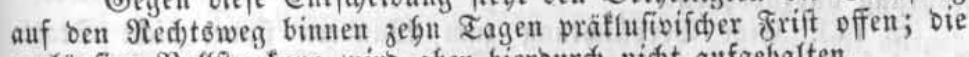
vorläufige 30 df freffung wirb aber bierburd) nidgt aufgebalten.

2) intsejoubere:

a) ber (sefellen tunb (5ebuillfent.

\$. 138. Die (Sefeflen und Begailfen find verpflidtet, bem $\mathfrak{A}=$ 


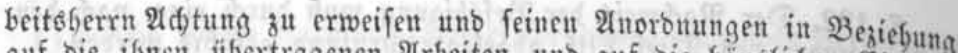

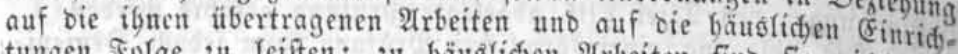

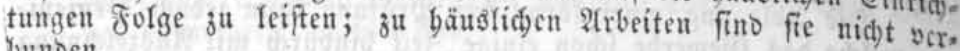
vunoen.

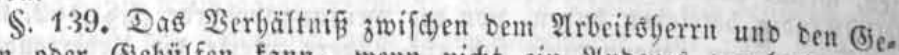

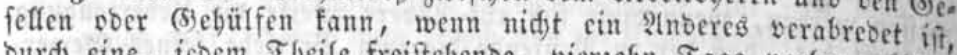
burd) eine, jebem Theile freiftelente, vierjefn Tage vorber erflärte IUffünoigung aufgeloft werben.

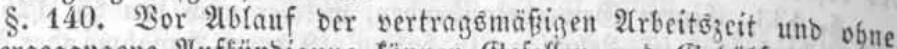
vorbergegangene 2luffünbigung fömen (B)efllen unb Bebülfen entlaf. fen werben:

1) wenn fie eines Diebftafls, einer Beruntreutung, eines lieberlichen

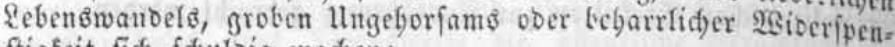
ftigfeit fid fduloig madien;

2) wenn fie, ber Berwarnung ungeadjet, mit Feuer unb fidjt un= vorfidtig umgeben;

3) wenn fie fid) Thätfidfteiten ober Sd)mägungen gegen ben 2 r. beitsherrn ober bie Mhitglieber feiner Familie erfauben;

4) wenn fie mit ben $\$ 2$ it glicoern ber Familie bes 2trbeitsherrn ober mit ibren Ditarbeitern veroäd)tigen llmgang pflegen, ober fonft bicfelben zum Bofen verleiten;

5) wenu fie zur gortíz̧ung oer 29rbeit unfäbig geworben, ober mit einer efellyaften Sirantbeit bebaftet fino.

Sn wiefern in ben zu 5 . gebad,ten gällen bem Entlaffenen ein 2 nfiprud) auf (Entidjabigung zuftele, ift nad bem befonbern Str. balt bes $\mathfrak{B}$ ertrags uno nad) ben allgemeinen gefegliden Boridgriften z̆ beurtbeifen.

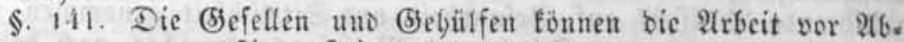
Iauf ber vertragemäfigen 3 eit uno ogne vorbergegangene 2 (uffinto gung verlalfen:

1) wenn fie zur fortfeksung ber Arbeit unfäljig werben;

2) wenn ber 2 trbeitsherr fid tyätid an ibnen vergreift;

3) wenn er fie zu Sandingen bat verleiten wodlen, welde wiber bie Sefetze ober wider bie guten Sitten Iaufen;

4) wenn er ifnen ben veriprodjenen Eogn ober bie fonftigen (jegen= leiftungen ofme genügende Weranlafïung vorentbält.

5. 142 Beim 2thang fönnen bie Befeflen uno Befülfen ein 3eugniß̧ über bie 21rt uno Dauer ifrer Befdäftigung forbern, wel-

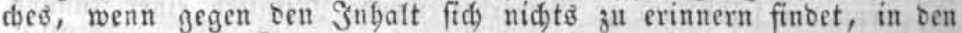

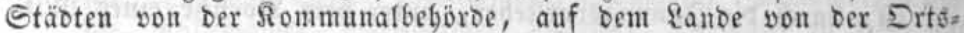
polizei-Dbrigfeit, foiten= uno ftempelfrei zu beglaubigen ift. Diefes Zeugniß ift auf $\mathfrak{B}$ erlangen ber (Befeflen uno Gebülfen aud auf ibre Jithrang auşzudegnen.

5. 143. Eire Berpflidtung zum 2 Banbern finbet nidit Statt. 2uf befonbere Unterftüz̧ung von Seiten ber Bewerbegenoffen baben wanbernbe (jefellen uno (S)egülfen feinen Infprud).

\$. 144. Den Biefellen und Gebülfen ift bie Beibegaltung ber zur gegenfeitigen Unterftügung vorbanbenen befonberen 2 Serbintoungen uno Saffen geftattet; eB bleibt febod) vorbebalten, bie Einridgtungen 
berfelben nad, Befüben abzuänbern uno zu ergänzen. Stud fönnen bergleichen Berbinoungen und Rafien mit Senebmitzung ber Ricgic=

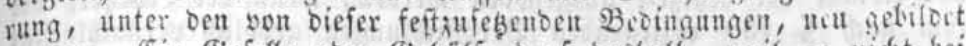
weroen. Ein (sefelle ober (5ebülfe barf beshalb, weil er uidgt ba einem Junungøggenolfen arbeitet, won bem Beitritte ju folden $2 \mathrm{er}$. binsungen uno Siaffen nidgt ausgefdolofïen werben.

$\$ 145$. Die Beftimmungen ber $\$ \$$. 134 bis 144 finbell aud auf Gabrifinbeiter Anwenoung.

\section{b) oer Eefrlinge.}

\$. 146. 216 fefrlinge find nur biejenigen gerionen zu betrad) te:, welde in ber burd) emen \&egrvertra; ausgefprodenen 2lbficht bei cincm Eegrberrn eintreten, um gegen Eegrgelo ober unentgeltlide burffoleiftung ein (S) werbe bis zu berienigen Fertigfeit zu erlernen, welde fie zu (Biefellen befäbigt (\$. 157).

\$. 147. Die Aufnabme eines \&ebrling erfolgt, wenn beriflbe fei bem Sienoffen einer Snuung cintritt, vor ber Jnnung.

Tritt ber Qefrling bei einem andern Stewerbetreibenben eill, fo crfolgt bie Aufnalme in ben Stäoten bor ber Rommunalbebobro, auf oem Yanbe vor ber Drtopolizei= Dorigfeit, unb gwar in biefen beioen fällen mit 3 uziebung zweier unbefdoltener Scmeinbemitglieber, wo

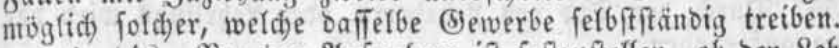

5. 148. Bor ber Aufnafme if feifzuftellen, of ber \&ebrberr be= fugt if, Segrfinge zu balten ( $\$ \$ S$. 126 bis 132).

Der Rebrling muß bartbun, baß̄ er lefen, fd́reiben unb red)nen

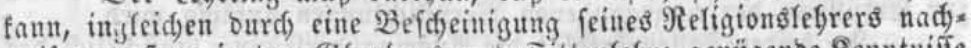
weifen, baß̈ er in ber (B) aubens: und Eittenlebre genügenbe Renntniffe befigt Yur aub erbeblidgen (Siründen barf einem Mangel an-biefen Renntuifien nadgefeben werben. Der Eeforberr ift alsbann verpflicid)= tet, für Die Rad)bülfe nad) ben शnorbungen ber Drtôfdulbegörbe ju forgent.

\$. 149. Die Berabrebungen über bie Rebrgeit, bą Refrgelo und bie fonftigen Bebingungen fino bei ber 2 ufuabme ju verzeidnen.

§. 150. Der \&efrberr muḱ fid angelegen fein laffen, ben \&ebr=

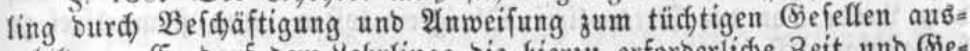
jubiloen. Er Darf bem selgrlinge bie bierzu erforberlide Beit unb (E)e legenbeit burd) Berwenoung zu anberen Dienffleiftungen nidst entzie= Gen. Der Rebrberr muß bemitbt fein, ben \&egrling fur 2roeitiams

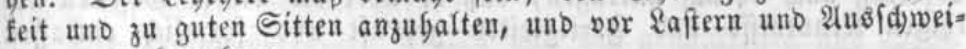
fungen zu bewabren.

\$. 151 . Der \&ebrling ift ber väterliden 3 udut bes \&ebrberrn un= terworfen unb in Abwefenteit bes \&ebrberrn aud) bem, benfelben ver= tretenten Befellen ooer (S)ebülfen zur golglamfeit verpflid)tet.

\$.152 Das Regrverbältnif́ fann in ben gällen, weld)e im $\$ .140$ bezeidunet find, won bem Eebrgerrn vor 2 lblauf ber \&ebrzeit aufgebo= ben werben. Eind für einen foldjen. Fall feine befonberen Berabre= bungen getroffen, fo ift bas \&ebrgelo nidht nur fitr bie bereits abgelaufene 3eit, fonbern aud) für bas Yaufenbe jabr fu ent= riditen. 


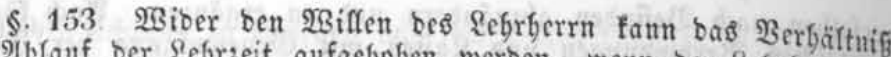
yor 2lblauf ber \&ebrzeit aufgeboben werben, wenn ber \&ebrberr bie ibm nad) $\$$. 150 obliegenden Berpflidjtungen gröblid vernad)läfigt

Bei Rebrlingen ber Benoffen von Gunungen bat bie Snnung, bei anberen Rebrlingen aber in ben Stäbten Die Rommunalbeboroe,

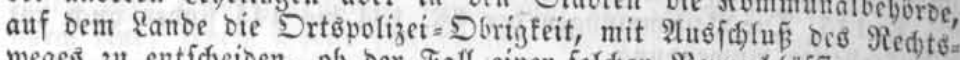
weges zu entfocioen, ob ber Fall einer foldyen Bernadblaffigung ober eimes fold)en Difibrauchs vorbanden iff.

In biefen fällen fann ber \&ebrberr zur Erftattung ber burq bie anberweitige Unterbringung bes Rebrlings entfegenben Debrfoften im $\mathfrak{R}$ (d) toinege angebalten werben

Daffelbe gilt bon bem Falfe, wenn bem Rebrberrn bie $\mathfrak{B}_{\text {efug }}$ nifi, eebrlinge zu balten, entjogen wirb $(\$ .130)$.

\$. 154. WBiber ben Willen bes Rebrberrn fann bas Berbältnî́ Бor ใُblauf ber \&ebrzeit aufgeboben werben, wenn ber \&ebrling ju ei= nem andern (S)enerbe ober zu einem anbern Berufe itbergebt. Dem Qebrberrn ift in biefem Jalle, wenn nidit ein 2nberes verabrebet wor. ben, Das Sebrgelo nod) für einen balbjäbrigen Seitraum nad 2ablauf bes Duartalo ju zablen, in weldem ber \&ebrling abgebt.

\$. 155. Durd ben Tod bes Rebrgerrn ober Rebrlings wirb ber Rebrvertrag aufgeboben.

Auf ben Antrag bes einen ober bes anbern $\mathfrak{I}$ geils ift ber \&efr= bertrag aud bann aufzubeben, wenn ber Rebrberr ober ber Rebrling zur Erfüllung ber eingegangenen Berpflid)tungen unfäbig wirb.

In beiden Fällen erfolgt oie Puseinanberfebsung binfid)tlid, bes Rebrgelbes nad) Berbältniß̄ bes bereits abgelaufenen Zgeils ber \&ebr: zeit jur ganzen Dauer befelben.

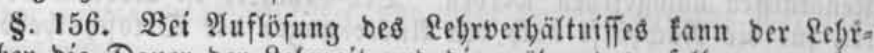
ling über bie Dauer ber Sebrjeit uno bie wabreno oerfelben erworbe: nen Renntniffe uno Fertigfeiten, fo wie über fein Betragen vom \&ebr= berrn ein Beugní̧ for:ern, weld)es, wenn gegen ben Snbalt fid) nid)to zu erimnern finbet, in Den Stäoten von ber Sommunalbebörbe, auf bem Ianbe von ber Drtspolizei $=$ Dbrigfeit foften = und ftempelfrei ju beglaubigen ift.

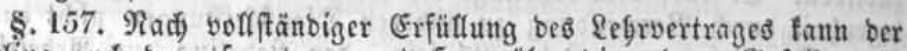
Qefrling aud) barauf antragen, bafi er über bie einem (Siefeflen no. tbigen Renntniffe uno Jertigfeiten geprüft uno förmlid entlaffen werde.

Die Sriffung uno Entlaffung bes Rebrlings erfolgt, menn ber. felbe bei bem (Senolien einer Şnung gelernt bat, burd) Die Sinnung.

5at ber Rebrling bei einem anderen (Serverbetreibenben in ber Qebre geftanden, fo erfolgt Die Yrüfung und Entlaffung, unter 3ujie bung geeigneter Sadyerftänoigen, in ben Stäbten Durd, Die Sommus nalbebörbe, auf bem Kanbe ourd die Drtspotizei=5origteit. Die Riom: munalbebörbe voer bie \$olizei = Dbrigfeit ift jebo() ermädtigt, bie

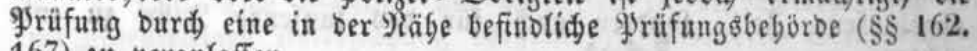
167) zu veranlaffen. 


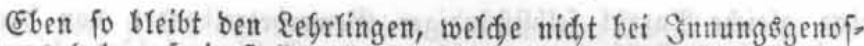
fen gelernt baben, freigefteflt, bie \$yrüfung vor einer \$riifunggbegüroe (SS. 16\%, 167) abzulegen. Diefe bat itgnen nadh genügeno beftanbe: ner Yrüfung, Gierüber ein 3eugni亩 zu ertbeilen, auf belfen Brunb bie Sommunalbehörbe voer bie Srtspolizei= Dbrigfeit bie Entlaffung be= wirfen uแb Das Entlaffung

\$. 168. Die Snnungen, Die Rommunalbeförben unb bie Drtş= polizei=Dbrigfeiten baben über bie 2tufnabme und Entlaffung ber \&effr= linge volfitäntige $\mathfrak{B}$ erzeicfniffe zu füfren.

§. 159. Für bie Aufnabme uno Entfaffung ber \&efrringe bürfen

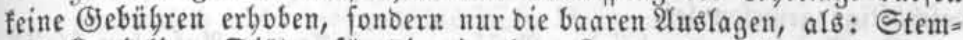
pel, Sopialien, Diäten für bie einzelnen Snumugğgenoffen uno Sad)=

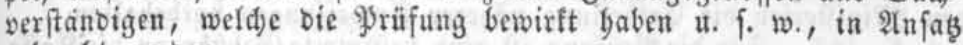
gebradjt werben.

5. 160. Werfonen, welde nad, ber ifber ifre thnterweifung in ge= werbliden אenntnififen uno Fertigfeiten mit felbfftänoigen Bewerbe= treibenben getroffenen $\mathfrak{H e b e r e i n f u n f t}$ nidjt als \&egrfinge anzufeben find

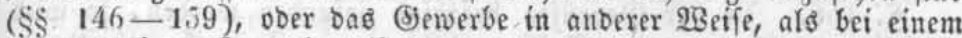
felbefftänbigen Bsewerbetreibenben, erlernt baben, fonnen, wenn fie bei ben (B)envffen ciner Sunung unterwiefen worben finb, bei ber $\}_{n}=$ nung, fonft aber bei ber Rommunalbejöroe ober Yolizeiobrigfeit bar= auf antragen, baßi fie über bie einem (S)efelfen nötbigen Sienntniffe uno Fertigfeiten (\$\$. 148, 157) geprifft werben unb bafi ignen, nad) gentigend beftanbener Srüfung, Gieriber ein 3eugní ertbeilt werbe.

$\$ 161$. Die Beftimmungen ber $\$ \$ 134$ biB 160 finben auf bie (3)efjuffen unb Refrefinge ber 2lpotbefer uno Rauffeute, ingleiden auf

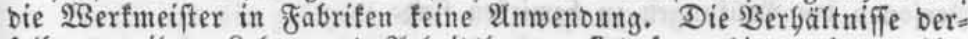
ferben zu ibren \&ebr= uno 2trbeitsherren fino fernerbin nad ben biš berigen $\mathfrak{B}$ orfdriften zu beurtbeilen.

\section{Titel Whit.}

9ु riffungen für bie 2 ufnagme in $̧$ กnungen unb für Die Befuguif zur $\mathfrak{A}$ nabme von 2 ebrlingen.

\$. 162. Für bie in ben $\$ \$ 108$ a. 132 angeorbneten 9 rëfungen fint beftänoige Drts= ober Diftrift

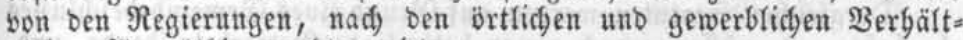
niffen, für nötbig erachtet wirb.

Die 9rüfungsbeforben werben aus ben gefdictteften unb gead)=

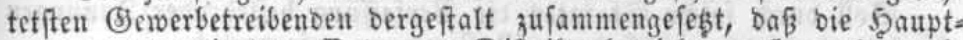
gattungen ber in bem Drte ober Diftritte betriebenen Semerbe barin vertreten finb. Die 2 Ritglieber werben ourd) bie Siommunalbebörbe

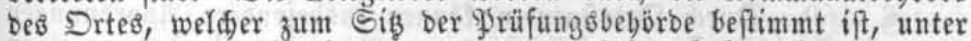

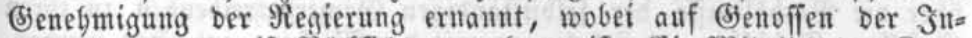

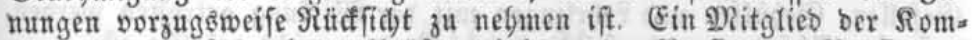

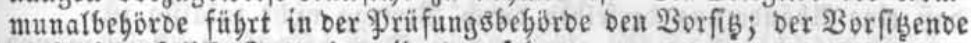
barf nidgt felbft Gewerbetrcibenber fein.

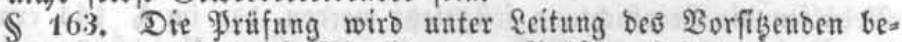
wirtt burd ein bis brei MRitglieber ber Yrifungsbegorbe unb burd 


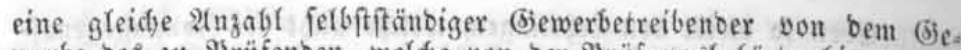
werbe bes zu Yjruffenben, weldse von ber \$rüfungsbeföroe bierzu aub.

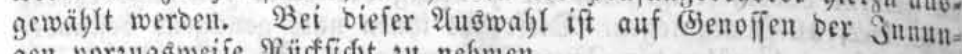

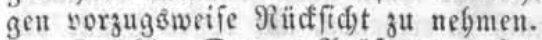

\$. 164 Der 3u Yुrüfenbe muß burd) \&öfung von Rufgaben bar. tgun, Daß́ er befäbigt fei, bie gewöbnfiden 2̂rbeiten feines (siewerbes

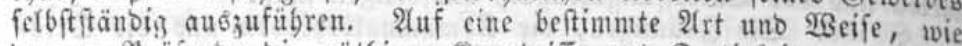
Der zu Priifenoe bie nötbigen Sienntuiffe uno fertigfeiten erworben babe, fommt eś fierbei nidit an; jebod) fann ein Rad)weis bariber verlangt werben, bafi berfelbe foun ein Jafr lang in bem (5emerbe bejdätigt gewefen fei.

Эn 2nfefung ber bei ber अrifung zu fteffenben 2ufgaben bleibt ben श्रinifterien bie Ertbeilung näberer Anweifungen vorbebalten.

\$. 165. Für bie grüfung ift eine beftimmte (5) bübr an bie §affe ber 9rüfungs=2Beborbe ju entridgten; auferbem bat ber ju Yrüfenbe feine weiteren Sioften zu tragen, al\& ben 2 fufwano, welder burd) bie aufgegebenen atreiten notbwenoig entitebt.

\$. 166. Sit oer (3)eprifte befäbigt gefunben worben, fo wiro bemfelben barüber von ber \$rüjungsbeborbe cin 3eugniß ertbeift.

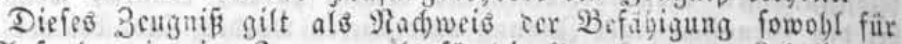
bie 2 ufnabme in eine Sumung, ałg für oie 2tunabme von Regrlingen.

Fine 2Sieberbolung ber Yyrifung fann von Demientigen, welder ein foldes 3eugníß befißzt, aud) bei Beränoerung feines 230 bnorts nidht berlangt werben.

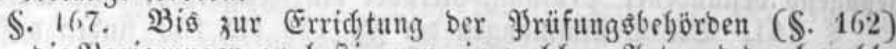
baben bie Regiernigen $z^{4}$ beftimmen, in welder 2 trt unb burd weldge Perfonen die Srifungen zu bewirten fino.

\section{Titel Ix.}

\section{D $r t$ s f $t$ a $t$ ute u.}

\$. 168. Die Borfdriften ber Titel VI. unb VII. in 2fnfebung ber Šmungen, fo wie ber Befeffen, (Bebülfen uno \&efrlinge fïunen für alle voer für eingefne 2 trten von (Sewerben, unter ben in $\$$. 170

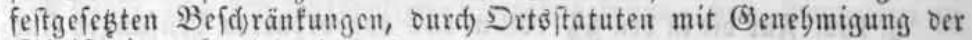
Dinifterien abgeänbert weroen.

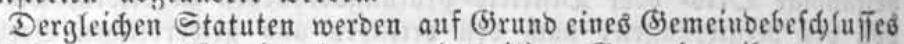

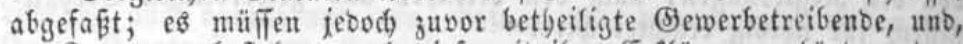
wo Jnnungen beftefen, aud biefe nit igrer Erflärung gebört werben.

Soll burd foldee Statuten bie Berfajiung beftebenoer Sunungen abgeänbert weroen, fo ift beren 3uftimumung erforderlid).

Tieu fid bilbenbe Snnumgen find an bie Drtsftatuten gebunben.

\$. 169. Durd) Drteftatuten fönnen insbefonbere 21noronungen über die Berbältniffe ber felbftifänoigen (Sewerbetreibenden ju ibren (5) efellen, SSebülfen uno Lefrfingen mit ber $2 B$ irfung getroffen werben, bap̧ eine Abänberung Derfelben burd) Bertrag nidjt zuläffig ift.

Deôgleidhen fann für alle an bent Drte befoüftigte (Siefelfen uno (3) bülfen bie Berpflidtung feftgefegt werben, ben im \$. 144 erwäbnten Berbinoungen uno $\mathcal{F}_{a} \mid \overline{f e n}$ jur gegenfeitigen Unterftibung beigu. 
treten, es barf ipbod) ein Interfdieb z vifden ben befeflen ober (be. bülfen ber Snnungsigenoffen unb benjenizen, welde bei anbern (S) betreibenten arbeiten, nidit angeoronet werben.

\$. 170. In 2 infegung Der Drtsftatuten $(\$ .168)$ finten forgenbe Befád)ränfungen Etatt :

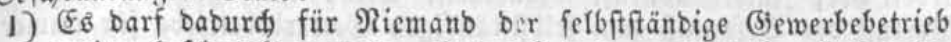
weiter befdräntt werben, als burd) Das gegenwärtige (5) feß̨ be: ftimunt ift.

2) Den Snnungsmitgliebern barf fein augf $230 r t b e i l$ in Beziebung auf oen (5iewerbebetrieb beigelent werben,

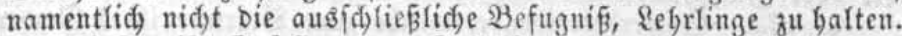

3) Die Befugní, (Sefellen oder Bjebülfen zu balten, barf niajt be= fódränft ooer eríd) wert wer pen.

4) Denjenigen, weldbe bie $\mathfrak{B} e$ fäbigung zum Betriebe igres (5)ewerbes vorfchriftomäbig nadgewiejen baben, Darf weber cine ernenerte Syrifung als Bebingung bes Eintritts in cine Junung auferfegt,

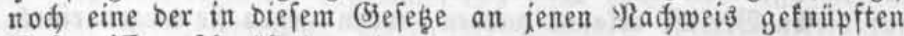
Befugnī̄e gefdumälert werben.

5) $\mathscr{A}$ in ben ourd) bie $\$ \mathbb{S}$. 126 bis 132 beftimmten Bebingungen ber Befugnifi, Regrlinge ju Galten, barf burd) bie Drtofftatuten nichts geänbert werben.

6) Ein 3wang zum Eintritt in bie Snnungen ift nid)t zuläffig; es barf aber auch bie 2 (ufnafme nidft von ber $23 i f f(u ̈ b r$ ber Innung genoffen, fonbern nur yon beftimmten, im Befeş ober in ben Etatuten aufgeiteflten Erforberniffen abjüngig gemadjt werben.

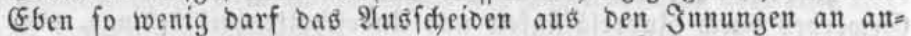
bere, als bie gefebliden Bebingungen gefnüpft werben.

7) Reine Snmung Darf für gef́d)lofien erflärt werben.

8) Die (Errid)tung von Snmungen Darf Durd) bie Drtşitatuten nid)t verbinoert werben.

(1) Folgente eingelne Beftimmungen bürfen burđ̆ bie Drtŝftatuten nid)t abgeänoert werben:

a. bie im $\$$. 119 angeorbnete $\mathfrak{B} e$ fdränfung bes Stimmred)t uno ber Theilnabme an ber Berwaltung ber Jnnungsange= Iegentyeiten;

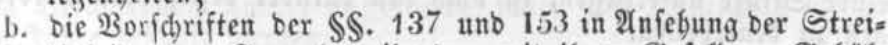
tigfeiten ber (5)ewerbetreibenben mit igren Sefeffen, (S) bül= fen uno Qebrfingen;

c. Die Beftimmung bes $\$ 113$, baßí eine $\mathfrak{B}$ erpflid)tung ber (5e= feffen zum $\mathbb{B g a n b e r n}$ nicht Statt finbet;

d. Die $\mathfrak{B o r f d r i f t e n}$ ber $\mathbb{S} \$$. 158 uno 159 in $\mathfrak{A n f e b u n g}$ ber $\mathfrak{B e r}=$ zeidhniffe über bie 2lufnabme und Entfaffung von Lebrlingen, ingleidsen ber für bie \&ufuabme und (Entlaffung zu entrid) tenden Roften.

\section{Sitel $x$.}

Berbreden unb Bergeben ber (5)

\$. 171. Die Entziebung ber $\mathfrak{B}$ efugniß̧ zum felbftifänbigen $\mathfrak{B}_{e}=$ triebe eines Semerbes als Strafe fann Statt finben für immer ober 
auf cine beftimmte 3eit; biefe barf nidt unter brei Dlonaten unb nicht iiber fünf Sagre betragent.

$\$ 172$. Giegen jeden Gewerbetreibenben, ber wegen eines ver=

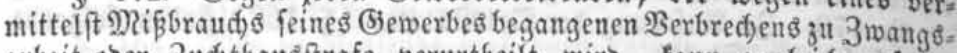
arbeit ober 3udythautsftrafe verurtbeilt wiro, fann zugleidg auf ben

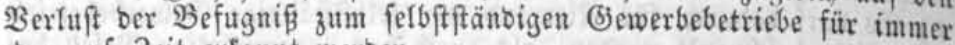
ober auf 3eit erfaunt werben.

(Es mufi auf biefen Berfuft erfannt werben, wenn ber Bewerbe= treibente fdyon frither wegen eines fold)en Berbredgens zu 3wangéar= beit ober 3udithaueffrafe verurtyeilt worben itt.

\$. 173. (Sewerbetreibende, weld)e zum Betriebe ifres (5ewerbes ciner befortoeren polizcilichen (B)enebnigung (Ronzeffion, 21pprobation,

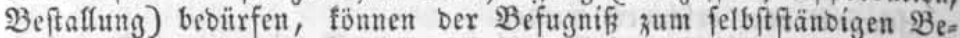
tricbe ibres Bsewerbes für immer voer auf 3eit verluftig erflärt werben, wenn fie wegen eines ifre Berufşpflidten verlę̧enben $\mathfrak{B}$ erbredens 3u 3wangsarbeit pber 3udbthautsftrafe verurtyeilt werben; es muß auf biefen $\mathfrak{B}$ erfuft erfannt werben, wenn gegen fie wegen eines fole d)en $\mathfrak{B}$ erbred)ens fdyon frïber auf Sreibeitşftrafe erfannt worben ift.

2uch fann auf ben Berluft jener $\mathfrak{B} e$ fugní 3eit erfaunt werben, wenn ber Bewerbetreibenbe wegen eines Bers

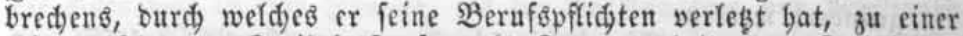
minter fdweren Freifeitsftrafe, als 3ranggarbeit ober 3udthaus= ftrafe, verurtbeilt wiro, nadoem fidon frither wegen eines foldjen Serbredjens auf greibeitşitrafe gegen ifn erfant worben ift.

\$. 171. Sft bie polizeilidye Benefmigung zur Betreibung besో (5ewerbes burd) 3uverläfigfeit uno Unbefdoltenbeit bebingt, ober ber (5ewerbetreibende zur betreibung feines (5efd)aftes von ber Dorigfeit befonbers verpflidjtet worosn, fo muß auf 2 erfuft der Befugniß zum felbftitänbigen Betriebe bes Bewerbeb für inmer erfanut werben,

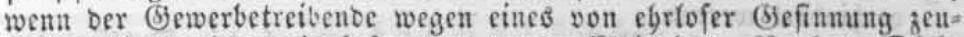
genten $\mathfrak{B e r b r e d}) e n d$, instbefondere wegen Deineibes, Raubes, Dieb= ftaly! ober Betrugs verurtbeilt wirb.

\$. 175. Sn wiefern Bergelyen ber Serwerbetreibenben gegen

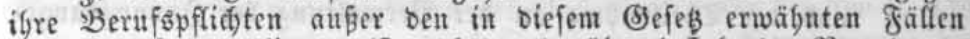
einer Strafe unterliegen, ift nad) ben barüber beftegenten Berorbum. gen zu beurtheilen.

\$. 176. 23er ofne vorgängige 2 (nmeloung, ober nađ erfolgter Huterfagung ein Esewerbe beginnt poer fortfeşt, bat, in fofern nidjt Die ftrengeren Strafen ber \$\$. 177, 178 und 180 cintreten, eine (3)

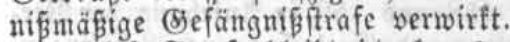

Diefe Strafe bleibt jebod auţgefdiloffen, wenn bas Bergegen eine Steuerbefraubationsftrafe nad) fid ziegt.

\$. 177.*) $\mathfrak{B e r}$ ben felbfțämbigen Betrieb eines Bewerbes, zu

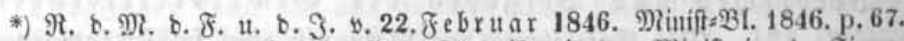

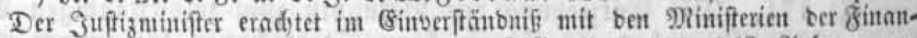
zen unb bes Smtern bie शुolizeibebörben auf (5runb bes \$. 243, 2ubang ju 
befien Beginte eine befonbere polizeilide Benefmigung (Ronzeffion,

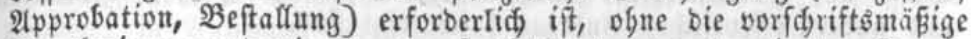
(5enebmigung unternimmt ober fortfegt ober yon ben in ber (bieneh= migung feftgefesten Bebingungen abweid)t, bat (Be)bbune bis zut jwei= Gunbert Thalern ober Bjefängníß bis zu orei MRonaten verwirtt.

Entbält bie 5antrung jugleid cin Steutervergelyen, fo foll nidyt auferbem nod) auf cine Steuerftrafe erfant werben, es ift aber bar= auf bei 3umelfung ber Strafe Rüfficht zu nefmen.

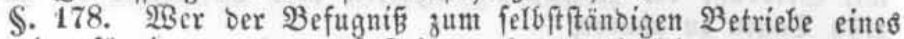
(S) werbes für immer ober auf 3eit burd) red̆tsfraftiges (Erfenntniß,

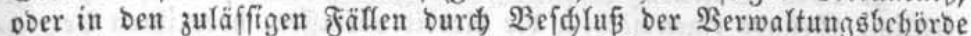
verluftig erflärt worben ift, unb biefem (Erfenntniffe ober Befduluffe zuwioer banbelt, foll mit Bjelbbufie bis zu zweifundert Igalern ober mit Bjefängní bis zut brei Monaten beftraft werben.

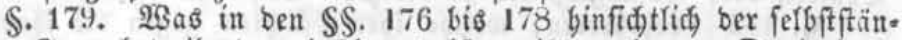
bigen Bewerbetreibenten beftimmt ift, gilt autd yon Denjenigen, weldje bie Steflvertretung eineş felbfftänoigen (Sewerbetreibenoen ïbernebmen (\$. 61).

\$. 180. Die Strafbeftimmung bes $\$$ S. 177 tritt aud gegen Dene ienigen cin, weld)er eine gewerblid)e 2 Inlage, zut ber mit $\Re$ iudfifidt auf bic Rage vber Befdaffenlyeit ber Betriebsftatte ober bes \&ofals eite befonbere polizeilidie (Jienelymigung erforberlid) ift, obne biefe (5iench= migung erridtet, voer von ben $\mathfrak{B}$ ebingungen, unter welden bie (Senebmigung ertbeilt worben, eigenmädtig abweidt, infonberbeit ofne neue (E)enefmigung eine $\mathfrak{B}$ eränberung ber $\mathfrak{B}$ etriebsftätte ober eine $\mathfrak{B} e r=$ legung bes lofals vornimmt.

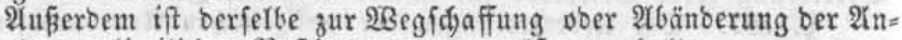
Yage, ben polizeilidyen Beftimunungen gemä̈̈, anzulbalten.

\$. 181. Bsewertetrcibente, weldhe iGre Bebülfen, Befeffen ober Irbeiter, voer bie Dbrigfeit zu gewiffen Sanofungen ober 3ugeftäno=

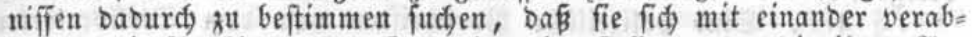

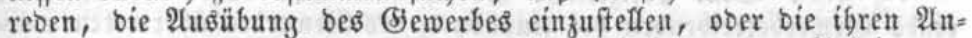
forberungen nidbt nadjgebenben (Sebülfen, BSefellen voer 2 trbeiter zu

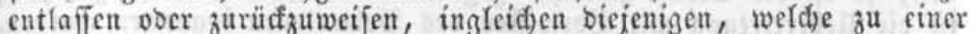

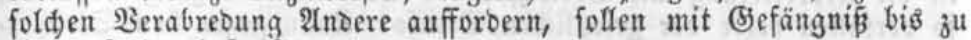
einem Sabre beftraft werben.

S. 182. Siefülfen, Befellen ober Fabritarbciter, welde entwe= ber bie Ssewerbetreibenbent felbft, ober bie Dbrigleit zu gewiffen 5and= lungen ober 3ugeftänoniffen baburdg zu beftimmen fudfen, baß fie bie Einfellung ber Arbeit ober bie Berfinderung berfelben bri einzelnen vber mebreren (s)ewerbetreibentoen verabreben, ober zu einer fold)en Berabreoung Atnbere aufforbern, folfen mit Gefängnį̧ bis zu cinem Salyre beftraft werben.

Diefe Beftimmung ift aud anzuwenben auf $\mathfrak{A}$ rbeiter, weldye bei

2(35. unb ber Eire.-Berorbnung y. 21. Mai 1830 für lefugt, bie in bent $\$ \$$. 170 bis 180 ber (5) efwerbeorbmung erwäbnten . Sontrnbentions = fälle zu ibrer

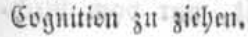




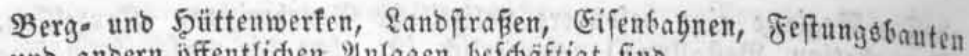
und anbern iffentfiden 2 inlagen bofdaffigt fino.

\$. 183. Die Biloung von Berbinoungen unter Fabrifarbeitern, (5) fellen, Bebülfen ober Qebrlingen obne polizeilidge Erfaubuif it, fofern nad) ben Rriminal = (S)efesen feine bätere Strafe eintritt, an

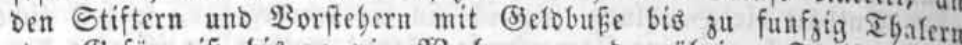

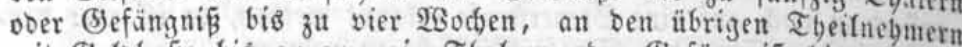
mit Sjelobue bis zu zwanjig Thalern ober (B)efängnif̧ bis fu viet. zefin Tagen zu afnoen.

\$. 184. Befeflen, Gebülfen unb Fabrifarbeiter, weftie ofne ge.

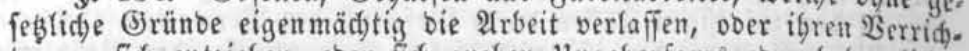
tungen fid entzieben, ober fich groben Ungeborfams ober bebarrlider

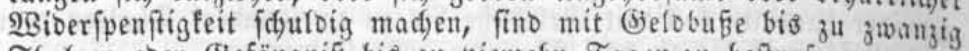
Thalern oder (j)efängní̧ bis zu vierzefn Tagen zu beftrafen.

\$. 185 Rebrberren, weldye ibre Yfflidten gegen bie ignen an. vertrauten Rebrlinge gröblich vernad)läffigen, fino mit Belobufe bi zu funfzig Thalern, ober im Falfe bes Hnvermögens mit verbältnif: mäßjiger Biefängnif́ptrafe zu belegen.

\$. 185. (5) werbetreibenoe, weldye bie von ber Dbrigfeit vorge. fofriebenen ober genebmigten Taxen ibberidreiten, Gaben Belobube bis zu funfaig Thalern ooer im Unvermögensfalle verbältnifmäfige (Siefänguifftrafe verwirtt.

Dadien fie, nad) vorgängiger zweimaliger Berurtbeifung wegen folder Bergeben, fid) eines Wergebens biefer Art von Reutem fduls big, fo tann zugleid) auf ben Derluft ber Befugni zur felbfteäntoigen Betreibung igres Bewerbes für immer vocr auf 3eit erfannt werben.

\$. 187. Die Hebertretungen ber polijeifichen Anorbnungen we= gen oes Marftverfebrs fino mit (5)elobuke bis zu zwanzig Thalern

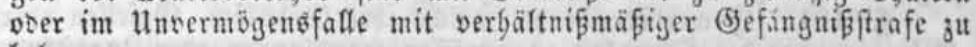
belegen.

$\$ 188$. Sino polizeilidje Borfdriften won bem Steflvertreter

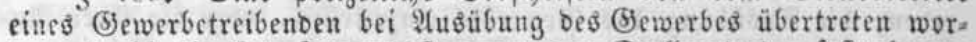
ben, fo ift bie Strafe zunädit gegen oen Eteflvertreter feftüleben; ift bie Hebertretung mit 230 rwiffen bes 2 ertretenen begangen worben, fo verfallen beide ber gefegtiden Strafe Ramn gegen ben Etellvertreter bie (5eloftrafe nid)t wollftreft werben, fo bleibt ber Woligribes Göroe überlaffen, nad) igrem (Ermeffen cie Geloftrafe von bem 2 ber. tretenen, weld)er bafitr fubfioiarifd verbaftet ift, einzieben ober, fratt beffen uno mit 2 erzidjtung bierauf, bie im Hnvermigensfalle an bie Etelle ber (Befobuise tretende Freibeitoftrafe jogleidy an bem Etell= vertreter volfitrecfen zu laffen.

Jit an eine foldbe Hebertretung ber Berfuft ber Ronjeffion, 2pprobation vier Beftaflung gefnüpft, fo finbet oerfelbe aud alb Folge ber vou bem Etellvertreter begangenen Llebertretung Etatt, wenn biefe mit Borwiffen bes Bertretenen begangen worben. Sit bics nid)t ber Fall, fo ift Der Berretene bei Berfuft oer Ronzeffion, Approbation u. f. w. verpflictet, ben Stellvertreter $j^{\text {ut entlaffen. }}$

\$. 189. 2Als Strafe faun ber Berluft ber Befugní̄ zum felbft=

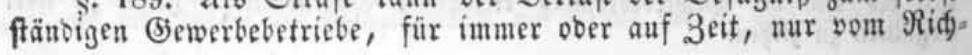


ter ausgefproden werben, foweit es fid nidt von Steuterbergeben banbelt, in 2 njebung beren es bei ben beftebenden $\mathfrak{B}$ orfid)riften ver= bleibt.

In 2tnfebung ber Rompetenz ber Befb̈rben zur Unterfudung unt Beftrafung ber $\mathfrak{B e r b r e d} e n$ uno $\mathfrak{B}$ ergeben ber Sewerbetreibenden bewenbet $\mathrm{e}$ bei ber beftelenten $\mathfrak{B}$ erfaffung; in ber $\Re$ geinprovinz finb icbod) bie Solizcigerid)te befugt, auf (Selobure bis zu funjig Thalern ooer (S) fängniß bis ju fed) 2 \&oden zu erfennet.

\section{Sd) I fibeftimmung.}

§. 190. Affe bis̆ferigen alfgemeinen unb befonberen Beftimmun=

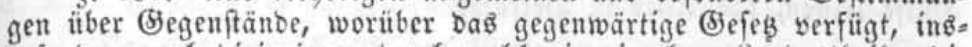
befonbere aud biejenigen, ourd) weldhe in eimjelnen sanbestbeifen bie Suben in ber Betreibung ftebender (jewerbe feitfer befdränft waren,

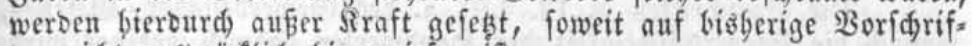
ten nidht ausorïflid) bingewiejen ift.

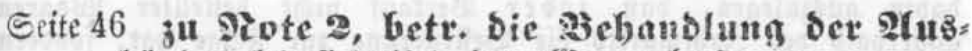 län๖er binfïchtlich Der (Sewerbepiteuer 2c.}

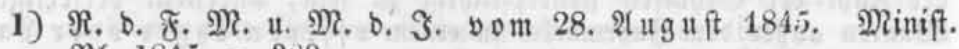
B̧. 1845. p. 3:0.

Ein in \&ofn uno Brot als (Ssebülfe bei einem intänoifden (S)e.

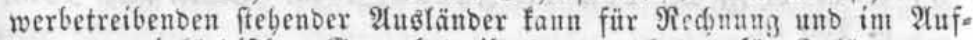
trage bes inlänbifacen (5ewerbetreibenben, nad) ben für Snlänoer gex gebenen Borfariften zum Saufirbanbel veritattet werben; madbt er

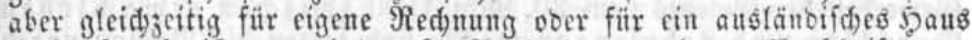

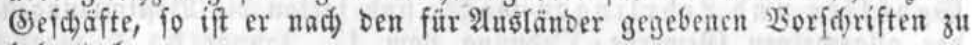
bebandefn.

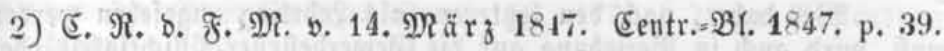

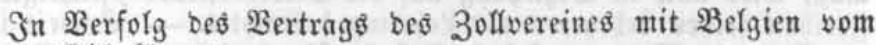
1. Sevt 1844 föunen

a. bie einem 3ollvereingftaate angebörigen fabrifanten unb 5̧anbeltreibenben in Belgien,

b. bie belgifden Fabrifanten unb Şanbeltreibenten, fo wie beren Reifende in ben 3ollvereingftaaten,

ofne Erlegung einer (5) werbefteuer umberziegen, 2 fnfätfe madjen uno (iebod) obne Mitfübrung von Waaren) Befteflungen fudjen, fofern fie in igrer 5ecimath (5emenbeftener zablen unb fid baritber aute weifen. 


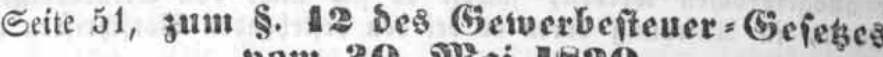 von 39 . MRi 1820 .}

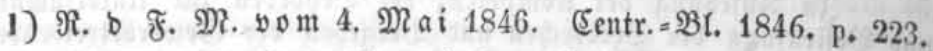

Sin bem \$. 12 bes Giemerbeftener= finb bie 2 Borte "unter 15 Эabren" lebiglid) auf "bie eigenen Rinter"

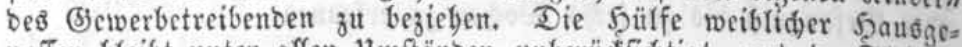

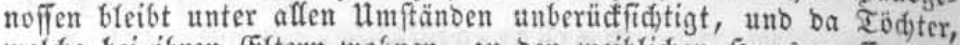
weld)e bei ifren Eftern wofnen, zu ben weibliden 5̧aubgenoffen gea tören, fo fommt nur bei ben Sabjen bes Bewerbetreibenden, welde 5 ülfe Ieiften, bas 2utter in betrad)t.

2) $\Re$ b. $\mathfrak{F}$. M. vom 28. Mai 1847. Centr $=$ Bł. 1847, p. 72.

Die Borfdriften \$. 12. Litt. a. bes Bewerbefteter = Befestes, wonad) bie Eteuterpflidtigfeit ber 5anowerfer baburd bebingt wirb, baf́ fie entweber aud auß̧er ben Sabrmärtten ein offenes Rager von

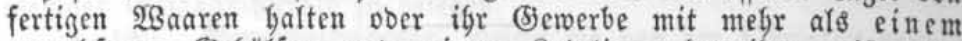
erwadffenen (B)efülfen uno einem Reforlinge betreiben, if nidt

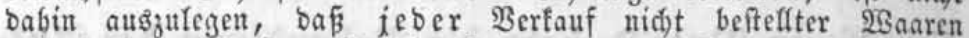
auferbalb bes Sabrmarfts bie Befteuerung zur golge bat, fonbern nur berjenige ift ber Steuer zut unterwerfen, ber, ofne fdjon wegen ber 3abl ber Gebjülfen ftenerpflidtig zu fein, unbeftellt verfertigte TSaaren aufer bem Gabrmartte in einem offenen \&ager ober \&a= ben zum feilen $\mathfrak{B}$ erfauf ausfellt.

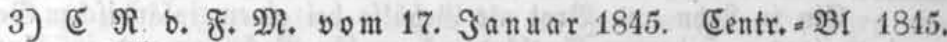
p. 100 sq.

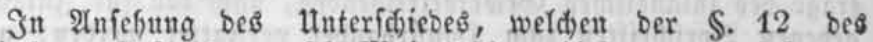
Bewerbefteuer= (5) feftes vom 30. Dlai 1820 zwifden erwad fenen

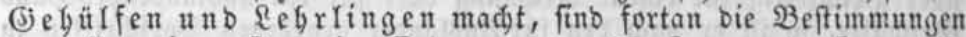
Dec allgemeinen Esewerbe $=$ Dronung vom 17. Sanuar b. 3. maak= gebent.

TBer bafer, nađ ben Yeşteren, als Sefrling angefefen werben

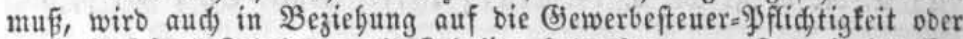
Freibeit feines \&ebrgerrn als \&egrling betrađtet. - Evweit inbefien

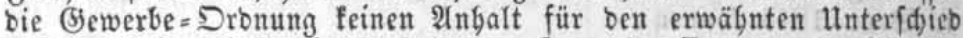
giebt, 子. B. bei ben im \$. 160 ber Bewerbe $=$ Dronung bezeidgeten \$gerfouten, bewenbet es bei ben früfer ertgeiften $\mathfrak{B}$ orfdfriften.

\section{Seite 53, วu \$. 19 a. Des Getwerbeftener= Grefebes.}

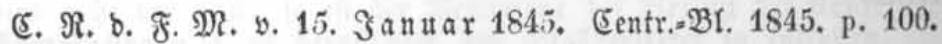

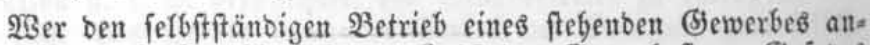

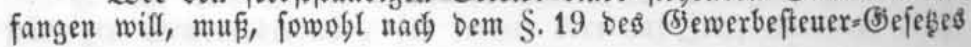




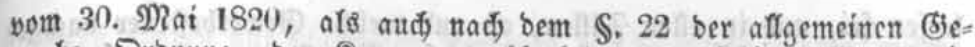
werbe $=$ Dromung, ber Rommunalbeförbe besienigen Drtes, in weldem bas Esewerbe ausgeutbt werben folf, $\mathfrak{A} \mathfrak{n}_{z}$ eige bavon maden.

Utm ben angefübrten beiben (S) efebesftellen zu genügen, bebarf อง nur einer Anzeige.

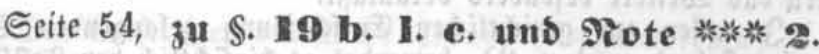

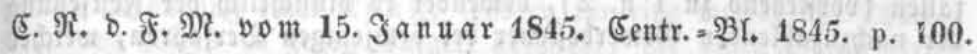

Da nad) bem $\$$. 20 ber (Sewerbe $=$ Dronung bie 3ufaffung fun: (5)ewerbebetriebe fortan in teiner Stad und bei feinem (Semerbe

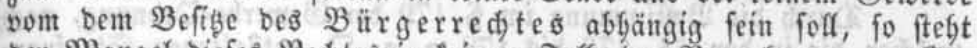
ber Wangel biefes Red)tes in feinem Faffe ber werbeftetter entgegen. $\mathcal{F}_{\mathfrak{s}}$ tritt baber bie in biefer $\mathfrak{2}$ eziefung in ber ङirfular $=\mathfrak{B}$ erfügung vom 9 . 2uguft 1839 ertbeilte $\mathfrak{B}$ orfdorift auper 2Birfjamfeit.

\section{Seite 65 , јu 111. Die Concurren vou Polijei= mit Generbefteuer $=$ Eontrabentionen betr.}

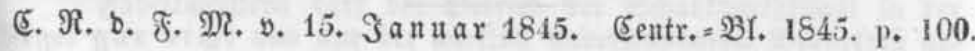

Rad ben $\$ S .176$ unb 177 ber allgemeinen (Sewerbe= Dromung tritt binfichtlich oer Beftrafung berienigen Şanblungen und Untera laffungen, welde zugleid ein (5) ewerbepolizei= unb ein (S) $=$ werbefteuer= 2 ergegen entbalten, in ben friberen Borfdriften in fofern eine 2 tenberung ein, als fortan, je nad ber Serfdiebenteit ber Fälle, entweber

1) nur bie Esewerbefteter= Defraubationêftrafe (\$. 176 cit.) pber

2) mur bie (Bewerbepolizei $=$ Strafe $(\$ .177$ cit.) zur 2umenoung fommt.

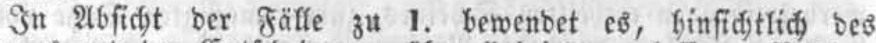
Berfabreng uno ber Entfdeibung, ifberalf bei ben erfaffenen Beftim-

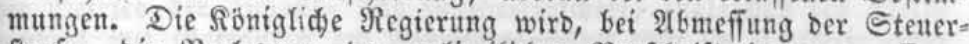
ftrafe, bie $\mathfrak{B e r l e k}$ ung ber polijeilichen $\mathfrak{B}$ orfdjrift in angemeffener $23 e i f e$ mit zu beridefiditigen wiffer.

Эn ben zu 2. vorftegent bezeidineten gallen, in benen bie Strafe bes verübten Stetervergeleng durd bie golizeiftrafe abforbirt wirb, fint bie gefdloffenen aften mit bem Eonzepte ber in ber erfent $3_{n}$ ftanz zu erlafienden E্tffheibung, - biefe mag auf Beftrafung ober Freilafiung lauten, - fofern Die Entfifeibung von einer 2 erwale

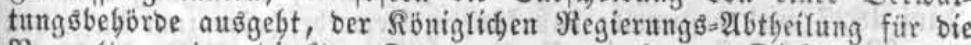
Serwaltung ber bireften Stentern 2c. vor żulegen. Diefe beftinimt, falls bas Conzept auf Freilaffung von ber Yyolizeiftrafe fautet, was in Beziegung auf bie etwa verwirtte (5ewerbefteuerftrafe zu veran=

Supplement. 
Iaffen féi, und in aflen Fällen, ob ano welde (5ewerbeftetter nađigezablt werben müffe, poer was in biefer $\mathfrak{B}$ eziegung nod nadjzubolen fei. Sautet bie Entideibung auf eine Yolizeiftrafe und tann eine befintive Beftimunting in 2(bfid)t ber (Semerbefteuer ergeben, fo wirb biefe $\mathfrak{B}$ eftimmung ertgeift, gleidgeitig mit bem Strafrefolute publizirt uno bie feftgefeste Steuter bemnădft cingezogen. Sind in $2 b_{b}$ fidt ber (S)ewerbeftener nod) Erörterungen erforberlid, fo wirb bes. Galb bie Yublifation ber polizeifiden (Entideibung nidit aufgebalten, fonbern bas 23 eitere befonbers veranlafist.

Sit aflen fur geridhtliden Entfdeibung gelangenden. Straf

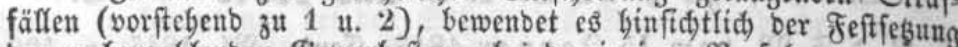
ber nadzuzablenben (S)ewerbefteuer bei bemienigen Serfabren, weldes bisher in ben geridtlich entificbenen Frozeffen wegen (Siemerbefteter= Eontrabention angewendet ift.

Durch bie Beftimmung im $\$$. 179 ber (jewerbe= Dronung, nad welder bie in ben $\$ \$ .176$ bis 178 a. a. D. entbaltenen Strafuprfdriften aud auf ben Stelfvertreter cines felbefftänbigen Bewer= betreibenben 21nwenoung finben, wiro in ber Anorbnung, nad) welder Derienige, für beffen $\mathfrak{R e d} n u n g$ ein ftebenoes fteterpflidtiges Sewerbe ausigeübt wirb, als ber Steuterpfliditige und als zur 2rmmeloung verpflidistet zu bebanbeln ift, niđts geänbert.

Die Roniglicye Regierung bat bie betgeiligten $\mathfrak{B e b j r b e n , ~ b e m ~}$ Borftebenden gemäß, mit Anweifung zu verfeben.

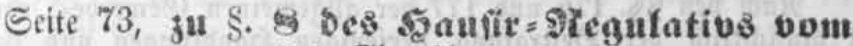 28. 2lpril $1 \geq 2$ s.}

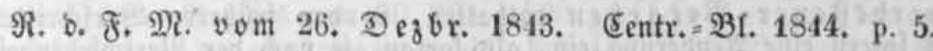

$2 B$ enn ber jubaber eines Bewerbefdeines frant ober auf läne gere 3eit unfäbig wirb bas (Sewerbe perfonlid zu treiben, fo unu fein 2 ertreter für feine $\}$ erfon einen befonberen Sewerbidein fojen, ber aber gegen (Eimziefung bes bem erfranten ober bebinberten (Jewerbetreibenben ertbeilten Sđ)eines, zum ermäjigten Sabe von 2, 4, 6 ober 8 Thalern burd) bie Regierungen ertbeilt werben barf.

\section{Seite 74, 3u Rote ** a.}

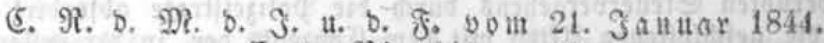
Eentr. $=$ B) 1844 . p. 29.

Unter Rufbebung ber (bier mitgetbeilten) Berfügung vout 19. Suni 1827 wiro beftimmt: Daß fünftig Sewerbefdeine jum 2 tufudoen

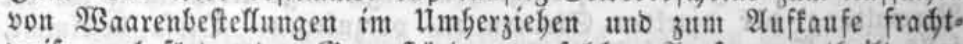
weife zu befürbernber (J̈egenftänbe nur folden jerfonen ertbeift wer=

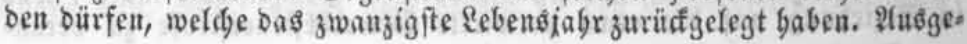


nommen bleiben nur biejentigen Ferforten von 17 bis 20 Sabren, welde pro 1843 uno 44 bereits einen (B)werbefdein erbalten batten.

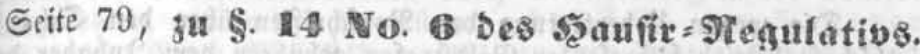

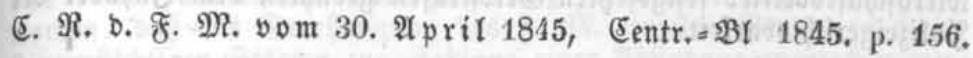

Das Berfertigen von $\&$ id tbilbern (Daguerrotypen) ift nid)t

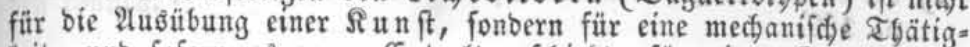
teit, und fofern $\mathrm{eSB}^{\mathrm{S}}$ gegen (Entgelt gefdiebt, für einen (5ewerbetrieb

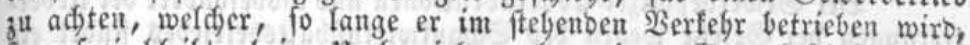
teuerfrei bleibt, beim Hmberzieben aber eines Semerbefdeines be= barf.

\section{Scite 94, 3ur Sab. Drove v. 8. Tebr 1835 tocgen bes Sleinbandels mit Getränfen zc.}

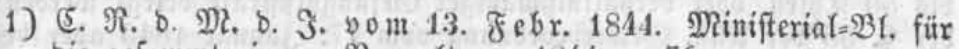
bie gefammte innere 9 erwaltung. 1844. p 76.

Fabrifmeiftern barf ber Betrieb ber Sdyantwirtbjdaft in ber Regel gar nidt unb nur bei wirflid) unverfembarem Sedoirfní̈ ge= fattet, auch follen bie bercits beftebenben (Eonceffionen biefer 2ht frenge controffirt werben.

2) Rabinetb= Drore yom 16. November 1846. Sef.=Sammt. 1846. p. 484.

2uf ben Beridt bes Staatsminifteriums vom 22. v. Me beo

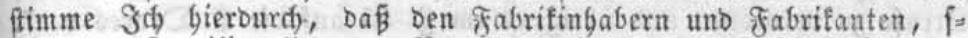

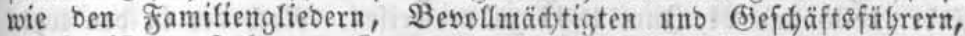
IBerfmeiftern, Faftoren, Romptoir = unb Fabrifgebirlfen Derfelben uno anderen von ibnen abfängigen Ferfonen, nad æablauf biefes Gabres ber $\mathfrak{B}$ etrieb ber Sd)ant- und Esaftrórtbfđaft, ingleiden bes filein= hanbels mit (Setränten am gabriforte felbft ober im umfreife einer Meíle um leşteren, niđ)t mebr geftattet fein, uno eine 2uts̊nabme von biefem $\mathfrak{B}$ erbot mur nadigefaffen werben foll, wenn nad, bem überein= ftimmenben Urtbeile ber Sommunalbeförbe, bes \&anoratbes unb ber Regierung, Dem in ber ifolirten \&age einer ₹5abrif begrimbeten $\mathfrak{B}_{\mathrm{C}}=$

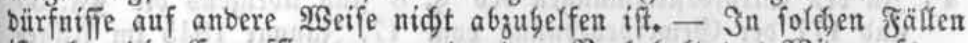
ift aber bie Eonzeffion nur unter bem 2 borbebalt bes $2 B$ iberrufs zu ertbeifen uno fofort zurüdfunebmen, fobalo Dem $\mathfrak{B}$ eburifuiffe auf an= bere $2 B e i f e$ genigt werben tann. 


\section{Seite 96 , зиแ \$. 8 Der Sab. = Srbre vou 2. Tebr. $183 \overline{5}$.}

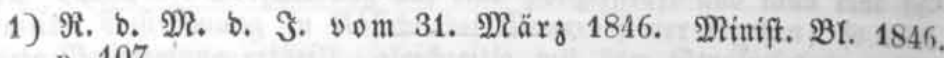
p. 107.

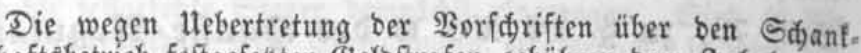

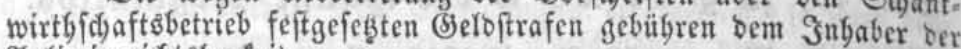
Solizeigeridftabarfeit.

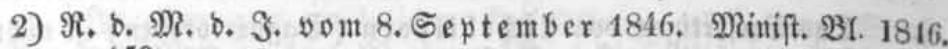
p. 159.

Bei Gewerbepolizei=Eontraventionen nub inşbefonbere bei Hebertretungen ber Ejefese wegen bes Sdanfwirtsidaftsetriebes finbet ein Denumziantenantbeil nidjt Statt.

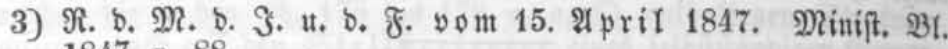
1847. p. 88.

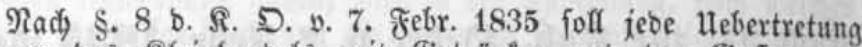
ber wegen Des Rleinlantels mit (B)etränfen uno ber (5)aft = ober Sd)anfwirtbfdaft ertbeilten Borfdriften mit ciner Belobufe von 5

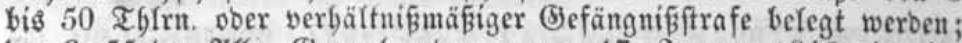
ber $\$$. 55 ber $2 \mathbb{A f f}_{\mathrm{g}}$. Bewerbeorbuning vom 17. Samuar 1845 aber be

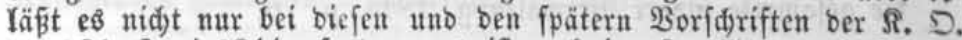
vont 21. Sunt 1844, fonbern es ift aud im \$. 177 l. c. beftimut:

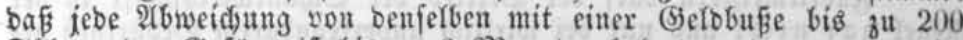
Thlrn. Doer Giefängníß bis zu 3 Monaten belegt, uno wenn jugleid, ein Steuterbergeben vorliegt, jwar nidjt auferbem nod auf cine Steuterftrafe erfaunt, aber barauf bei 3umeffung ber Strafe $\Re$ iütefidift genommen werben folf. Die (Sewerbeoronung fat alfo bie Strafe ber polizeifiden $\mathfrak{l}$ ebertretung nidjt $u$ uter bem in ber $\Omega, D . v$. 7 . Februtar 1835 feftgefe(t)en Minimum beftimmen wollen, weil fie fid fonft nidift barauf befdränft Gaben würbe, blos ein anberes Maximum ber Strafe zu veroronen uno itbrigens im $\$ 55$ auf bie $\Omega$. Drores v. 7 .

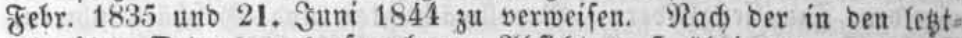
gebaditen Drores ausgefprodenen $2(b f i d) t$ muß Janblung zugleid ein Eteuervergeten entbält, bie Strafe für beibe Sergegen gober afs für bie bloke Wolizeiilbertretung beftimmt werben,

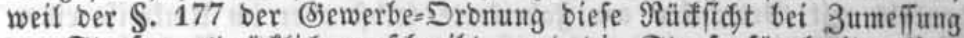

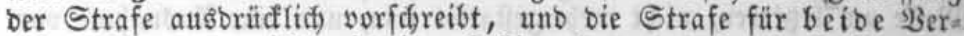
gefen zufammen nid)t niebriger beftimm werben fann als für cinß Derfetben, nämlid bas Steutervergelyen.

4) 3 u ben Strafbeftimunungen bes $\mathbb{\$} .8$ fint übrigens bie $\$ \mathbb{S} .55$ unb 177 ber Gewerbeoromang vou 17. Jamuar 1845 im 2tffgemeinen zu vergleiøen.

Ceite 97. Die bier mitgetbeifte Sab.= Drbre ift nidgt yom 21 . Suli, fonbern yom 21. Juni 1844. 


\section{Seite 103, jur 9ote 1. Die 93rauiteuer $=$ Fita tionen betr.}

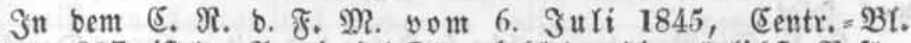
1845. p, 217, ift ben 9 rovinzial=Steuerbebörben bie möglidifte $\mathfrak{B e f u ̈ r}$ berung ber Braufteuerfixationen burd Erleidterung in ber Eontroffe

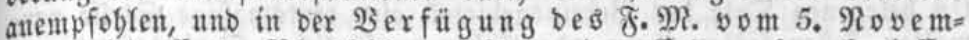
ber 1845, (Eentr.=91. 1845. p. 281, zu bem (Enbe aud nad)gelaffent

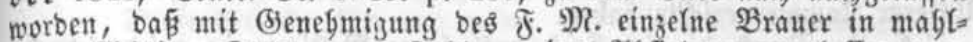
fteuerpflidigen Stäbten zur Jablung einer 2lbfinbung zugelaffen wer= ben föment.

\section{Eeite 106, fur Pote I. 1. u. 2.}

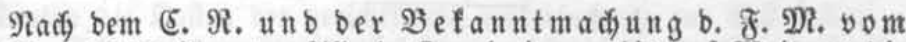
22. $\mathfrak{M}$ a 1847 ift unter 2 fferb. (S)enefmigung bis auf 28 eiteres bie Eteuervergütung, welde nad) ber Befantmadjung vom. 18. Dftober 1838 zum Betrage von 10 Yf. pro Duart für ben über bie 3offver= einşgrenzen auß̊gegenden $\mathfrak{B}$ ramutwein betwilligt ift, bemienigen $\mathfrak{B}_{e}=$ trage von 9 \$p. pro Duart gleidgeftellt worben, weldyer nad, ber befanntmadung vom 12. Dezember 1841 für ben nad Bayern, 29 ürtemberg, Baben, Sceffen, Naffau uno grantfurt ausgefügrten $\mathfrak{B r a n u t =}$ wein gewälgrt wirb.

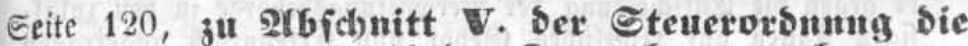 Tevifionsbefuguifi ber Steucrbeamten betr.}

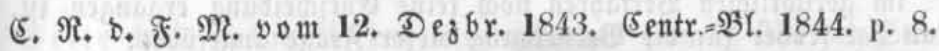

Das Betreten ber Feftungswerfe zur $\mathfrak{B}$ erginberung von Sdfeid)= banbel ift nur ben von ben Steuerbelobroen fpeziell zu bejeidnenben Steuerbeamten geftattet, welde zu bem Enoe von ber Eommanbantur befonbere auf bie \$erfon lautenbe Regitimations-ßarten erlalten, bie fie frets bei fidi) fübren, refp. ben infpicirenben Militair=9serfonen sor=

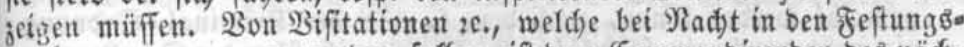
werfen vorgenvumen werben folfen, ift bem (Sommanbirenben bes näd):

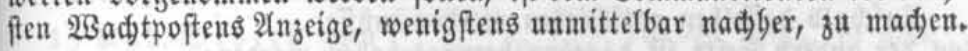

\section{Seite 125, зи \$. 59 Der Steneror\$ung.}

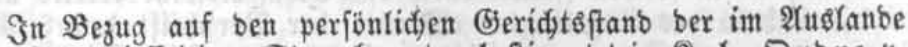
ftationirten bieffeitigen Steuterbeamten beftimmt bie $\Re a b .=D$ r b re $\mathfrak{v}$. 26. 2 pril 1844. (5. S. 1844 pag. 112 : 
TSir 2c. verorbuen, zur Befeitigung ber über ben orbentliden

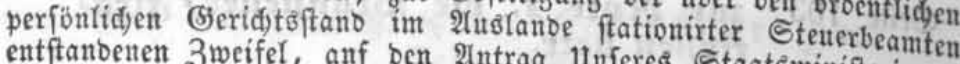
entftanbenten 3weifel, anf ben Intrag Huferes Staatominifteriumb,
was folgt:

\$. 1. Die Beamten, weldye in Forge bes mit mefreren Deutidjen Staaten gefdilofienen 3ollvereins an cinem auberbalb Huferer Etaa

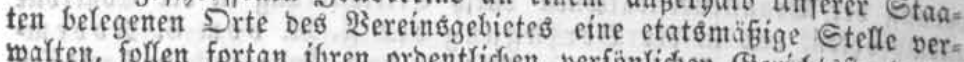

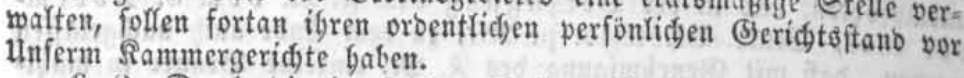

S. 2. Durd bie in $\mathbb{S}$. I entfialtene Beftimmung wirb jebod, wenn bie Beamten vorger einen orbentfiden perfönliden (Seriđtếfano int biefigen \&anben gebabt baben, in $\mathfrak{B} e$ ziefung auf ifre perfönlidjen Eigenfifiaften uno Befugnifie (jura status) und bie (Erbfolge in igren

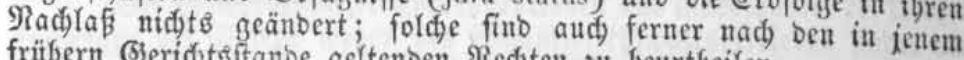

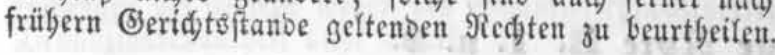

\section{Seite 134, ju \$. 93 c. Der Stenervrbutug.}

5infiátlid) ber 3 utäffigfeit oer 3 urüufnabme einer Yrovofation auf rechitiches (jegor gegen ein Refolut ber Berwaltungebegöbe be=

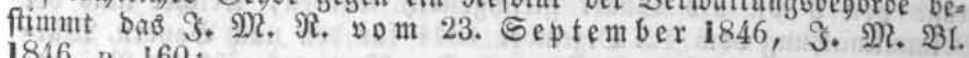
1816. p. 160: gebradgt worben:

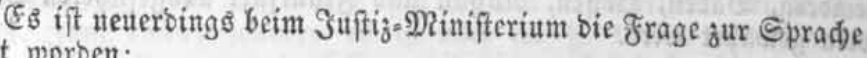

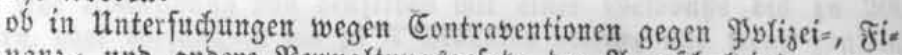

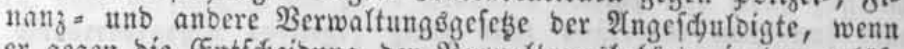
er gegen bie (Entfocibung Der Serwaltungobegbroc in ben zuläf=

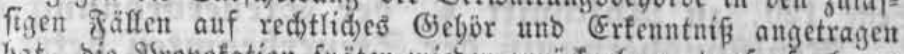
Gat, bie grosotation fpäter wieber zurüctnegmen barf, fo fange im geridttliden Berfabren nod feine Entfdeibung ergangen ift. Man sat früber für bie Berneinung biefer Jrage angefübrt:

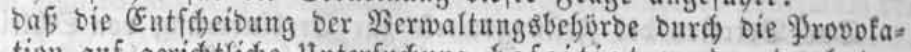
tion auf gerid)tlidge Unterfudjung be feitigt werbe, ourd ben $23 i b e r n u f$ ber grovofation alfo nidit wicber bergefteflt werben

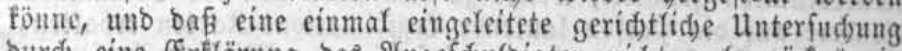

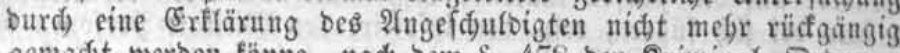
Bemadit werben fönne, nad) bem $\$ .478$ ber firiminal = Dronung

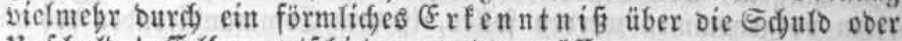
unfdulb beffelbent entfoieben werben mixffe.

Bon ber anbern Seite if bagegen bervorgeloben worben:

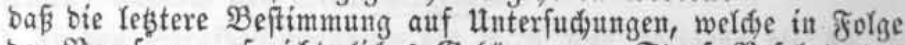
ber Berufung auf ridjterficies Eegör gegen Straf $=\Re$ efolute ber Berwaltungsbejörben eingeleitet werben, feine Anwentung finben fötne, $b a$ in folden gäflen burdy bas Straf $=\Re$ efolut bereits iiber

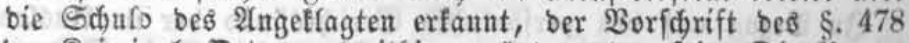
ber Srimiual $=$ Dronung mitgin gentitgt worben fei. Die Firovo= fation auf geridstlidge Entfdcioung lyabe vielmelyr bie Matur ei- 


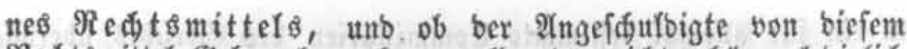

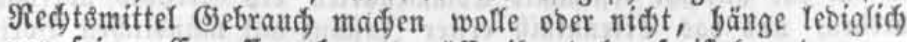
won feinem Ermeffen $\mathfrak{a b}$; $\mathfrak{e}$ s muiffe iGm baber freiftegen, bem er= griffenen Nedbtömittel wieber fu entiagen. Daraus folge bent von felbft, baß్ wenn ber 2ngefduloigte feine \$rowotation auf

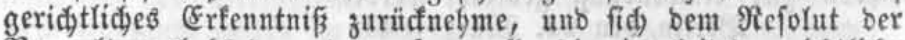
Berwaltungobegörbe unterwerfent wolle, bie eingeleitete geridtlidge Unterfudfung wieber alfgeboben werben muiffe.

Diefe Srrünbe für uno wiber fint in beut friberen Spezial= falle Sr. Maieftät bent Rönige zur Entfdeibung vorgetragen worbent,

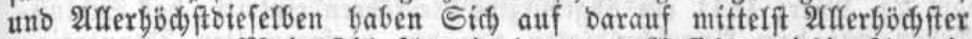
Drbre vom 25. Mai 1844 für bie Ie gुtere 2infidet, mitbin für bie

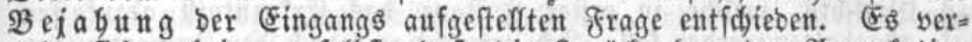
felyt fidi babei von felbft, baf́ bie Zurüanalyme ber Yrovofation nur fo lange für zuläffig eradjtet werben fanu, als in bem geridjt= liden $B e r f a b r e n$ nod) tein Ertenntnif́s ergangen ift, uno baß̧ bem Yro=

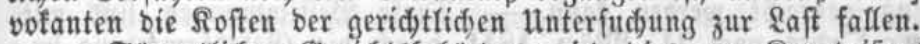

Sämmtliden Beridstsbebjorben wiro bies zur Renntnifnafme uno geeigneten $\mathfrak{B}$ eriadfidjtigung bierourd mitgetbeilt.

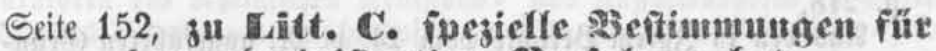 Das abuiniftrative Serfabreu betr.}

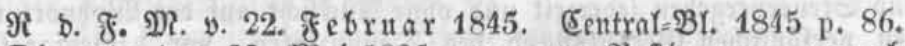

Die unter bem 22. Pai 1835. ergangene Beftimunung, wonad) bie in ben Hnterfutdungen wegen Steuterbefratbationen ergangenen

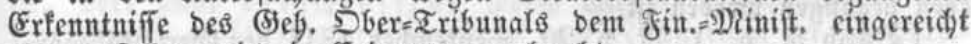
werben follen, wirb in Erimerung gebradst.

Seite 153. 3u Litt II 1 a. vergleighe bas zum \$. 93. Der Steter= oromung Seite 134 mitgetfeilte $\Im$. $9 \pi$. $\Re$. volt 23. Septbr. 1846.

\section{Seite 154, ju T. Getreffend Dic Competent Der Intergericbte.}

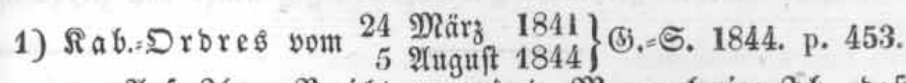

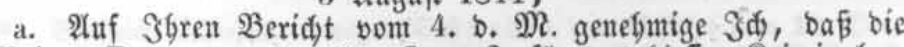
in Meiner Drore vom 31. 2uguft v. S. für bas biefige Ririminalge= ridet gegebene Beftimunung, nad welder Hnterfudungen,

1) welde polizeimäpig gefüibrt werben,

2) wegen $\mathfrak{B}$ ergegen, bie mit Yeidter förperfider 3ürdtigung, bödy.

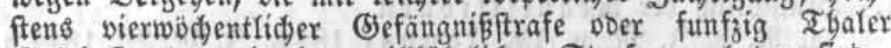
SElbbufe ober mit einer wiffeutbrliden Strafe zu abnoen find, 
ant ein für alfemal beftimmte (Eommiffarien bes (5erid)ts überwiefen werben, unb bas Erfenntniß̄ erfter Snftanz auf münolidgen Bortrag bes 3nquirenten von einer aus brei $\mathfrak{M}$ itgliebern beftebenben 21btbei= lung oes (S)erid)ts abgefajt wirb, bei affen follegialifd formirten Beriditen zur श्tnwentung gebradit werbe.

Berlin, ben 24 . März 1841 .

b. 2uf ben Beriđt)t bes Staatominifteriums vom 20. v. MR.

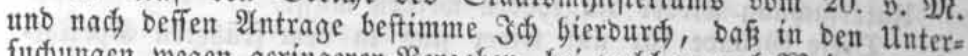
fudungen wegen geringerer $\mathfrak{B}$ ergeben, bei weldjen nad 2 Reiner Drore

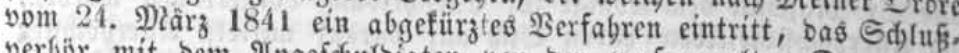
verbör mit bem 2 ngefduldigten vor ber verfammelten Deputation

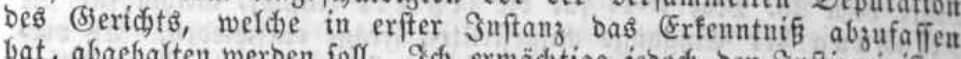
Gat, abgebalten werben foll. G(h) ermäd)tige jebod) ben Juftizminiffer, 2usnabmen biervon zu geftatten, wenn biefe Alnoronung bei ein.

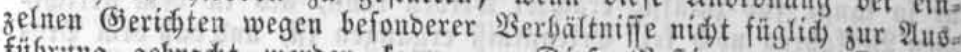
fiubrung gebrad)t werben fann. - Diefe Beftimunugen find mit Meiner Drore vom 24. Deärz 1841 burd) bie Eefeşfammlung be= fant zu maden.

Eromannoborf, ben 5. Auguft 1844.

2) $\mathfrak{R a b}=$ Drore vom 14. September 1844. Э. DR. BI. 1844. p. 218 .

2tus ben in Ggrem Berid)te vom 24. พ. M2, angefübrten (5rün. ben bin 3 d) Damit einberitanben, bafi bie Unterfudutugen wegen $30 f_{*}$ uno Stenervergeben jeoergeit uno obne Rücficht auf ben 230 hnort und ben perfönlichen (Sjertd)tôftand bes Demuziaten, yor basienige (Se, ridft (Dber $=$ ober Hntergerid)t) geboren, in beffen 2 esire bas Ber= geben begangen worben ift.

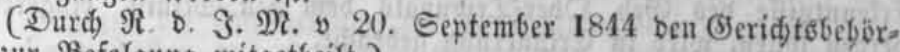
ben jur Befolgung mitgetgeilt.)

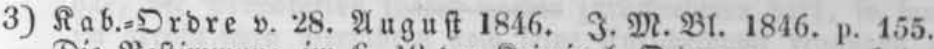

Die Beftimmung im $\$$. 19 Der Rriminal = Dronung, wouad ben ber Jnquifitoriats=(Einrid)tung beigetretenen luntergerid)ten bie llnterfudfung uno 2 bfaffung Des Erfenntniffes erfter Şnftanz in poldsen Sachen zuftegt, in benen (Sefängnififtrafe bis zu vier 230 den Statt finbet, ift aud bann anzuwenden, wenn bie Strafe bes 2 Bergebens in (Bjefängnif́ ober Strafarbeit von iener Dauer beftebt. Die Seridte

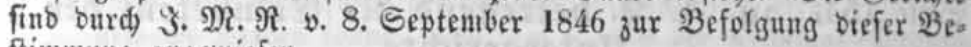
ftimmung angewiefen.

\section{Seite 156. 3u . Th 3erfabren in \$er geridbtlidben Itnterfucbung betr.}

A. Sinfiditlidy ber Requifitionen

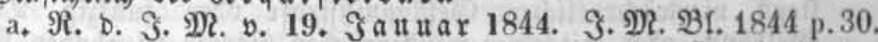
Requifitionen an bas Berfiner Stabt=-ङeriddt finb in linter- 
futhungs=Sadjen an bas bortige \&oniglide Rriminals (5) eridit zu abreffiren.

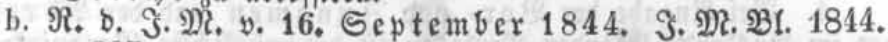
p. 207.

Şinfidttid) bes $\mathfrak{B e r f a b r e n s}$ bei Requifitionen und Erfaffen nach

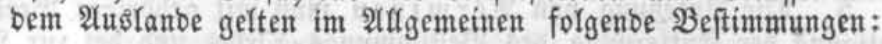

\section{Requifitionen utb Şnfinuationen nad bem श्Austanbe auferbalb Der beutichen 3 undes = Staatent.}

\section{A. $\Im$ m arigemeinen.}

1. Ein unmittelbarer Sdgriftwedffel zwifđuen ben infänbifden

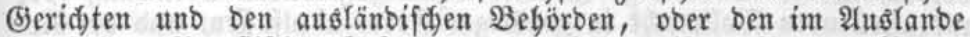
angeftellten Sreufifiden Befanbtẹn uno biplomatifichen 2 (genten ift ber Regel nad nidjt zuläffig, vielmebr muß zu aflen Snfinuationen, $\Re e=$ quifitionen und fonftigen (Eorrefponbenzen nad) bem 2 (uslanbe, mit

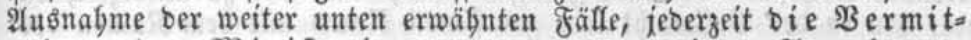
telung bes Mlinifteriums ber auşwärtigen 2 ngelegen= beiten nadigefudt werben.

Die Hntergeridste baben fid zn biefem $\mathfrak{B}$ efuf an bas ignen vors

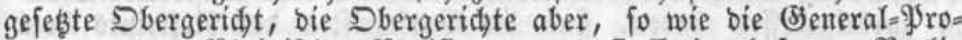

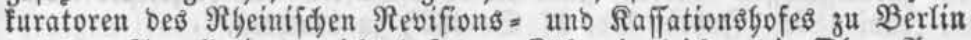

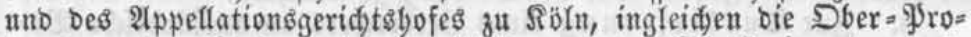

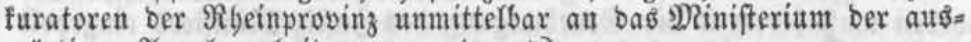

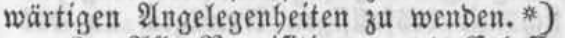

2. 2flle Requifitionen unb Erlaffe müffen entweber offen, in

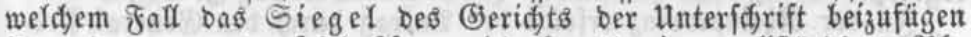
ift, boer zwar verfdloffen, jebod mit einer volffänbigen 2 bs (d) rift bes verfd)loffenen Sd)reibens bem Winifterium ber auşwärtis gen 2 thgelegenteiten eingereidft werben.

3. 3ur $\mathfrak{B}$ ermeibung uniotbiger \$orto=

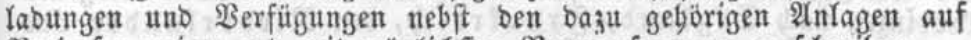
Brief papier uno mit möglidfter Raumerfparung zu fdareiben.

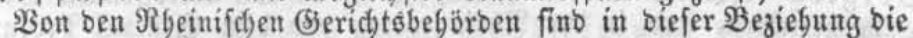

Neffripte vout 28. Februar 1832, Rottner $\mathfrak{B b}, 3$ S. 449 unb fu bead)tent.

$$
\text { " 20. 2Räz 1835, " " } 5 \text { " } 96
$$

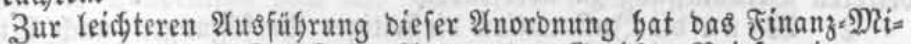
nifferium geftattet, bafi auf ben 2 (ntrag ber Berid)te Briefpapier ge= ftempelt, und ifnen gegen Begablumg verabfolgt werben barf, fo wie,

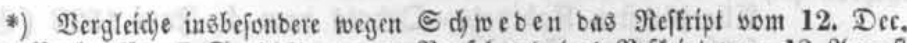
1802 ( $\Re$ a be Bo. 7 Б. 281); wegen $\Re$ u 1818 (3abrb. Bb. 12 ङ. 16), unb yom 10. Suli 1826 (3abrb. 2bb. 27 క. 264), wegen Franfreid) bas Reifript vom 5. 2)?ai 1826 ( $3 n$ brb. $2 B$ b. 27

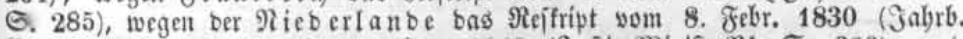

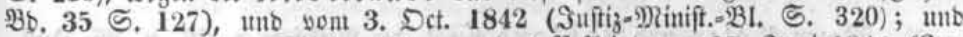
wegen ungarn unb Бiebenbürgen bas Reffript vom 17, Suni 1843 (Sแftij.=Pinift.-381. S. 156). 
baß̧ Utrunben, weldye auf 2 riefpapier autsefertigt finb, bei bem Stempelmagazin in Berlin zur Stempelung vorgelegt werben fömen.

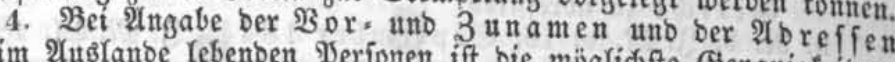

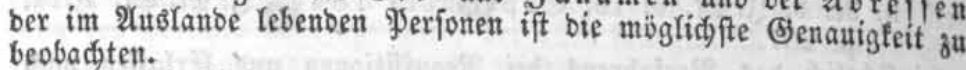

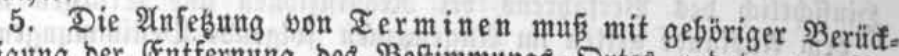

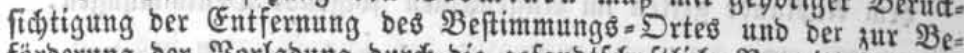

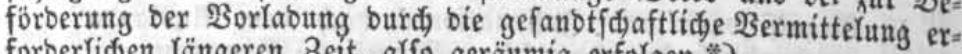
forberlid)en längeren 3eit, alfo geräumig erfolgen. *)

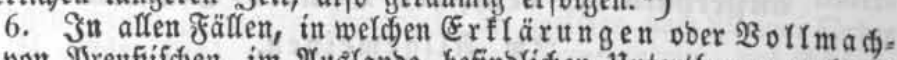

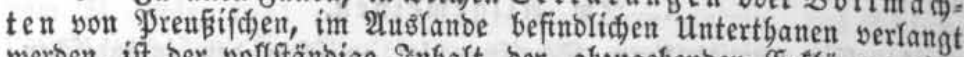
werben, ift ber volfftänbige. Snbalt ber abzugebenben Creftärung ober ausfuffelfenben $\mathfrak{B o f l m a d t}$ in geböriger form abyufaffen, unb ber $\Re_{e}=$ quifition beizulegen, bamit bie भyerion, yon welđer bie Erflärung ober Folfmadt verlangt wirb, bie in ifrer $\mathfrak{2}$ utter [pradie aufgenommene Urfunbe leidst uno volffänbig faffen fann, utno nur zut unterzeiđnnen

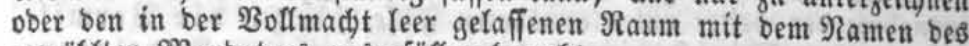
gewäblten Manbatarß auşzufüffen braucht.

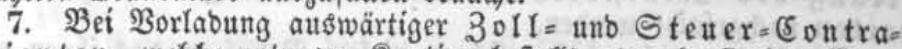
wententen, welde entweder Raution beftellt, ober fonfiscirte $2 B a a=$

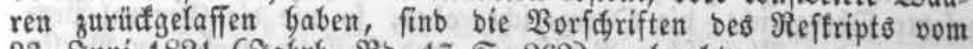
23. Suni 1821 (SaGrb, Bb. 17 S. 262) zu beadten.

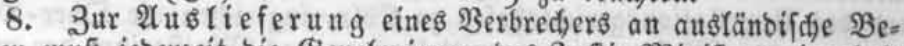
Görben muß ieberzeit bie Benebmigung bes Suftiz=MRinifters eingefolt

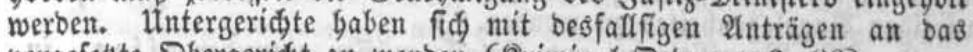
vorgefeste Sbergerid,t gu wenten (尺riminal=Dronung \$. 96).

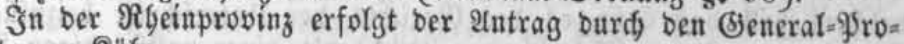
turator zu Röln.

\section{B. Sn Bezug auf eingelne Staaten.}

1. Snfinuationen, welche aut ben lin f s ber E్fbe belegenen Srovinzen nad (Englanb, Franfreid, ben Rieberlanben unb

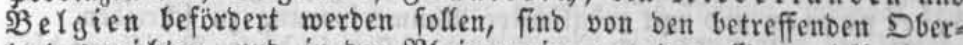

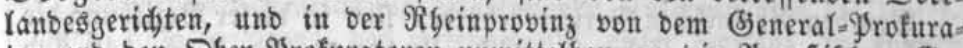
tor und ben Dber=95rofuratoren unmittelbar an bie \$reusifden (Se-

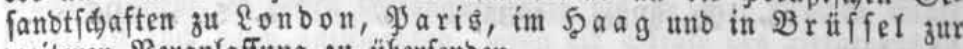
weiteren $\mathfrak{B}$ eranlaffung zu itberfenben.

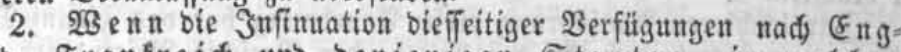
rano, grantreid unb benienigen Staaten, in welden

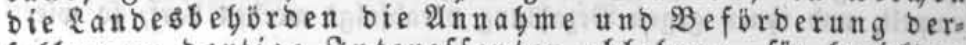
felben an bortige ontereffenten ablegnen, für bewirt ju eradten fei, ift nadi ben

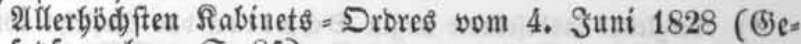
fesffammlung $\subseteq .85$ )

uno vom 21. Suni 1836 (ङౌefę̧fanmlung S. 202),

*) WBegen 1819 (Эabrb. 2B. 14 S. 22 unb 25). 


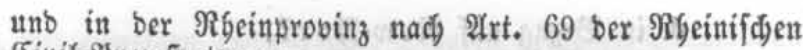
fu beurtbeilen.

(5ivil=9yrogeforonung

In Bezug auf Frantreid if bierbei nod auferbem bas $\Re e=$

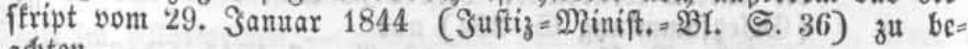
aditen.

3. Bei Requifitionen, welde nad, Franfreid unb benieni=

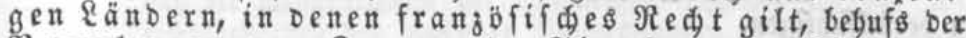
Bernebung yon 3 eugen ober 2 bnabme won Eiben ge= ridtet werben, fino bie Beftimmungen ber

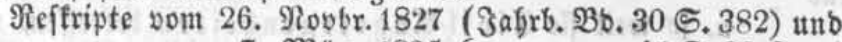

$$
\text { " 7. När } 1835 \text { (" " } 45 \text { ङ. 294), }
$$

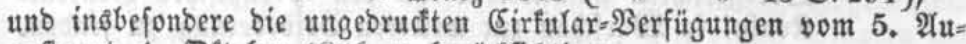
guft utt 1. Ditober 18.36 zu beriuffiditigen.

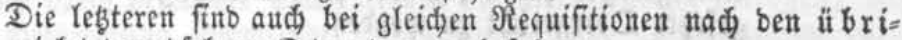
gen nid)t beut(d)en Staaten zu befolgen.

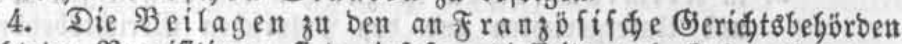
gerid)teten Requifitionen find, infofern bieffeitis nod) (Sebraud) bavon ou mad)en ift, nid)t im Driginal, fonbern in beglaubigter थibforift

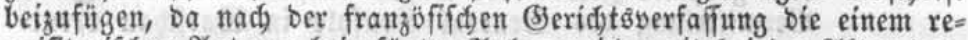
quifitorifden $\mathfrak{A}$ trage beigefügten $\mathfrak{A}$ lagen ieberzeit bei ben $\mathfrak{A}$ ften beญ̊=

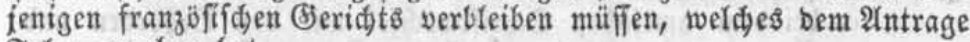
Folge gegeben bat.

5. Bei Requifitionen nadi ben Ricberlanben in SrozeBs=, $\Re a$ d $l a E=$ und anoern (5ivil=2Angelegenbeiten, insbefonbere atth) wegen $\mathfrak{B}$ eruebmung von Zeugen tub $\mathfrak{A} b$ nafme von Eiben tyt nach ben in ben

Reftripten vom 23. Juni 1836 (Jabrb. Bb. 47 S. 535),

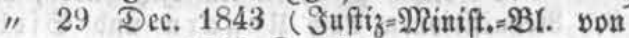
1844 S. 20),

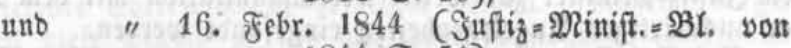
1844 S. 54)

entyaltenen Beftimmungen zu verfabren.

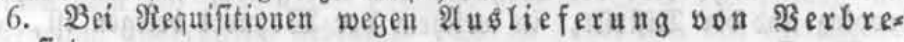
d) ern find:

a. iu $\mathfrak{B e g u g}$ aif $\mathfrak{B e r}$ gien,

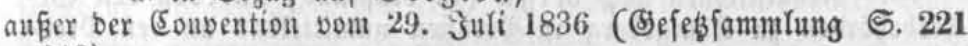
$-2 \cdot 26)$

bie Reffripte ๖. 26. Det. 1836 (Jafrb. Bb.48 S.498),

"11. Jant 1837 (Lottner $\mathfrak{B b . 6}$ S.15-16),

"23. Febr. 1837 (" " 6 ङ. 94),

"27. 21prif 1837 (Sabrb. 23b. 49 S. 524);

b. in $\mathfrak{B} e z u g$ anf bie Rieberlanbe,

bie Reftripte ๖. 9. Robbr. 1836 (Jabrb. 2B. 48 S. 505) "18. " " (Lottuer Bb. 5 S.399);

c. in $\mathfrak{B e}_{\mathrm{e}} \mathrm{g} g$ auf $\mathfrak{F} \mathrm{ranfreid}$,

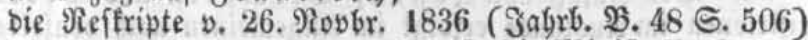
unb

"1 17.Sept.1840 (Juftiz= $=$ Rinift. $=2 B$ L.S.318) 
d. in $\mathfrak{B}$ ezug auf $\mathfrak{R}$ ew $=2$ orf

bas Refteript y. 22. Mai 1837 (Jabrb. 23b. 49 S. 525);

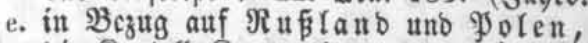

bie Sartell= Sonvention vom 20/8 Mai 1844 Irt. 15 ff. (ङ)efesfammlung S. 204) uno

bie 2Ang. Werfitgung vom 12. 2uguft 1844 (3uftiz=D)i3ั Gerüaffid tigen. nift.: 2 Bl. S. 186)

fino

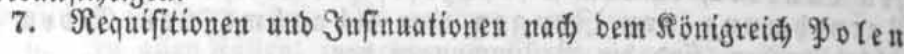

a. fo weit fie (sivil=2Angetegengeiten betreffen, you ben Dbergeridten unmittelbar an ben Wreufifidjen Benerale Ronful in $\mathfrak{B}$ arfdaut fur weiteren $B$ eforberung zu fenben. Untergeridjte baben fíd mit folden 2(nträgen an bas vor: gefezte Dbergeridt ju wenten.

b. in Rriminalfad)en ift zwifden ben bieffeitigen Doer=

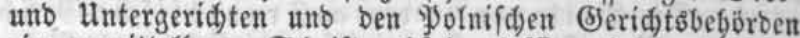
ein utmittelbarer Sdyriftwedfel zuläffig, fofern baburd fein gröferer Seit $=$ Doer Roften $=\mathfrak{2}$ lufiwano als burd bie Bermittefung bes (Beneral = Sonfuls in $\mathfrak{B}_{\text {arf }}$ d)au verur= fadit wirb.

c. bei bem amtliden Sdrriftwedfer mit ben 3 egbroben unb Beamten im Rionigreid) Ysolen fint biefelben nidft als

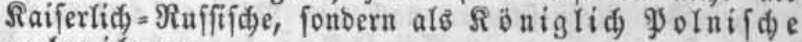
zu bezeidfnen.

d. bei Requifitionen an ben Dober = Molizeimeifter ber Stabt 23 arfifau Gaben bie bieffeitigen (Seridite bie 9roving, in welder fie ibren 2 mtsfith baben, anzugeben.

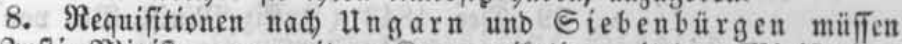
bem Suftiz=Dinifter zur weiteren Sommunifation mit bem MRinifterium ber auswärtigen 2 ngelegenleiten eingefanbt werben.

Bei Erlaffen an Einwobner ber Rorbamerifanifien grei= ftaaten if nidit blos ber 230 gnort bes 2Tbrefīaten, fonbern aud bie Yrovinz unb ber Diftrift, in weldyem ber 230 gnort belegen ift, auf Der 210reffe anzugeben.

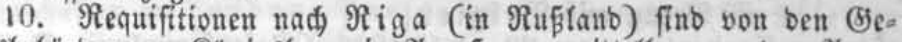

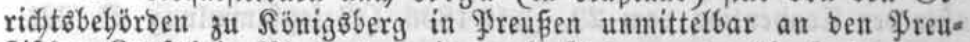
fifden Sonful in Riga zur weiteren beförberung zu überfenben.

11. WBo fid im 2uslanbe 9reusifde go ftanftalten befinben, if bie Snfinuation geridytlidjer Serfügungen burd bie go fo zu bewirten. Dies gifl zur Zeit namentlid yon Snfinuationen nad Siraf au unb nad Sevenaer in ben Rieberlanbent.

Erfenntniffe, weldje an im 2tuglanbe wofnenbe Yarteien zu infinuiren fint, werben, wo bies zuläffig ift, - wie in golen uno

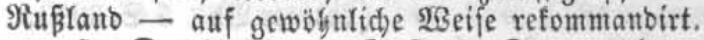

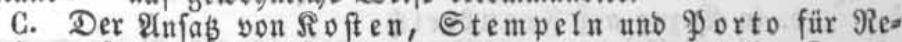

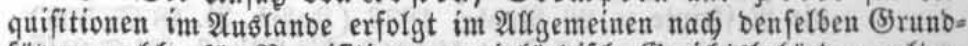

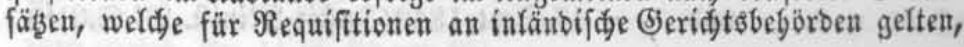


fofern nidyt mit eingehnen auşwärtigen Staaten bejonbere Berabrebun= gen bariber getroffen finb.

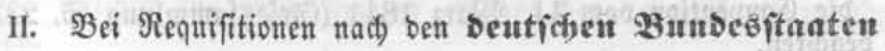
gift im Affgemeinen - abweident yon ber oben unter I. A. Rro, 1 erwägnten Borfd)rift - ber Errumbfał,

Daß̉ bie Requifitionen ber bieffeitigen (Seridste an bie Bee=

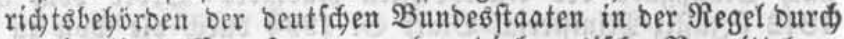
unmittelbare Eorrefpondenz ofue biplomatiffoe Bermittelung befürbert werben.

Dies finbet namentfid) $\mathfrak{A}_{\text {nwwenbung: }}$

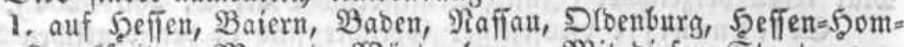

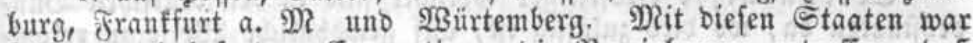
friber burd) befonbere (Sonventionen bie Sereinbarung getroffen, baf bie Beförberung fämmtlidjer Requifitionen uno Snfinuationen burd) ben (Jeneral= Srofurator zu ßöln bewirft, utto baburd) ber unmittel=

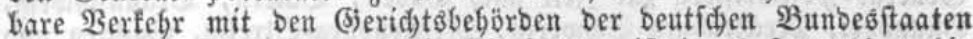
vermieben werben foffte. Diefe (Eimrid)tung if jebod) fpäterbin babin mubificirt:

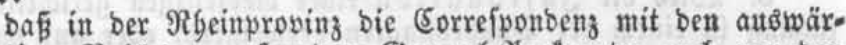
tigen $B$ efjorben aufer bem Seneral=\$ुrofurator aud, von ben Dber = Wrofuratoren ber Eanbgerifite uno bem Suftiz= Senate zu EGgrenbreitftein zu füfren ift, uno ebenfo in ben übrigen

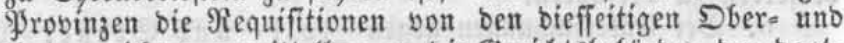
untergeridften unmittelbar an bie Gierid)tsbefobroen ber beutt= fden Bunbesftaaten zu beförbern fino.

2. In Betreff ber iubrigen $\mathfrak{B}$ unbesftanten bat fid audi olune förmlidige Staatônerträge faft alfgemein ber Brunbfaßs feftgeftellt,

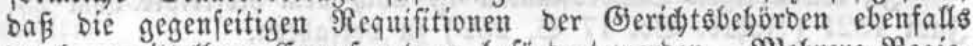
burd) unmittelbare (Eorrefponoenz beförbert werben. Diebrere Regie= rungen Gaben biefe 9raxis in ben mit ifnen gepflogenen Unteryanb=

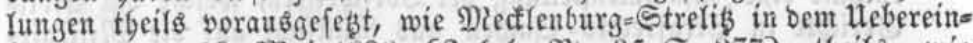
fummen vom 18. Nai 1830 (3abrb. Bo. 35 S. 277), theils, wie

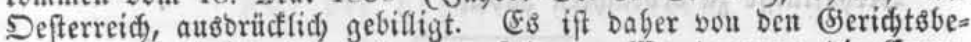
Göroen aud fünftig Giernach) zut verfabren. 290 bagegen bie Eorre= fpondenz mit ben Bebäroen einzelner beutfder Bundesftaaten bisber

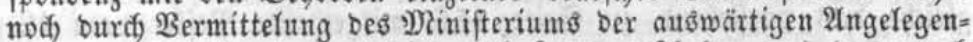
beiten erfolgt ift, ba muß bies aud ferner gefđénen, uno bann nady ben oben unter I. A. angefübrten êffgemeinen Beftimmungen verfabren werben.

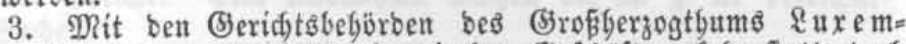
burg finbet zwar ebenfalls ein biretter Geféfätsoverfegr fiatt, bod

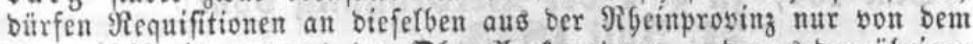
(S)eneral=9rofurator und ben Der= Yrofuratoren, und aus ben übrigen grovinzen nur vont ben Deergeridten beforbert werben. Die Unter= geridgte Gaben fid mit bergleiden Requifitionen an bas yorgefeste Dbergeridit fut wenten.

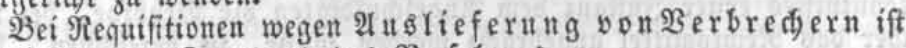
in $\mathfrak{A}$ fefung ber form und bes $\mathfrak{B}$ erfabrens 


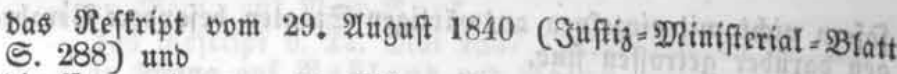
zu beadten.

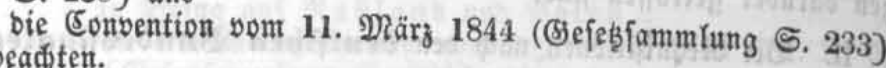

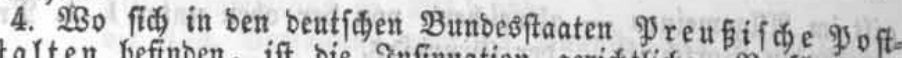
a nftalten befinben, ift bie Snfinuation geridgtlider Berfügungen

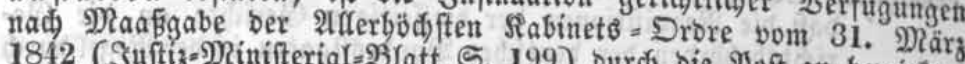
1842 (Suftiz-2hinifterial=2Blatt S. 199) burd) bie Yoft zu bewirten. Die im 2utslanbe vorbandenen \$reukifden Moftanftalten find in ber

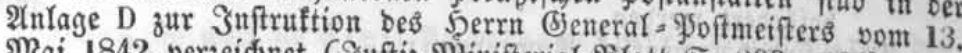
Mai 1842 verzeidnet (Suftiz=2linifterial=2latt $5.203-204$ ).

Exfenntuiffe Diesfeitiger (Seridste fint in ben bentfden Bun= besftaaten $b a$, wo bies zuläffitg ift, auf gewölgnlidide $23 e i f e$ zu refom= manbiren.

Dergleiđen 3 ufenoungen finb nad ber Mittbeilung bes Serrn Beneral - Yoftmeifters zur 3eit nad) Baben, Baiern, Braunidjweig,

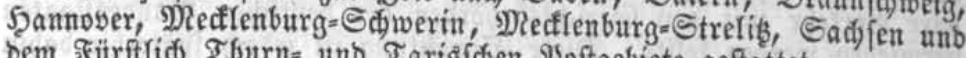
bem Fürffric, Thurn= und Taxisfiden Woftgebiete geftattet.

5. 2 Biro bie $\mathfrak{S}$ f finuation einer biesfeitigen geridtliden $\mathfrak{B e r}=$ fügung in einem ber $\mathfrak{B}$ unbebffaaten verweigert, ober auf mieberbolte Sabreiben besbalb nidgt geantwortet, fo if in ben grovingen, in wels

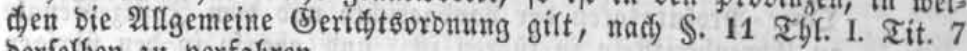
Derfelben zu verfabren.

6. Bei Unterfudungen gegen $30 \mathfrak{l l}=$ unb Steuer $=$ Contra= venienten in ben 3ollvereins = Staaten finb bie in ben 2 rt. $8-10$

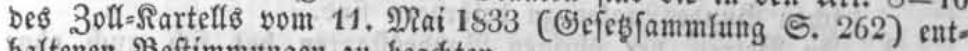
baltenen Beftimmungen zu beadten.

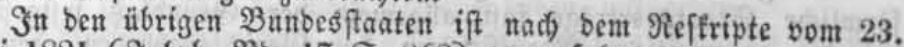
Suni 1821 (3abrb. $\mathfrak{B b}, 17$ S. 262) 3u verfabren.

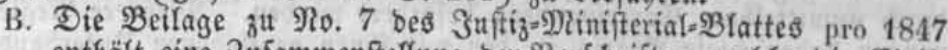
entbält eine 3ufammenfteflung ber Borfdriften, welde bie (Eivite

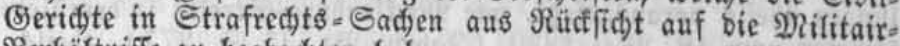
Berbältniffe zu beobadten baben.

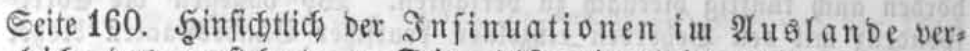

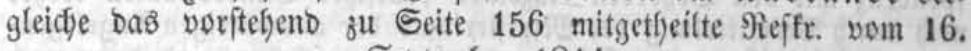
September 1844.

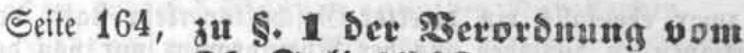 21. Tuli 1843.}

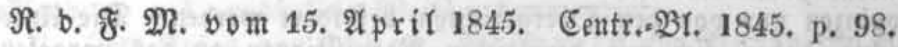

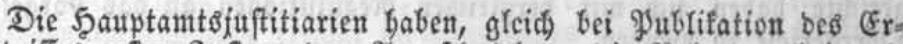

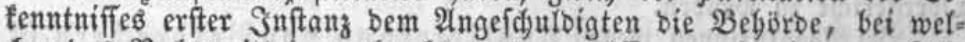

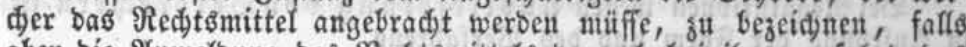

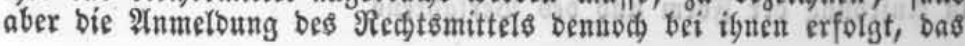


betreffenbe Sđdriftftüf ben 2 etbeiligten mit bex nötbigen Befebrung entweber fogleiđ zurüđł ridide, weldes in erfter Suftanz erfannt bat, ungefäumt zu ïberfenben.

\section{Seite 164, zu Pote h.}

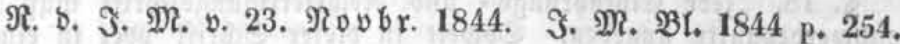

Die Seridte werben miebergolt angewiefen bie Borfariften bes

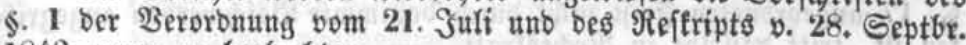
1843 genau zu beobaditen.

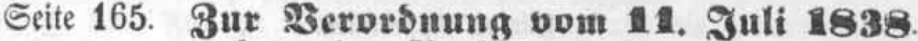 betr. Die Rechtsuittel ic.}

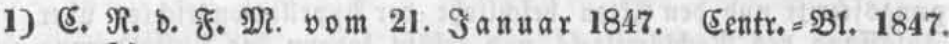
p. 14.

Die Beroronung yom 11. Suli 1838 ift burd bas Bsefes vom 21. Juli 1846 für aufgefoben ou erađtem, es treten alfo, fobalo eine Steuerunterfưungsfache in bie zweite Snftan gelangt, bie 3oridrif=

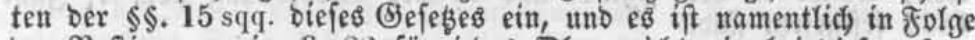
ber Beftinmung im $\$$. 22 für iebes Sbergerid)t ein bei biefem fun= girenber $\Im u f t i z=$ ( wäblen.

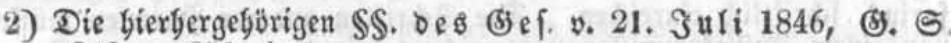
1846. p. 291, lauten:

Für bie böberen Snftangen.

a. (5)emeinfane Borjdriften.

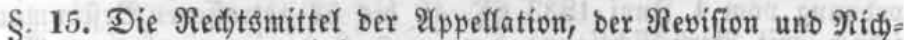
tigfeitsbeffinerbe werben bei bem Serid)te erfter Snftanz (马. 30) nur angemeloet. SGre Cinfübrung uno Rechtfertigung mit ben wei= teren $\mathfrak{B e r y a n b l u n g e n ~ b a r i t b e r ~ g e b o r t ~ v o r ~ b a s ~ i n ~ b o j e r e r ~} \mathrm{Snftan}_{3} \mathrm{er}=$

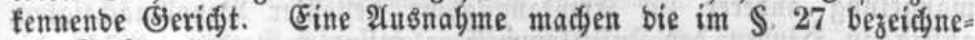
ten Sadjen.

\$. 16. Sür bie Anmelbung (§. 15) genügt bie Grfflärung, baß ber 22nmerbenbe fid ilber bas ergangene Erfemtni befdmert. Sie ift an feine Form gebunben, uno fann bemzuforge münolid zu gyro= tofoll ober fdriftlid obne 3ubiegung eines Suftizfommiffarius erfol: gen. 2(ud auf ben Ramen, mit weldem bas Redtsmittel bezeidnet

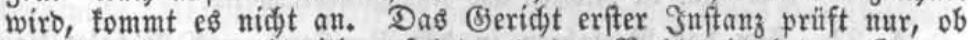

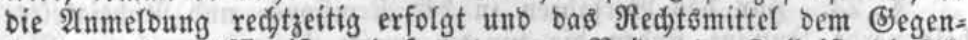

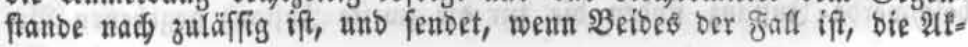


ten, unter Benadjidjtigung ber Sarteien, fofort an bas Beridgt bäGerer Snftanz.

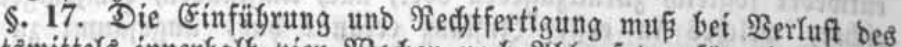

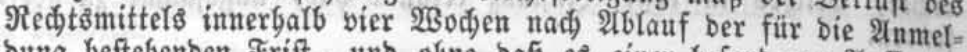
bung beftegenben grift, unb olgne baßs es einer befonberen भufforbe= rung bazu bebarf, bem Ejeridte Göberer Suftanz uno zwar ftets fdifriftlid überreidht werben. Nur aus Şinbertungsgrünben, bie in ber Sadje felbft liegen, fann biefe grift angemefilen verlängert werben.

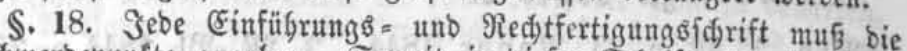
Befdyerbepunfte angeben. Soweit in biefer Sdifift ober in eitrem Rađtrage zu berfelben bas ergangene Grfenntnís vor 2tblauf ber im \$. 17 angeorbueten grift nidst butra beftimmte $\mathfrak{B}$ eidjwerben angegrif= fen ift, tritt baffelbe in $\Re e d$ tśt fraft.

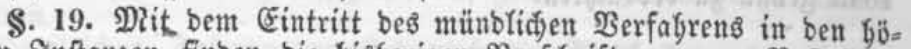
beren Snftangen finben bie bişerigen $\mathfrak{B}$ orfdriften wegen $\mathfrak{B}_{\text {eftellung }}$

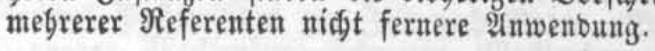

b. Sür bie 2appellationt.

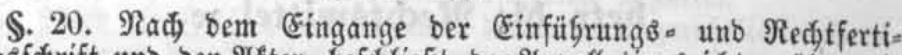

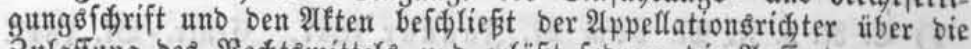

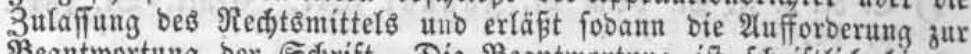
Beantwortung ber Sdgrift. Die Beantwortung ift fdriftlid bimnen einer vierwödentliden, nutr aus ben im $\S .17$ angegebenten Grünben

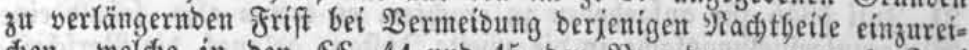
den, weld)e it ben $\$ \$ \$$. 44 und 45 ber Verorbunng vom 1. Suni 1833 feftgefestef finb.

§. 21. Pur Bffentlide Bebörben unb foldje gerfonen, welde

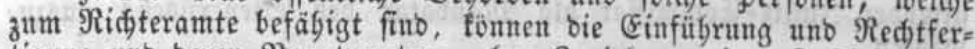
tigung unb beren $\mathfrak{B}$ eantwortung ofne 3 uziegung eines Suftijfommiffarits (d)riftlid einreiden. Die Schriften anberer yarteien müffen yon einem Suffizfommifiar unterzeidnet fein.

\$. 22. Sft bie Beantwortung eingereidyt ober barauf $B$ Berzidit

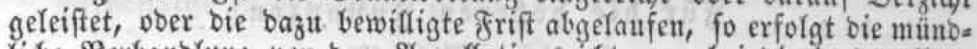
lide $\mathfrak{B e r b a n b l u t n g}$ vor bem 2 ppeflationsridter, wobei bie in ber $\mathfrak{B e r}=$ pronung yom I. Suni 1833 SS. 49 bis 53 getroffenen Beftimmungen, jebod) mit Berücffichtigung ber im $\$$. 9 ber gegenwärtigen $B$ berorb. nutng yorgefifriebenen 2tbänberungen, eintreten. Die Bortabutng ber Sarteien zur münblichen Berganblung unb Entfideibung tann, in Er: mangelung anberer zur Emufanguabme beftellter Bevollmádytigten, gültig zu Sänben ber Suffiglommiffare infinutirt werben, welde bie eingereid̆ten Sd)riftfäß̧e unterzeidjnet Gaben, wemn biefelben bei bem erfennenben Seridte zur Yrozępraxis befugt fino ober an bem Sige

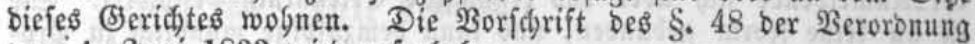
yom 1. Suni 1833 wiro aufgeboben.

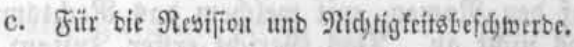

\$. 23. Für bas $\mathfrak{B e r f a b r e n ~ i n ~ b e r ~ \Re e v i f i o n s ~ = ~ u n b ~ \Re i d j t i g f e i t s " ~}$ befdwerbe = Suftanz finben bie fitr bie zweite Snftanz gegebenen $\mathcal{B}_{e}$ 
ftimmungen gleidffalts 2Anwenbung. ftebenben befonbern Borfdriften gu befolgen:

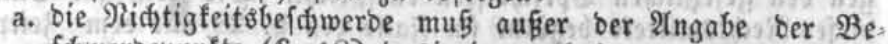
fdjwerbepuntte (S. 18) başjenige enthalten, was̆ ber 2 rtifie! 8 ber Detlaration vom 6 . 21pril 1839 voriddreibt.

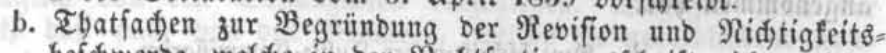

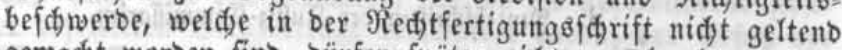
gemadht worben finb, buirfen fpäter nidjt vorgebradjt werben.

c. 2 Benn bie Beantwortung ber Revifion uno Ridtigfeitsbe= (d)werbe binnen ber beftimuten Frift (S. 20) nidft eingebt,

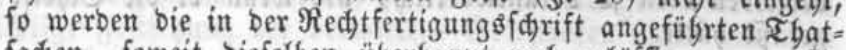
fachen, foweit biefelben übergaupt nod) zuläffig waren, für gugeftanben angenommen.

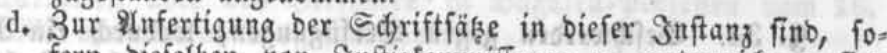
fern biefelben von suftigfomminaren zu untergeidnen fino

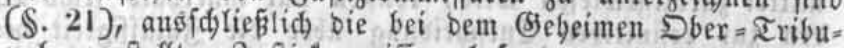
nal angeftellten Suftizfommiffare befugt.

5. 24. Für bie mintolidge Berbanolung uno bie barauf ergegente Entideibung bei ben Senaten beg Esebeimen Dber- Iribunals ift bie

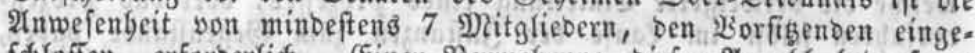
fdloffen, erforberlid. Einer Sermegrung biefer 2tnzagl bebarf es aber aud bann nidt, wenn es auf 2tbantoerung zweier gleidfförmigen Erfenntniffe antommt. Die Beftimmung in $\Re 0.7$ Der Drore vom 19. Sulfi 1832 (Siefesfammlung S. 192) wiro aufgeloben.

S. 25. Das gylenum bes (Segeimen Dber=2ribunals hat in ben Fäflen ber No. 3 uno 4 ber Beroronung vou 1. 2uguft 1836 (ङefetffammlung Seite 218) nidjt blos iiber bie zweifelbaft gewordene

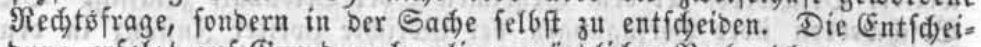
bung erfolgt auf Grunb nodjmaliger münolider $\mathfrak{B}$ erbanblung vor verfammeltem अrenum.

\$. 26. Den bei ignen aufgetretenen Sadjwaltern ber gartheien theilt bas Begeime Dber $=$ Tribunal 26 f d riften bes mit ben Entidei=

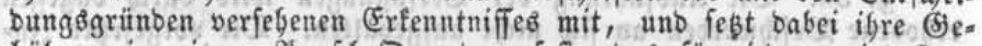

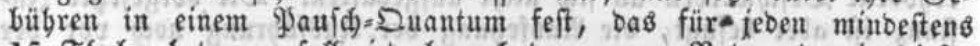
15 TGaler betragen fort, jeopd aud ben ganzen Betrag ber in biefer

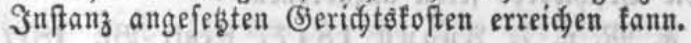

\section{2rffgemeitte Beftimungen.}

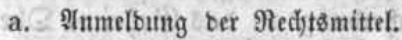

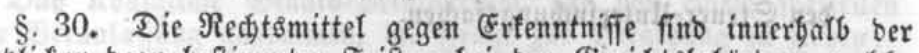

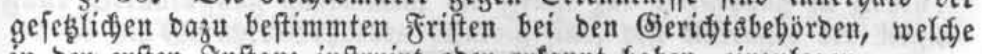
in ber erften Suftanz inftruirt ober erfannt baben, eingulegen.

b. Rechtsazmittel ber Reftitution.

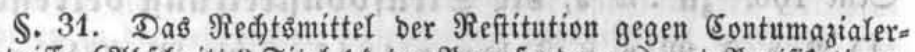

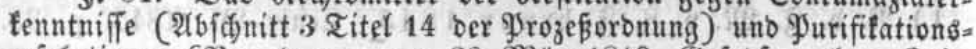
refolutionen (Beroronung vom 28. Dä̈r 1840 , Siefeşfammlung Seite 102) ift zujulaffen, aud went erbeblide Seinberungsurfadeut nidjt 
angegeben unb befdeinigt finb, bas Reftitutionsgefud aber im uebri= gen ben gefeßsliden $\mathfrak{B o r}\{d r i f t e n$ entipridst. Die Frift gur Einlegung biefes Reditsmittels beginnt in Falle bes $\$$. 28 mit bem 3eitpunte,

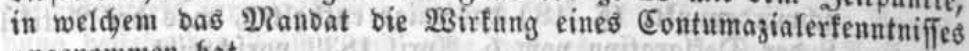
angenommen bat.

\section{d. Trozefídriften ber Suftiz-Evmmiīarien.}

§. 33. Der Suftiz= (5ommiffar, welder cine Rlage, RTagebeant* wortung ober anbere Wrozęfidriften unterzeidnet, ift für ben Snbalt berfelbent eben fo verantwortlia, als wenn ex bie Sdjrift ferbft $a b$. gefajt bätte.

\section{e. Befjuwerbejad)et.}

\$. 34. Befdwerben gegen $\mathfrak{B e r f u ̈ g u n g e n , ~ w o b u r d ~ e i n ~} \Re e d j t 8=$ mittel zuritigewiefen wiro, fönen nur innerbalb fed) $2 B 0 d$ en bei ben zur befinitiven Entfjeibung über bie Zuläffigfeit bes Red)ts. mittels berufenen Beridgten ber boberen Snftanz angebrad)t werben.

\$. 35. 2ud, anbere $\mathfrak{B}$ efdwwerben gegen geridjtlide $\mathfrak{B}$ erfügungen,

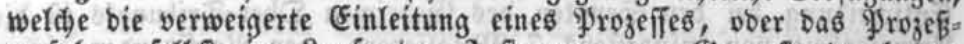
verfabren felbft in \&aufe ber Snftanzen zum Siegenftanbe baben, follen fortan bem Snftanzenzuge ber gegen Erfenntniffe zuläfigen Red)tômittel folgen. Sie fino gegen Berfügungen ber (Seridite erfter Snftanz bei bem (S)eridjte zweiter Snftanz anjubringen, bei befien Fentfdeibung $e s$ in ber Regel bewenbet. Nur bann, wenn in ber

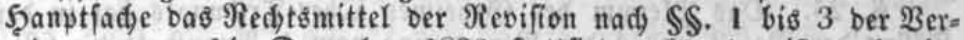
orbnung yom 14. December 1833 ftattfinben tonnte, ift nod eine

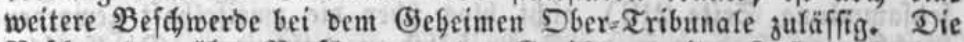
Befdwerben über $\mathfrak{B}$ erfügungen ber (Berid)te zweiter Suftam in ben bei ifuen anbängigen Sadjen, in welden ein orbentlides vber aufer=

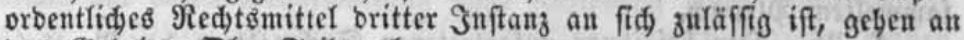
bas Bjebeime Dber=Tribunar.

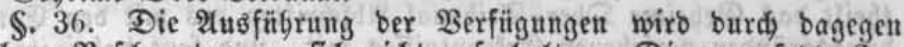
erbobene Befdwerben an fidh nidt aufgebalten. Die vorgefeste Jnt

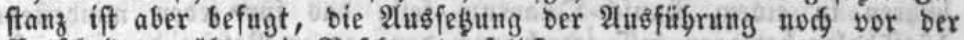
Entfdeioung über bie Beffweroe felbft anzuoronen.

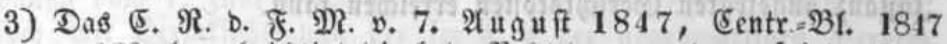
p. 120, benadridtigt bie betr. Bebörben von ber erfolgten 24 wabl eines Sufti $=$ Evmmiffars zur Bertretung bes ₹rscus in allen zur Entifeidung an bas Esebeime Dber=? ribunal gelangen= ben Steuer=Unterfud)ungริ\{ađ)en.

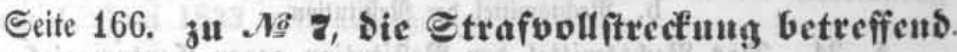

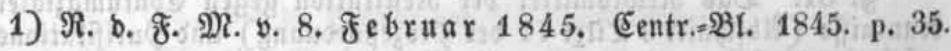
$2 B e n n$ fid bei Revifion ber Strafgelber = Extrafte ergiebt, $b a \equiv$ in erlebigten Zofl= ober Steuer=\$rozeffen bie Strafe bes vier = ober mebr= 
fad)en: Betrages ber vertürżten (Befälle, entweber in folge cines

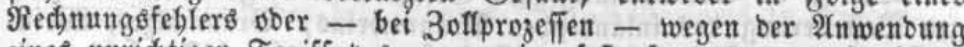
eines unridtigen Tariffases, zu gering feftgefest worben, fo if $e^{\mathfrak{S}}$ niđht zuläffig, bie gegen red) tófräftige $\Re$ efolute befettirten Strafbeträge nad)träglid) von ben Demunziaten cinzuziegen. Dagegen fann ber Infidet, baß̧ aud bon ben Beamten, welde bie unterbliebene greft= feşung ber befettirten Strafbeträge verfouloet baben, ber Erfałs ber

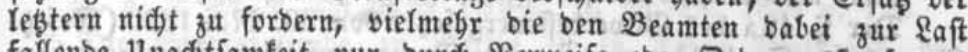
fallenbe Unadtfamteit nur burd) Berweife ober Drbnunggftrafen zu riigen fei, nid, beigeftimmt werben, ba ibre Bertretungšverbinblidfeit für bie ridtige Feftfeģung ber verwirften Bield ftrafen nidyt nur ben allgemeinen gefeslidjen $\mathfrak{B}$ orfduriften entiprid)t, fonbern im $\$$. 24 ber gnftruftion utber bas Berfabren in Bagateff=\$srozeffen vom 16. Suth 1837 ausbriađlid augigefprod)en ift.

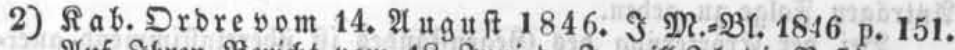

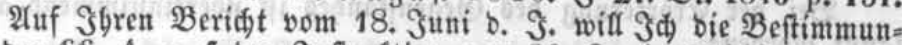

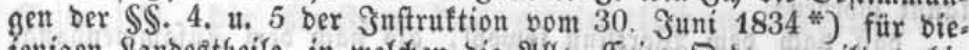
fenigen Ranbestgeile, in weld)en bie $2 \mathrm{Al}_{\mathrm{g}}$. Erim.: Drbunng gilt, babin

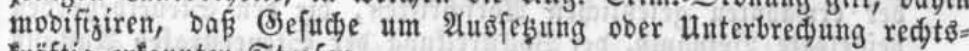
fräftig erfannter Strafen

a. wenn bas (Sefud) auf eine in ber $9 e r i o n$ bes Berurtbeilten eingetretene $\mathfrak{B e r a ̈ n b e r t u n g ~ b e r ~ i m ~} \mathbb{S} .4$ jener Snftruttion be= zeidineten 2 rt geftitbt ift, unb bie nadigefudide Jrift ben 3eitraum von $4280 d e n$ nidst iiberfteigt, won berienigen

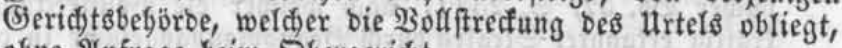
of ne $\mathfrak{A}$ nfrage beim Dbergeridt,

b. went bas (5efud burd eins ber im $\mathbb{S}$. 5 ber gebaditeu gn= ftruftion bezeidneten $\mathfrak{B}$ erbältniffe beranlafit wirb, unb bie nad)gefudste Frift ben 3eitraum von 4 :Boden nid)t ïber= fteigt, von bem betr. Dbergeridyt ofue Anfrage beim Suftiz= Minifter, nad pflidtmäpigem Ermefien bewilligt werben tömnen.

\section{Seite 169, zu m. u. m. Die Siftirung fochon angetre- tener Ctenerftrafent betreffent.}

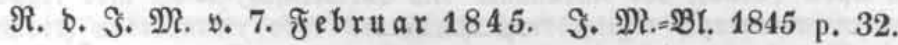

Das Röniglidge Staatśs=2Rinifterium bat von einem fpezieffen Fafle $\mathfrak{B e r a n l a f f u n g}$ genommen, bie Jrage zur Beratbung zu zieben:

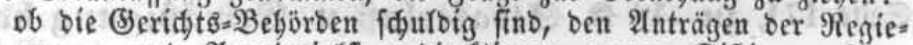
rungen unb \$rovinzialfteuerbireftionen wegen Siftirung fodon angetretener Steuterftrafen Folge zu Yeiften?

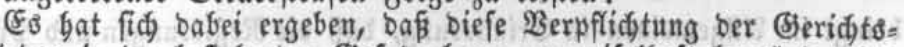
Bebörben in ber beftegenten Esefeßgebung ungweifelgaft begrünbet fei.

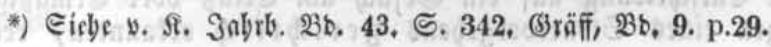


Der \$. 95 ber Dronutug 3im Befelse bom 8 . Februar 1819 wes

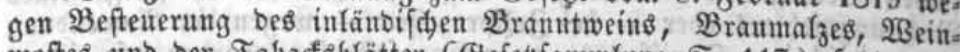
moftes und ber Tabacfsblätter (Befesfanunfung S. 117.) feşt auğ: briatlid feft:

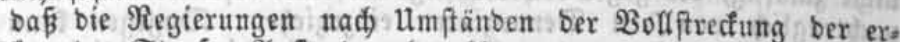
faunten Strafen 21nftand geben fönnen, uno baß bie Seridgte bem, was besfalb an fie ergegt, zolge zu leiften baben.

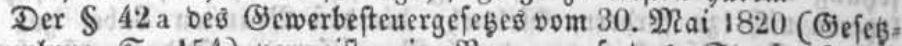
Sammluting S. 154) verweift, in Sejug auf bas Strafverfabreit

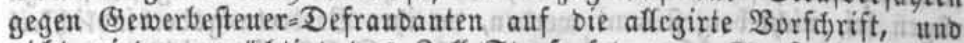

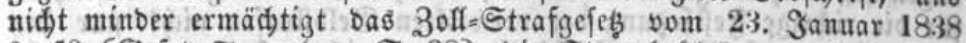

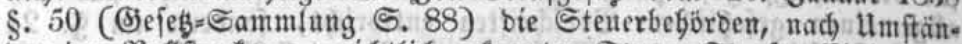
ben ber $\mathfrak{B o l f f t r e c t u n g}$ geridetlid) erfannter Steuer=Strafen (Eingalt zu thun, inbem es zugleid, bie (Jeriddtşbebörben anveift, ben beøfallfigen 2nträgen Folge zu geben.

Bei ber Erorterung bes Begenftanbes ift ïbereinftimmeno anertannt worben:

Daß̧ nad) bem 2 Bortfinn fowohf, als nad, bem 3 ufammenfange Der crwäbnten gefegliden $\mathfrak{B}$ orfádriften, bie ben Eteuerbeborben beigelegte $\mathfrak{B}$ efugní, ber $\mathfrak{B}$ olf frefung ber Steuerftrafen $\mathscr{A}$ (nftand zu geben, auf idon angetretene Strafen in bemifelben Maake, fo wie, wie auf nod nid)t angetretene, 2tnwenoung finbe,

Daß aud bie 2tferbjofte Drore vom 29. 2tuguft 1838 (Jabrs

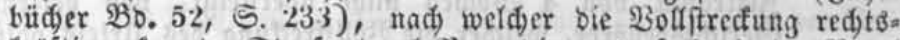
fräftig erfannter Strafen burd) Begnabigung\$gefud)e in ber Reget nidt aufgebalten werben foll, biefe Befugnif oer Steuerbegörben

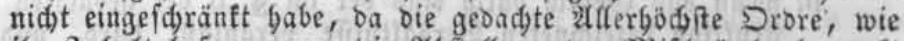

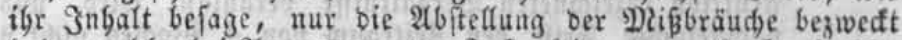
babe, welde bei 29uwendung ber 3nftruftion vom 26 . 3uni 1831 bervorgetreten waren, bie Steuerbeborben aber gefegtid befugt feien, bie $\mathfrak{B}$ olfftrefiung ber Steuerftrafen beliebig zu beanftanben ooer zu fiftiren, ofune bafi es Gierbei barauf anfomme, ob bies

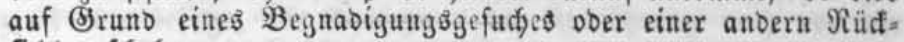
fid)t gefdebe.

Sämmtlide (Seriđłtógegörben i werben bierburd angewiefen, fid in sortommenden fäflen nađ ben obigen (s)unbfäßen zu ad)ten.

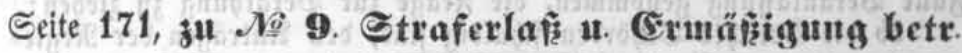

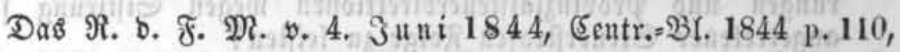
bringt in $\mathscr{2}$ flgemeinen in Erinterung, Daß bie Regierungen uno Wroy.= Steuerbeborben burd) baร ( Sircular v. 4. Suni 1836 angewiefen fiub,

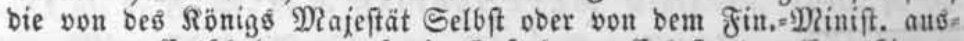
gegangene (Entfdeibung auf ein (sefud) um Erlaß̧ Doer (Ermäßigung einer wegen eines Steuerbergebens geriditlidi) erfannten, redists. 
Fräftig feftfegenben Strafe, fobalb bieferbe ignen zugegangen ift, fos fort zur Semntnis bes betr. \&andes= Juftiz. Eollegiums ju bringen.

\section{Seite 173, ; $\mathbf{H}$. Die unbeitreiblichen Roften betr.}

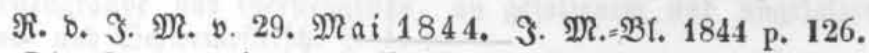

Die Staotgemeinbe zu Berfin ift in Folge Bertrages vom 10-16. Dejember 1846 von aflen \&aften ber Eivil $=$ und Eriminal $=$ (3) $=$ rid)t sobarfeit befreit, was fid auf alle gälle erftrectit, in benen fonft nad) \$. 9 ber Erim.:-Drbntng bie Roften unb baaren 2utsfagen ben

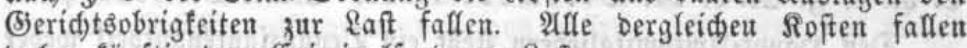
bager fiunftig bem Eriminalfond fur Eaft.

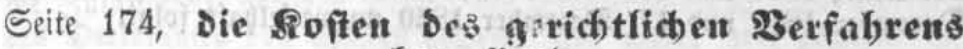 betreffens.}

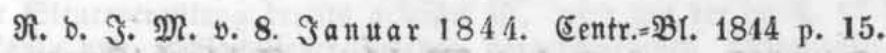

Auf ben 2 ntrag ber fdlefifdien \$rovingialfänoe if in bem \&anb= tags=216idiebe vom 30. December 1843 befitimmt:

baß bie Roften in Unterfudungss=Sadjen gegen bie unvermögen= ben grauen unb bie nod) im väterlident Jaufe befindliden sint= ber berienigen Soloaten, weldge den in einigen Stäbten nod bez ftebenben Snvaliden $=$ Eompagnien angeboren, fünftig auf bie Stantşaffen itbernommen werben follen.

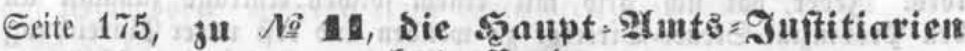 betreffent.}

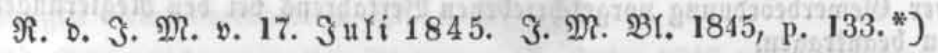

Die guifrung ber geridftlidfen Unterfudfung wegen $30 \mathfrak{l l}=$ uno Steuer=2Bergehen, wenn feine anbern Bergegen bamit concurriren,

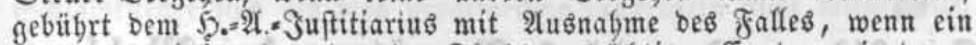
frember, unbefanter ober ber Fludit veroäd)tiger (Eontrabenient won ben Steuer = Doer Berwaltungsbeamten an ein benadjbartes (Beridgt zur 2Aufbewabrung abgeliefert worben ift, für welden gall bie $\xi_{\text {n }}$ fruftion vom 28 . Suni 1839 (马. M. Bl. p. 252) bie Beftimunungen entbält.

ISenn mit ben $30 \mathfrak{l l}=$ ober Steuervergegen gemeine $\mathfrak{B}$ erbredjen

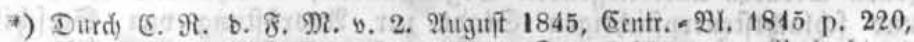

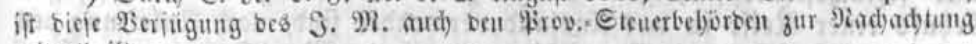
mitgetlyeitt. 
concurriren, fo ift bem betreffenben Dbergeridgte bavon 2 tngeige zu maden, weldes zu erwägen uno entfideiben bat, ob bie Fübrung ber

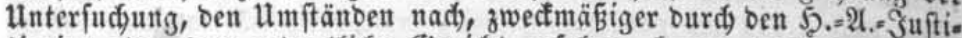
tiarius ober bas orbentlide beridgt erfolgen fann; bas legtere ift

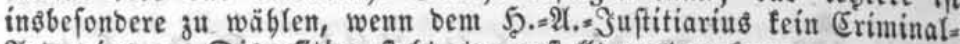
Actuarius zur Dispofition fegt ober geftellt werben fann.

\section{Ceite 183, ju To 1\%, Den Denutiantenantbeil betr.}

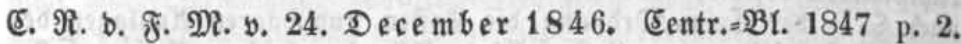

Den 5aupt-21mtsamitgliebern fteft ein Denunziantenantheil weber in Stempel = nod in 3off = unb Steuer= Sontraventions=Saden $\mathrm{zu}$, was refp. aus bem Sduluffe ber Suffruction für bie J Jauptämter yom

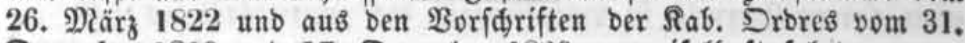
December 1819 uno 17. Desember 1820 unzmeifelgaft folgt.

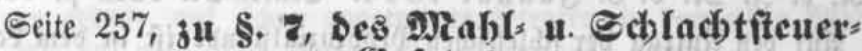 Geietses.}

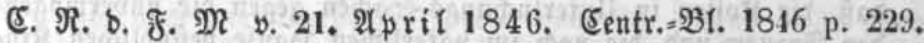

Rad ber neben ben $\$ S .27,28,38$ u. 41 ber Bewerbeorbnumg vom 17. Santar 1845 zur Anwentung fommenben 2 oridorift bes $\mathbb{S}$. 7

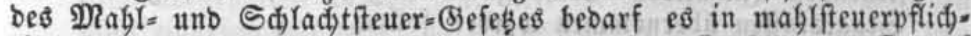
tigen Stäbten zur 2(nlegung einer mit thierifđen Siräften ober Dampf

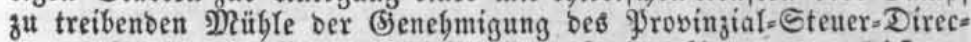
tors. Seber bat fid alfo mit einem folden 2 ntrage zunädft an bent Wrovinzial=Steuer= Director zu wenbent uno erft unter (Einreidung

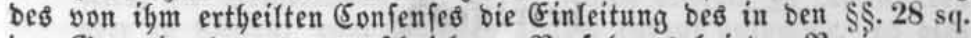
ber Bewerbeorbnung vorgeidriebenen Berfabrens bei ben Regierungen ou beantragen.

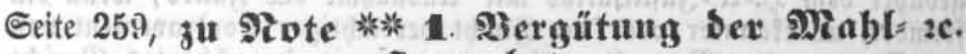 fituer betr.}

1) (ab. Drore v. 19. Aprif 1844. Eentr.=Bl. 1844. p. 141.

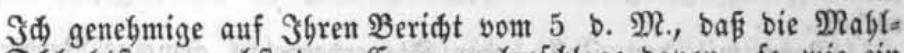
unb Edladtfteter nebft bem (Eommunalgufdlage bavon, fo wie ein Theil bes Debitspreifes für bas verbraud,te Sal von benienigen, jenen Steuern unterliegenben Esegenftänben, welde aus einer małle uno fd)lađtfteuerpflidtigen Staot zur 2 tustrifftung von Seefdiffen

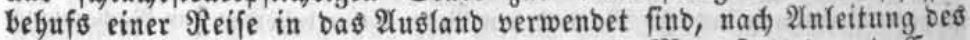

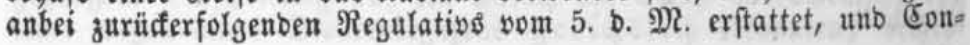


traventionen gegen biefes Regulativ nad ben barin $\$$. 12 unb 13

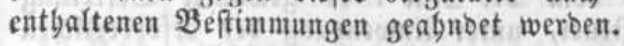

2) Das in ber vorgebadten ( vom 1. 2prit 1844*) beftimmt im 28sefentficisen:

Die Erftattung wirb gewäbrt für bie eingelabenen Rebensmitter an $\Re$ oggen= unb $\mathfrak{2} B$ eizenmebl, an $\mathfrak{B}$ rod aus biefen Meglforten, an

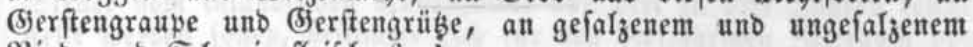

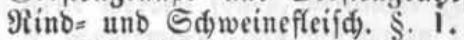

Der Sdifferbeber ober guithrer bat bie fdriftlide Declaration barïber bem betr. Saauptamte einzureiden. \$, 2 .

Rad 2tbgabe ber Declaration bürfen Esegenftänbe ber $\$$. 1 be=

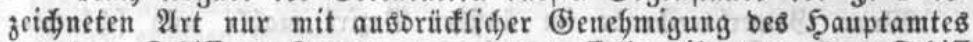
won bem Sdjiffe entfernt werben, uno baffelbe gilt, wenn bas Sdjiff nadi ber 2tbreife genötbigt wirb in ben 5yafen eiter anbern mabl= uno fdiladtfteuerpflidtigen Stabt eimzulaufen. \$. 11.

Sebe Unridtigfeit in ber abgegebenen Declaration, weldye auf bie 3uläffigfeit unb ben Betrag ber Steuervergitung zum Bortbeil bes Declaranten von Einfluß̧ gewejen fein wirbe ober gewefen ift, fo wie jebe Berleşung ber im $\mathbb{S}$. 11 gegebenen Beftimmung, im Fall bie Steutervergittung bereits geleiftet ift, wirb mit ber im \$. 17 bes 9) Rabl = uno Edjladtfteuer= (jefépes vorgefdriebenen Defraubations = Etrafe, eine fonftige Unridtigfeit ber Declaration ober Riditbead =

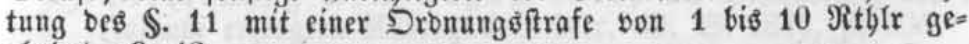
abnoet. \$. 12.

2Siro in Beziefung auf ben für ein Seefdiff beftimmten ober eingenommenen Wroviant, von bem SdiffBrbeber, beffen Bevollmäd)= tigten, bem Ediffiffübrer ober von einer zur Bemannung gebjrigen yerfon cine Mabl- ober Sd)ladtfteuer-Defraubation burd Serleşung ber vorftefenten ober ber allgemeinen gefeglidien $\mathfrak{B}_{\text {eftimmungen bes }}$ gangen, fo taun bie nadgegebene Steuer=Eritattung für ienes Sdjif auf immer ober wäbreno eines beftimmten Zeitraums verfagt wero ben. $\$ .13$.

Die 3uriufnabme unb bie 2 enberung affer vorftegenben $\mathfrak{B e f t i m}=$ mungen bleibt vorbebalten. \$. 14.

3) Sämmtlide wegen ber IGeuerung iu Gabre 1847 geitweife ergangenen Beftimunungen wegen Suspenfion uno Erftattung Der Mable unb

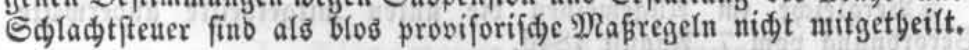

\section{Eeite 263, zu 9rote 2 C.}

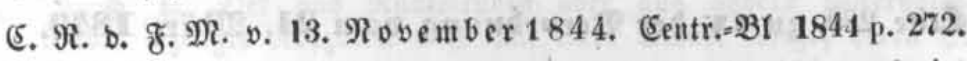
Mittelft 厄ab. Drore vom 8. November 1844 ift genefmigt worben, Daß̧ bie wegen des Dextrin's und ber gerófteten

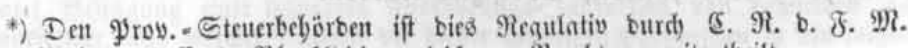
y. 12. Miai 1844 (Entr.-BI. 1844 p, 141 zur Bead)tung nitget)cilt. 
Stärfe naW ber Berf. yom 21. Mai 1841 gewäfrte Befreiung von ber (Fingangs - Mablfteuer, unter Anwenoung ber erforberliden

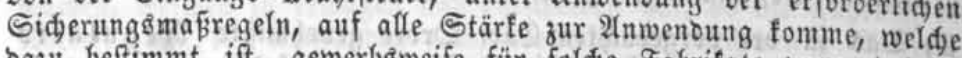
$b a_{z} u$ beftimmt ift, gewerbsweife für folde gabrifate verwenbet $z^{u}$ werben, bie nidst zum Genuffe für 2 enjajen beftimmt fino.

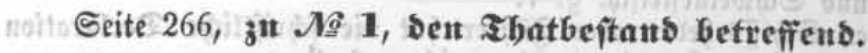

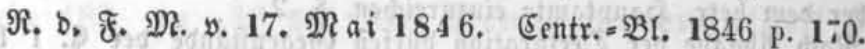

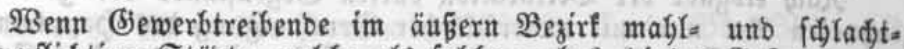

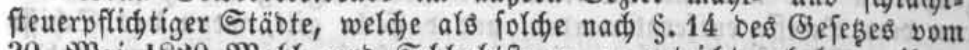
30. Mai 1820 Mabl= uno Sddladtfteuer zu entridten baben, ibren Betrieb bebufs ber Esewerbefteuer anmeloen, fo ift nidst anzunelgmen,

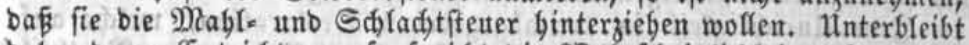
baber beren (Entridtung, fo fprid)t bie $2 B a b r$ fdeintidfeit bafür, baß

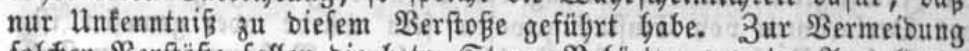

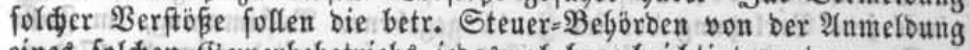
eines folden (jewerbebetriebs jebesmal benadridtigt werben.

\section{Seite 272. 3и III a. Siab. Orbre v. 20. Juni 1830.}

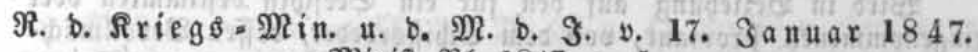
Minift,$=$ Bl. 1847, p, 5 .

Die Beftimmungen ber Rab. Drbre v. 20. Suni 1830 finben

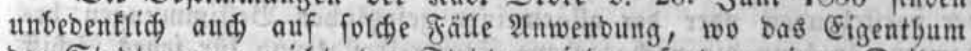
Der Stabtmauern nidht ber Stabtgemeinbe, fonbern einem Dritten zuftebt.

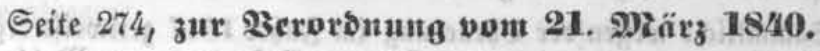

Bergleide im $2 \mathfrak{H}_{g}$ emeinen bie unten mitgetgeifte anberweite Berorbnung vom 7. 2uguft 1846.

\section{Seite 280, zu IV Der Berorbuutg vou 21. MEärz 1840.}

Diefe Strafbeftimmungen fint burdi bie $\$ \$ S .17$ sq. ber unten

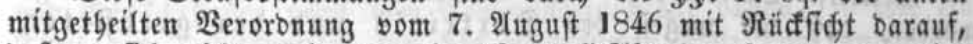
Daß̧ es fid nidt megr um eine Sontrofl=2logabe, fonbern um eine wirflidge Steuer ganbelt, mobifizirt worben. 
Seite $283,3^{\text {th }}$ Artifel 4 ber $\mathfrak{u}$ ebercinfunft v. 8. MRai 1841 .

\section{1) Rab. Drbre v. 1. JuYi 1844. (5. S. 1844.p. 182.}

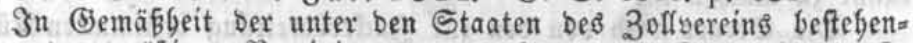
ben vertragşmäfigen ßereinigung, wonah bom 5 , September $b$. Э.

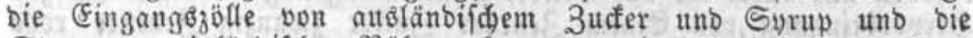

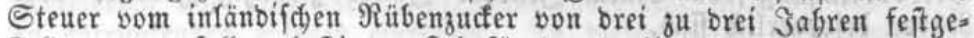
ftellt werben folfen, beftimme Sh) für ben breijäbrigen Zeitraum vom 5. Eeptember 1844 bis babin 1847 ie.

II. Die Steuer von bem au $\Re$ Rüben ergengten $\Re$ ofzufer fofl 1 Thlr. für ben $30 l_{z}$ entner betragen unb von ben zur 3udferberei=

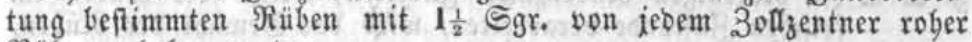
Riiben ergoben werben.

2) Die Rab. Drore y. 25. Suni 1847 , J5. S. 1847 , p. 241. beftimmt, daß biefe Steuerfäbe nod bis zum 1. September 1848 unverändert in 2tnwenbung fommen follen.

\section{Seite 285, zแr 3erorbuung v. 30. Guli 1841 twegen Be. ftenerung Deตื औübenzuders.}

1) Beroronung v. 7. If u guft 1846 , bie Beffeuerung bes im

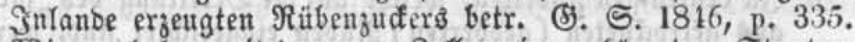

2Bir 2c. Gaben mit ben zum Zollvereine gegorenben Staaten, in Bemä̈bleit beß 2trtifers 2 ber Hebereinfunft vom 8. 2Rai 1841 (Gefesfammlung Seite 151), allgemeite und itbereinfitimmente geiebs lide Borfdriften wegen ber Befteuerung bes im Unfange bes 30 lle vereins ergeugten $\Re$ übenjufers vereinbart, uno verorbnen auf bent 2ntrag unferes Finam $=$ Minifters - unter $\mathfrak{B}_{\text {e }}$ ugnalme auf bie Drore vom 1. Suli 1844 (ङ3efeßfammlung 182), burd weldje bie Sojbe ber von bem $\Re$ Ritbenzuder fu entridtenben Steuer bis zum 1. September 1847 feftgefegt iff; bagegen unter gleidjeitiger 2 tufbe= bung ber Beroronung wegen Erfebung einer Controle-2lbgabe vont

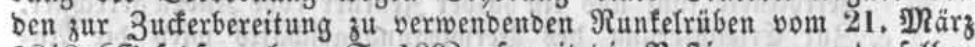
1840 (ङeféfammlung ङ. 109), foweit bie Beftimmungen berferben nod gulltig find, - wie folgt: *)

\section{I. $\mathfrak{U T I}_{\mathfrak{B}}$ emeine $\mathfrak{B}$ eftimungen.}

1) Sob be ber Stetuer.

\$. 1. Der aus Runfelrüben ober aus anbern zuferbaltigen Rüben ergeugte Robjucter wirb mit einer Steuter belegt, beren Şbge

*) Die Berorbuntg vom 7. 2uguit 1846 if ben भुrov. = Steuerbehörbent

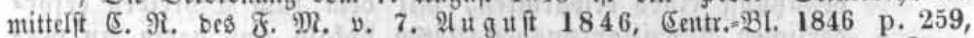
unter $B$ cifügung ciner befonbern vilusfübrutgs-Snftruftion von bemielben Tage, zugejertigt, aus welder lebteren bie bieber geborigen Borjdrifiten in ben folgentent joten zur Berorbmutg jelbịt mitgetbeilt finto. 
ie für eine breiääfrige, mit bent 1. September begimnente Weriobe

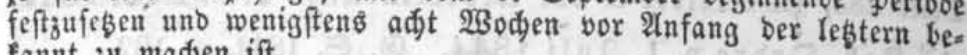
fannt zu maden ift.

Die Steuer wirb von ben fur 3uterbereitung beftimmten $\Re$ tüben erfoben unb babei bis auf weitere Beftimmung angenommen, baß̧ zur Servorbringung von Cinem Zentner 3uterer zwanzig 3entuer rolge Riuben erforberlid fint.

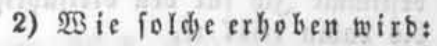

a. auf ben Brunb fpegieller (jectidits Ermittelung.

\$. 2. a. Sn benjenigen $\Re$ übenzuterer=gabrifen, welde bie $\Re$ tüben im

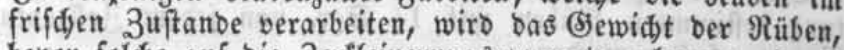
bevor foldse auf bie Zerfleinerungşapparate gelangen, burd amtlide Berwiegung ermittelt, fu weldem $\mathfrak{B}$ effufe in einer ieben folden gabrif, unb in jeber von ber eigentliden $\mathfrak{F}_{\mathfrak{a}}=$

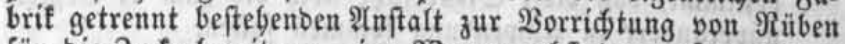
für bie 3ufferbereitung, eine $2 \mathbb{B}$ aage nebft ben erforberfiden

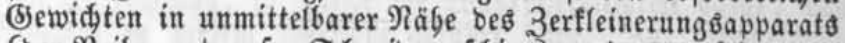

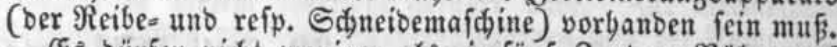

(5) bürfen nidjt weniger als ie fünf 3entner $\Re$ iubent auf bie $\mathfrak{B a a g e}$ gebradt werben. Die Sewidhtsermittelung burd 马robeverwiegungen ift unzuläffig.

b. Sn benjenigen Fabrifeu, weldje auf bie Bereitung beş 3ưfers aus getrodneten (geborrten) $R$ üben eingeridutet fint, werbeu

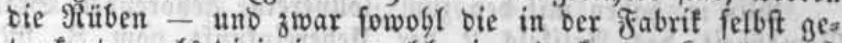
troctneten, als biejenigen, weld)e in getrodnetem (gebörtem) 3uftanbe von auşwärtigen Trofnunģanftalten bejogen ober in foldem 3 uftanbe von anberen gyerfonen erworben werben - vor ibrer cFinbringung in bas gofal, in weldem fidb bie Extraftionsgefäße befinben, auf ciner, nebit ben erforberliden (Sewid)ten von Dem Jabrifinfaber in unmittelbarer $\Re a ̈ b e$ beß gebadjten Eolats ju Galtenoen $2 B a a g e$ verwogen, uno es werben, Befufs ber 2togabenentrid)tung, auf jeben Zentner getroctnete fünf unb ein halber Zentner robe খeüben gerednet.

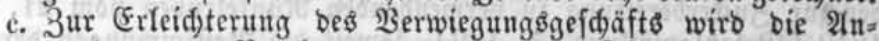
wenbung von Brüctenwaagen geftattet. Die zur Berwiegung

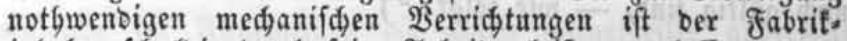
ingaber fdulbig burd) feine 2rrbeiter leiften zu laffen.

d. 3um Befufe ber amtliden $\mathfrak{B}$ erwiegung ber Rüben fino bie Fabrifanten verpflidetet, foldge baulide Einrid)tungen unb

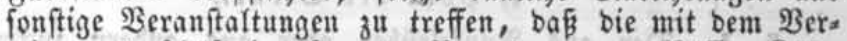

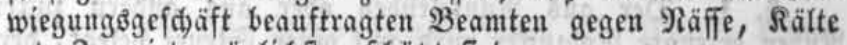

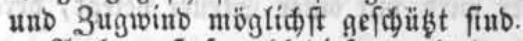

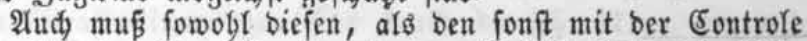
beauftragten Steuerbeamten in bem Fabrifgebäube bie Mit= benugung eines erwärmten, nit beut zum Sdreiben erforberliden Mlobifiar ausgeftatteten Lofals uno barin ein ver=

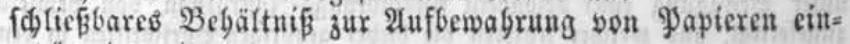
gerätumt werben. 
b. in 23ege ber frixativn.

§. 3. gär Fabrifen, weld) innerbalb einer Betriebsperiobe (von

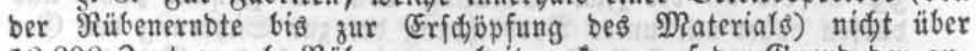
10,000 Zentner robe $\Re$ uiben verarbeiten, fann auf ben Srunb ber angemeloeten uno revibirten Materialvorrätbe eine Fixation ber bafür gu entridtenben Steuter eintreten. In biefem falle unterbleibt bie

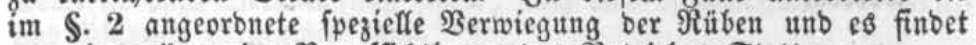
nur eine affgemeine Beauffidtigung bes $\mathfrak{B}_{\text {etriebeg Statt. }}$

Solfte jebod im Eaufe ber Fabrifation fid ergeben, baj bie Renge ber fur $\mathfrak{B}$ erarbeitung beftimmten $\mathfrak{R}$ üben unridjtig angegeben

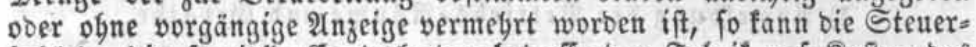
bebörbe bie fpezielle Sontrole ber betreffenden Jabrif auf Roften bes Sngabers berfelben anorbnen.

3) Bon wem unb wann bie Steuter zuentriditen ift. pfliditet.

§. 4. 3ur Entridtung ber Steuer if ber Fabrifinbaber ver=

Der won ber Şebeftefle bes ஒెezirf's am Sd) luffe eines jeben Ra= Yenber $=$ Donats feftgeftellte uno bem Steuterpflidytigen befannt gemadyte Sefäflebetrag muß binnen brei Tagen nad) (Empfang ber amtliden Bered)ung eingezahlt werben. In wiefern biergut weitere $3 a b l u n g s=$ friften zu bewilligen finb, bleibt ber Beftimmung bes finanz=-2) inifters borbebalten.

\section{4) ErIá ober Eritattung ber Steuer.}

\$. 5. Ein Erlaß̧ Doer eine 3urürfallung ber Steuer aus bem Srunde, weil wäbreno ober nad) ber fabrifation Materialien ober bie baraus bereiteten Fabrifate unbraudbbar geworben pber burd, ein zu= fälliges Ereignifi verloren gegangen find, finbet nidit Statt.

\section{5) Berjäbrung.}

\$. 6. Bei Erbebung ber $\Re$ übenzuder = Stetter finbet, fowohl ge= gen ben Steuerpflidtigen als gegen Den Stant, eime einjäbrige ßer= jäbrung in ber 2 rt Statt, Daß nur binnen Jabregfrift, vom Tage Der Steuerentridtung an, ein 2 nfprud auf Erjaß wegen fut viel ge= zablter Befälle angebrad)t, uno bā̄ nur bimnen gleidjer Jrift, von gleidem 3eitpuntte an, eine Radforberung an ben 2 bgabepflidistigen wegen 3u wenig erbobener Steuter gelteno gemadit werben barf.

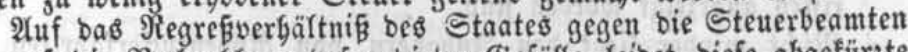
unb auf bie Radzablung befraubirter (Sefälle leibet biefe abgetürgte Berjäbrungşfrift teine Ânenbung.

6) Befdränfungen be Betricbs.

\$. 7. a, Der vereinigte Betrieb ber 3ucferfabrifation aus $\Re$ ïben unb

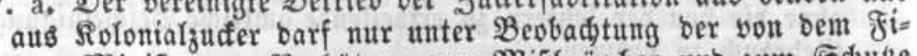

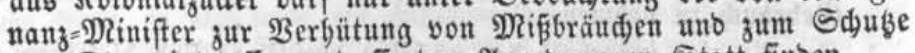
bes Steuterintereffe ju treffenben 2 Anorbuningen Statt finben.

b. Rubenzucter= Fabriten innerbalb bes Grenzbezirts unterliegen, au= 
Eer ben in ber gegenwärtigen $\mathfrak{B}$ erorbnung enthaltenten $\mathfrak{B}_{\text {effim }}$

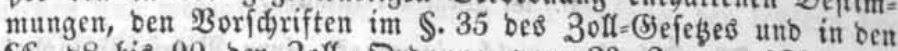
SS. 88 bis 90 ber 3olf-Dronung vom 23. Sanuar 1838 utto

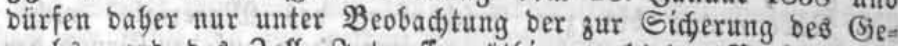
werbs = unb bes $30 \mathbb{f}=$ Sntereffe notgig eradbteten $B$ ebingungen uno Befdränfungen fortgefę̧t ober net angelegt und betrieben werben.

\section{Borfariften über bie Ergebung unb Eontrolirung ber Steuer.}

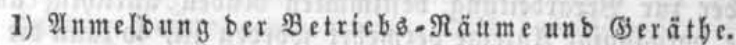

§. 8. a. $\mathfrak{B e r}$, um 3 ưfer aus $\Re$ üben zu bereiten, eine Fabrif anlegen ober fonft Einridjtungen treffen will, ift verpfliditet, foldes ber Steuterbebeftefle, in berent Begirf bie gabrif liegt, minbeftens

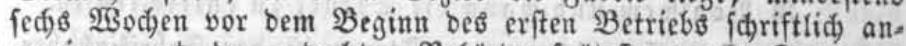
zulzeigent uno ber gebadten Beförbe fpäteftens adjt $\mathfrak{T} a g e$ vor Eintritt biefes lesteren Seitpuntt seine Nadjweifung, nady einem

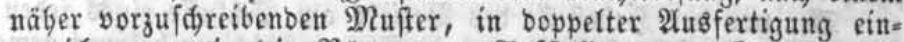

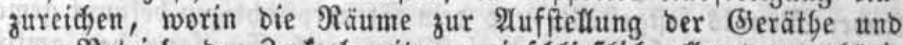
zum Betriebe ber 3ưferbereitung, einf́d)lieflid aller baz̆u gefjörí= gen ober bamit im 3ufammenlange ftelenten Borbereitungen utb

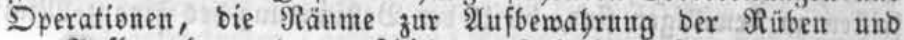
zur Alufbewabrung ber verfdiebenen Fabrifate, ferner bie zu be=

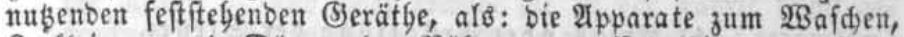

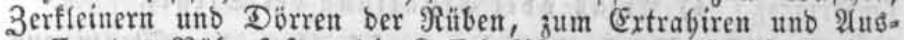
preffen bes Riltenfaftes, bie Reffer, भyfannen uno fonftigen Bore

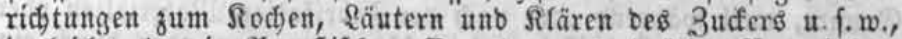
ingleiden ber in Yreukifden Duarten ausgebrüdte Rauminbalt ber Reffel unb gुfannen, yon jebem biefer (jerätge befonberş, gee nau uno volffänoig angegeben fein müffen.

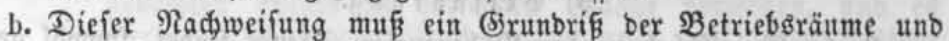
Der Steflung ber barin befinbliden feitftebenten Bserätbe, nad ber von ber Steuterbegb̈rbe zu gebenben näberen 2fnleitung, zwei= fad) beigefügt, ein Exemplar, von ber Steuterbebeftelfe befdjeinigt, in bem gabriffofale aufbewabrt unb bie Darin bejeidjnete Stel: lung ber (B)eräthe fo lange unveränbert beibebalten werben, afs 2bänberungen nidft burd (Einreidung eines anberweiten Grunb= riffes angezeigt worben fint.

c. Nidgt minter liegt ben 3nbabern von Riubenzudferfabrifen ob, wenn neute Gerätbe ber unter a bezeidneten 2rt angefduafft ober bie bereits angemeloeten ganz ober zum Theil abgeänbert wer: bett, vor voer unmittelbar nad bem Empfange ber Gerätbe ber

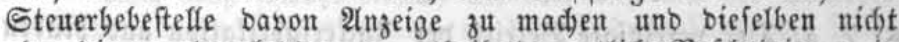
ogne bie von ber Yekgtern zu ertgeifenbe amtliđe Befdeenigung in (S)brauch) zu nebmen.

d. Bur $\mathfrak{A n}_{3}$ eige innerbalb ber nädfften brei Tage finb biefelben aud) verpflidstet, wenn bereits angemeloete (Bcräthe gailz ober jum 
Theil, zum 3mefe ber Fabrifation, in ein anberes lofal ge bradjt werben. *)
2) Bezeid)ung unb Bermefiung ber (5erätbe.

§. 9. Die in ben $\mathfrak{B}$ etriebsräumen vorljanbenen feftifefenben $\mathrm{Be}=$ räthe werben nadi ber Beftimmung ber Stetterbeborbe numerirt, welde,

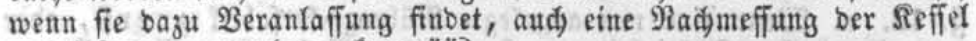
und gsfanten vornegmen fann.*"*)

Die Pummer unb ben angegebenten ober ermittelten Dutartinfalt mußs ber Fabrifinfjaber an ben (Serätgen beutlich bezeichnen uno biefe Bezeidjunng gegurig erbalten Iaffen; wie foldse zu bervirfen unb wo fie anzubringen fei, wirb für jebes (Serätl) von ber Steuterbelobrbe be= ftimmt.

\section{3) Amtlide Beideinigung bariber.}

\$. 10. Die Steutrfebeftelle ift verpfliditet, über bie 2 nnmel= bung, Bermefijung uno $\mathfrak{B}_{\text {e }}$ eidjung ber Eeräthe cine Befdeinigung zu ertbeilen. Niur burd folde Befdeinigungen, welde in bem gas

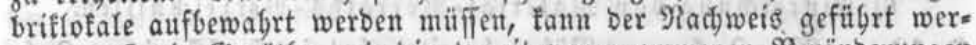
ben, baß bie (Serätţe uno bie Damit vorgenommenen Seränberungen vorfdriftşmäfig angemelbet worben.

\section{4) 2 uffidyt ber Eteuerbebjube.}

\$. 11. a. Die angemelbeten Betriebşräume unb bie barin vorbanbenen

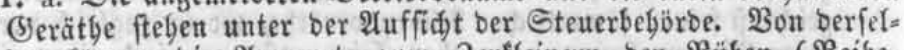

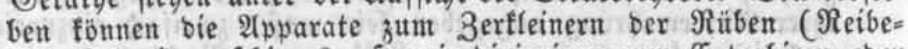
uno Eduneibemafdinen), io wie biejenigen zum (Extrabiren ober

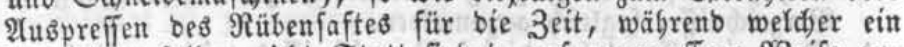
Betrieb berfelben nidyt Statt finbet, auf angemeffene $2 B$ eife au=

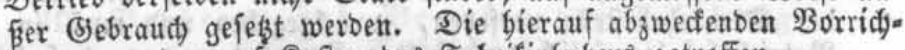
tungen werben auf Soften bes Fabrifinbabers getroffen.

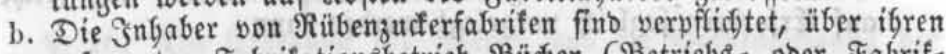
gefanmten Fabrifationsbetrieb $B$ Büner (Betrieb $B=$ ober Fabrif $=$ biid)er), aus welden bie Menge ber verarbeiteten PRiben uno

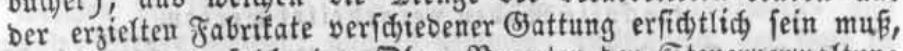
zu füfren und folde ben Dber $=$ Beamten ber Steuerverwaltung

*) Die 2tmeige vou ber 2(nij)affung neter (Scräthe unt vout ben mit bent

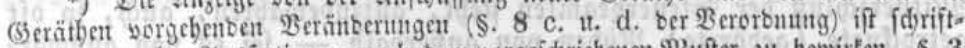
lich in Doppelter 2tusfertigung nad) bent vorgeidyriebenen \$lufter zu bewirfen. \$. 3 D. Snftr. v. 7. etuguft 1846 .

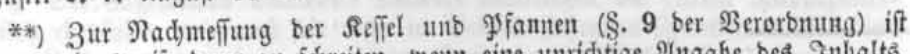

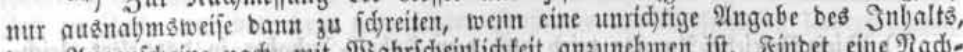

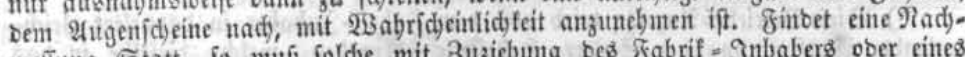

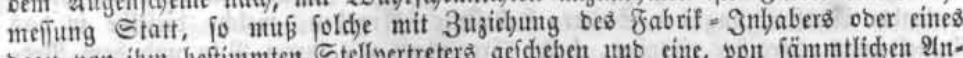

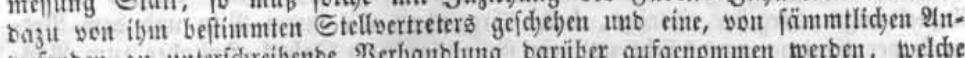
wejenben zu unteridgreibente Berbanblung bariber aufgenommen werben, welde

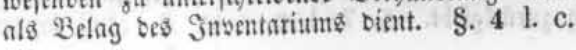


(Dber= ontroleuren, Dber=§nipettoren ober nod böber ftefenben Beamten), fo wie beren $\mathfrak{B}$ ertretern jeberzeit, anbern Beamten aber nur, wenn biefelben baju yon ber भrovingial = Steuerbegöbro befonbers beauftragt finb, auf Erforbern vorjulegen.

\section{5) 2 nuelbung bes Betriebs.}

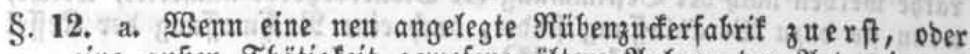
eine auker Thätigfeit gewefene ältere 2Inlage ber Ât wieber in Betrieb gefest werben foll, fo mus ber Snbaber foldees ber Steuerbebeftelle be be Bezirfs vierzefn Tage vor bem mutbmaß̧= Yiđen $\mathfrak{B}$ eginne bes $\mathfrak{B}$ etriebs fdriftlid, anzeigen uno fid von ber= felben eine Befdeinigung Dariiber ertbeilen laijen. Diefe $2 \mathfrak{m}_{\mathrm{g}}$ eige muE zugleid) bie A2ngabe entgalten, $\mathrm{ob}$ unb mit weldjen regelma: Eigen Unterbredungen ber $\mathfrak{B}$ etrieb Statt finben foll*).

b. Befinben fid Berätge unter amtlidem $\mathfrak{B}$ eridiluffe, fo veranlafit bie Stenerbebeftetle, baß̧ fïh ein Beamter jut 2tbnabme beffelben redftzeitig in ber Fabrif einfinbe.

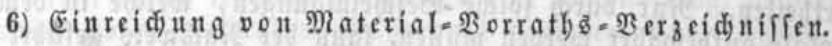

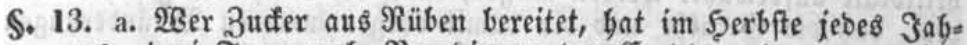
rest, brei Tage nadi) Beentigung ber (Frnote unb, wenn biefe ither ben Shluf bes MRonats November binaus bauern follte, fpäteftens am Yesten Tage bes gebaditen Monats, ber Steuer= bebeftefle ein nad) einem befonbern $\mathscr{D u f t e r}$ anzufertigenoes $\mathfrak{B}$ er.

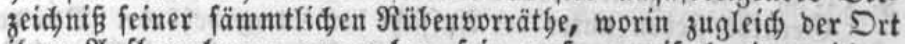
ibrer 2 Anfbewabrung angegeben fein muß $\beta$, zweifad einjureiden, aud jeben fernern 3 ugang an Rïben, zur Nadjtragung in bem Bergeidniffe, fogleid, anzumeloen.

b. Das eine Exemplar biefes Berzeidniffes wirb, mit bem $\mathfrak{D i f a}$ ber Steuerbebeffelle verfeben, juricfgegeben und mus in bem

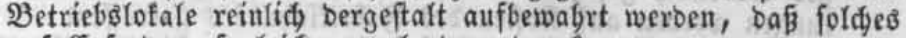
auf Erforbern fogleidi vorgelegt werben fann.

7) Befonbere $\mathfrak{B}$ oridififen für bie $\mathfrak{s}$ abrifen, in welden ge trof nete $R$ ub $b$ en verarbeitet werben.

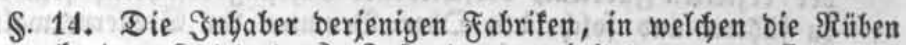
in getrod netem (geborrtem) 3uftanbe verarbeitet werben, fino ver=

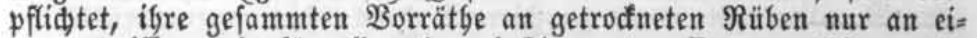
nem gewiffen, ein für alfemal zu beftimmenben Drte, welder unter

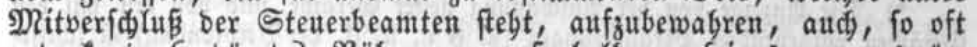
getrocinete (gebörrte) Nitben von auferbalb - fei es von auswär= tigen Trofnungsanftalten oder von britten \$erfonen - bejogen wer=

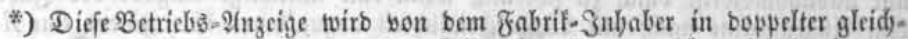
Inutenter 2fusfertigung ber Steuter = Sobeftelle itbergeben, weldje biejclbe in bas 2hmelbungs - Negifter cinträgt, beibe Eremplare mit ibrem $\mathfrak{B i f a}$ uno bem $\mathfrak{B}$ ermerfe ber Eintragung verfiebt uno ein Erentplar bem fabrif = Jnljaber zum 2tuEweije über bie geidjebene Melbung zutridfiebt. \$. 7. 1. c, 
ben follen, ber Steuerbebeftefle foldues fpäteftens am Nadmittage bes vorbergebenoen זages fdriftlid antumelden.

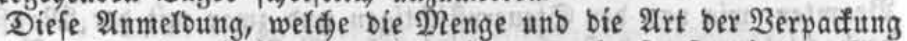
ber eingubringenden $\Re$ itben, ben Drt ilgrer Scerfunft, fo wie bent Tag unb bie Stimbe ber Einbringung enthalten mußi, fann, nad ber $2 B a b l$ bes Fabrifinbabers, entweber für jeben eimgelnen Transport ober für einen längeren Beitraum im $\mathfrak{B}$ oraus gemadt werben.

3ur angemeloeten Stunbe ber Einbringung if bie श्Anfunft eines Steuerbeamten abzuwarten unb in beffen (Segenwart alsbann fogleid) - ie nadbem bie Rüben fofort verarbeitet werben folfen ober nid)t im erftern Falle beren Berwiegung, im anbern Falle beren 2lufnabme

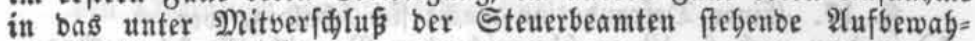
rungstofal zu bewirten.

Sollen bemnädft Rüben, Bebufs ber Berarbeifung, aus bem Aufbewabrungstofale entnommen werben, fo finbet fid ein Stenerbe= amter in ber gabrif ein, um bas Lofal gu offnen unb unter feiner

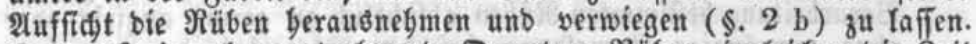
Das auf einmal zu entuebmenbe Duantum $\Re$ üben, ingleiden bie Zeit ber Entnabme wirb für jebe Fabrif, nad Maáigabe des Statt fin= benben 2 etriebs, son ber Steuerbebörbe beftimmt.

8) Berpflidtung zur Befolgung ber Eontrole= $\mathfrak{B}$ oridriften.

\$. 15. Die in ber gegenwärtigen $\mathfrak{B e r o r b n u n g ~ u n b ~ i n s b e f o n b e r e ~}$ in ben vorftebenben 9aragrapben 8-14 ertbeilten Eontrole=2Borfdjriften ift nidjt nur Derjenige, welder bie Zuderfabrifation betreibt ober für feine Rednung betreiben läpt, fonbern aud ein Seber, welder babei bejđäfigt ift, zu beobadten fdulbig.

\section{Bebörben unb Beamten zur Erbebung unb भuffiめt.*)}

\$. 16. Die Erbefung ber Stener uno bie Beauffidytigung ber

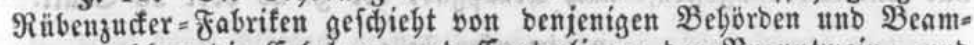
ten, welden bie Erbebung uno Eontrolirung ber Branntweine unb

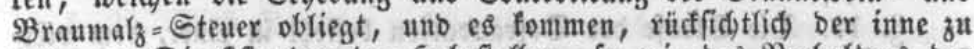
Galtenden Dienftfunben ber 5ebefteflen, fo wie bes Berbaltens ber Beamten gegen bie Steuerpflidtigen und biefer gegen jeue, bie Bora forriften ber $\$ \$$. 56 uno 57 ber Steuer $=$ Dronung vom 8 . Februar 1819 in 9 Anwendung.

๑) Der allgemeinen Bstriebs e (Eontrole unterliegen bie firirfen Rübentzưfer-

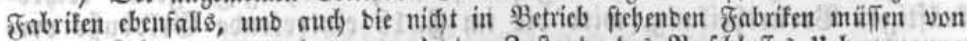
3eit zu 3eit, um von bem unverlebten 3uptanbe bes Derf zu nebmen, befudyt werben.

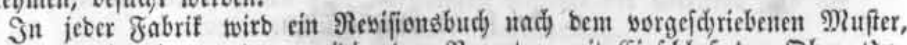

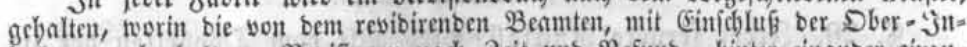
ipeftoren, abgebaltenen Nebifionen uad) 3 eit uto $\mathfrak{B}$ efuno, binter einanber einzutragen fub. \$. 26 u. 27. 1, c. 
Ridyt minber follen bie in ben $\$ \$ S .49$ uno 53 bis einfdflięli 55 biefer Steuer $=$ Dronung entbaltenen $B$ eftimmangen fowoht son ben Beamten, wie von ben Steuerpflidtigen und zwar mit Der Maaßgabe bcobad,tet werben, baß, foweit in biefen Beftimmungen von Brannt. weinbrennern bie Rebe ift, folde auf Diejenigen zu bejieben finb, welde Sưfer aus Rüben bereiten.

\section{Bon ben Strafen un bem Strafuerfabren.}

$$
\text { A. Etrafen. }
$$

1) Etrafe ber Eteuer. Defraubation.

\$. 17. Einer Defraubation madit fid fofuloig, wer

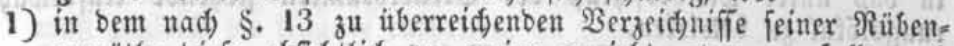
worrätbe biefe abfictlid su gering angiebt, ooer - falls nad) \$. 3 bie Entridtung ber Steuter in fefter Summe zugeftanben worben if 7 bie Menge ber nad bem Firationsyertrage zur Berarbeitung beftimmten Räben abfíttlid gu gering angiebt ober phne oorgängige 2tmmeloung bei ber Steuerbeböroe vermegrt; fermer, wer

2) Da, wo bie Rüben im frifđen Suffanto verarbeitet werben, ber. gleiden Räben, bevor beren (sewidjt amtfid) ermittelt worben ift, in bie 3ertleinerungsapparate aufnimmt ober fonft einer fur 3udergewinmung bienenden Dperation unterwirft; ento lich, wer

3) Da, wo bie Rüben im getroctneten 3uftanbe verarbeitet werben, getrodnete Rüben, bevor beren (Sienwidt amtlich ermittelt worben ift, in bie Extraftionsgefäke bringt ober fonft einer zur 3uter" gewinung bienenben Speration unterwirft poer getroctnete $\Re$ ite ben obne vorgängige 2fmmelbung bei ber Steuerbegörbe in eine Rübenzưferfabrif einfüfrt.

Siann in ben fäflen unter 2 uno 3 ber 2 tingerd)urbigte nadjwei= fent, bá̈ er eine Defraubation nidst Gabe veriben wollen, fo finbet

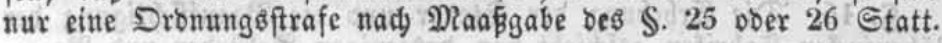

\section{a. im erften falle.}

§. 18. Die Strafe ber Defraubation beftegt in einer, bem vier= fađjen Betrage ber vorentgaltenen Steuer gleidfommenben Belobufie, weldje febod niemals weniger als 10 Thlr. betragen foll.

Die vorentyaltene Steuter felbft ift unabbängig von ber Strafe fut entridten.

\section{b. im erften Mitufalle.}

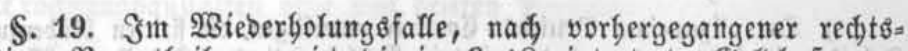

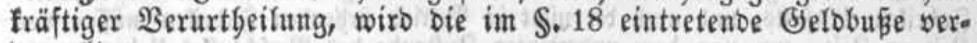
boppelt.

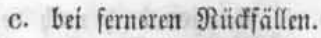

\$. 20. Seber fernere Reüffall wirb mit bem Doppelten ber in

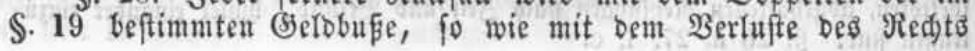




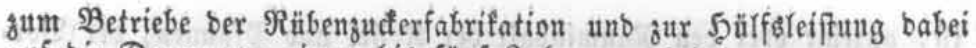
auf bie Dauer von einem bis fünf Jabren geabnot.

d. Etrafe Der Defraubation unter eridfwerenten ttmftänten.

\$. 21. Die Strafe ber Defraubation wiro um bie Scälfte gefdjärft, wenn in ben unter $\Re$ o. 2 unb 3 bes $\$ 17$ gebadten fallen

1) unter amtlic)em 2 erf (Fxtraftionsigefäfe eigenmäd)tig in $\mathcal{B}$ etrieb gefeß̧t, ober

2) nidt angemeloete Serffeinerungsapparate ober Extraftionsigefäpe gebraudst, ober

3) nidit angemeloete Räume fu einer fur Zưfergeminnung bienen= ben Dperation benust worben find.

\section{e. Strafe ber Ibeilunfyme.}

§. 22. Die Strafen ber Piturbeber, Gebürfen u. Begünftiger einer Defrattbation, fo mie Derienigen, weldye an ben Bortbeilen bes $\mathfrak{B e r}=$ gebens nach beffen $\mathfrak{B}$ erübung wiffentlid) $\mathfrak{x}$ geil nebmen, fino nad ben allgemeinen Strafgeichen zu beftimmen.

Die für ben $\Re$ iudfall beftimmte Strafe trifft aber nur biefenigen Theilnebmer einer Defraubation, welde fid felbft eines $\Re$ iuffaffs (d)ulbig gemadit baben.

\section{2) Betedinung ber verfïrzten Steuer unb ber Defraubationefrafe.}

a. wemt unangemelbete (5erätfe umbefugter 23 cife benub̧t worben,

\$. 23. Sinb unangemelbete (5)exätbe zur Bereitung von $\Re u ̈ b e n=$ fucfer benust worben, fo werben bie verfürzte Steuter uno ber $\mathfrak{B}_{e}=$ trag ber Defraubationsftrafe nad berienigen Mienge ber $\Re$ iuben bee red)net, welde wäbrend ber leb̧ten fed) Monate vor bem Iage ber Entbecfung auf bem unbefugter $\mathfrak{B}$ eife gebraubiten (Sierätbe bat ver= arbeitet werben tönnen, in fofern nidat entweber eine gröfsere Steuterverfïrgung ermittelt, ober volffändig erwiefen wirb, Dafí ber Betrieb in ber angenommenen 2 (usbebnung nid)t Statt gefunben bat.

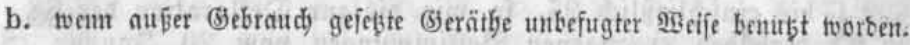

§. 24. Sinb Serätbe, meldje bie Steuerbebibre auß̧er (Sebrauth gefegt batte, eigenmädstig wieber in Betrieb gebrad)t worben, fo werben, unter gleidjer $\mathfrak{B}$ orausfełung wie am Edlufie beł $\mathbb{S}$. 23, bie verfïrgte Steuer uno ber Betrag oer Defraubationgftrafe nad

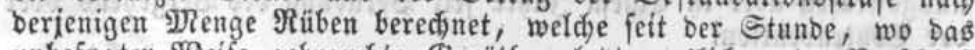

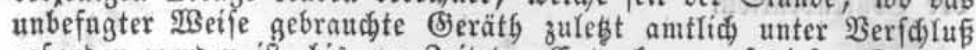
gefunden worben ift, bis zur Zeit ber Entbecfung auf biefem Serätbe bat verarbeitet werben fönnen.

3) Befonbere Strafbeftim mugeri.

a. Strafe ber unterlaffenen ober unrichtigen 21ngeige ber (Geräfbe unb ber unterla|lenen (Serä́fbe $=\mathfrak{B}_{e_{3}}$ eidjunung.

\$. 25. 2Ber bie Jabrifgerätbe ober bie baunit vorgunefmenben

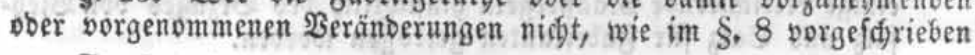

Supplement. 
if, anzeigt ober ben Raumintalt ber Refiel unb 9 fannen, ber $\mathfrak{B}$ or: furift besీ $\$ 8$ zuwiber, zu gering angiebt ober bie im $\$ .9$ vorge= (d)riebene Bezeidjung ber SSerätbe unterlä̧̆t, verfällt in eine Strafe won 5 bis 20 Thlr., welde bei $\mathfrak{W}$ ieberbolungen auf 20 bis 50 I blr. erbögt wirb.

\section{b. Beifrafung fonftiger llebertretutugen.}

§. 26. Die Uebertretung folder, in biefer Berorbnung entbalte-

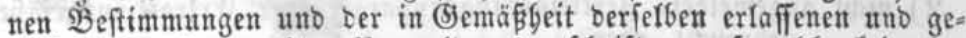
börig befannt gemadjten Berwaltungsvorfdriften, auf welde feine be= fonbere Strafe gefeşt worben, foll mit einer Gelbbuge sou 1 bis 10 Iflr. geabnot werben.
4) $\mathfrak{B}$ erto anblung
(5) clb. in zreifeitsftrafe.

\$. 27. 2Benn eine Belobufie von bem Berurtbeilten wegen feines Llnvermögens nidht beizutreiben ift, tritt an beren Stelle eine ver=

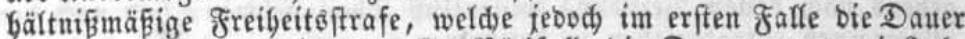
yon einem Sabre, bei bem erften Rüuffalle bie Dauer von zwei Sab. ren unb bei ferneren Rüđffäfen bie Dauter von vier Sabren nid)t überfteigen, bagegen aber im britten ober in einem ferneren アiütfalle nid)t unter einem balben Gabre betragen foll.

5) Sonftige Strafbeftimungen.

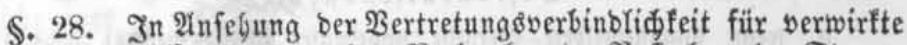
Eelofirafen, ber Concurrenz anbrer Berbredyen, ber 2 eftedung ber Steuter beamten uno ber 23 iberfeßslid) feit gegen leß̧tere gelten bie Beftimmun= gen ber $\$ \$ .83,84$ uno 86 bis einid)liefflid 89 ber Steuer=Dronung yom 8. Jebruar 1819, fo wie ber Deflaration vom 6. Dftober 1821.

\section{B. Straf= $\mathfrak{B}$ erfabren.}

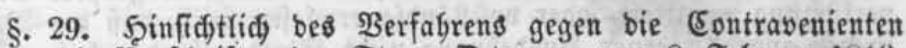
fommen bie : Borfdriften ber Steuer-Drbnung yom 8. Februar 1819.

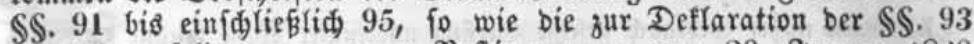
und 94 berfelben ergangenen Beftimmungen vom 20. Januar 1820 uno 27. September 1833 zur 2 unwendung.

\$. 30. Die burd biefe Berorbnung für bas $\mathfrak{B}$ ergeben ber De= fraubation beftimmten Strafen verjäbren in fünf Sabren, bloke Dro. nungsftrafen aber in Einem Sabre feit Beribung Des Bergebens ober Der Eontrabention.

\section{Seite 287, zu शrote 1 c.}

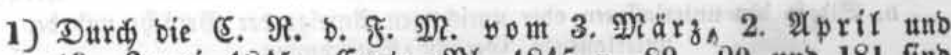

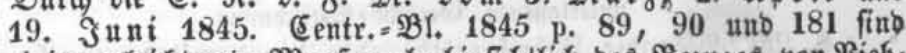

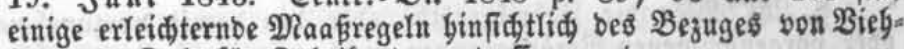
falz und Salz für gabrifanten getroffen worben. 
2) (5 R. unb Befanntma 4u

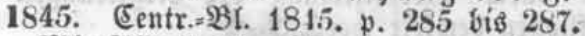

Mit Afferbödfter (5ienebmigung ift ber Yreis für bie Tonne

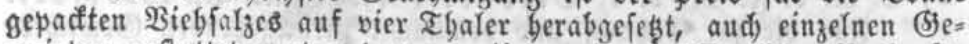
meinben geftattet worben bas von ifnen aus ben öffentliden Berfaufï = fteflen entnommene $\mathfrak{B i e b f a r}_{3}$ burd zuberláffige gerfonen weiter an Bemeinbe $=2$ Angebörige abzufeßen $\mathcal{D}$ as $\mathfrak{B}$ iebfal wiro aber nur zum (5) bie Rab.-Drore vom 21. Suni 1838 beftimmten $\Re$ ügen nid)t auf anbere Art verwentet werben. Die allgemeine 2 uffift tiber bie $\mathfrak{B e r}=$ wenbung ftebt ben Steuerbeamten ju, welden auf Erforbern bie nö= tbige 2ubfunft gegeben werben muß; bie mit bem 2 erfaufe an bie

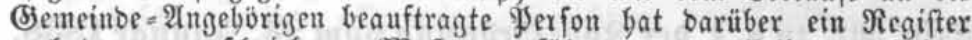
nad) bem vorgefdriebenen $\mathfrak{R}_{\text {ufter }}$ zu fübren und baffelbe ben $\mathrm{Dber}$ infpectoren uno Dbercontroleuren jur Einfid, vorzulegen refp. nad)

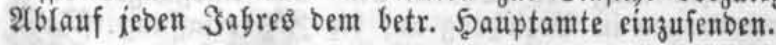

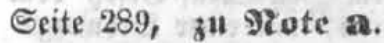

Itnter ben zoflvereinten Staaten ift in $\mathfrak{B e r f o l g}$ ber $\mathfrak{M}$ änzconben: tion vom 30. Suli 1838 aud ein $\mathscr{P}$ ünzcartel unter bem 21. Dftober 1845 abgefdilofien worben (5). S. 1846 p 47 $)$, wonad fid bie contrabirenden Staaten gegenfeitig verpflichten ifre 2 ngebörigen we= gen eines Münzvergetsens gegen einen andern ber contrabirenten Etaaten eben fo zu beftrafen als weun bas $\mathfrak{B}$ ergegen gegen bas cigne Münzregal begangen wäre. Dies beziebt fid aud) auf bie Stantşe fdulbfdeene ober anbere Dergleidjen iffentlidbe Yyapiere. Unter ge= wiffen Mobificationen ift gegenfeitige 2usfleferung ber Berbred)er verabrebet. Für bie Dauer biefes mit ber $\mathfrak{M}$ ünzconvention vom 30. Suli 1838 ablaufenden Mänzcartels ift burd bie $R a b .=D$ rore vom 26. September 1846, (5). S. 1846. p. 477, in Bezug auf bie verbunbenen Etanten, ber in ben Ireufifden Strafgefezen ge=

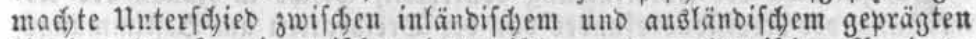

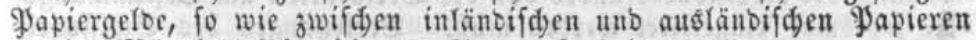
Der im Rünztartel Eejeidueten 2 rt, aufgéboben worben.

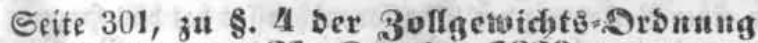 vou 31. Sctober 1839.}

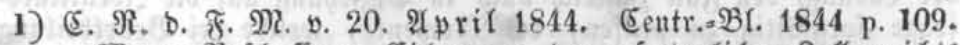
23 egen $\mathfrak{B}$ cidjaffung, Eidung zc. ber erforberlid)en Bollgewidte foll bie Rormal $=$ Eid)ung $=$ (Eommiffion in Berfin nid)t ferner requi= rirt werben, aud) foff bie Befdaffung ber (Bewidgte überbaupt nidyt

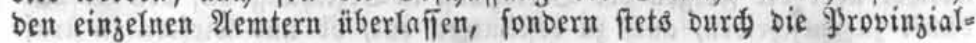


Steutrbeförben, event. burd, Bermittefung ber Regierungent ober grov. Eidungto- Eommiffionen bewirtt werben.

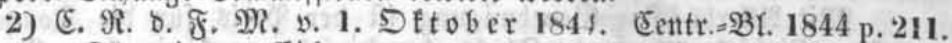

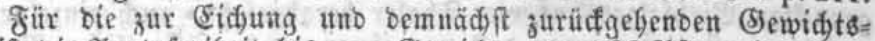
ftüfe if bie भyortofreibeit bis zum (Sewid)te von 200 \$fo, mit einer Sopt bewilligt, wenn bie Gewwidgtsfticte nidjt blos fonoern poftmä́big

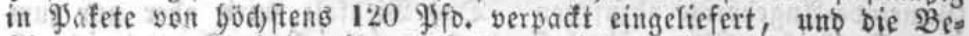

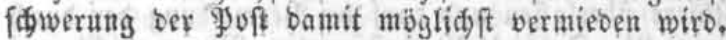

\section{Seite 302, 3и 8. I Der 3olf=Dronutg vout 28. Januar 1838.}

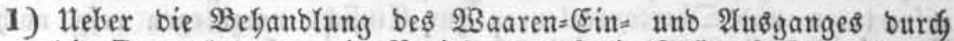
bie Doermünoungen in Bezichung auf bie 3ollverfafifurg ift von bem Fin. =Ninifterio bas Regulativ vom 31. Januar 1846 Eentr. $=$ Bi. 1846. p. 171 sq. erla jen, worin $\$ .70$ beftimmt

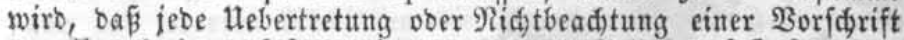

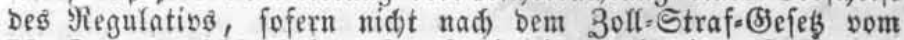
23. Sanuar 1838 bojgere Strafe eintritt, mit einer Drbunngsz ftrafe von 1 bis 10 Iffr. gealunbet werben foll.

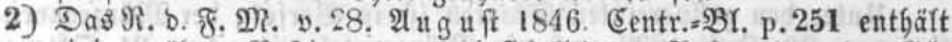
einige näbere Beftimmungen binfidutliđ ber Bebanolung bes (3)its tertranģ:ortes unb ber 23 aarenabfertigung auf bem interbalb

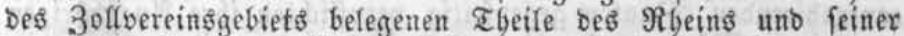
conventiwnellen Mebenflüffe, mit Bezug auf bas biefen Begenftant im Affgemeinen betreffende $\Re$ egulatio vom 15. December 1841 unb bie 3nftruction vout bemfelben $\mathfrak{x}$ age, Sentr. 2Bl. 1842. p. 2 .

Rad) biefem Regulatio ift bas Duplicat bes Manifeftes

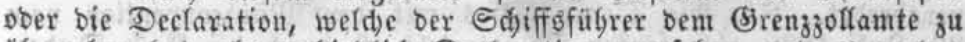
iibergeben bat, als verbinblidje Declaration anjufeben, uno es werben

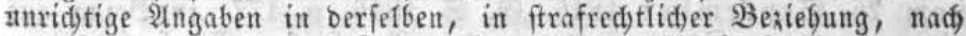

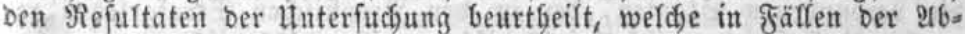

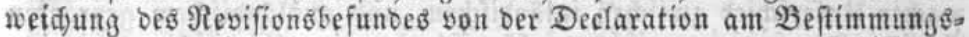

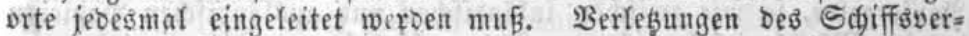
fd)Luties, weldje olne $\mathfrak{B}$ erbinbung mit anberen, bober zu beftrafenben Bergegen Statt gefunben baben, werben, wenn nidgt glaubbaft nad)= gewiefen werben fann, baß fie burd 3ufaff entftanben, mit Dronumg,

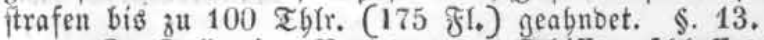

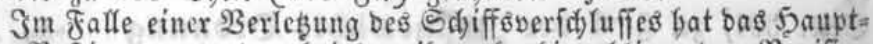

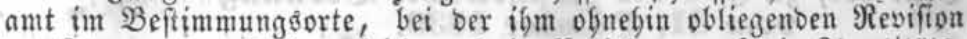

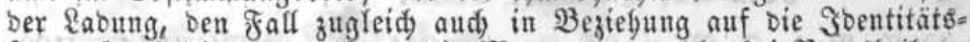
frage forgfältig zu prifen, bie Momente, weld) bei Beurtheiluth biefer grage in Betradt fommen, zufammentufteffen, unb fofort an ben Srovinzial = Steuer $=$ Direftor erfdoppenden Beridjt zu erftatten, welder über bie Folgen ber Derleşung in Besiefung auf ben (Befälles punft zu entfideiben, aud) zu beftimmen bat, ob uno wiefern in ftraf= 


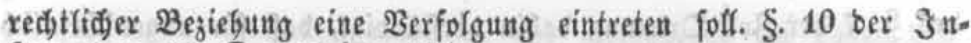
ftruct. v. 15. December 1841 .

$2 B$ enn wegen anberer 3 umiberganblungen blop eine Dronungs= ftrafe zu erfennen ift, fo fann biefe uno bie Drbnungeffrafe wegen ber $\mathfrak{B}$ erffflufperfeģung in einer, bas Maximum von 100 Thlr. (175

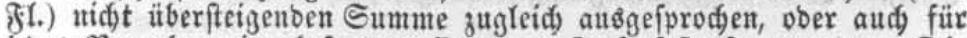
iebes $\mathfrak{B}$ ergegen eine befonbere Dromungsffrafe feftgefęt werben. Die Begörben müffen bei Fefteesung von Dronungsftrafen wegen $\mathfrak{B e r}=$ fđlufperleģungen ben 3wedf berferben gebörig im 2 tuge baben. Sie

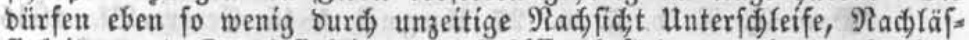
figfeiten unb Sorglofigfeiten ber Sdiffer beförbern, als burch tiber= mäpige Strenge in Sallen, welde eine milbe Beurtbeilung zuIaffen, ber wünfdenswertben allgemeinen (Einrid)tung ber Sdiffe zum $\mathfrak{B}$ ber: fd) luis entgegen wirten. l. c.

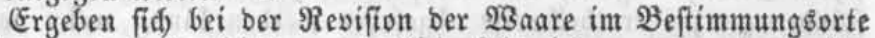

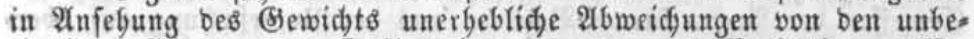
ridtigten 2 tngaben ber Deffaration ooer won ben Beridjtigung $8=E_{r}=$ flärungen, fo foll bešbalb feine $\mathfrak{B e r f o l g u n g}$ in frafredytlidjer $\mathfrak{B}$ egies bung eintretell.

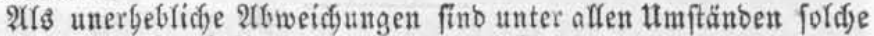
angufeben, weldje zwei - orocent nidft überfteigen.

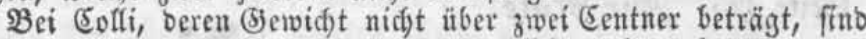
20weidungen bis ju 5 grocent als unergeblid) zu betradisten,

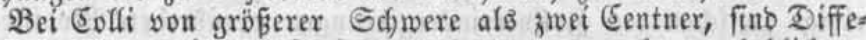
renzen zwifdeen zwei uno fünf Yrocent nur bann als unergeblich zut

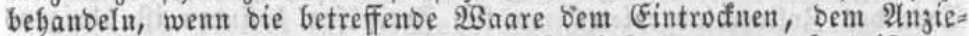

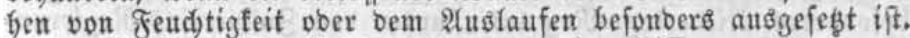

Entifeben 3 weifel barüber, ob eine Differenz als unerijeblich angufegen fein mö́de, fo entíd eibet ber Dber-Snfpeftor.

Dem Dber=Snjpettor ftebt überbaupt bie Befugníz zu, in affent

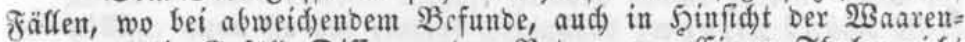
(Sattung, bie Befäfle=Differen? ben Betrag, von Einem I Taler nidt iiberfteigt, nad) bilfigem (Ermeffen bas Strafverfabren zu fuşpenoiren. \$. 13. 1. c.

Die 5auptämter in 3wifdenorten, bei welden thnridgtigfeiten in ber urfprüngliden Deflaration entoectt werben, Gaben, bei fefts feellung bes Tlyatbeftanbes uno bei ben weiteren 30 orfegrungen zur

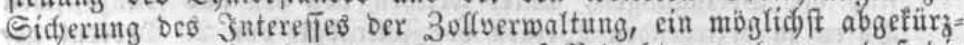
tes Berfabren einjulgalten, uno barauf Bedadjt ju negmen, Daß bie betreffenben $2 B a a r e n$ uno bie aufgenommenten $B$ erfandlungen fobalo nur immer thunlifi an bas, zur weiteren Befandiung ber Sadje com= petente 2 mt bes̉ Beftimmungsort gelangen. §. 14. 1. c.

\section{Seite 305. 3u \&. 7 Dex 3 oft=50buนng vout 23. gnuนar 1838.}

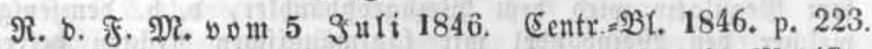

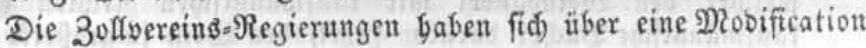


bes $\$ 7$ ber $30 \mathbb{l l}=$ Dronung babin verfänbigt, baß für augenfd)einliđ nid̆t zum Sgandel beftimmte zollpflidige (Segenftänbe, weld)e bie auf

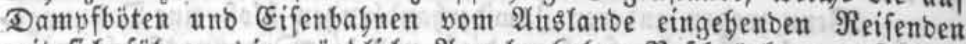
mit fid) fübren, bie münolide 2 ngabe (obne Befơränfung auf einen gewiffen Zollbetrag) als genügend angefeben werben faun.

\section{Seite 317. 3u \$. 15. Der 3ollorsmung.}

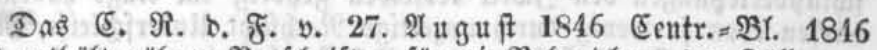
p. 250 entyält näfere $\mathfrak{B}$ orfdriften für oie Bebanolung ber Fäfle, wo

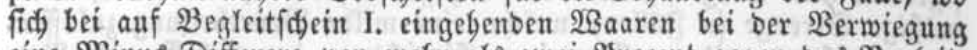
eine Minus-Differen; von mefr als zwei 9rocent gegen bas Begleit=

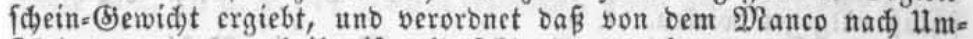
ftänben ganz ober theiflweife abgefefen werben fann, wenn nad bem Ermefien ber Yrov.= Stetter=2Behorbe aus ber Unterfutdung auf über=

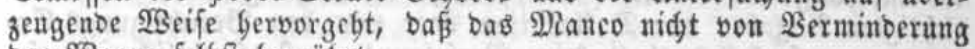

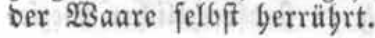

\section{Seite 325. 3ur viote.}

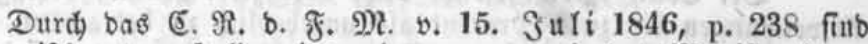
einige zwifd)en ben 3ollvereinstegierungen verabrebete Mlobificationen bes alfgemeitten Rieberlage = Regutfatios befant gemadt. Für bie Drte bes 3offvereing̈gebietes wo fidg Freigäfen befinben ift übrigens

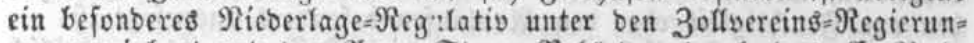

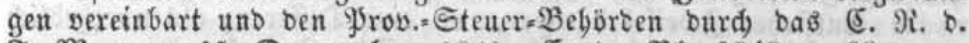
ף. MR. bout 15. Dejember 1841, Eentr.=BR., 1842 p. 69 juge= fertigt worben.

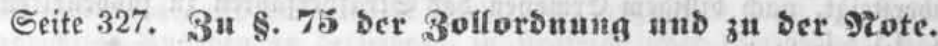

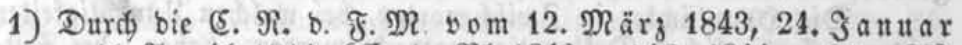
u. 16. Aprif 1814 (Eentr.=21. 1843 p. 142. 1844 p. 21 u. 85) fint bie $\mathfrak{B}$ ebingungen, unter weldgen von ben aut frangöfifdjen

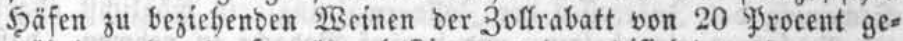
wäbrt werben barf, näber beftimunt uno mobifizirt worben.

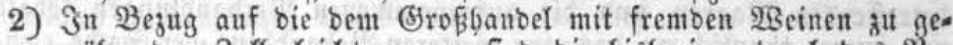

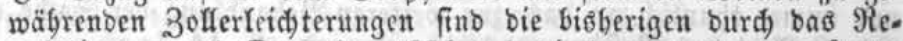
gulativ vom 24. Dezember 1824 unb bie bagu ergangenen fpätes ren Beftimmungen ertbeilten $\mathfrak{B}$ orifdriften anberweit rebigirt uno

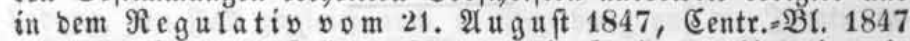
p. 124 zufammengefteflt, weld)es an bie Stetle ber bisgerigen in

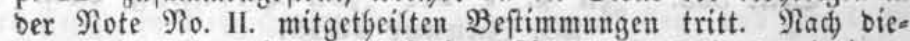

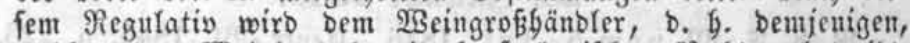
welder ben 23 einfanbel mit faufmännifden Red)ten betrcibt,

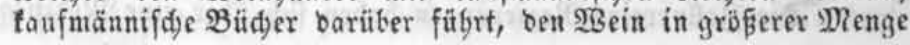




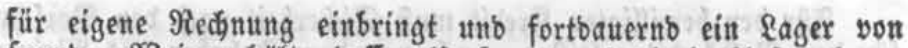
fremben $2 \mathcal{B}$ einen bält, beffen $u$ mfang burd Die in 2 nfpruth ge= nommenen Bugeftänonifife bebingt wirb, gewiffe Erfeidterungen gewäbrt, welde befteben:

1. für ben zum 2 b fał̧e innerbalb bes Zollvereinsgebiets beftimmten $\mathfrak{B e i n}$

a. in einem Erlaffe am Eingangs-30lle, fo wie

b. in einem fortlaufenten (eifernen) 3ollfrebit von eiter be: fimmten Menge 28 ein burd 2 ewilligung eine Rrebitlagers, uno

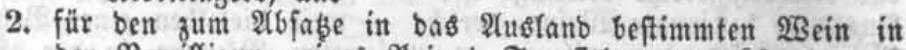
ber Bewilligung eine\& \$rivat = Tranfit lager及. (\$. 1 u. 2 Des Reg:)

Der 3oll= Erlá̧ beträgt entweber:

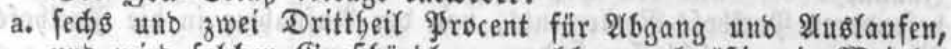
unb wirb fold)en Grob́bänblern, weldje regelmäß̈ig ein 2Beinla= ger von minbeftens 60 Drgoft 2 Bein tiberbaupt - fei es ver=

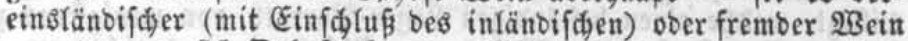
- Doer von 25 Dxhoft fremben $2 B_{e}$ ins balten, bann gewäbrt, wenn fie gemögntidgen $2 B$ ein in einer $\mathfrak{M}$ enge von ze $n$ Dxhoft, ober

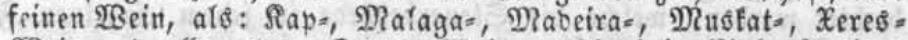
2Bein unb afle anbere Sorten 2Bein, weldse beim Einfaufe einen

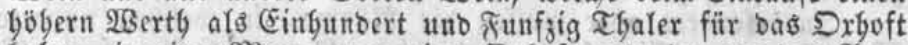
baben, in einer Menge von vier Drboft entweber auts bem 2 lus $=$

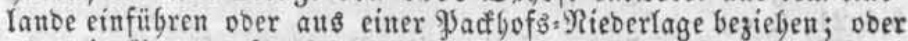

b. zwaltzig Wrocent fitr 2tbgang, Aluslaufen, Einzelrung uno Sał, unb wirb benjentigen (Brofobanolern, welde regelmäßig ein 28 eins lager you minbeftens 120 Drlyoft $2 B$ ein übergaupt - fei es ver-

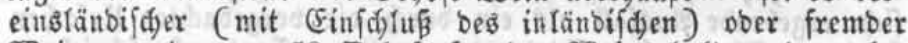
2Beit - Dber yon 50 Drbuft fremben $2 B e i n s$ balten, bann be $=$ wifligt, wenn fie auf einmal wenigftens zw anzig Drgoft $\mathfrak{B}$ ein

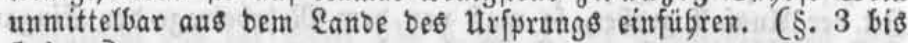
5 l. c.)

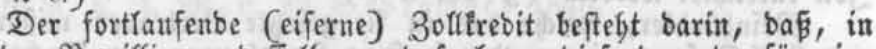
Folge ber Bewifligung beffelten uno fo lange biefe bauert, für eine

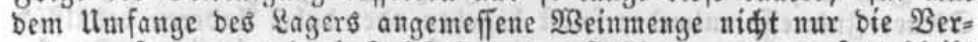

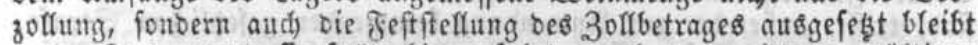
itno erftere, went fie fpäterbin erforgt, nadi bem alsbaun gilltigen 3olltarife zut Teiften ift.

Bon affen 23 ein, welden eine Shanblung hiber ben igr bewillfigten eifernen Sirbitbetrag Ginaus cinfüfrt, mufi, in fofern nidst geitweife cine Errbobung biefes Rrebitbetrages angeftanben wirb, ber Eingangs= 3oll fofort entrid)tet werben, wobei jebod) bie Bewilligung bes ges wöfnlidjen (selbfrebits (nad) ben bafür beftelgenben Borfdjriften) nidt

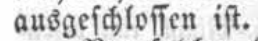

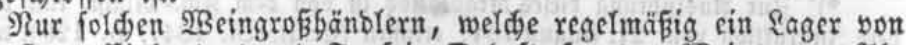
minbeftens Cinfunbert unb ₹unfig Dxboft fremben $2 B$ ein faķe im Bereing gebiete yarten, fann ein fortlaufenber (eiferner) Rrebit bewilligt werbert. (\$. 9 u. 10 l. e.) 
Für ben bewilligten Rrebit muß Sidgergeit nad ben $\mathfrak{B o r}[$ driften für ben Selbtrebit geléftet, aut yon bem 3ngaber bes 2 Beinlagers

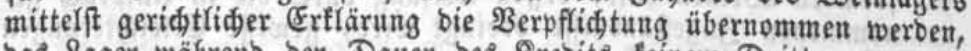
bas \&ager wäbrenb ber Dauer bes Rrebits teinem Dritten ju ver' pfänben.

Die Refler utub fonftigen Plufbewabrungsorte, fowie beren $\mathfrak{B} e r=$ änberungetr müffen ber Steuterbegörbe jebesmal fífiftliđ angemelbet werben. ( $\$ .13$ u. 14.1. c.)

ISein=Tranfittäger fint unverzollte Srivatfäger an Drten, benen bas Rieberlageredht berwilligt ift, für folde, zum 2rbfaß̧e nad bem IutGanbe beftimunte $2 B e i n e$, weldye - weil biefelben einer Befanb. fung bebürfen poer weil $e s$ an geeigneten Raumen in ber offent*

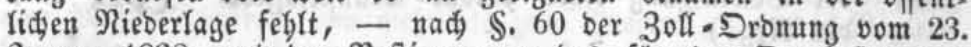
Samuar 1838 uno ben Beftimmungen beß für ben Drt beftegenden

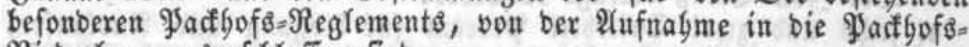
Rieberlage ausgefdilofien fint.

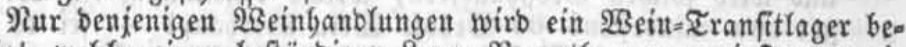
willigt, welde sinen beftänbigen \&ager=2orrath von wenigftens 3 wei=

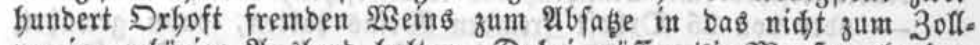

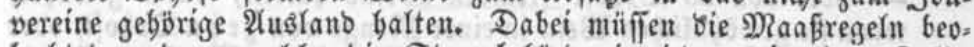
badjtet werben, weldse bie Steuerbebörbe in jebem eínzernen Falfe,

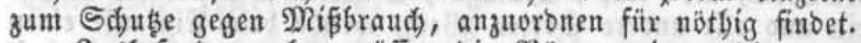

Snsbefonbere aber müffen bie Räume, in weldjen unverzollter I3ein lagert, böllig abgefoubert unb wobl verfd́ließ̧bar fein. (\$. 19 bis 21. 1. c.)

Bei ben Tranfitträgern wirb eine $\mathfrak{B}$ ergütung für ben, burd) Sab̧,

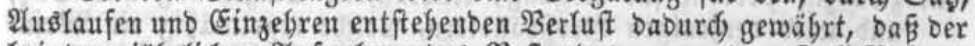
bei ber jäbrliden 2ufnalyme bes Beftanbeß gegen den Soll-Beptano fid) ergebenbe 2 tusfall als ein burdi bie vorgebaditen $\mathfrak{H} r$ fadjen ent=

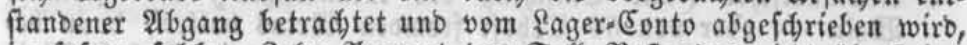

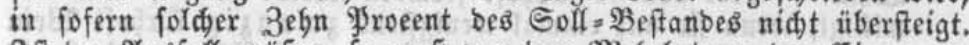

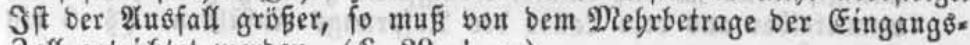
3oll entridutet werben. ( $\$ 29$. 1, c.)

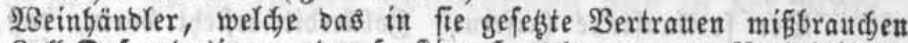
unb $30 \mathbb{f l}=$ Defrautbationen ober forfitige 5aanofungen zum Rachtgeil bes Eteuter='sntereffe entweber ferbft begefen ober babei 2unberen beguifflid fint, trifft, aufer ber zur 2 Anmenoung fommenben gefegzliden Strafe, ber $\mathfrak{B}$ erluft ber Befugniffe uno 2 bortgeile, weldje bas gegenwärtige Regulatio gewäbrt.

Die lekste Folge baben aud Diejentigen zut getwärtigen, welde ben $\mathfrak{B}$ oridgriften biefes $\Re$ egulativg zuwiber banoeln ober bie barin aufgeftellten $\mathfrak{B}$ ebingungen nid)t erfüllen. (\$. 34. 1. c.) *)

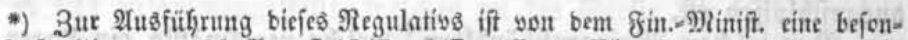
bere Snftruftion voun 21. Iuguft 184? erlafien (5entr.-91. 1847, p. 129), weld)e bie näberen $\mathscr{U}$ nweijungen für bie Steuerbenmten zur Bebanblung bes (5egenftanbes entbältu. im \$. 25 befonbers anorbnet, baß̄ alle fopfen, weldje entfteben, um eint zelae $23 e$ einbänbler in ben (5)enti ber burd) bas Regulativ zugeftanbenen Bor- 


\section{Seite 364. 3u III. Den 30Iltarif betreffenb.}

1) Dittelft $R a b .=$ Drbre vom 10. Detober 1845 (B). S. $1845, \mathrm{p} 605$ ) ift ber für bie Saffre 1846,1847 unb 1848 gül. tige 30 oftarif publicirt unb ben 9 rov.- Steuter=2Bebobroen burd) bas

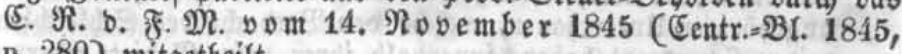
p. 280) mitgetbeilt.

2) Mobificationen bes 3olftarifs uno ber barin entfyaltenen 3olfs fäßze finto eingetreten burd:
a. bie Rab.=Drore vom 10. Detuber 1845 , (5. S. 1845 p. 655.
b. Den 2ertrag vom 16. Detober 1845, (5. S. 1845 p. 707.
c. bie Rab.=Drbre yom 24 . Rovember 1845, (5). S. 1845 p. 748.
d. bie Rab.- Drore vom 28. Detwber 1846 , (5). S. 1845 p. 465.

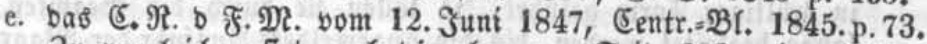 3u vergleiden find aud bie vben zur Seite 283 mitgetbeilten Rab.

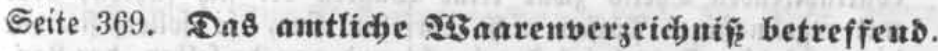

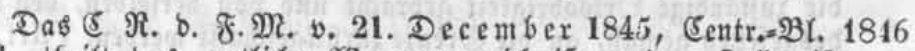

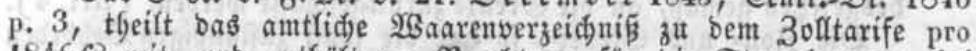
$1846 f_{8}$ mit, unb entbält sour 2 ead)tung für bie Steuterbeanten bei

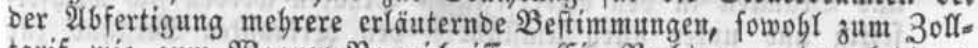

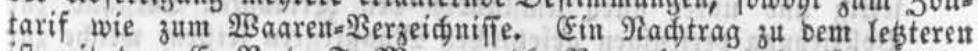

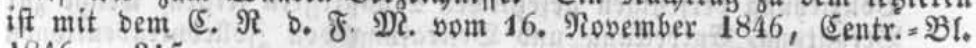
1846 p. 315 , ergangen.

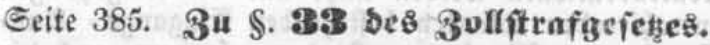

Fergleidfe bas zur Seite 134 \$. 93 c. ber Steuterorbmung mit=

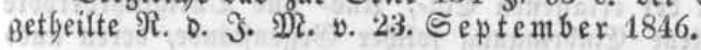

\section{Seite 398. 3ur uebereinfunft vom 1. Movbr. 1837.}

1) 3wiffien Yreupen, Braunfdweig unb ben äbrigen Staaten bes 3otfvereins einerjeits uno 5annover uno ben ifbrigen Staaten Des Steuervereins anbererfeits ift unter beut 16. Detober 1845. (5) ธ. 1845 p. 289) eine anberweite $\mathfrak{H e b e r e i n f u n f t ~ z u r ~} \mathfrak{u} n t e r=$ brüđung bes Sdileidgandels getroffen werben, welde mut. mutand. biefelben Beftimmungen entfălt wie bie oben allegirte.

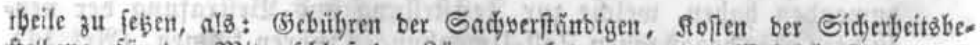

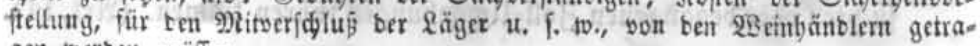
gen werben mülifen. 


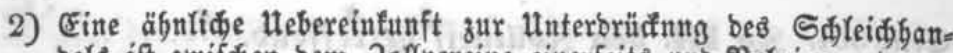
bels ift zwifden bem 3oflvereine einerfeits und Belgien anberer= feits unter bemt 26. Эun ni 1846 ((5). S. 1847. p. 5.) getroffen worben. Sn biefer thebereinfunft verpfliden fid bie contrabi= renben Theile wedfelfeitig bie bem anberen contrabirenben Theile angegbrigen Untertbanen, welde ben $\mathfrak{B}$ erbadyt bes Sd) IeidGanbels wiber fin erregt baben, innerbalb igrer refp. Sebiete iiberwaden ơt Yaffen.

Demzufolge folfen Untertbanen bes anberen contrabirenben Theils, wenn fie $\mathfrak{W a a r e n}$ ofgne gefestiden 2 Austweis transportiren, beim $B$ etreffen burd bie $30 \mathfrak{o l}=$ und Steuerbeamten angebalten unb bie Gefeste bes ganbes, wo fie betroffen worben fint, gegen

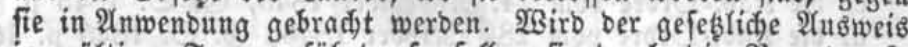
in guiltiger form gefülyrt, fo follen fie burd) bie beamten fo

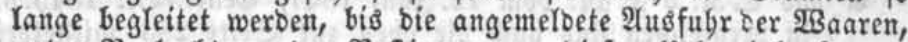
unter $\mathfrak{B}_{\text {eobadjtung ber }}$ Beftimmungen biefer Hebereinfunft, gefdeben ift.

$B$ enn bes Sdileidganbels verbäd,tige Untertganen bes anbern contrabirenton Theils zwar teine $\mathfrak{B}_{\text {aaren }}$ bei fidy fübren, aber mit regelmäßigen Yäffen nidgt verfegen fint, fo folten fie vor bie zuftänbige Drtsobrigfeit gebrad)t unb von berfelben, ben \&ane

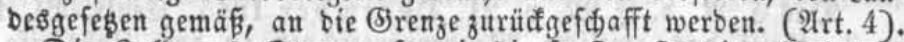

Die 3oll= uno Steuer=, fo wie bie fonft zuftänbigen Beljürben unb Beamten in ben beiberfeitigen Etaaten werben fid wedffer. feitig uno unter alfen $\mathfrak{u m f t a ̈ n b e n}$ ben verfangten $\mathfrak{B e i f t a n b}$ zur

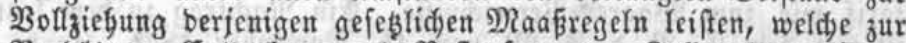
$\mathfrak{B}$ erbitung, Entbectung uno Beftrafung von Zoflcontraventionen bienlidy fint, bie gegen einen biefer Staten verfudit ober be= gangen werben.

Hunter Boffcontraventionen werben nidt nur bie Hmgefungen ber in ben contrabirenben Staaten beftegenben (Eingang $8=2 \mathfrak{A t}^{8}=$ gangs: unb Durdgangs= 2Abgaben verfanben, fonbern aud bie

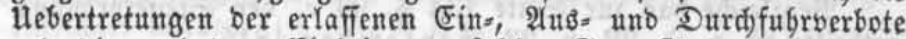
unb bie verbotene Einbringung foldfer Bsegenftänbe, beren auss (d)liefliden Debit bie Regierungen fid vorbebalten baben, wie z $\mathfrak{B}$. von $\mathrm{Sal}_{3}$ unb Spieltarten in grreuken. Şierbei verftebt es fid won felbit, bafi bie $\mathfrak{B e r b o t e}$ ber lebtgebaditen (Begenftänoe ofme $2 B$ irfung bleiben, wenn uno foweit bie Regierang bes be= tyeifigten Staates bie Einbringung ber gebad)ten Eegenfänbe unter gewiffen $B e b i n g u n g e n$ geftattet. (2rt. 9)

Die vorgebaditen Beforben unb Beamten follen insbefondere beredtigt fein, bei $\mathfrak{B}$ erfolgung won Sdileidflänblern ober von Spuren begangener $30 \mathfrak{d l}=\mathfrak{l l m}$ gebungen, fid) auf baj angrenzenbe (3) ebiet bes andern contrabirenben I beils ju begeben, um bie bor=

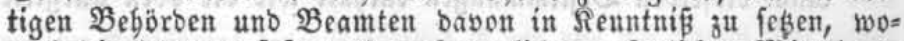
nadi bie letgteren fofort alle erforberliden gefegliden $\mathfrak{N i t t e l}$ ane zuwenben baben, welde zur Feftitellung uno Beftrafung ber ver=

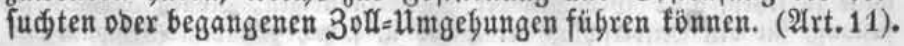


Der im Artifel 9 erwähnte Beiftanb ber Bebörben beiber TGeile zur Entbeđ̛ung ober Unterbrüđung ber 3oll= Eontraben= tionen begreift namentlid bas SammeIn aller Beweişmittel bea züglich ber voffbraditen ober verfudjten 3olf. ltmgefung zu bem Zwede in fid, um beren $\mathfrak{B}$ erfolgung burd bie Beridt bes Lanbes, in weldem fie begangen worben ift, zut erleidtern.

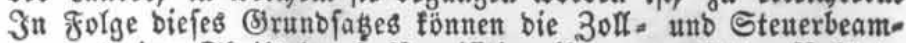

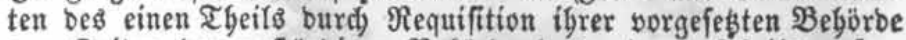

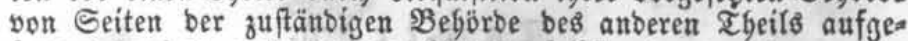
forbert werben, entweber vor leşterer felbft, vber vor ber compea

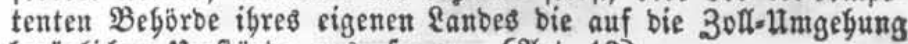

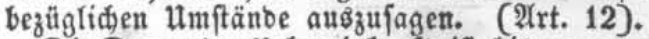

Die Dauter ber $\mathfrak{H}$ ebereinfunft ift bis zum 1. Santar 1851 unb bemnädffit im Falfe ber nidst erfolgten Riübigung von einem Sabre zum anberen feftgefest. (2irt. 16).

Seite 403. 3ur Befountmadung vou 13. Dec. 1841.

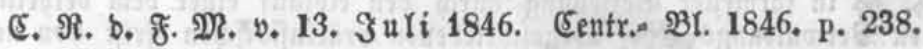
Einer Hebereinfunft unter ben 3ollvereings Staaten gemä̈B wiro won Frudtfäften, benen Branntwein nur zum 3weđfe ber Ergaltung beigemifidt if, teine Hebergangsostbgabe erboben. 


\section{sta $\boldsymbol{a} \boldsymbol{t} \mathbf{r} \boldsymbol{a} \mathbf{g}$.}

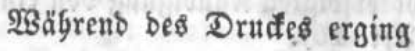

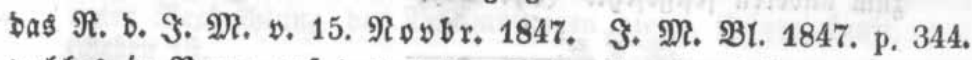
weldes in Befug auf bas (oben Seite 5) mitgetbeilte Befę vom 8. 2Aprit 1847 Eompetenz= Eonflicte betreffeno, beftimmt:

Die Entídeibung bes im $\$$. 1 erwäbnten Beridtsbofes fei nad $\$$. 13 in formefler $\mathfrak{B}$ eziegung burd, ben 26 laut einer bem betbeilig:

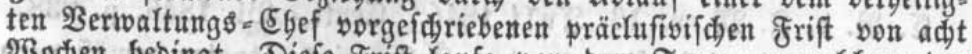
230 den bebingt. Diefe Frift laufe von Dem $\mathfrak{T a g e ,}$ an weldem ber Berwaltungsbegjobre bie zuleßgt eingegangene Erflärung ber \$arteien,

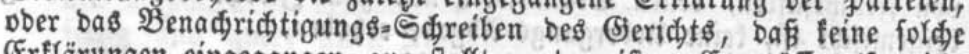
Erflärungen eingegangen, zugeftellt worben ift. (E's múffe alfo nid)t nur ber 26 lauf ber Frift, welde ber YJartei zur Erflärung inber ben Sompeten $z=$ Conflict beftimmt worben ift, zu ben 2 ften angezeigt, fon= bern aud in beiben fä̈len, wenn eine Erftärung und wenn feine eingegangen fei, ber $\mathfrak{T a g}$ ber int $\$$. 6 vorgefdriebenen Dittbeilung ber Creflärung an bie betreffende $\mathfrak{S e r w a l t u n g s b e b o r b e , ~ o b e r ~ i n ~ b e r e n ~}$ Ermangelung, ber vorgefdriebenen Benadjridtigung, zu ben थften befdeinigt fein.

Die 2 nwenbung auf bas in ber $\Re$ geinproving zu beobady. tente $\mathfrak{B e r f a b r e n}$ ergebe fid aus bem $\$$. 8 bes Befeses yon felbft. 
Chronologifores :isgifter.

\section{4.}

Esite

รnftr. v. 30. Эuni .............. 83

\section{1.}

Rab.=5rbre v. 24. März . ........ 71 Regul, v, 15. Decbr. . . . . . . . . . . . 100 Snftr. v. 15. Decbr.

\section{8.}

Rab.= \$rbre v. 15. Ipril . . . . . . . 3

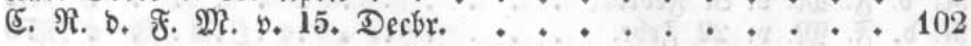

\section{3.}

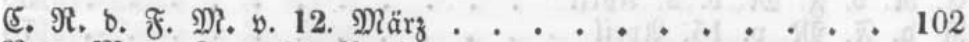

$\Re$ ๖. M. ๖. $\Im$ v. 27. Roubr. . . . . . . . . 3

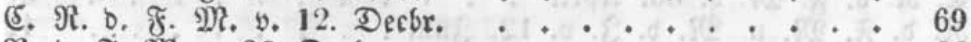

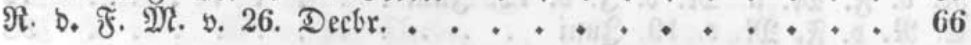

\section{4.}

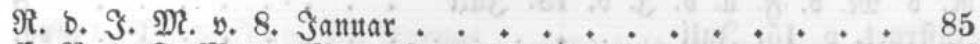

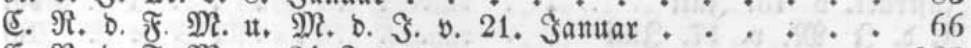

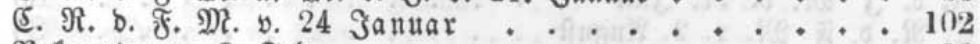

Befanntm. y. 8. Febr. . . . . . . . . . 29

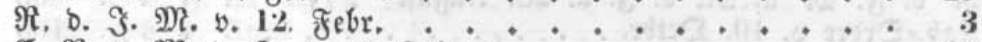

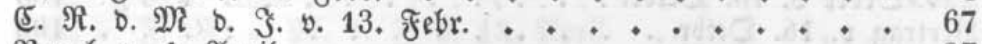

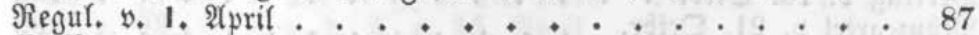

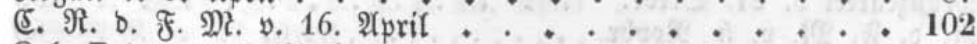
$\Re_{\mathfrak{a} b}=$ Drbre v. 19. $\mathfrak{A}_{\text {pril }} \ldots \ldots \ldots \ldots$

Supplement. 


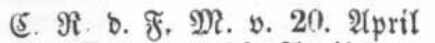

Rab, D Drore v. 26, April .

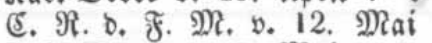

Sab.=Drore v. 25. Mai

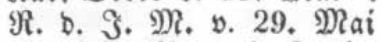

85 $\Re$ o. $\mathfrak{J}$ M. v. 4. Эuni 凡ab.,Drore y. 1. Juli $\Re a b=$ Drore v. 5. Auguít. R. ๖. 3. M. v. 12 . $2 u g$. $\Re a b=$ Drore v. 14. Septbr.

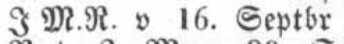

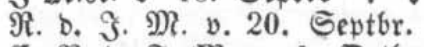

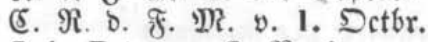
$\Re a b=$ Drore v. 8. Novbr.

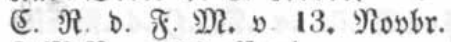

\section{18.5.}

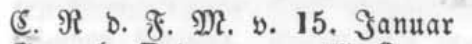

(j) werbe $=$ Dronung v. 17: Sanuar

(5) fes v. 17. Şanuar.

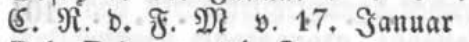

Rab.= Drore v. 24. Samuar

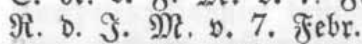

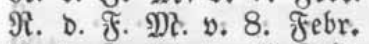

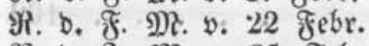

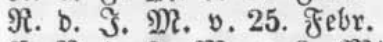

83

82

70

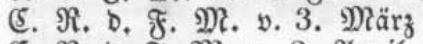

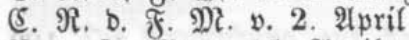

$\Re$ ○. F, פR. v. 15. Alpril

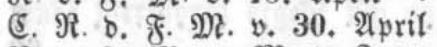

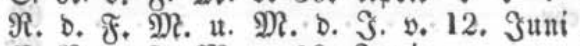




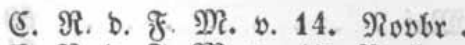

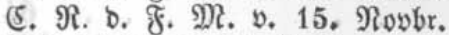
$\Re a b=$ Drore v. 24. Rovbr.

105

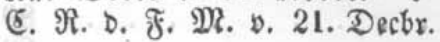

\section{6.}

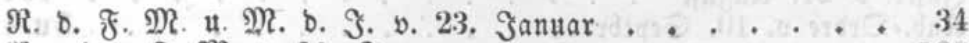
Regul, D. F श2. v 31. Samuar .......... 100

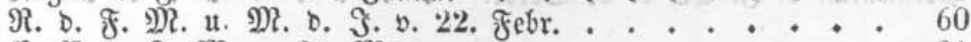

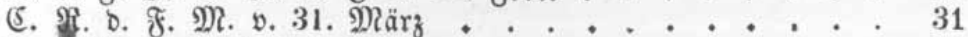

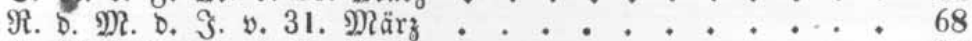

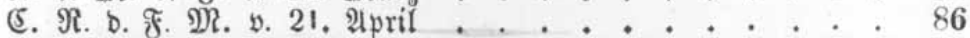

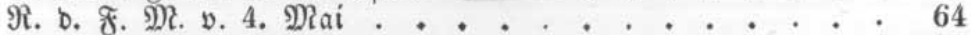

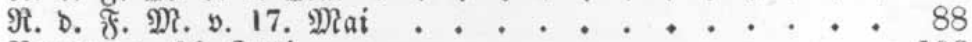
Bertrag v. 26. Şuni . • . . . . . . . . . . 106

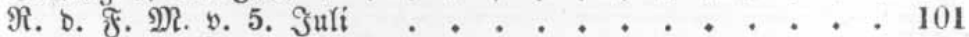

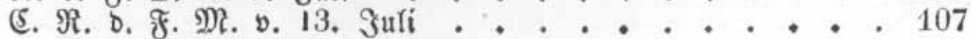

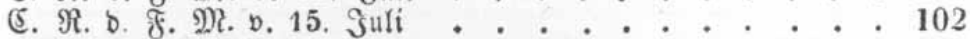
(ङ) еfeв v. 21. Suli ............. 79 Rab.=Drore v. 7. Auguft. . . . . . . . . . 3 Beroronung v 7. Auguft

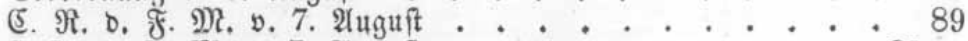

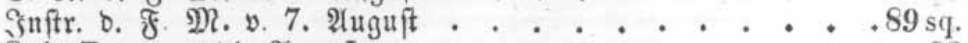
$\Omega a b=$ Drore v. 14 . 2uguft

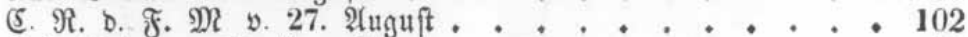
Rab. Drbre v 28, 2uguft . . . . . . . . . 72 $\Re$ o $\mathfrak{F}$ : v 28. Auguft . . . . . . . . . . 100

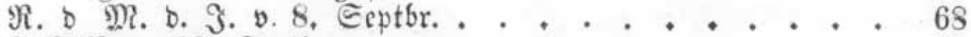

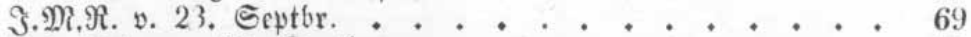
$\Re_{\mathfrak{a b}}=$ Drore v. 26. Septbr. . . . . . . . . . . 99 Rab,=Drore v. 5. Detbr. . . . . . . . . . . . 3 $\Omega_{\mathrm{ab}}=$ Drbre v. 25. Detbr. Rab $=$ Drore v. 16. Novbr. Befanntm. b. 3. פR. v. 3. Decbr. 3

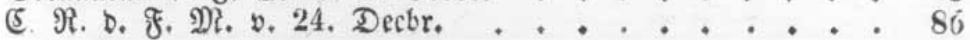

\section{9.}

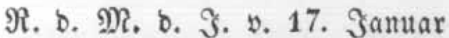




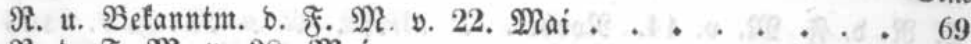

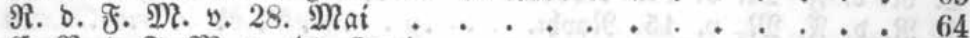

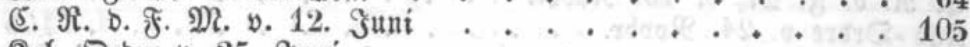

Rab.=Drbre v. 25. Juni . . . . . . . . . . 89

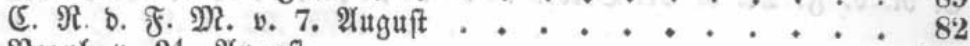

Regul. v. 21. 2uguft... . . . . . . . . . 104

Эnitr. v 21. Auguft . . . . . . . . . . . . 104

Лab.=Drbre v. 10. Septbr. . . . . . . . 3 u. 4

Betanutm. ๖. Э. M. v. 2. Detbr. . . . . . 3 